\title{
Scope of Work for Integration Management and Installation Services of the National Ignition Facility Beampath Infrastructure System
}

\author{
P. D. Coyle
}

April 25, 2000

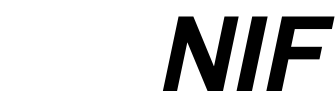

The National Ignition Facility

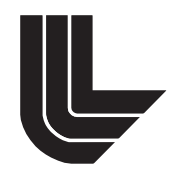

LAWRENCE LIVERMORE NATIONAL LABORATORY

University of California • Livermore, California • 94550 


\section{DISCLAIMER}

This document was prepared as an account of work sponsored by an agency of the United States Government. Neither the United States Government nor the University of California nor any of their employees, makes any warranty, express or implied, or assumes any legal liability or responsibility for the accuracy, completeness, or usefulness of any information, apparatus, product, or process disclosed, or represents that its use would not infringe privately owned rights. Reference herein to any specific commercial product, process, or service by trade name, trademark, manufacturer, or otherwise, does not necessarily constitute or imply its endorsement, recommendation, or favoring by the United States Government or the University of California. The views and opinions of authors expressed herein do not necessarily state or reflect those of the United States Government or the University of California, and shall not be used for advertising or product endorsement purposes.

Work performed under the auspices of the U. S. Department of Energy by the University of California Lawrence Livermore National Laboratory under Contract W-7405-Eng-48.

This report has been reproduced

directly from the best available copy.

Available to DOE and DOE contractors from the

Office of Scientific and Technical Information

P.O. Box 62, Oak Ridge, TN 37831

Prices available from (423) 576-8401

http: / / apollo.osti.gov/bridge/

Available to the public from the

National Technical Information Service

U.S. Department of Commerce

5285 Port Royal Rd.,

Springfield, VA 22161

http:// www.ntis.gov/

OR

Lawrence Livermore National Laboratory

Technical Information Department's Digital Library

http:/ / www.llnl.gov/tid/Library.html 


\section{CONTENTS}

Page

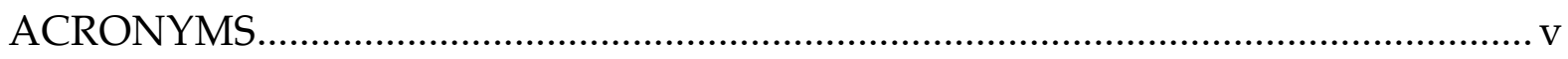

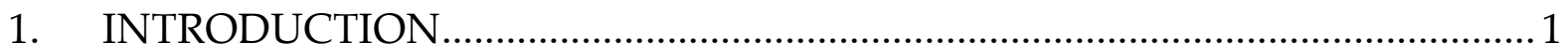

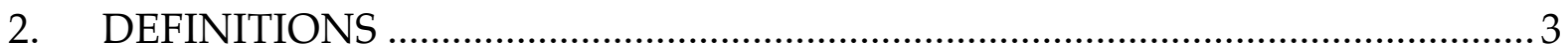

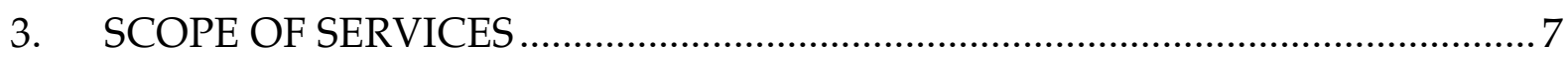

3.1 General Requirements.....................................................................................

3.1.1 Subcontractor Duties .....................................................................................

3.1.2 Subcontractor Management Requirements ............................................. 11

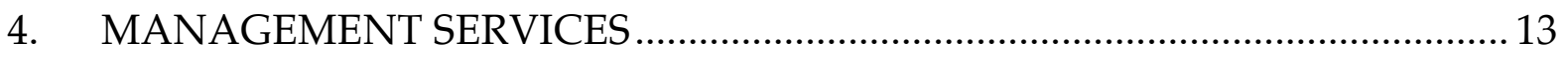

$4.1 \quad$ BIS Project Management Plan (PMP) ................................................................... 13

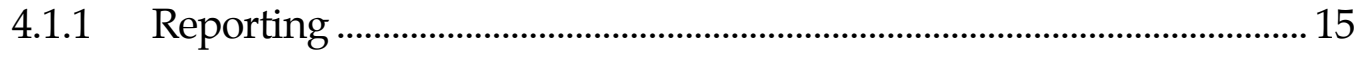

4.2 Other Plans ........................................................................................................ 16

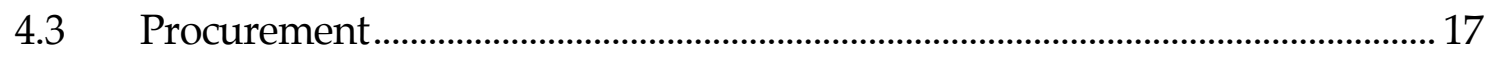

4.4 Construction Cost Estimating …………………............................................ 24

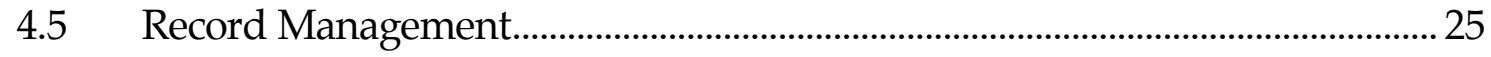

4.6 Construction Management Document Control ....................................................2

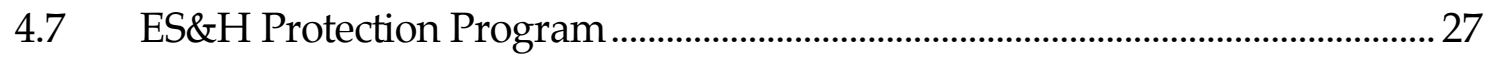

4.7.1 Construction Safety Program.................................................................. 27

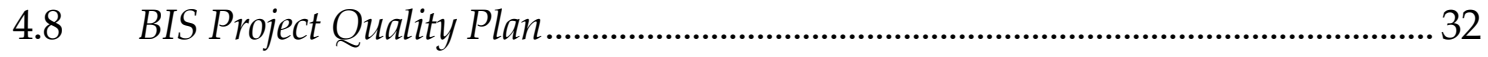

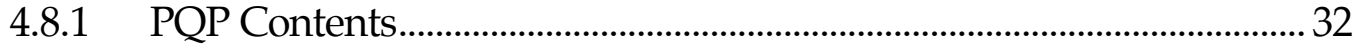

4.8.2 Software QA/QC Plan............................................................................... 35

4.8.3 Construction Quality Control ................................................................. 35

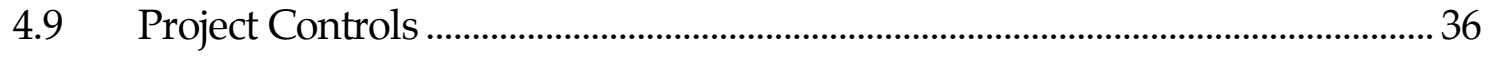

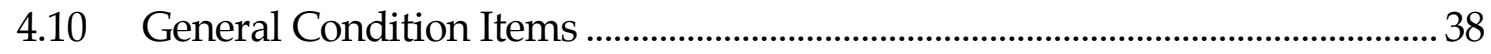

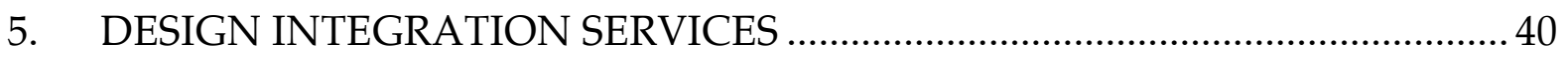

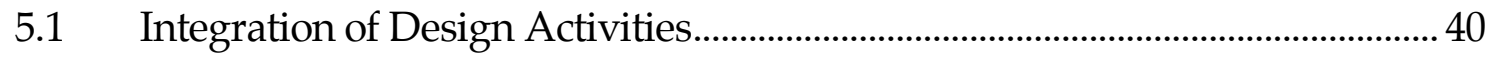

5.2 Managing the Design Integration Process........................................................... 43

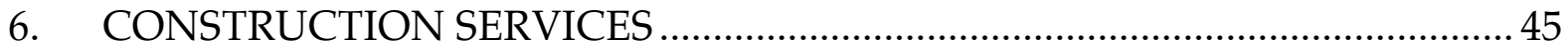

6.1 Support for Buildability/Constructability Reviews............................................ 45

6.2 Construction Packaging....................................................................................... 47

6.3 Construction Documents.................................................................................... 47

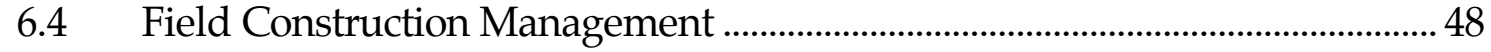

6.5 Testing Services ............................................................................................ 50 


\section{CONTENTS (Continued)}

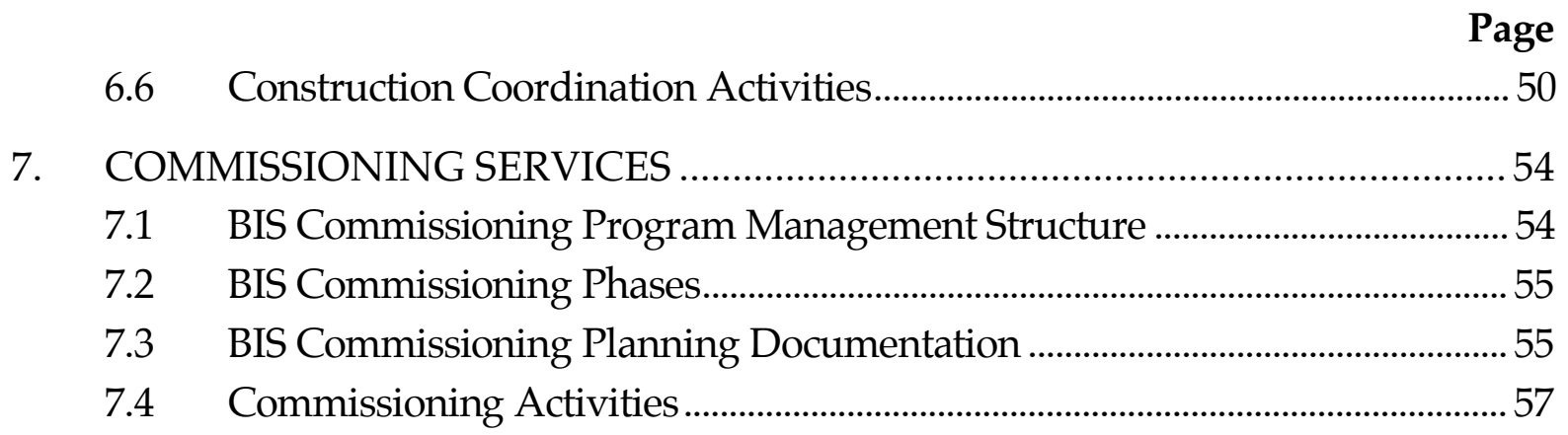

APPENDIX A: IMI SUBCONTRACTOR DELIVERABLES

APPENDIX B: LIST OF IMI KEY MILESTONES

APPENDIX C: CURRENT STATEMENT OF WORK-BEAMPATH

HARDWARE AND BEAMPATH UTILITIES CONSTRUCTION 


\section{ACRONYMS}

A-E

APM

BIS

CCP

CSP

DOE

ES\&H

GFE

HASAP

HVAC

ICS

IMI

ISM

JHA

LLNL

LRU

LTAB

NIF

$\mathrm{OAB}$

OSHA

PLC

PM

PMP
Architect-Engineer

Associate Project Manager

Beampath Infrastructure System

Clean Construction Protocol

Construction Subcontract Package

Department of Energy

Environment, Safety, and Health

government-furnished equipment

Hazard Assessment Safety Action Plan

heating, ventilating, and air conditioning

Industrial Control System

Integration Management and Installation Services Subcontractor

Integrated Safety Management

Job Hazard Analysis

Lawrence Livermore National Laboratory

line-replaceable unit

Laser and Target Area Building

National Ignition Facility

Optics Assembly Building

Occupational Safety and Health Administration

Programmable Logic Controller

Project Manager

Project Management Plan 


\section{ACRONYMS (Continued)}

$\begin{array}{ll}\text { PQP } & \text { Project Quality Plan } \\ \text { QA } & \text { Quality Assurance } \\ \text { QC } & \text { quality control } \\ \text { RFI } & \text { request for information } \\ \text { SA } & \text { Subcontract Administrator } \\ \text { SOR } & \text { Safety Observation Report } \\ \text { SPA } & \text { Safe Plan of Action } \\ \text { SST } & \text { safety sampling technique } \\ \text { TBD } & \text { to be determined } \\ \text { TSA } & \text { Task Safety Analysis }\end{array}$




\section{INTRODUCTION}

The goal of the National Ignition Facility (NIF) project is to provide an aboveground experimental capability for maintaining nuclear competence and weapons effects simulation and to provide a facility capable of achieving fusion ignition using solidstate lasers as the energy driver. The facility will incorporate 192 laser beams, which will be focused onto a small target located at the center of a spherical target chamber-the energy from the laser beams will be deposited in a few billionths of a second. The target will then implode, forcing atomic nuclei to sufficiently high temperatures and densities necessary to achieve a miniature fusion reaction. The NIF is under construction, at Livermore, California, located approximately 50 miles southeast of San Francisco, California.

The Regents of the University of California, managing and operating under Prime Contract W-7405-ENG. 48 with the U.S. Department of Energy (DOE), at Lawrence Livermore National Laboratory (LLNL), shall subcontract for Integration Management and Installation (IMI) Services for the Beampath Infrastructure System (BIS). The BIS includes Beampath Hardware and Beampath Utilities. Conventional Facilities work for the NIF Laser and Target Area Building (LTAB) and Optics Assembly Building $(\mathrm{OAB})$ is over 86 percent constructed.

Beampath Hardware and Beampath Utilities include beampath vessels, enclosures, and beam tubes; auxiliary and utility systems; and support structures. A substantial amount of government-furnished equipment (GFE) will be provided for installation as part of the infrastructure packages. Assembly, installation, and construction of Beampath Hardware and Beampath Utilities are complex tasks. Multiple structures and utilities must be placed, aligned, assembled clean, tested, and maintained. Much of this work is in extremely congested spaces that are elevated 10 to 40 feet above the floor.

Appendix A provides a list of Subcontract deliverables. Appendix B provides currently planned schedule milestones, which identify design completion, area availability (beneficial occupancy), and construction completion. These milestones are extracted from the current NIF Project schedule. The dates are preliminary, do 
not yet satisfy NIF Project need dates, and will be refined with the Subcontractor and NIF Project Management. There are additional deliverables and milestones not included in Appendices A and B, but which will be identified and submitted by the Subcontractor as part of the required workplan. Appendix $C$ provides the current Statement of Work for the Beampath Hardware and Beampath Utilities Assembly, Installation, and Construction. This is preliminary and informational only. It is based on the current in-progress design information and is intended to provide an overview of the current planning basis for the scope of the completion of the BIS assembly, installation, and construction work. This scope will be defined in detail as the design is completed and construction documents are assembled for bidding to lower-tier subcontractors or self-performance by the Subcontractor. The milestones in Appendix B reflect activities by Construction Subcontract Package (CSP). The Subcontractor will develop schedule logic and milestones for self-performed work and Trade Line lower-tier subcontracts as they are identified and planned in detail. However, these existing milestones do indicate the current schedule-planning basis for the completion of the BIS assembly, installation, and construction work defined in Appendix C. 


\section{DEFINITIONS}

Architect-Engineer (A-E) - The A-E is the professional services Subcontractor (to the University, not to the IMI Subcontractor) responsible for completing the design of the BIS utilities, and for engineering services to the BIS Design Team for the BIS beampath construction packages. The A-E is responsible for their means, methods, sequencing, and procedures used for execution of their design scope. The A-E performs basic construction support services during the construction phase. These services will include, but not be limited to, attending the preconstruction meetings; reviewing construction submittals, material samples, product reports, University reports, and test data; reviewing requests for information (RFIs); providing design changes and some cost estimates for modifications to the construction subcontract(s); reviewing operating and maintenance manuals; and providing general construction observation to the University and Subcontractor.

Beampath Infrastructure System (BIS) Design Team-The BIS Design Team is responsible for completing the design of the BIS beampath installation/construction packages. The BIS Design Team is comprised of University employees and other personnel assigned to the BIS organization that report to the BIS Design Deputy. The BIS Design Team is responsible for their means, methods, sequencing, and procedures used for execution of their design scope.

The BIS Design Team performs basic construction support services on work for which they are responsible during the construction phase. These services will include, but not be limited to, attending the preconstruction meetings; reviewing construction submittals, material samples, product reports, University reports, and test data; reviewing RFIs; providing design changes and some cost estimates for modifications to the construction subcontract(s); reviewing operating and maintenance manuals; and providing general construction observation to the Subcontractor. 
In addition, the BIS Design Deputy may require the BIS Design Team to attend the Subcontractor's weekly construction coordination meetings and, at the conclusion of construction phases, to provide a record of documentation services.

BIS Management Team-The BIS organization is comprised of University employees and other personnel who report to the BIS Associate Project Manager (PM). The BIS Management Team includes several critical roles: The Beampath Infrastructure System Associate Project Manager (BIS APM) is a University employee assigned to the NIF Project to manage design, fabrication, assembly/installation, construction, and commissioning phases of the. The BIS APM has Deputy APMs for Design, Construction, Commissioning, and Business Operations. These Deputies (referred to throughout this document as (BIS) Design, Construction, Commissioning, or Business Operations Deputy) are the points of contact with the Subcontractor. The Conventional Facilities Design Manager reports to the Design Deputy and is the point of contact for BIS interfaces with Conventional Facilities for Construction (Title III) issues.

Construction Services-Throughout this document, Construction Services refers to services during the assembly, installation, and construction phases. Where "construction" is used, it refers to all the phases from assembly, to installation, through construction, unless specifically noted otherwise. "Construction Services" and "construction" are used for brevity. It is recognized that there are assembly, precision cleaning, and other preparatory activities for GFE items performed by others that are not the responsibility of the Subcontractor.

Government Furnished Equipment (GFE) - The term GFE refers to hardware or systems procured separately and provided to the Subcontractor for assembly and / or installation as part of the BIS construction subcontracts or self-performed work. The majority of this GFE is designed and procured by the BIS organization. Some of this GFE is designed and procured by other parts of the NIF Project. The Subcontractor is responsible for development and monitoring the status of a complete and coordinated equipment list for all GFE and distributing and installing all material and equipment received from and furnished by the University (GFE). Additional Subcontractor responsibilities for GFE (and potentially Special Equipment that may 
be included in the equipment list) will be identified through development and University approval of a comprehensive Materials Management Plan (to address handling and warehousing; applicability to current inventory, transferred materials and equipment, and new purchases).

Both GFE and Special Equipment, described below, are distinct from any Subcontractor-procured long-lead items.

Special Equipment-Special Equipment refers to non-BIS, NIF Project-designedand-fabricated equipment, or other non-BIS, NIF Project-directly-procured equipment that is not to be installed as part of the BIS installation scope. This Special Equipment will be subsequently installed into the BIS by others, or will interface with the BIS. Line-replaceable units (LRUs) are an example.

Subcontract Administrator (SA) - The Subcontract Administrator is a University employee assigned, by the LLNL Procurement and Material Department, to the NIF Project. The SA is knowledgeable about University procurement processes and is responsible for converting NIF procurement needs into proper actions.

The SA's function and authority include providing contractual documentation and support for the Project, conducting subcontract modification negotiations, processing subcontract modifications, and generally acting as an advisor on contractual matters to the BIS APM, BIS Construction Deputy, and balance of BIS Management team. The SA shall advise the Subcontractor on the required forms, required bonds and insurance, contractual document formatting, and information needed for procurement processing.

Subcontractor-The Subcontractor is directly responsible for integration management, construction, and commissioning work as defined in this Scope of Work. The Subcontractor shall plan, coordinate, direct, integrate, monitor, provide quality assurance (QA), and supervise all the work of lower-tier subcontractors, as well as all self-performed work. (Subcontractor shall provide quality control (QC) of self-performed work with QA provided by the University.) The Subcontractor shall provide construction services for the BIS project and, in doing so, will be responsible 
for the job-site safety, quality, means, methods, sequencing, and procedures used in performing the construction and related activities. The Subcontractor is responsible for tracking and trending the cost and schedule for each element of work either selfperformed or subcontracted.

In providing integration management, design integration, construction services, and commissioning services described in this Scope of Work, the Subcontractor's Design Integration Services shall coordinate the post-award BIS design activities performed by the A-E, BIS Design Team, and balance of NIF Project, including, but not limited to, activities such as definition of package content, arrangement, format, and production schedule. Design Integration Services shall extend through Title III engineering, construction, and commissioning as appropriate.

In its Design Integration Services role, the Subcontractor shall assist the NIF Project team in preserving the integrity of the system and subsystem requirements during detailed design. Nothing in this subcontract shall be construed to mean that the Subcontractor assumes any of the contractual design responsibilities or duties of the A-E or the BIS Design Team.

The Subcontractor is solely responsible for construction means, methods, sequence, and procedures used in the construction of the BIS and for related performance in accordance with its subcontract with the University. The Subcontractor shall plan, develop, and execute the commissioning of the BIS. The Subcontractor will participate in the planning and execution of the operational testing and commissioning of the NIF.

The Subcontractor shall provide advice to the BIS/APM on issues associated with the overall Program management of the organization as part of this Scope of Work. 


\section{SCOPE OF SERVICES}

\subsection{General Requirements}

This Scope of Work is for Integration Management and Installation (IMI) Services corresponding to Management Services, Design Integration Services, Construction Services, and Commissioning Services for the NIF BIS.

The BIS includes Beampath Hardware and Beampath Utilities. Beampath Hardware and Beampath Utilities include beampath vessels, enclosures, and beam tubes; auxiliary and utility systems; and support structures. A substantial amount of GFE will be provided by the University for installation as part of the infrastructure packages.

In working with the BIS Project Team, A-E, BIS Design Team, and Subcontract Administrator, the IMI Subcontractor shall be responsible for the management and performance of the BIS assembly, installation and construction, and commissioning. The Subcontractor shall review and recommend, for University approval, administrative and technical matters, including changes, associated with the Project.

The Subcontractor shall report to the BIS APM, with integrated assignment of Subcontractor key personnel into the BIS organization, e.g., with the Design, Construction, and Commissioning functions, from the award of this subcontract through completion of assembly, installation, construction, and commissioning of the BIS.

\subsubsection{Subcontractor Duties}

\subsubsection{Management Services}

- Prepare and execute self-performed and lower-tier subcontracted work plan. The University shall review and approve the plan and any changes to it.

- Hold lower-tier subcontracts (including prequalification of lower-tier subcontractors, solicitation, award, and management).

- Award the lower-tier subcontracts to "Trade Subcontractors" (e.g., mechanical, electrical, piping) who will perform work with their 
own forces under the direct field supervision of the Subcontractor in their role as the assembly, installation and construction subcontractor. ("Business Trade Subcontractors" with lower-tier subcontractors for closely associated subtier work such as insulation for piping are satisfactory, subject to University consent.)

- Prepare and implement a BIS Project Environment, Safety, and Health (ESEH) Program Plan and Construction Safety Program that meets the requirements of the Construction Safety Program for the NIF (inclusive of appendices and addenda).

- Develop and implement a Clean Construction Protocol (CCP) process that complies with applicable BIS cleanliness specifications.

- Develop and implement a BIS Project Quality Plan that meets the requirements of the NIF QA Program.

- Develop and implement a plan for coordinating with Universityfurnished independent inspectors for areas such as review and approval of the Subcontractor's QA and QC programs; validation of progress and performance on self-performed work and lower-tier subcontracts; and other independent oversight topics.

- Prepare and manage a comprehensive BIS master project schedule including design reviews, procurements, and the integration of the assembly, installation and construction of the BIS and completion of conventional facilities with the remaining equipment installation and start-up activities of the NIF Project.

- Develop and implement an earned-value process, integrating resource-loaded schedule and work plans, and productivity performance measurement system for the overall contract including lower-tier subcontracts and self-performed work

- Provide key personnel and maintain an effective, fully staffed organization at the LLNL site and the A-E's office in order to expedite the interaction between the Subcontractor, lower-tier subcontractors, 
the A-E, the BIS Design Team, the NIF Project Office, and the NIF Special Equipment teams, and execute the work.

- The Subcontractor will make selected employees available to serve project teams where the BIS APM deems appropriate (seconded personnel). Such personnel will be under the supervision and control of the BIS Management Team, and the BIS Management Team shall be responsible for their work.

\subsubsection{Design Integration Services}

- Coordinate BIS design activities between the BIS Design Team, the University-subcontracted A-E, and other NIF Project design teams, including, but not limited to, definition of package content, arrangement, format, and production schedule. The Subcontractor shall assist the NIF Project team in preserving system integrity and subsystem requirements during detailed design.

- Perform ongoing scope and cost control through implementation of design-to-budget and build-to-budget processes integrated with the ongoing BIS design activity.

\subsubsection{Construction Services}

- Perform constructability services analysis integrated with the ongoing BIS design activity. Prepare and validate the assembly, installation, and construction sequence and procedures needed to perform the assembly, installation, construction, and commissioning of the beampath and the beampath utilities. The validation of these procedures and the design will be demonstrated by proofing procedures through use of models, mockups, test fit, and trial assembly, installation, and construction in designated areas of the laser and target buildings.

- Plan, coordinate, direct, and document construction activities required to assemble, install, and construct the BIS in accordance with approved drawings, specifications, requirements, and criteria. 
- Fabricate, assemble, and install specific Industrial Control System (ICS) subsystem assemblies and perform associated software Programmable Logic Controller (PLC) logic coding.

- Develop and monitor status of complete equipment list. Distribute and install all material/equipment received from and furnished by the University (GFE).

- Have direct responsibility for work in the field. Plan, coordinate, direct, integrate, monitor, QA, QC, and supervise the work of lowertier subcontractors as well as the work that is self-performed. Control construction means, methods, techniques, sequences or procedures, and safety programs or procedures.

- Self-perform or establish an alliance with qualified firms for key elements of the work, such as the beampath hardware installation.

- Provide the Project general-conditions items and site-support services customarily provided by a construction contractor, unless provided by the NIF Project.

\subsubsection{Commissioning Services}

- Develop and execute the BIS commissioning program. The program shall be developed in close cooperation with the NIF Commissioning Team and shall be structured in accordance with the NIF Commissioning Plan. The NIF Commissioning Team is comprised of NIF Project University employees and other personnel who report to, or support, the NIF Commissioning Manager.

- Demonstrate and recommend acceptance (by the University) of the system equipment (where applicable), installation, performance, and functionality, including ICS, in accordance with the design intent, through the planning and execution phases of Validation, Activation, and Final Acceptance Testing.

- Validation-Define and verify the critical process parameters, critical quality attributes, and test protocols of the BIS subsystems. 
- Activation-Verify conformance to functional and performance requirements including factory inspections, factory acceptance tests, cleaning, installation, inspections, readiness reviews, startup, shakedown, and integrated operations.

- Final Acceptance Testing-Obtain final University acceptance of the BIS. The execution of this effort is a joint effort of the University, Subcontractor, and lower-tier subcontractors. A University representative (Commissioning Authority) shall be assigned sole responsibility for final acceptance of the BIS.

\subsubsection{Subcontractor Management Requirements}

The Subcontractor shall manage the ES\&H, technical work, cost and schedule for the services described herein. The Subcontractor shall provide management, supervision, labor, materials, supplies, equipment, and lower-tier subcontracts (except as otherwise indicated), and shall plan, schedule, and coordinate effective performance of services described herein. The Subcontractor shall provide construction safety, QC and QA services for the BIS in accordance with the provisions of this subcontract. (Additional independent inspection and oversight QC and QA functions will be provided by the University.)

The Subcontractor shall:

- Be responsible for QC and QA, including quality assurance over the lower-tier subcontractors' QC Programs.

- Utilize the personnel named and/or otherwise identified in the approved Staffing Plan to perform services required under this subcontract.

- Become thoroughly familiar with and act in conformance with the University procurement process.

The Subcontractor shall not be responsible for design deficiencies of the A-E or BIS Design Team. 


\subsubsection{Training of Personnel}

It shall be the responsibility of the Subcontractor to provide Universityrequired training to Subcontractor team members on work under this subcontract. Subcontractor personnel shall be made aware of applicable LLNL and NIF Project regulations, procedures, and policies affecting the conduct of their work. Training shall be arranged and conducted as needed during the subcontract. 


\section{MANAGEMENT SERVICES}

\subsection{BIS Project Management Plan (PMP)}

The Subcontractor shall prepare and submit an updated BIS PMP for University approval within 25 working days after award; maintain it throughout the duration of design, construction, and commissioning for accurate reference; and submit updates to the plan, for University approval, at least semiannually, or more frequently as warranted. The PMP describes the project requirements and anticipated methods for executing the work planned for each phase and for all participating organizations. The plan includes the following sections:

Project Definition-Known project characteristics described in general terms that reflect the Subcontractor's basic understanding of the project.

Project Objective-The NIF's and BIS's schedule, budget, physical, technical, and other objectives for the project defined.

Organization Chart-A summary chart showing inter-relationships among the Subcontractor employees, Subcontractor lower-tier consultants, lower-tier subcontractors, SA, A-E, BIS Design Team, NIF System Engineering, BIS APM, and the BIS Management Team. The chart must show those organizational elements participating in each project phase. Major project participants, whether firms or individuals, will be identified; their roles and responsibilities defined clearly; and the relationships and lines of communication among all identified. Using the chart, project participants will be able to determine who is responsible for what at all times. The chart must also explicitly define the Safety Program alignment with the organization, and roles and responsibilities. The chart must also present project team interaction with the balance of the NIF Project site activities, such as OAB operations, conventional facilities; heating, ventilating, and air conditioning (HVAC); and utilities during completion of construction, activation, and commissioning.

Roles and Responsibilities-An organizational chart identifying Subcontractor staff and their operational duties and responsibilities, described for each project phase. 
Deliverables-A table of Subcontractor-planned deliverables. This table shall address deliverables in Appendix A and include additional deliverables defined in the other plans submitted with the PMP or called for in other sections of this Statement of Work.

Staffing Plan-A plan indicating timing of staff mobilization, augmentation, and demobilizations.

Written Procedures-Written procedures required for coordinating the project among the Subcontractor, the A-E, the BIS Design Team, the NIF project team, and the lower-tier subcontractors. Indicate lines of communication and management controls, showing clearly and simply where authorities are vested and/ or the approval functions with levels of authority. Tasks that require written correspondence, as opposed to those that can be handled orally, will be clearly identified along with the party responsible for preparation of the correspondence and issuance of oral directives.

Schedule Management-A BIS Master Plan and Schedule (developed and maintained by the Subcontractor) integrated with the NIF Master Schedule in compatible format. It will be used to determine design, construction, and commissioning package delivery data, procurement, Subcontractor and lower-tier subcontractor milestones. By using the Master Plan and Schedule, milestones will be tracked and reported. Additional details regarding schedule management shall be provided in the Subcontractor's Project Controls Plan.

Cost Management-A program (established by the Subcontractor) to develop budgets and manage costs for each package and general conditions and the overall Scope of Work. The Subcontractor will maintain current obligations, estimated future commitments, and forecast final costs. Additionally, monthly, cumulative, and forecast final costs will be developed and maintained for staffing and other nonconstruction tasks. The Subcontractor shall develop and implement an earned-value process, integrating the resource-loaded schedule and workplans, and productivity performance measurement system for the overall contract, including all lower-tier subcontracts, self-performed work, and other non-construction tasks. It is 
recognized that lump-sum, lower-tier contracts and level-of-effort work will involve different approaches from the classical earned-value techniques. Additional details regarding cost management shall be provided in the Subcontractor's Project Controls Plan.

ES\&H-The Subcontractor shall establish a program to integrate ES\&H as a line management responsibility in execution of this overall scope of work. See Section 4.7 for details.

Change Management-The Subcontractor shall identify the baseline budget for each CSP as agreed to in the Subcontract Total Estimated Cost as of the date of the subcontract award. The baseline budget may be changed due to factors such as additional scope, design error, non-compliant vendor supplied items, or changes in site conditions. When a potential change is identified, a field change notice shall be forwarded to the BIS Project management Team outlining the change, a Rough Order of Magnitude ( $\mathrm{ROM}$ ) cost estimate of the change, and an analysis of schedule impact. The BIS Management Team will have the responsibility to approve the change order, request additional information, or disapprove the change. Once approved, where appropriate, the change notice will become a change order and will be processed in accordance with the NIF Project Control Manual, Procedure 6.4, Engineering Change Requests. Additional details regarding change management shall be provided in the Subcontractor's Project Controls Plan.

\subsubsection{Reporting}

Monthly-The Subcontractor shall submit a Monthly BIS Project Progress Report in accordance with Article 6A of the Subcontract Schedule of Articles. The report summarizes cost and schedule performance versus plan, earned value, BIS project progress/accomplishment highlights, project photographs, concerns, safety issues, deficiencies, and action items. The report addresses progress related to engineering, procurement, construction, commissioning, and a monthly look-ahead of schedule milestones. 
Weekly Status Report-The Subcontractor shall submit a Weekly BIS Project Status Report summarizing on-site manpower by Subcontractor and lower-tier subcontractors, safety items/occurrences from the previous week, progress/accomplishment highlights, weekly milestones, concerns, actions, and upcoming key meetings.

Daily Field Log-Daily field logs provide a record of job site conditions, manpower, equipment, testing, LLNL activity, weather, activities, issues, and documents and communications. The Subcontractor shall keep accurate and detailed written records of project progress during various stages of construction, and shall maintain a detailed daily log of events that occur at the job site. These logs must be available to the SA or BIS Management Team and must be turned over to the BIS Management Team upon completion of this subcontract. The Subcontractor shall collect lower-tier subcontractor daily reports and file them.

\subsection{Other Plans}

The PMP shall also incorporate a summary of the following additional planning documents. These planning documents will be submitted with the PMP, and updated versions will be submitted, within 25 working days after award, for University approval. Subsequent updates to these plans will be submitted for University approval at least semiannually, or more frequently as warranted. The requirements for these planning documents are described in sections 4 through 7 of this Statement of Work.

- $\quad$ BIS Project Quality Plan

- $\quad$ BIS Project ESEH Program Plan

- Design Integration Plan

- Software and Controls System Implementation Plan

- Construction Execution Plan

- $\quad$ Software QA/QC Plan

- Construction QA/QC Plan 
- Buildability Plan

- $\quad$ Training Plan

- $\quad$ Procurement Plan

- $\quad$ BIS Project Controls Plan

- Commissioning Plan

- Configuration Management Plan

- Software Configuration Management Plan

- Materials Management Plan

- Record Management Plan

\subsection{Procurement}

Procurement Plan-The process for procuring construction lower-tier subcontractors for the BIS is critical to maintaining the safety, cost, schedule, quality, and small business participation objectives of the Project. The University recognizes the importance of utilizing best commercial practices with respect to procurement, while at the same time maintaining Federal Acquisition Regulations/Department of Energy Acquisition Regulations compliance to the extent required by the Subcontract Schedule of Articles and General Provisions. In order to achieve these objectives and to effectively implement the procurement process, the Subcontractor shall submit a Procurement Plan for review and approval by the University. The plan will address the following topics and provide detailed strategies accordingly:

- $\quad$ Time-phased plan for procurement as it relates to current CSP schedule.

- Approach to identification of long-lead Subcontractor-procured items for either self-performed or eventual assignment to lower-tier subcontractors based on scheduling considerations.

- List of potential lower-tier subcontractors, by trade.

- Subcontracting process/flow chart and authorizing matrix.

- Lower-tier subcontractor prequalification and selection criteria. 
- Development of union trade jurisdictions.

- Management of change orders and modifications.

- Handling claims.

- $\quad$ Risk mitigation.

- Lower-tier subcontract type/structure determination.

- $\quad$ Small Business Plan.

- Base lower-tier subcontract terms and conditions.

- $\quad$ GFE and property management system

- Interaction with BIS and NIF Project Controls

- $\quad$ Standardized forms (Representation and Certifications, Bonding, etc.)

- Description of contents of project procurement file and document management process

- Staffing requirements and organization chart

- The Procurement Quality Plan (PQP), an element of the BIS Project Quality Plan, describes the Subcontractor's quality measures for procurement. This system should address:

- Inclusion of applicable technical and administrative requirements, such as specifications, codes, standards, tests, and inspections in procurement documents.

- Evaluation of qualifications of prospective suppliers.

- Methods of acceptance of purchased items (such as review and approval of lower-tier subcontractors submittals, source verification, receipt inspection, pre-installation and post-installation tests, certificates of conformance, or a combination of these methods).

Prebid Services-The Subcontractor shall provide pre-bid services: prequalifying lower-tier subcontractors, developing all bid documents, conducting prebid meetings, coordinating response to questions, issuing addenda as necessary to clarify ambiguities, and coordinating the bid review. 
- Bidders Prequalification-The Subcontractor shall prequalify lower-tier subcontractors for the BIS work not self-performed by the Subcontractor. The University shall have the right of refusal for lower-tier subcontractors.

Solicitation/Advertising-The Subcontractor shall prepare the solicitation documents and advertise using their own best practices.

Prebid Meeting and Site Visits-The Subcontractor shall conduct the prebid meeting. The meeting is to be attended by the prospective prequalified bidders for the lower-tier subcontracts and may include the SA and the BIS Management Team. The Subcontractor shall perform the following:

- Schedule, coordinate, and publicize the meeting.

- $\quad$ Prepare an agenda before the meeting.

- $\quad$ Arrange for a sign-in sheet.

- $\quad$ Record minutes during the meeting.

- Plan required follow-up actions, with the participation of the SA and the BIS management team.

- Conduct follow-up actions, amendments, and/or communications to all offerors.

Addenda-The Subcontractor shall conduct the prebid site visit and prepare any necessary subcontract addenda for issue to listed plan holders immediately following the prebid site visit. The Subcontractor shall follow up with actions for any addenda as required. The BIS Management Team, A-E, BIS Design Team, and SA will participate as appropriate.

Bid Review and Award-When construction bids are received, they are reviewed by the Subcontractor. The review shall evaluate price proposal versus estimate, technical competency of the bid, the lower-tier subcontractor's responsiveness to the bid, ability to meet schedules, etc. The final decision to award the construction subcontract, based on the findings of the review, shall be made by the Subcontractor. 
Refer to Article 7 of the Subcontract Schedule of Articles for threshold lower-tier subcontract or individual modification dollar values that require University review and consent prior to award. The Subcontractor, in turn, shall prepare the lower-tier subcontract. The Subcontractor shall maintain a BIS project procurement file.

Change Order Process and Administration-The Subcontractor shall establish a subcontract change order processing system for initiating, defining, coordinating, tracking, and documenting self-performed and lower-tier subcontract changes. The system must encompass potential subcontract changes, subcontract changes in progress, and completed subcontract changes. The process must address coordination with University-furnished independent inspectors for validation of progress and performance on self-performed and lower-tier subcontracts and for supporting the overall process for change orders for self-performed work.

The subcontract change-order processing system must provide for the following, at a minimum:

- Defining the roles and responsibilities of the parties involved.

- Identifying, evaluating, and justifying the need for change orders.

- Defining the scope of each change order, including technical, cost, schedule, and ES\&H impacts.

- $\quad$ Tracking potential, pending, and completed change orders, including a change-order numbering system.

- $\quad$ Prescribing steps necessary to process change orders.

- $\quad$ Listing required documents and forms.

The Subcontractor shall prepare documentation necessary to issue the change order. Upon receipt of any change proposed by a self-performed team or lower-tier subcontractor, the Subcontractor shall review the merit thereof and recommend rejection or approval. Refer to Article 7 of the Subcontract Schedule of Articles for threshold dollar values that require University review and consent prior to award. 
Independent Cost Estimate-The Subcontractor shall prepare an independent cost estimate of the change, considering direct costs, time impacts, and lower-tier subcontractor's overhead and profit. The Subcontractor shall include a detailed breakdown of labor, material, and equipment costs for the various work elements. Markups for overhead and profit, as allowed by the lower-tier subcontract, will be shown separately. The source of cost data must be indicated, and the estimate must be signed by the preparer and dated. The Subcontractor's cost estimate is to be prepared before receipt of, and independent of, the lower-tier subcontractor's proposal. For self-performed work, the change-order process shall address coordination with University-furnished independent reviewers for independent estimates.

Quotation Reviews and Negotiations-The Subcontractor shall review all quotations received from the lower-tier subcontractor and shall develop a cost and technical analysis. This analysis is a one-page (or longer as appropriate) written evaluation of the lower-tier subcontractor's quotation. The analysis should identify how the quotation compares to the Subcontractor's estimate, by element; questionable costs; excessive unit costs; differences in scope, quantities, or markups; and suggested negotiation strategies. The Subcontractor is to conduct the negotiations for lower-tier subcontractor quotations, being most familiar with the field conditions generating the change and having prepared or reviewed the estimate and technical analysis. The Subcontractor is authorized to negotiate change orders for lower-tier subcontracts. Refer to Article 7 of the Subcontract Schedule of Articles for threshold individual modification dollar values that require University review and consent prior to award. For self-performed work, the change-order process shall address coordination with University-furnished independent reviewers.

Change Order Impact Assessment-The Subcontractor shall determine whether a change will extend or shorten the specified construction completion date and include appropriate schedule impacts, e. g., time extension, in all change orders. The Subcontractor shall also analyze the 
lower-tier subcontract's schedule subnetwork for verification of schedule impacts, e. g., time extensions.

Errors and Omissions-If the reason for a change appears to be an error or omission, the Subcontractor shall make an initial assessment of the A-E or BIS Design Team's responsibility, including documentation of the deficiency. The Subcontractor's notation of possible error or omission must be made prior to proceeding with issuance of the change. The Subcontractor's assessment of the A-E or BIS Design Team's responsibility will be based on a review of the subcontract documents and other circumstances leading to the change. The University shall make the final decision on liability and also on whether to pursue recovery from the A-E. In the case that it is the BIS Design Team's responsibility, the BIS APM shall initiate the appropriate action.

Progress Payment-The Subcontractor shall develop the processing of selfperformed and lower-tier subcontractor progress payments. The process will address coordination with University-furnished independent inspectors for validation of progress and performance on self-performed work and lower-tier subcontracts.

The Subcontractor is responsible for monitoring progress payments to the lower-tier subcontractors as described in the contract. Where applicable, the Subcontractor shall manage lower-tier subcontracts' award fees.

For the self-performed work and services other than lower-tier subcontracted work, application for progress payment will be submitted to the SA by the Subcontractor.

Labor Standards-The Subcontractor shall interview employees of the lower-tier subcontractors for proper classification and rate of pay as required by the lower-tier subcontractor's subcontract; submit interview information on a "Labor Standards Interview" form; and confirm that the lower-tier subcontractor has posted the effective wage rate at the site.

The Subcontractor shall review all lower-tier subcontractor payrolls after receipt from the lower-tier subcontractor to verify payment of required minimum wage 
rates, and shall maintain a current list of next-level-down, lower-tier subcontractors as provided by the lower-tier subcontractor.

Security-The Subcontractor shall monitor, advise, and assist the lower-tier subcontractor(s) in meeting requirements of the University and the LLNL Security Departments in obtaining access to the LLNL facility. The Subcontractor shall use the services of the LLNL Security Department where necessary. The Subcontractor shall notify the LLNL Security Operations Office of overtime work (with workers' names) or of any unusual working hours, special traffic conditions (such as major concrete pours), or any other situation where the LLNL Security Department has reason for concern or may be helpful to the Project.

Security escorts for self-performed or lower-tier subcontractor(s) working in yellow or blue-badge areas are provided by the LLNL Safeguards and Security Department, which establishes the rules for their limitations and use. It is anticipated that the Subcontractor will not require any work on the BIS to be performed in a yellow- or blue-badge area. The Subcontractor must be aware of LLNL security requirements.

Claims Management-Should disputes arise with any lower-tier subcontractor, the Subcontractor shall act immediately and with perseverance to resolve them. To assist in claims management, the Subcontractor shall implement alternative dispute resolution techniques, which may involve using a Project Neutral to avoid claim escalation. Timely response to and restitution of claims as quickly as possible will be implemented to minimize conflicts between lower-tier subcontractors.

Claims Analysis-The Subcontractor shall review and manage claims from the lower-tier subcontractor(s) and protect the University's interests.

Dispute Resolution-All lower-tier subcontracts will contain language indicating that disputes will be resolved by the Subcontractor and that they agree to the use of alternate dispute resolution techniques, which may involve using a Project Neutral to assist in rapid resolution of the dispute. Refer to the Subcontract for other dispute resolution related information, i.e., Partnering, Project Labor Agreement, and Owner-Controlled Insurance Program. 


\subsection{Construction Cost Estimating}

Design to Cost Process-The Subcontractor shall implement a design to a construction package cost target process. The Subcontractor leads the process by following several steps:

- Working with the BIS APM to establish a budget for each CSP, which shall be reflected in the Subcontractor-submitted PMP.

- Working with the A-E and BIS Design Team to review the defined construction packages for bidability and completeness, and resolving any package ambiguities.

- Prior to bid or solicitation, preparing a CSP cost estimate, broken down by systems, and containing sufficiently detailed quantities to facilitate comparison upon receipt of bids. The estimate must contain components of overhead, general conditions, and fee.

- Working with the BIS Design Deputy, A/E, and BIS Design Team, in resolving variances between the established CSP target price and bids.

- $\quad$ Trending the CSP target estimates as additional drawings or drawing revisions are issued and additional design details are developed.

- $\quad$ Supporting the change management process by estimating the costs of changes identified by engineering change order, for both new scope and buildability and bidability issues.

Cost Variance Estimating for Scope Changes-The Subcontractor shall provide estimating services to assess the validity of submitted lower-tier subcontractor change requests by ensuring that the change is clearly defined as being a scope addition or design error, or is conditions-related. The Subcontractor shall prepare a detailed estimate of the change in a manner that provides comparison and analysis of the change request.

Project Controls, Cost Tracking, and Reporting-The Subcontractor construction cost estimating capability shall support the Project Controls systems, cost tracking, and reporting requirements described in this Statement of Work. 


\subsection{Record Management}

The Subcontractor shall be responsible for overall record management for its BIS project work scope. The Subcontractor shall prepare and implement a Project Record Management Plan that identifies records and procedures required to manage them through subcontract completion and turnover to the University. The Subcontractor shall set up job files, working folders, and record-keeping systems. The plan shall identify required record management corresponding to Management Services, Design Integration Services, Construction Services, and Commissioning Services.

\subsection{Construction Management Document Control}

As part of an overall Record Management responsibility described in Section 4.5 above, The Subcontractor shall set up job files, working folders, and record-keeping systems. The Subcontractor shall maintain the following records until subcontract completion:

Construction Data-Cost estimate, subcontract, lower-tier subcontract, task plan and back-up data, Beneficial Occupancy Form, Final Acceptance Form, schedules, and cost data.

Submittal Log-Log showing submittal number, specification section, sub-tier contractor name, subject and title, dates received and returned, and engineer response (as noted on stamp).

Submittals-The Subcontractor shall establish and maintain a system for tracking submittals, review and take appropriate action on all submittals required by the construction subcontract documents, and distribute submittals as required. The Subcontractor shall review all submittals and take action to correct as necessary prior to distribution to the A-E or BIS Design Team. The Subcontractor shall verify necessity of A-E or BIS Design Team involvement and, if warranted, the Subcontractor shall note problems on the submittals/RFIs prior to forwarding to the A-E or BIS Design Team. The submittal process applies to self-performed work or work performed by lower-tier subcontractors for RFIs, shop drawings, fabrication drawings, descriptive literature, test reports, product or materials samples, certifications, warranties, and operations and maintenance manuals. 
The Subcontractor shall review all submittal schedules, whether for self-performed work or lower-tier subcontractor work, for reasonableness.

The Subcontractor shall coordinate the submittals from their receipt to their approval and return, whether self-performed or lower-tier-subcontractorsubmitted, and monitor the time of submission and the processing of shop drawings, samples, and other separate self-performed or lower-tier subcontractor submittals. If submittals are not being received in a timely manner, the Subcontractor shall ascertain the reason and action as deemed appropriate to eliminate lags and delays. The Subcontractor shall notify the BIS management team promptly of any delays in processing submittals, whether self-performed or from the lower-tier subcontractor, A-E, BIS Design Team, or others. The Subcontractor shall monitor that submittals are submitted and approved in sufficient time to avoid delaying project completion.

Change Order Log-The Subcontractor shall maintain a Change Order Log including change order number; description; identification of lower-tier subcontractor; Subcontractor and University estimates (where applicable), notation on cause for change; lower-tier subcontractor quote and date; agreed price; and Subcontract Modification number.

Change Order Records-A separate file containing pertinent data will be maintained for each change order, including as a minimum:

- $\quad$ Correspondence (letters, field memos, etc.).

- $\quad$ Set of plans and specifications (hard copies).

Turnover of Documents and Records-At the project's conclusion, the Subcontractor shall transfer all documents and records to the University and the BIS APM. This transfer shall include operating and maintenance manuals, submittals, shop and vendor drawings, warranties, daily logs, and any other records required by the Subcontractor for the facility historical record. Additionally, the Subcontractor shall provide this information earlier, as required, to support NIF Operations' preparation of operating plans, procedures and training; commissioning; and NIF Management Prestart Reviews, etc. 


\subsection{ES\&H Protection Program}

The Subcontractor is in the line management chain responsible for ES\&H matters on the NIF Project site. The Subcontractor is accountable for implementing measures to create a universal awareness that promotes safe and environmentally responsible practices at the work site, and that will achieve the NIF Project's management objectives in preventing accidents and illnesses and preserving the quality of the environment in compliance with all applicable regulations.

The Construction Safety Program for the NIF, referred to in Section 4.7.1, tiers down from the NIF ES\&H Management Plan. The Construction Safety Program addresses safety as well as the NIF environmental protection planning and implementation. The Subcontractor Safety Program will be part of the Subcontractor's BIS Project ES\&H Program Plan.

Integrated Safety Management (ISM), including the environmental component of ES\&H, is required for execution of all activities associated with the NIF Project, including the Subcontractors work scope.

The BIS Project ES\&H Program Plan shall identify required management processes and technical ES\&H requirements and procedures.

\subsubsection{Construction Safety Program}

\subsubsection{Responsibilities}

The Subcontractor is in the line management chain responsible for safety on the NIF Project Site. The Subcontractor is accountable for providing a safe work environment for all personnel on site. As such, the Subcontractor's Project Management Team shall implement a NIF Project Site-wide safety program as part of the ES\&H program. This program will apply to all personnel entering the NIF Project Site, including all lower-tier subcontractors working under the direction of Subcontractor. The Subcontractor's PM or Construction Manager shall be the sole point of contact between the Subcontractor and the University for safety issues. As defined in the NIF Project Construction Safety Program, a University employee is designated as the point of contact for safety issues. 
Safety is a line management responsibility to be implemented as part of the technical scope. Safety management includes core management processes and technical safety requirements and procedures. The Construction Safety Program will identify the required management processes and technical safety requirements required at the NIF Project Site.

All personnel on site are responsible for complying with the site's safety requirements, including University, non-University, and vendor personnel. There are no exceptions. All levels of project management shall be responsible for implementation of safety requirements by personnel on site.

The Subcontractor shall assign one Site Safety Supervisor to this project for every 75 to 100 workers on site. Lower-tier subcontractors are required to have a designated full-time site safety representative at all times when conducting work. Site Safety Personnel shall provide safety expertise, safety training, monitoring and auditing of the project's safety program. Subcontractor Corporate Safety personnel shall routinely assist, monitor, and audit this project for program quality and effectiveness. At a minimum, one of the site safety supervisors shall be a certified Emergency Medical Technician who will provide a capability for on-site first aid during all work times.

\subsubsection{Project Safety Program}

The Subcontractor shall create, implement, manage and control a comprehensive project-specific Safety Program. The program will establish the minimum acceptable safety requirements for this scope of work. The Subcontractor's Project Management team shall integrate any additional requirements from the Construction Safety Program for the NIF (NIF-0001321, with latest revisions) into the project's Safety Program. This program shall be approved by the University as noted in Section 4.2, Other Plans. The project safety requirements, as defined by the Safety Program, will be part of each lower-tier subcontractor's contract. Each lower-tier subcontractor shall also complete and submit a BIS-project-specific ES\&H program plan to the Subcontractor, covering their scope of work. The BIS Project Safety Program will include, but not be limited to, the following: 
Lower-Tier Subcontractor Safety Prequalifications-Potential lower-tier subcontractors shall be required to forward safety management planning information and five years of historical safety data to the Subcontractor in support of their ES\&H program. This information will be reviewed for completeness and taken into account during lower-tier subcontractor prequalification and selection. Selection criteria will be reviewed and approved by the University.

Safety Orientation-All personnel are required to complete a project-specific Basic Safety Orientation training prior to entering the project. This Safety Orientation will be prepared and presented by Subcontractor personnel. The University and lowertier subcontractors shall arrange for the Safety Orientation training for their personnel with the Subcontractor in advance. No personnel will be allowed to begin work without this training.

Hazard Assessment Safety Action Plan (HASAP) - A HASAP will be jointly developed by the Subcontractor and the University to assess the potential hazards presented by this phase of the project and to identify the appropriate safety training and other preventive measures that will be implemented. The University shall also provide input and support during the development of this document. Since work scopes often change during the course of work, the HASAP will be a living document that is to be revised by the Subcontractor accordingly to address any new hazards identified.

Job Hazard Analysis (JHA)-The JHAs will tier down from the HASAPS. A JHA identifies the task steps that need control, identifies the hazard(s), establishes the Control Action(s), and defines specific training prerequisites. The Subcontractor shall review and accept the JHA prior to performing any on-site work activity.

Safe Plans of Action (SPAs)/Task Safety Analysis (TSA) Meetings-SPAs will be developed for work-related tasks in the field. Subcontractor field supervision (foremen, supervisors) and craft employees shall complete these documents daily. TSA Meetings will be conducted by field supervision twice per shift, before beginning work and after lunch/dinner. 
Safety Observation Reports (SORs)/Safety Sampling Techniques (SSTs)—SORs will be conducted daily to correct unsafe acts/conditions immediately, document these findings, and record the corrective actions taken in the field. SSTs will be used to further define the underlying cause(s) of particular topics of non-compliance, as identified by the SOR findings.

Imminent Danger-The Subcontractor shall stop work immediately if any conditions are observed that may present an immediate threat of disabling injury or death. Procedures for stop-work actions will conform to NIF Procedure 3.3, Stop Work Action.

\section{Incident and Corrective Action Reporting/Investigation-Lower-tier} subcontractors shall report all incidents and near misses (including non-injury incidents) to the Subcontractor immediately. All incidents and near misses must be investigated and documented and appropriate corrective actions implemented to prevent reoccurrence. The Subcontractor must establish and lead an Incident Review Committee to investigate all accidents that occur on the project. Incident investigations are to be conducted as fact-finding activities, not faultfinding exercises. Investigation results are maintained by the Subcontractor and forwarded to BIS and NIF Project Management. The main purpose of Incident Reporting/Investigation/Corrective Action is to improve technical and management process execution.

Safety Adherence Policy-The Subcontractor shall implement a safety adherence policy for the project site. This policy will be included in all lower-tier subcontracts issued and enforced by the Subcontractor. Enforcement may include revoking site access for personnel who violate project safety procedures or suspension and/or termination of lower-tier subcontractors. The following list outlines some of the major items to observe, or which may be called to the attention of the lower-tier subcontractor during the periodic reviews:

- Occupational Safety and Health Administration (OSHA) Accident Report Form and Form 200, Injury log.

- Documentation of weekly safety meetings. 
- Required OSHA Records including, but not limited to, 29 CFR Part $1926.29, .251, .550, .552, .601, .602, .701, .800, .803, .850, .900$, etc.

Safety Inspections/Audits-The Subcontractor shall manage, direct, and coordinate Health and Safety inspections that may be conducted by any entity on the project, including local, state, federal regulatory agencies, the University, or DOE. The Subcontractor line management shall perform a monthly safety self-assessment to be included in the monthly reporting to the University.

Data Collection/Analysis-Lower-tier subcontractors shall report all project workhours and related accident data to the Subcontractor in writing, weekly and monthly. The Subcontractor shall monitor, track, compile, evaluate, and analyze all project safety data weekly and monthly. Summary reports will be provided to the University at least monthly, which will include monthly and project-to-date OSHA incident rates, at a minimum.

Drug Screening-All subcontractor and lower-tier subcontractor employees assigned to this project are required to a have a confirmation on a pre-employment drug screen. Drug screening will also be given automatically in the event of an accident, or reasonable suspicion. The Subcontractor shall establish the required minimum acceptable test panel and cut-off levels

Security - Only authorized personnel (U. S. Citizens only, and no minors, except as specifically approved by the University) are permitted to enter the project site. The Subcontractor will establish a security gate/guard system, and only properly trained and authorized personnel will be permitted to enter.

Construction Site Bulletin Board-The Subcontractor shall display the following notices at the job site:

- $\quad$ Safety Notices.

- " $\quad$ Notice to Employees."

- U. S. Department of Labor OSHA requirements. 
- Emergency telephone numbers for Medical Assistance and Fire Department.

- $\quad$ Safety posters.

- Miscellaneous notices.

- Equal Employment Opportunity posters.

- Davis-Bacon wage rate determination.

- Any other notices of general interest to the construction employees.

- Safety Manager's Daily Report.

\subsection{BIS Project Quality Plan}

The Subcontractor shall develop and implement a BIS PQP that complies with the QA requirements of the NIF Quality Assurance Program Plan (NIF0000618)—specifically, the implementation directions contained in the NIF Project Control Manual-and thus meets the intent of DOE Order 5700.6C. The Subcontractor shall maintain its existing QA documents and procedures on the job site.

The PQP will be prepared in the Subcontractor's format and will describe the Subcontractor's organization, policies, plans, procedures, forms, and methods to be employed in ensuring that the quality and system requirements are achieved and verified. The Subcontractor shall submit the PQP with the PMP, and updated versions will be submitted, within 25 working days after award, for University approval.

\subsubsection{PQP Contents}

The PQP describes the organizational structure, functional responsibilities, levels of authority, and lines of authority and communication for those managing, performing, and assessing work adequacy.

The PQP describes the Subcontractor's system for QA for all Management, Design Integration, Construction, and Commissioning Services. A specific Software QA/QC Plan shall be provided to describe the quality measures for this element. 
Acceptance testing to confirm that the BIS facilities, beampath hardware, and utilities meet technical requirements (such as thermal uniformity, cleanliness, alignment, and vibrational stability) as designed and constructed shall be addressed.

The Subcontractor shall participate in BIS operational testing and commissioning. (Prerequisite activities involve support to the NIF Project to develop an integrated plan.) The PQP includes the Subcontractor's approach for acceptance testing, operational testing, and commissioning.

Identify Qualified Firms-The Subcontractor will identify names and qualifications of outside testing and / or consulting firms that may be considered to support the QA activities when needed. These names and qualifications shall be included in the monthly reports as they are identified and placed under subcontract. Update field manuals will be updated as information is submitted.

Documents and Records-The PQP defines the requirements for identification, collection, and maintenance of QA records by the Subcontractor. QA records are those maintained to demonstrate conformance with specified requirements and the effective operations of the PQP. This should include provisions for retention, protection, traceability, accountability, retrievability, and the transfer of required documents and records to the University.

Documentation and records that need special processing and control, such as computer codes or information stored on magnetic media or optical disks, must be maintained and controlled by the Subcontractor in a manner that allows timely retrieval.

Procurement Quality-The BIS Procurement Plan is described in Section 4.3 of this document. The PQP describes the Subcontractor's quality measures for procurement to ensure selection of lower-tier subcontracts for the BIS completion and other procured items and services meet established requirements and perform as specified.

Management Assessment-The PQP describes the Subcontractor's plan for establishing, scheduling, performing, and documenting periodic assessments to 
evaluate compliance with approved procedures, to determine the effectiveness of the quality program, and to identify problems that hinder the achievement of quality, safety, and environmental requirements. When deficiencies are discovered, the plan should include provisions for documenting the actions taken to correct the deficiency and, when applicable, determining the root cause of the deficiency and actions taken to prevent recurrence.

Documentation Procedures-Documentation procedures included in the PQP will embody the methodology of identifying, recording, tracking, and verifying correction of defects/omissions or other rework. The Subcontractor's procedures shall be used for the following:

- Preparing noncompliance reports/rejection of work.

- $\quad$ Preparing testing requests/inspection requests/record of test results.

- $\quad$ Tracking logs/methods against the project schedule.

- $\quad$ Recording of omissions and defects.

- $\quad$ Preparing inspection reports/daily diaries/project records.

- Preparing lower-tier subcontractor and self-perform job reports/daily reports.

- Inspecting/testing installed work and materials.

- Verifying that work related to defects and omissions is completed-approval of corrective work.

- Assuring that rejected materials are not incorporated into the work.

Personnel Qualification-The PQP describes the Subcontractor's qualifications for specific job categories such as designers, engineers, managers, supervisors, inspectors, independent assessment personnel, and other personnel performing work that requires special skills or abilities.

Organization Chart/QA Personnel-The PQP includes a chart or description of the organizational structure of Subcontractor personnel on-site related to QA activities, listing their complete responsibilities and their reporting procedures. Indicate how 
this plan will be used by each on-site function related to the Subcontractor's QA activities. Provide names and resumes of Subcontractor personnel for inspection and other QA activities. These resumes shall be included in the Monthly Reports as staff members are identified and added to the project team. Update field manuals as information is submitted.

Special Inspection and Testing Agencies-The PQP includes names and qualifications of outside testing and/or consulting firms that may be considered to support the QA activities when needed. These names and qualifications shall be included in the Monthly Reports as they are identified and placed under subcontract; update field manuals as information is submitted.

\subsubsection{Software QA/QC Plan}

Software QA/QC Plan-The Subcontractor shall develop and submit a Software $Q A / Q C$ Plan that addresses the overall quality requirements, consistent with the Software and Controls System Implementation Plan.

\subsubsection{Construction Quality Control}

Construction QA/QC Plan-The Subcontractor shall develop and submit a detailed Construction $Q A / Q C$ Plan 30 calendar days prior to the start of construction activities for each lower-tier subcontract or self-performed package. The Construction $Q A / Q C$ Plan will be used by the Subcontractor and the University to define specific QA/QC elements for each construction package. (Additional independent inspection and oversight QC and QA functions will be provided by the NIF Project. The Subcontractor Construction QA/QC Plan also addresses coordination with Universityfurnished independent inspectors for areas such as QA of Subcontractor's QA/QC program, validation of progress and performance on self-performed and lower-tier subcontracts, and other independent oversight topics.) The Subcontractor shall submit five copies of the Construction QA/QC Plan for review and approval and maintain one copy at the project site for use of the inspection personnel. 
The Subcontractor shall list by specification section or other means all elements of work on the project that will require inspection and/or testing. The plan will include at least the following considerations:

- Type of inspection or test needed to approve.

- Special requirements related to any construction elements.

- Timing of inspections/testing_-relation to project schedule.

- Who performs inspections-schedule for performance.

- Method of recording inspection/testing.

- Special or important inspection needs; areas of high risk or liability; areas where problems may be expected.

Visitor Log-The Subcontractor shall maintain a $\log$ at the job site to record the presence of all visitors who enter the construction job site. When so required by the BIS APM or designee, the following procedures will apply:

- All personnel shall sign the log when reporting or leaving the construction job site.

- The $\log$ must indicate purpose of the visit, location(s) where access was provided, names and position of personnel, and number of hours each individual spent on the site.

- The original log will be maintained by the Subcontractor; copies of entries for each month will be sent monthly to the BIS APM.

- The log must be available for inspection by the BIS APM or SA at all times.

\subsection{Project Controls}

Project Master Schedule-The Subcontractor shall prepare the BIS Master Schedule, which will incorporate the self-performed and lower-tier subcontractor's schedules. The initial schedule shall be submitted with the PMP. The Subcontractor shall annotate this schedule monthly, showing actual progress achieved and any delays, changes in logic, and change-order work. The schedule will show major project 
milestones. It must also be sufficiently detailed for use in deploying the BIS, e.g., detailing design, procurement, fabrication, assembly, preparation for installation, installation, testing, integration, and commissioning activities; their relationships to each other; and their interaction with conventional facilities and other NIF Project activities (such as delivery of LRUs or other special equipment). It will show start dates, completion dates, and planned duration. This schedule will be controlled, maintained, and integrated with the overall NIF Project Schedule. It will be used to monitor project performance. Primavera Project Planner software, version 3.0, will be used to create and maintain schedules. Construction schedules will be cost-and resource-loaded. Mutually agreed-to procedures will be established and used for integrating the Subcontractor schedule with the BIS schedule and the overall NIF Project schedule.

The Subcontractor shall develop other more detailed, near-term look-ahead schedules for use in Construction Coordination activities such as weekly meetings with individual lower-tier subcontractors and the overall team.

Lower-tier Subcontractor Schedule Review-The Subcontractor shall receive and review the lower-tier subcontractor's initial Critical Path Method Schedule submittal and make the final recommendation of acceptance or rejection, subject to University review and consent. The Subcontractor shall verify that each activity is reasonably priced, that the schedule is not front-end loaded, that the workflow is logical, and that manpower loading is reasonable. The Subcontractor shall receive and review lower-tier subcontractor schedule updates required to be submitted with each request for payment and monitor the progress of the lower-tier subcontract relative to established milestones. The process must address coordination with Universityfurnished independent inspectors for validation of progress and performance on self-performed and lower-tier subcontracts.

Schedule Delays-The Subcontractor shall anticipate delays and advise the BIS management team and SA whenever problems are predicted. The Subcontractor should highlight schedule concerns in the Subcontractor's weekly progress meeting 
with the self-performed team and lower-tier subcontractors. If a delay in the work is identified, the Subcontractor shall take several proactive steps:

- $\quad$ Report the delay to the BIS management team and SA.

- Assess the impact of the delays.

- Determine whether or not the delay is excusable.

- Recommend an appropriate course of action to overcome or mitigate the delay.

If delays continue and it appears that the lower-tier subcontractor is not cooperating in correcting the problem, the Subcontractor shall identify and implement subcontract enforcement actions. Examples follow:

- $\quad$ Show cause and/ or cure notices.

- Withhold payments, retainage.

- Exact full or partial termination.

\subsection{General Condition Items}

"General Condition Items" refer to the provision of facilities or performance of work by the Subcontractor that includes, but is not limited to, items listed below. "Professional Services" refers to services provided by the Subcontractor personnell performing Management, Design Integration, Construction Management, or Commissioning services.

- Temporary toilets are to be supplied for BIS construction crews on site; toilets must be pumped a minimum of twice weekly.

- Temporary fencing around the construction site BIS laydown area(s).

- Refuse disposal for the BIS lower-tier subcontractors on site throughout the contract duration.

- Consumables and office supplies necessary to perform the work in accordance with the subcontract (For "Professional Services", the University provides consumables and office supplies). 
- Digital camera and related software for inspector's photography.

- $\quad$ BIS construction-site access control.

- Provision for the routine cleanliness and special cleanliness of the conventional and BIS facility, including installation and maintenance of air locks and positive atmospheric overpressure on clean areas.

- The University shall provide the following:

Office space, furniture, and equipment for "Professional Services" Subcontractor personnel located on the job site. The site office will be equipped with facsimile units, copying machines, refrigerator, and microwave machines for use by the "Professional Services" Subcontractor personnel at the job site. In the event that it is mutually agreed to be necessary, the Subcontractor will provide offsite office space, furniture, and equipment for use by the Subcontractor.

Personal computers and specific versions of selected software (e.g., Microsoft Office 95/97, not 2000, Windows) for networking into LLNL's system for "Professional Services" Subcontractor personnel located on site to enhance compatibility and enhance communications. Additionally, Expedition, P3, Lynx, and other specialized packages will be provided for specific uses as agreed to by the University.

Basic utilities such as water, electricity, and telephone connections as required for the Subcontractor self-performed construction trailers and lower-tier subcontractor's construction trailers on-site (however, the University does not pay for the phone services). 


\section{DESIGN INTEGRATION SERVICES}

\subsection{Integration of Design Activities}

The Subcontractor shall provide design integration liaison and consultation services for the NIF Project. The activities will include liaison among the Subcontractor, A-E, BIS Design Team, and the NIF Project team. The goal is to assist BIS and the balance of the NIF Project in assuring that drawings, specifications, and other design documentation are performed by the design agencies on time and are of sufficient detail to support the construction schedule. The Subcontractor shall work with the design agencies to minimize their errors and omissions; however, any review of design documents performed by the Subcontractor is not for the purpose of determination of fault or elimination of errors or omissions. The University understands the complexities associated with the design integration activities and does not seek to establish liability of the Subcontractor for errors or omissions associated with its design integration activities. Design control and control of the technical aspects of the design deliverables will remain with the A-E and BIS Design Team. The NIF Project approval of final design and other documents shall constitute a waiver of any claim by the University related to the Subcontractor's design integration, liaison, reviews, and consulting services.

The Subcontractor shall integrate design activities between the A-E and BIS Design Team by holding periodic meetings to coordinate alignment of design interfaces. For major (QA Level 1) components, systems, and structures, the Subcontractor shall review the "as designed" interfaces for compatibility.

The Subcontractor will:

- In accordance with the BIS Master Schedule, ensure that design deliverables are appropriate for the construction packages and schedule their issuance to support construction and commissioning.

- Assure that the final design documents that are bid are sufficient in content and industry standard in format that the lower-tier trade subcontractors can reasonably bid and adequately perform the work. 
- Perform buildability and constructability reviews. A buildability review is a review to ensure feasibility of implementation of assembly and installation. A constructability review means a review of design documents to provide recommendations related to construction, including analysis of construction methods, availability of materials and labor, factors related to construction, and alternative designs. Make recommendations whenever design details adversely affect constructability, cost, or schedule. Review comments will be dispositioned with the relevant design organization. Coordinate modeling and construction validation "proofing" results and findings with the design team to incorporate changes in bid packages or addenda.

- Chair intra-NIF Project review of design progress to obtain stakeholder input to support commissioning, operations, maintenance, and integration with other NIF Project team activities.

- $\quad$ Perform ongoing design integration reviews. Design integration reviews will focus on the adequacy of interaction among CSPs and among design agencies. The Subcontractor will not be accountable for interfaces within the design work or for coordination between design agencies; those responsibilities remain with the design agencies.

- Chair design coordination meetings among the various design agencies.

- Analyze monthly schedule performance for design agencies and report analysis to the BIS Project Team.

- If directed, analyze earned-value performance of the A-E. However, the Subcontractor will not have access to the A-E's business-sensitive rates.

- $\quad$ Support BIS Project Management's efforts for A-E, BIS Design Team, and other NIF Project organizations' accountability for schedule performance.

- Perform periodic "Design to Budget" reviews with design agencies' input, various design review inputs, and by performance of cost 
trending against a cost target and change-order analysis. The Subcontractor shall monitor the design process to identify new requirements not included in the baseline design/cost estimate. New requirements, even if essential to the performance of a system, will be processed as an engineering change request.

Some parts of the construction estimate are inadequately supported by detail design. As design develops, these areas will be targeted for re-estimating to upgrade the estimate and reduce the potential use of contingency dollars. The Subcontractor shall immediately notify the NIF BIS management team if the design team manager determines that the cost target cannot be met.

The Subcontractor shall designate a senior engineering Design Integration Manager to lead a design integration team and provide leadership to design integration activities. The individual shall posses excellent leadership, organizational, communication, and inter-personnel skills.

Because of the significant design effort ongoing at the A-E's office, full-time liaison support will be required in their Pasadena location. Liaison engineers performing work in Pasadena shall transition to the project site when appropriate to assume duties in field support and commissioning.

The Subcontractor shall perform the various reviews in an economical and efficient manner consistent with the time available. The Subcontractor shall identify and document key coordination requirements, perform reviews, and document comment disposition with the design organization. For Subcontractor-scheduled meetings, the Subcontractor shall prepare a complete agenda prior to each. Meeting minutes will include all action items, responsible parties, and deadlines. The Subcontractor shall provide minutes to attendees and the BIS management team.

The Subcontractor shall prepare and submit a Design Integration Management Plan with the proposal. The Plan will include the following elements:

- Objectives of the Design Integration activity.

- Roles and relationships. 
- Organization chart.

- Detailed description of liaison activities.

- $\quad$ Ongoing integration reviews.

- Intra-NIF Project Design Milestone reviews.

- $\quad$ CSP/Buildability/Constructability-construction integration.

- Design-coordination meetings.

- Design-schedule management.

- Integration of design activities with configuration management requirements.

- Proofing and validation results and findings.

- Documentation and disposition of review comments.

- Design to cost.

- $\quad$ Staffing Plan.

- Activity schedule

- Design-to-budget methodology

\subsection{Managing the Design Integration Process}

The Subcontractor shall manage the Design Integration Process to support construction and commissioning in accordance with the NIF Project Execution Plan and Configuration Management requirements. The objective is to minimize changes and rework and their associated costs.

Existing NIF Project and Design agency procedures will be followed. Existing procedures will be modified or supplemented, as required, after team consensus. Where additional procedures are necessary, the NIF Project may consider the Subcontractor's best practices for adoption.

The Subcontractor shall bring discipline into the design integration processes by applying the NIF Quality Assurance Program Plan in an effective and graded manner together with the Subcontractor's best practices as adopted by the NIF Project. 
The Subcontractor's PM shall be accountable to the BIS APM and shall address issues associated with the work process. As approved by the BIS APM, the PM shall be supplemented periodically by various staff engineers from the Subcontractor to assist in this effort. Staff engineer duties include:

- Chair monthly status meeting attended by the functional groups within the BIS Project team, including external design agencies and Subcontractor representatives. The monthly meeting's purpose is to report on work process issues and communicate progress on open issues.

- $\quad$ Seek out work process issues by informal assessments of the various processes utilized by system engineering, project management, configuration management, design engineering, commissioning, and the Subcontractor.

- Resolve process issues directly with the process owners. The staff engineers should have the design and project management experience, and interpersonal skills to provide cross-functional leadership with minimal support. 


\section{CONSTRUCTION SERVICES}

"Construction services" refers to services during the assembly, installation, and construction phases. Where "construction" is used, it refers to all the phases from assembly, to installation, through construction, unless specifically otherwise noted. It is recognized that there are assembly, precision cleaning, and other preparatory activities for GFE items performed by others that are not the responsibility of the Subcontractor.

\subsection{Support for Buildability/Constructability Reviews}

The Subcontractor's construction personnel shall support ongoing Design Integration services by participating in buildability, constructability, and bidability reviews and

- Assisting the A-E and the BIS Design Team in preparing CSPs that are biddable and constructable, having Quality Level 1 interfaces that are in accordance with the NIF Interface Control Document (updated as required).

- Preparing appropriate general-condition items for inclusion in the construction lower-tier subcontracts or self-performed packages.

A Beampath Buildability Team will be assembled by the Subcontractor to work closely with the BIS Project Management Team to develop and document a matrix of materials/ equipment, logistics, installation, testing, certification, and configuration management activities necessary for construction and commissioning of the facility.

- The Subcontractor will develop a detailed approach and methodology to accomplish the objectives, specifically relative to a plan for installation of the Beampath that is coordinated with installation of other NIF Project elements.

- The Subcontractor will identify key Beampath elements (CSPs, Functional System Descriptions, Bid Packs, etc.).

- The Subcontractor will become familiar with current engineering and installation direction, identify sources, and obtain copies of available 
documented data. Data voids are to be identified and solutions recommended.

- The Subcontractor will expand on the 3D CAD modeling effort initiated by the A-E and the BIS Design Team. The Subcontractor will develop a "Baseline" Beampath Installation Map and Sequence 3D CAD model that can be analyzed and tested "virtually" prior to incurring time, expense, and risks of mock-ups and field test fits.

- Using this 3D CAD model, the Subcontractor will scrutinize, analyze, and test the Baseline Beampath Installation plan relative to:

- Control requirements such as safety, quality, schedule, staffing and costs;

- Materials handling, equipment, logistics and management;

- Required special training in the areas of safety, quality, cleanliness and procedures;

- Required special tooling relative to assembly, installation, construction, inspection, certification, and calibration.

- Based on this 3D CAD analysis, the Subcontractor will identify possible design and installation issues, possible installation "work around" opportunities, and selected specific areas of the Laser Bay, Switch Yard, and Target Bays where more thorough detailed analysis and physical mock-ups will be required.

- The Subcontractor will use selected physical mock-ups to analyze, test, and optimize an installation plan for the Beampath. Mock-ups will also be used for special training of installation personnel in areas of safety, quality, cleanliness, and installation procedures as well as the identification of possible requirements for special tool(s) for manufacturing, assembly, installation, construction, inspection, certification and calibration.

- $\quad$ Based on lessons learned from mock-up analysis, the Subcontractor will develop a plan to proceed to "test fit" or proof a minimal (but adequate 
and representative) number of components and subsystems into the Laser Bay, Switch Yard, and Target Bay areas to validate the recommended installation plan and procedures. The proofing will also address Beampath utilities as necessary. The proofing is intended to provide high confidence in the assembly sequences and procedures and thus the cost, schedule, and quality of the overall installation.

- The Subcontractor will coordinate modeling and construction validation "proofing" results and findings with the Design Integration and design team to incorporate changes in bid packages or addenda, prior to initiating work.

- Upon acceptance by the BIS AMP of the final recommended installation plan, the Subcontractor will proceed with the overall Beampath installation process per the accepted plans and protocols.

\subsection{Construction Packaging}

The Subcontractor shall evaluate the requirements of the NIF Project and the design of the BIS and, as part of the Procurement Plan, develop an appropriate approach to construction packaging for self-performed and lower-tier subcontracted work that meets the overall schedule and budget constraints of the NIF Project. The Subcontractor shall work interactively with the BIS APM and BIS management team in developing this plan.

Proposed changes to the approach to construction packaging shall be reviewed and approved by the BIS APM and BIS management team and shall be documented in the Subcontractor's Procurement Plan. Proposed changes will be addressed in the monthly report.

\subsection{Construction Documents}

The Subcontractor produces the complete lower-tier subcontract construction documents. Technical portions of the lower-tier subcontract bidding documents, drawings, details, and specifications for construction are provided by the A-E or BIS Design Team with liaison by the Subcontractor. The Special Requirements, General Requirements, and Security and Site Access Provisions of the General Requirements 
are prepared by the Subcontractor with input from, and coordination with, the SA, BIS APM, A-E, and BIS Design Team.

\subsection{Field Construction Management}

Preconstruction Meetings-Prior to the start of construction by the Subcontractor or lower-tier subcontractor, a preconstruction meeting will be held amongst the Subcontractor and self-performed or lower-tier subcontractor principals along with any lower-tier subcontractor representatives. The SA, representatives of the BIS Management Team, A-E, and BIS Design Team may participate when appropriate. The meeting agenda will be prepared by the Subcontractor. In general, the agenda should cover project organization, roles, and responsibilities of all parties; project controls; project ES\&H program plan requirements; the QA/QC Plan; inspection requirements; the scope of work; project rules and procedures; and reporting requirements. The Subcontractor shall publish minutes of each of these meetings within three days of the meeting and distribute to attendees.

Construction ES\&H Program Plan-The requirements for project ES\&H and specific safety plans and development of lower-tier subcontractor ES\&H and specific safety plans are outlined in Section 4.7 of this document.

Inspection Services-The Subcontractor shall inspect all work performed by the self-perform team and lower-tier subcontractor(s) in accordance with the $Q A / Q C$ Plan to verify conformity with Construction Subcontract requirements.

The Subcontractor shall verify that workmanship, materials, and equipment installed by the lower-tier subcontractor meet or exceed the requirements of the lower-tier subcontract Drawings and Specifications.

The Subcontractor shall plan and coordinate inspections with the self-perform team

and lower-tier subcontractor(s) to minimize impacts on construction operations, and confirm that critical inspections occur as required.

The process shall address coordination with University-furnished independent inspectors for QA of the Subcontractor's QA and QC program, validation of 
progress and performance on self-performed work and lower-tier subcontracts, and other independent oversight topics.

The Subcontractor is responsible for the following activities:

- Daily inspections.

- Completion of BIS daily inspection logs to record work inspected.

- Rejection of material or workmanship not conforming to lower-tier subcontract requirements and documentation of such with a nonconformance notice.

- Maintenance of inspection records. Preparation of reports for all Subcontractor inspections, identifying both items that have been satisfactorily completed and items that require correction. The process for maintenance of inspection records shall capture and file inspections by University-furnished independent inspectors.

- Maintenance of an active list of deficiencies and omissions, indicating corrective status.

- A marked-up set of drawings with addenda, changes, and RFIs for verification of the self-performed team's and lower-tier subcontractor's official as-built drawings.

- Review of lower-tier subcontract drawings, specifications, and approved submittals in preparation for upcoming inspections.

- Participation in making arrangements for all hookups, connections, and outages for utility extensions. These activities are to be in accordance with existing procedures of the Facilities Operations Division of the LLNL Plant Engineering and LLNL Facilities Maintenance Department.

- Participation and recommendation of all equipment tests and acceptance tests.

- $\quad$ Preparation of punch lists. 
- In-plant inspection of vendors and suppliers, when applicable or stipulated in the specifications, or required for QA, to be conducted as required by the Subcontractor, University, or the A-E. Special tests using outside laboratories or consultants may be requested by the BIS management team or Subcontractor. Copies of all test reports shall be sent to the Subcontractor and the BIS management team, who have the option to witness all such tests.

\subsection{Testing Services}

The subcontractor shall initiate and perform testing services in accord with the following, as a minimum:

- The Subcontractor shall obtain testing services from qualified laboratories or firms.

- Subcontracted testing services will be performed in strict compliance with requirements of the A-E or BIS Design Team-generated subcontract specifications. Tests above and beyond those specified may be performed after BIS management team and SA approval, based on Subcontractor recommendation. Testing services will be coordinated with ongoing work at the site for efficiency and in a manner that does not delay work in progress.

- The Subcontractor shall monitor and direct the testing and analysis, the reporting, and the distribution of test results.

- The Subcontractor shall arrange, as necessary, any special inspection services required for compliance with specifications.

\subsection{Construction Coordination Activities}

Construction Supervision-The Subcontractor shall assign competent supervisors for the self-performed work team and all lower-tier subcontractors. Their responsibilities shall be clearly defined in terms of the organization chart, role, and responsibility described in Section 4.1. In the event that lower-tier subcontractor supervision is not satisfactory, the Subcontractor shall take steps to resolve the issue. 
Weekly Coordination Meeting-A weekly progress meeting will be held to facilitate good communication within the project team. This meeting will be chaired by the Subcontractor and attended by representatives of the self-performed team(s), each lower-tier subcontractor, the SA, BIS Management team, and other interested parties as necessary. An agenda in an established format will be developed in advance that allocates time to address issues, coordinate activities, and communicate status. Topics to discuss include safety management issues (mandatory - each meeting), overall status/issues, current milestone status, revisions, design issues, problem areas, and any schedule coordination requirements. Subcontractordeveloped near-term look-ahead schedules will be used ( 3 weeks unless otherwise mutually agreed to). Decisions arising out of this meeting will be published in notes within two working days of the meeting.

Coordination with Conventional Facilities, Special Equipment, and GFE-Construction activities under this subcontract will be coordinated with the University for Special Equipment and GFE and the Conventional Facility Subcontractors to minimize interference and delay.

CCP Implementation-The Subcontractor, working closely with NIF Project Contamination Control personnel, shall implement a CCP process that complies with the applicable cleanliness specifications of the project. The Subcontractor shall:

- Appoint a Field CCP Manager who acts as the primary liaison between the design and construction teams and NIF Project contamination control personnel, develops and conducts the CCP training outlined below, and develops a means of monitoring the cleanliness of the work and resolving contamination control problems during construction.

- Hire supplementary support personnel as required to assist the Field CCP Manager in the performance of tasks required in the CCP specifications.

- Ensure that construction scheduling is optimized to prevent contamination to sensitive segments of the BIS. 
- Implement protocol levels at appropriate times and locations to comply with the CCP specifications.

- Provide for temporary cleanrooms and staging areas commensurate with the cleanliness requirements and work plan for the project.

- Ensure that cleaning processes and procedures used by lower-tier subcontractors meet the requirements specified.

- Provide for gowning, cleanroom commodities, and other contamination control supplies needed to accomplish the work according to the CCP specifications, except for those items to be supplied by the University.

- Develop and conduct training for all personnel in a professional fashion in accordance with the CCP specifications to include:

- Training for project and subcontract management personnel;

- $\quad$ Level 1 \& 2 Training for construction employees;

- $\quad$ Level 3 \& 4 Training for construction employees;

- Special Training for BIS QA/QC personnel;

- Special Training for employees who perform clean connections and work inside vessels.

- Manage contingencies of construction sequences where it is not advisable to follow specified CCP rules through the use of Protocol Deviation Requests as defined in the CCP specifications.

- Enforce the discipline of CCP rules and exercise sanctions as required to this end.

GFE Coordination-the Subcontractor shall coordinate the delivery of GFE by developing and monitoring the status of a master equipment list, schedule of requirements, and timely notification of responsible NIF Project personnel. Additional Subcontractor responsibilities will be identified through development and University approval of a comprehensive Materials Management Plan (to address handling and warehousing; applicability to current inventory; transferred materials and equipment; and new purchases). 
Daily Reports-The Subcontractor shall develop a form for all daily reports. Each self-perform work team and each lower-tier subcontractor shall complete a daily report and submit it daily to the BIS Construction Deputy or designee. The report should include at a minimum the name of the supervisor, number of employees, equipment on site, lower-tier subcontractors on site with personnel, names of visitors, work in progress, safety issues, quality issues, and delays experienced.

Record Drawings-The Subcontractor shall verify that self-perform teams and lower-tier subcontractors maintain redlines and update the drawings regularly. These must include actual locations and routings of services, all changes from the original documents, field changes, final details, actual dimensions, and other similar items on the drawings. The A-E and University shall verify redline accuracy and completeness, or may negotiate with the Subcontractor for verification services, prior to preparation of record drawings by the design teams. 


\section{COMMISSIONING SERVICES}

\subsection{BIS Commissioning Program Management Structure}

The Subcontractor shall be responsible for developing and executing the BIS commissioning program (includes specific BIS ICS subsystems throughout). The program shall be developed in close cooperation with the NIF Commissioning Team and shall be structured in accordance with the NIF Commissioning Plan (future). The NIF Commissioning Team is comprised of NIF Project University employees and other personnel who report to, or support, the NIF Commissioning Manager.

The University's BIS Commissioning Deputy shall have responsibility and authority to review and approve the commissioning plan. The BIS Commissioning Deputy shall be a member of the NIF Commissioning Team.

The University shall designate a BIS Commissioning Authority(s) with responsibility for acceptance of all inspection, test, and final acceptance test activities. The BIS Commissioning Deputy shall be the point of contact for all coordination between the Subcontractor's commissioning team and the BIS Commissioning Authority(s).

The Subcontractor shall designate a Commissioning Manager who is responsible for all Subcontractor commissioning activities, including review and approval of the Construction QA/QC Plan and the lower-tier subcontractor inspection and test plans. The Commissioning Manager shall have a team of direct-report and cross-matrix support personnel to accomplish the planning and execution activities assigned to the Subcontractor as described in this Scope of Work. The Commissioning Manager shall manage (coordinate) the efforts of lower-tier subcontractors in performing commissioning work included in lower-tier subcontracts. The Commissioning Manager shall be accountable to the BIS Commissioning Deputy.

The Quality Control responsibilities of the Subcontractor's commissioning team shall be separate from the Subcontractors Construction QC activities. The Subcontractor's commissioning team is an extension of the University's commissioning team and provides the University recommendations for system 
acceptance. As such, the Team shall interface with the Construction QC Manager in the development and approval of the Construction QC plan, establish guidelines for the control and traceability of all inspections, reports, test results, O\&M Manuals, and warranty documentation.

\subsection{BIS Commissioning Phases}

In general, BIS commissioning shall be a systematic process of demonstrating and accepting the system equipment, installation, performance, and functionality in accordance with the design intent. BIS commissioning shall consist of three planning/execution phases: Validation, Activation, and Final Acceptance Testing.

Validation-Validation is the process of defining and verifying the critical process parameters, critical quality attributes, and test protocols of the BIS subsystems. This effort includes significant requirements mining, or gleaning of the NIF document system. The Subcontractor is responsible for planning and executing this effort. This effort must also be closely coordinated with the requirements of an ongoing reverification effort by NIF Systems Engineering.

Activation-Activation includes actions required to verify conformance to functional and performance requirements, including factory inspections, factory acceptance tests, cleaning, installation, inspections, readiness reviews, startup, shakedown, and integrated operations. The planning for this effort is the responsibility of the Subcontractor. The execution of this effort is a joint effort of the Subcontractor and lower-tier subcontractors.

Final Acceptance Testing-Final Acceptance Testing is the process of obtaining final acceptance of the BIS from the University. The execution of this effort is a joint effort of the University, Subcontractor, and lower-tier subcontractors. A University representative (Commissioning Authority) shall be assigned sole responsibility for final acceptance of the BIS subsystems and the BIS.

\subsection{BIS Commissioning Planning Documentation}

Commissioning planning/execution documentation to be prepared by the Subcontractor includes the following: the BIS Commissioning Plan, the BIS Validation 
Plan, the BIS Activation Plan, the BIS Final Acceptance Plan, and the BIS Commissioning Completion Reports. The University's BIS Commissioning Deputy shall review and approve each commissioning plan prior to execution by the Subcontractor. Each plan is to be considered a controlled document from date of approval.

BIS Commissioning Plan-The Subcontractor shall develop the BIS Commissioning Plan in accordance with scope and format guidelines contained in the overall NIF Commissioning Plan. The BIS Commissioning Plan will present the commissioning program's objectives and requirements for the various commissioning effort phases. The master plan will include activities expected to be performed, deliverable lists, responsibilities, schedules, and outlines of tests to be conducted. It will also present acceptance criteria for each critical system. It will address specific activities required to support Management Prestart Reviews. Specific tests, QC and QA activities, and other commissioning work to be performed by the self-perform team and lower-tier subcontractors will be identified and coordinated with the Design Integration Team, the A-E, and the BIS Design Team for inclusion in the appropriate bid document specifications.

BIS Validation Plan-The BIS Validation Plan includes establishing the critical process parameters, development of the requirements traceability matrix, and identification and development of the required test protocols. Test protocols will include installation qualifications, operational qualifications, and performance qualifications. The Subcontractor must understand that development of the BIS Validation Plan requires significant efforts in gleaning relevant information from the NIF documentation system. This effort must be coordinated with, and complementary to, similar efforts underway by NIF System Engineering.

BIS Activation Plan-The BIS Activation Plan addresses activities associated with documentation review, physical inspection, and testing of BIS components, subsystems, and the entire BIS. The plan will include detailed procedures for activities including factory inspections, factory acceptance tests, cleaning, shipping receiving report, warehouse/storage maintenance, installation, inspections, readiness reviews, startup, shakedown, and integrated operations. 
BIS Final Acceptance Plan-The BIS Final Acceptance Plan includes the requirements, procedures, and performance criteria for the final system acceptance test. For the final acceptance test, the entire BIS must be in its full-up operational configuration, being controlled in a manner similar to, or as close as practical, to actual NIF "firing" operations. Final system acceptance is the responsibility of the University's Commissioning Authority.

BIS Commissioning Completion Report-The Subcontractor shall submit the BIS Commissioning Completion Report within 30 days following final system acceptance by the University's Commissioning Authority. The Report will include all documents leading up to system acceptance, including component and subsystem inspection, factory test, and final test documentation. The Report may be submitted incrementally by BIS subsystems as they are completed.

\subsection{Commissioning Activities}

For the following commissioning activities, the University reserves the right of review and approval of the Subcontractor's programs, approaches, plans, documents, and deliverables.

- $\quad$ The Subcontractor shall plan, organize and host a BIS Commissioning Conference at LLNL within 90 days following subcontract award. The purpose of this conference is to receive comments on the BIS Commissioning Plan from commissioning specialists in industry and government. The conference shall be scheduled for one day, and copies of the BIS Commissioning Plan shall be provided to each attendee one week in advance of the meeting.

- The Subcontractor's commissioning responsibilities include submitting non-compliance reports to the University for non-conforming materials, processes, failed tests, failure of lower-tier subcontractors and suppliers to follow requirements of the contracts, etc. The University recognizes that there is additional non-conformance reporting for GFE and Special Equipment addressed by other parts of the NIF Project, not the Subcontractor. 
- The Subcontractor shall submit weekly progress reports on BIS commissioning activities. The progress reports shall include inspection and test activities as well as progress in developing required commissioning plans.

- The Subcontractor's Commissioning Manager shall participate in NIF and BIS commissioning planning meetings.

- The Subcontractor's Commissioning Team shall review the BIS designs to determine whether requirements for commissioning were taken into consideration in time to incorporate feedback into the designs. Requirements for commissioning may include valves, pressure gages, and sample ports that would otherwise not be required for operations. If deficiencies are noted, they must be brought to the attention of the Design Integration organization.

- The Subcontractor shall be responsible for preparing and managing the University's training plan and other plans, such as system operating procedures, for BIS systems.

- The Subcontractor's training responsibilities include training for the University provided by lower-tier subcontractors and suppliers of equipment and systems. Tasks include verifying requirements for training that are included in lower-tier subcontracts and procurements and the scheduling of training sessions. University personnel targeted for this training are security, controls, management, operations, and maintenance personnel.

- The Subcontractor shall be responsible for managing the lower-tier subcontractor and supplier O\&M Manual submittals. Tasks include verifying that requirements for O\&M Manuals are included in the lower-tier subcontracts and equipment procurements; receiving submittals; and maintaining a library of the documentation until such time that the documents can be transmitted to the University.

- The Subcontractor shall support the University in conceptualizing a maintenance approach for NIF. The purpose is to recommend to the 
University the type of maintenance program required and the suggested timing on when maintenance activities should be initiated. The Subcontractor shall create a listing of spare parts necessary for startup and the first year of operation.

- The Subcontractor shall be responsible for managing the warranty program for BIS systems. Tasks include verifying that requirements for warranties are included in lower-tier subcontracts and equipment procurements; obtaining and filing of warranty documentation; and serving as a point of contact for requesting services for equipment under warranty.

- The Subcontractor shall maintain document files of components, subsystems, and systems; factory inspections; factory acceptance tests; cleaning; shipping receiving reports; warehouse/storage maintenance; installation; inspections; readiness reviews; startup; shakedown; integrated operations; and final acceptance testing. The documentation shall be filed by the NIF Functional System Description. The Subcontractor's Commissioning organization shall also be required to include in the document files reports filed by the Construction Quality Control activity. This approach provides a single point of control for all construction and commissioning quality control documentation. The University recognizes that there is additional documentation for GFE that has been addressed by others, not the Subcontractor. The Subcontractor shall be responsible for assembling copies of all supporting BIS documentation and shall work with the balance of the NIF Project team to assemble the BIS documentation received and developed up to the time of the Subcontract award and as necessary through the period of Subcontract performance. 



\section{APPENDIX A: IMI SUBCONTRACTOR DELIVERABLES}

\section{Table Description}

A-1. Deliverables from the IMI Subcontractor 


\section{Appendix A to Scope of Work for IMI Services}

\section{APPENDIX A: IMI SUBCONTRACTOR DELIVERABLES}

Initial deliverables from the Subcontractor, including due dates and location of each deliverable's description in this document, follow in Table A-1.

There are additional deliverables that will be identified and submitted by the Subcontractor with the required PMP and updated on a regular basis or more frequently if needed. The other plans submitted with the PMP are expected to identify additional deliverables to be provided per the individual plan schedules. 
Appendix A to Scope of Work for IMI Services

Table A-1. Deliverables from the IMI Subcontractor

\begin{tabular}{|c|c|c|}
\hline Deliverable & Due Date & Section \\
\hline $\begin{array}{l}\text { BIS Project Management Plan (PMP) - See } 4.1 \text { for } \\
\text { PMP contents. }\end{array}$ & $\begin{array}{l}\text { Updated and submitted for } \\
\text { University approval within } 25 \\
\text { working days after award; } \\
\text { maintain this document } \\
\text { throughout the duration of } \\
\text { design, construction and } \\
\text { commissioning for accurate } \\
\text { reference; and submit updates } \\
\text { to the plan on a semiannual } \\
\text { basis, or more frequently if } \\
\text { needed. }\end{array}$ & 4.1 \\
\hline $\begin{array}{l}\text { The PMP shall also incorporate a summary of the } \\
\text { following additional planning documents. These } \\
\text { planning documents will be submitted with the } \\
\text { PMP. The requirements for these planning } \\
\text { documents are described in sections } 4 \text { through } 7 \text { of } \\
\text { this Statement of Work. } \\
\text { - } \quad \text { BIS Project Quality Plan } \\
\text { - } \quad \text { BIS Project ESEH Program Plan } \\
\text { - } \quad \text { Design Integration Plan } \\
\text { - Software and Controls System Implementation Plan } \\
\text { - Construction Execution Plan } \\
\text { - Software QA/QC Plan } \\
\text { - Construction QA/QC Plan } \\
\text { - Buildability Plan } \\
\text { - } \quad \text { Training Plan } \\
\text { - } \quad \text { Procurement Plan } \\
\text { - BIS Project Controls Plan } \\
\text { - Commissioning Plan } \\
\text { - Configuration Management Plan } \\
\text { - } \quad \text { Software Configuration Management Plan } \\
\text { - } \text { Mecord Management Plan }\end{array}$ & $\begin{array}{l}\text { The other plans summarized } \\
\text { in the PMP are expected to } \\
\text { identify additional } \\
\text { deliverables to be provided } \\
\text { per the individual plan } \\
\text { schedules. }\end{array}$ & 4.2 \\
\hline
\end{tabular}


Appendix A to Scope of Work for IMI Services

\begin{tabular}{|c|c|c|}
\hline Deliverable & Due Date & Section \\
\hline Monthly Project Progress Report & monthly & 4.1 .1 \\
\hline Weekly Status report & weekly & 4.1 .1 \\
\hline Daily field logs & daily & 4.1 .1 \\
\hline BIS Project procurement file & $\begin{array}{l}\text { (always available and turned } \\
\text { over at end of project) }\end{array}$ & 4.3 \\
\hline $\begin{array}{l}\text { A-E and BIS Design Team design to cost results } \\
\text { - establish estimated construction cost for each } \\
\text { construction documents package } \\
\text { - trend estimates and VE cost estimates }\end{array}$ & $\begin{array}{l}\text { Per Design Integration Plan } \\
\text { schedule }\end{array}$ & 4.4 \\
\hline Cost estimates prior to bid & $\begin{array}{l}\text { Per Design Integration Plan and } \\
\text { Procurement Plan schedule }\end{array}$ & 4.4 \\
\hline All documents and records & $\begin{array}{l}\text { (always available and turned } \\
\text { over at end of project) }\end{array}$ & $4.5,4.6$ \\
\hline Hazard Assessment Safety Action Plan (HASAP) & Per Project Safety Program Plan & 4.7.1 \\
\hline $\begin{array}{l}\text { Safe Plans of Action (SPAs), Safety Observation } \\
\text { Reports (SORs) } \\
\text { Safety Sampling Techniques (SSTs) }\end{array}$ & $\begin{array}{l}\text { Daily for work-related tasks in } \\
\text { the field } \\
\text { As required from Observation } \\
\text { Report findings }\end{array}$ & 4.7.1 \\
\hline Accident investigation results & Within TBD fix of occurrence & 4.7.1 \\
\hline Accident analysis summary data & At least monthly & 4.7.1 \\
\hline Construction $Q A / Q C$ Plan & $\begin{array}{l}30 \text { calendar days prior to the } \\
\text { start of construction activities } \\
\text { for each sub-subcontract or } \\
\text { self-performed package. }\end{array}$ & 4.8 .3 \\
\hline Visitor Log & (always available) & 4.8 .3 \\
\hline BIS Master Schedule & $\begin{array}{l}\text { Updated monthly (and as } \\
\text { required) }\end{array}$ & 4.9 \\
\hline A-E and BIS Design Team review results & $\begin{array}{l}\text { Per Design Integration Plan } \\
\text { schedule }\end{array}$ & 5.1 \\
\hline $\begin{array}{l}\text { Biddability/Constructability review results for } \\
\text { feedback into designs }\end{array}$ & $\begin{array}{l}\text { Per Design Integration Plan } \\
\text { schedule }\end{array}$ & 6.1 \\
\hline
\end{tabular}


Appendix A to Scope of Work for IMI Services

\begin{tabular}{|l|l|c|}
\hline \multicolumn{1}{|c|}{ Deliverable } & \multicolumn{1}{c|}{ Due Date } & Section \\
\hline Construction Documents & Per BIS procurement schedule & 6.3 \\
\hline Field Construction Management meeting minutes & $\begin{array}{l}\text { Within two days of the } \\
\text { meeting }\end{array}$ & $6.4,6.6$ \\
\hline Inspection Reports & Per QA/QC Plan & 6.4 \\
\hline Test Results & Per QA/QC Plan & 6.5 \\
\hline Redlined drawings & $\begin{array}{l}\text { Always available, and } \\
\text { coordinated with } \\
\text { Commissioning plan and } \\
\text { schedule }\end{array}$ & 6.6 \\
\hline $\begin{array}{l}\text { BIS Commissioning Plan, BIS Validation Plan, BIS } \\
\text { Activation Plan, BIS Final Acceptance Plan, and BIS } \\
\text { System Commissioning Completion Reports }\end{array}$ & $\begin{array}{l}\text { Per Commissioning plan and } \\
\text { schedule }\end{array}$ & 7.0 \\
\hline $\begin{array}{l}\text { Specific tests, QC and QA activities, and other } \\
\text { commissioning work to be performed by the self- } \\
\text { perform team and lower-tier subcontractors for } \\
\text { inclusion in the appropriate bid document } \\
\text { specifications }\end{array}$ & $\begin{array}{l}\text { Per Design Integration and } \\
\text { Sommissioning plan and } \\
\text { schedule }\end{array}$ & 7.0 \\
\hline
\end{tabular}





\section{APPENDIX B: LIST OF IMI KEY MILESTONES}

\section{Table Description}

B-1. Currently Planned Design Completion and Bid Package Completion

B-2. Currently Planned Area Availability (Beneficial Occupancy)

B-3. Currently Planned Construction Completion

B-4. Currently Planned BIS-Related Milestones in the Conventional Facilities Schedule 


\section{Appendix B to Scope of Work for IMI Services}

\section{APPENDIX B: LIST OF IMI KEY MILESTONES}

The currently planned key schedule milestones that identify design completion, area availability (beneficial occupancy), and construction completion are presented in Tables B-1, B-2, B-3, and B-4.

- Table B-1 indicates design completion and bid package completion by CSP.

- Table B-2 indicates area availability (beneficial occupancy).

- Table B-3 indicates construction completion.

- Table B-4 presents two BIS-related milestones in the Conventional Facilities schedule.

These are preliminary, do not yet satisfy Project need dates, and will be refined with the Subcontractor and NIF Project Management.

These milestones and the current schedule reflect activities by CSP. The Subcontractor will develop schedule logic and milestones for self-performed work and Trade Line lower-tier subcontracts as they are identified and planned in detail. However, the existing milestones and the schedule they are extracted from do indicate the current schedule planning basis for the completion of the BIS construction work defined in Appendix C.

Appendix C provides the current Statement of Work for the Beampath Hardware and Beampath Utilities Construction. 
Appendix B to Scope of Work for IMI Services

Table B-1. Currently Planned Design Completion and Bid Package Completion

\begin{tabular}{|l|l|c|}
\hline \multicolumn{1}{|c|}{ Activity ID } & \multicolumn{1}{|c|}{ Activity Description } & Early Finish \\
\hline FIBP16M00 & Bid Package for CSP-16 Complete & 1-Aug-00 \\
\hline FIBP14AM00 & Bid Package for CSP-14A Complete & 23-Aug-00 \\
\hline FIBP19M00 & Bid Package for CSP-19 Complete & 3-Jul-00 \\
\hline FIBP14BM00 & Bid Package for CSP-14B Complete & 25-Aug-00 \\
\hline FIBP15BM00 & Bid Package for CSP-15B Complete & 9-Nov-00 \\
\hline FIBP15AM00 & Bid Package for CSP-15A Complete & 16-Nov-00 \\
\hline
\end{tabular}

Note: Above dates reflect design package available plus 10 days. While bid and award activities are included in the schedule, summary milestones have not yet been tabulated. While these milestones reflect bidding by CSP, the Subcontractor will develop additional schedule logic and milestones for self-performed work and Trade Line sub-subcontracts.

Similarly, the dates tabulated below for availability by area are key milestones. It is anticipated that the CSP construction completion dates will be redefined as selfperformed work and Trade Line sub-subcontracts are identified and planned in detail. However, these milestones do indicate the current schedule planning basis for the completion of the BIS construction work defined in Appendix C.

It is anticipated that commissioning services will continue beyond BIS construction completion based on mutual agreement. 


\section{Appendix B to Scope of Work for IMI Services}

Table B-2. Currently Planned Area Availability (Beneficial Occupancy)

\begin{tabular}{|c|c|c|}
\hline Activity ID & Activity Description & Early finish \\
\hline FIOABM0010 & AVAIL: OAB Infrastructure Construction Complete & 24-Aug-00 \\
\hline FICB4M0011 & AVAIL: CB4 Initial Occupancy & 27-Jul-01 \\
\hline FICB4M0010 & AVAIL: CB4 Infrastructure Construction Complete & $6-F e b-02$ \\
\hline FICB3M0010 & AVAIL: CB3 Infrastructure Construction Complete & 27-Feb-02 \\
\hline FILB2M0020 & AVAIL: LB2 Co-Occupancy PASS & 24-Apr-02 \\
\hline FILB2M0010 & AVAIL: LB2 Infrastructure Construction Complete & 10-May-02 \\
\hline FISY2M0010 & AVAIL: SY2 Infrastructure Construction Complete & 1-May-02 \\
\hline FICB1M0010 & AVAIL: CB1 Infrastructure Construction Complete & 29-Nov-02 \\
\hline FICB2M0010 & AVAIL: CB2 Infrastructure Construction Complete & 20-Dec-02 \\
\hline FITB0M0010 & AVAIL: TB Infrastructure Construction Complete & 7-Nov-02 \\
\hline FISY1M0010 & AVAIL: SY1 Infrastructure Construction Complete & 17-Mar-03 \\
\hline FILB1M0010 & AVAIL: LB1 Infrastructure Construction Complete & 24-Apr-03 \\
\hline
\end{tabular}


Table B-3. Currently Planned Construction Completion

\begin{tabular}{|l|l|c|}
\hline \multicolumn{1}{|c|}{ Activity ID } & \multicolumn{1}{c|}{ Activity Description } & Early Finish \\
\hline FICSP17M00 & CSP - 17 Construction Complete & 24-Oct-00 \\
\hline FICSP12M00 & CSP - 12 Construction Complete & 2-Oct-00 \\
\hline FICSP13M00 & CSP - 13 Construction Complete & 16-Jul-01 \\
\hline FICSP15A00 & CSP - 15A Construction Complete & 10-Aug-02 \\
\hline FICSP14A00 & CSP - 14A Construction Complete & 30-Aug-02 \\
\hline FICSP19M00 & CSP - 19 Construction Complete & 5-Sep-02 \\
\hline FICSP16M00 & CSP - 16 Construction Complete & 12-Dec-02 \\
\hline FICSP15B00 & CSP - 15B Construction Complete & 7-Nov-02 \\
\hline FICSP14B00 & CSP - 14B Construction Complete & 24-Apr-03 \\
\hline
\end{tabular}

Appendix $\mathrm{C}$ also includes descriptions of the following two additional milestones which are key to BIS, but are included in the Conventional Facilities schedule. They address the Master Oscillator Room (MOR) and the Preamplifier Module Maintenance Area (PAMMA). In each case, the milestone indicates the BIS activities associated with Conventional Facilities CSP-9 are complete. These milestone dates are currently under re-evaluation.

Table B-4. Currently Planned BIS-Related Milestones in the Conventional Facilities Schedule

\begin{tabular}{|l|l|c|}
\hline \multicolumn{1}{|c|}{ Activity ID } & \multicolumn{1}{|c|}{ Activity Description } & Early Finish \\
\hline CF9M2900[KSH1] & $\begin{array}{l}\text { MOR ready for special equipment } \\
\text { installation }\end{array}$ & TBD \\
\hline CF9M4009 & $\begin{array}{l}\text { PAMMA ready for special equipment } \\
\text { installation }\end{array}$ & TBD \\
\hline
\end{tabular}





\section{APPENDIX C: CURRENT STATEMENT OF WORK-BEAMPATH HARDWARE}

AND BEAMPATH UTILITIES CONSTRUCTION 


\section{APPENDIX C: CURRENT STATEMENT OF WORK-BEAMPATH HARDWARE AND BEAMPATH UTILITIES ASSEMBLY, INSTALLATION, AND CONSTRUCTION}

This appendix presents the current planning basis for the scope of the completion of the BIS construction work. It is structured as follows:

- The General Scope section overviews the general scope of the BIS construction work, the Subcontractor's general construction services responsibilities, and related activities and requirements called out in typical subcontract specifications sections and appendices.

- The Beneficial Occupancy Milestones section defines the construction services completion conditions and indicates the specific status of the various BIS subsystems and facilities for currently planned milestones. The finished product or deliverable is described for each milestone.

- Subsequent sections describe the details of the work for the BIS based on current design information such as specifications. These include:

- Laser Bay Interstage Enclosures

- Spatial Filter Vacuum Vessel Enclosures

- Main Amplifier and Power Amplifier

- Roving Mirror Diagnostics Enclosure

- Periscope

- LM-1

- Switchyard Enclosures

- Precision Diagnostic System

- Laser Bay, Switchyard, and Capacitor Bay Utilities

- Target Bay Utilities and Beam Path Enclosures

- Specific Industrial Controls Subsystems

The description of the current statement of work presented in this appendix is preliminary and informational only. It is based on the current in-progress design information and is intended to provide an overview of the current planning basis for the scope of the completion of the BIS construction work. This scope will be defined in detail as the design is completed and 
construction documents are assembled for bidding to lower-tier subcontractors or selfperformance by the Subcontractor.

Some referenced items such as Appendices A, E, and F as called out in the General Scope section are not included as part of this document, but indicate the kind of items that will be included in the actual construction subcontract documents.

\subsection{GENERAL SCOPE}

A. The general scope of the NIF Beampath Infrastructure System (BIS) Project is to install equipment, utilities, specific industrial control system (ICS) subsystems, and their appurtenant support structures within the completed NIF buildings. Much of the equipment is GFE. Upon completion of the NIF Beampath Infrastructure System Project, the NIF will be available for sole beneficial occupancy by LLNL. At that time, LLNL will continue the construction work at NIF with the installation of special equipment, for example, the optics and diagnostics, as well as other components and systems. While some preliminary testing and verification of subsystems will occur during the NIF Beampath Infrastructure System Program, there will remain a significant amount equipment installation, system testing and verification that will occur after LLNL has taken sole beneficial occupancy.

B. The exact scope of the NIF Beampath Infrastructure System Project is set forth in the general conditions, drawings, and technical specifications of the contract documents. Should there exist any discrepancies between the scope set forth herein and the scope set forth in the contract documents, the contract documents will govern.

C. The Integration Management and Installation (IMI) Services Subcontractor, a subcontractor to the University, will provide all labor, equipment, and non-GFE materials necessary to perform the work set forth below.

D. The IMI subcontractor is required to coordinate with the other University subcontractors for access and use of the facility. This work requires coordination with University subcontractors responsible for the installation and acceptance testing of the Laser Bays and Switchyards. Prerequisite activities include final building closure, HVAC systems start-up, and epoxy floor painting.

E. The IMI subcontractor is responsible for maintenance and protection of the clean environment in the Laser Bays for its portion of the work, as detailed in Specification Section 01625.

F. The IMI subcontractor is responsible for access provisions for manpower and materials required to perform the work.

G. The IMI subcontractor is responsible for coordinating its access requirements with the University and all other subcontractors.

H. Two bridge cranes, each rated at 25 tons with an alarm at $105 \%$, are located in each Laser Bay. These cranes are available for use during this work. The subcontractor is 


\section{Appendix C to Scope of Work for IMI Services}

responsible for coordinating its crane requirements with the University and all other subcontractors. In addition, the IMI subcontractor shall supply operators for these bridge cranes who have successfully completed four-hour training on the use of cranes provided by the University.

I. The functions listed below are to be handled for IMI as a stand-alone package from any other work the subcontractor may have on this site:

1. Request For Information procedure requirements as defined in specification 01320.

2. Material Submittal procedure requirements as defined in specification 01300 and delineated in Specification Divisions 2 through 16.

3. Quality Control and as defined in Specification Divisions 2 through 16 and the Quality Control Plan as defined in specification 01400.

4. Substitutions as defined in specification 01630.

5. Contractual issues such as Administrative Requirements as defined in specification 01010, Applications For Payment requirements as defined in specification 01027 and Change Order Procedure requirements as defined in specification 01035.

6. Staffing requirements as defined in specification 01010, provided the requirements for combining positions as defined in 01010 are met.

7. Coordination and Meetings as defined in specification 01039.

8. Construction Schedule requirements as defined in specification 01310 and Appendices B, C and D.

9. Temporary Facilities, Controls and Site Clean-up as defined in specification 01500.

10. Project Close-out requirements as defined in specification 01720.

11. Operations and Maintenance Data requirements as defined in specification 01730.

12. Warranty requirements as defined in specification 01740.

13. Cost Breakdown/Schedule of Values as defined in specification 01010 and Appendix A.

14. Construction Safety Plan requirements as defined in Appendix E

15. SWPPP requirements as defined in Appendix F. 


\section{BENEFICIAL OCCUPANCY MILESTONES}

\section{PART 1 GENERAL}

\subsection{DESCRIPTION}

A. The Beneficial Occupancy Milestones listed define the contract completion conditions for the IMI Subcontract and confirm the specific status of the various systems and facilities.

B. This milestone will denote Beneficial Occupancy and the beginning of sole-occupancy of the OAB by LLNL.

1. The Conventional Facilities work is complete.

2. The punch list is complete.

3. The utility installation is complete.

4. The air sampling system is complete.

5. All of CSP-17 work is complete.

C. This milestone will denote Beneficial Occupancy and the beginning of sole-occupancy of Capacitor Bay 4 by LLNL. Access to the bays will be required by the Infrastructure Contractors for coordination for the completion of punch list. All of the infrastructure construction and installation of utilities is complete and statically tested. The area is operating at a cleanliness level of Class 100,000 and is temperature stable to 68 degrees

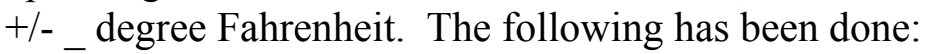

1. All 480/208/120 volt power is installed, checked out, and operational.

2. All doors have been installed and are operational (manually lockable with electric lock hardware installed but not yet automatically operable).

3. The area is broom clean.

4. All wall openings have been sealed.

5. Mezzanine steel is installed.

6. All lighting is installed and operational.

7. All Fire protection is installed and operational.

8. All infrastructure installation of power conditioning module equipment including the shells and control racks has been completed.

9. The shrapnel shields are permanently installed.

10. All control racks and wireways are installed with power supplies connected and the cooling operating in the balanced mode.

11. All control cables, AC power cables and fiber optics are installed and continuity verified.

12. Compressed air system for switches and other functions has been installed and is operational.

13. Gas exhaust system has been installed and is operational.

14. Crane hoists have been installed and are operational. 


\section{Appendix C to Scope of Work for IMI Services}

15. Ground bus is installed, connected and tested.

16. The fiber optic cables for the network tuning and safety are installed and connected to the patch panel and tested through the patch panels.

17. Grounding enclosure for high voltage cables is installed.

18. All high voltage cables are installed and tested.

19. All high voltage cables have connected to the amplifier but not to the capacitors.

20. Capacitor bay / laser bay wall has been sealed and fire-block has been installed in and around cable enclosure.

D. This milestone will denote Beneficial Occupancy and the beginning of sole-occupancy of Capacitor Bay 3 by LLNL. Access to the bays will be required by the Infrastructure Contractors for coordination for the completion of punch list. All of the infrastructure construction and installation of utilities is complete and statically tested. The area is operating at a cleanliness level of Class 100,000 and is temperature stable to 68 degrees

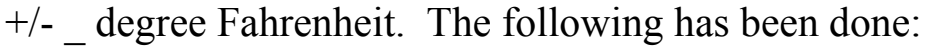

1. All 480/208/120 volt power is installed, checked out, and operational.

2. All doors have been installed and are operational (manually lockable with electric lock hardware installed but not yet automatically operable).

3. The area is broom clean.

4. All wall openings have been sealed.

5. Mezzanine steel is installed.

6. All lighting is installed and operational.

7. All Fire protection is installed and operational.

8. All infrastructure installation of power conditioning module equipment including the shells and control racks has been completed.

9. The shrapnel shields are permanently installed.

10. All control racks and wireways are installed with power supplies connected and the cooling operating in the balanced mode.

11. All control cables, AC power cables and fiber optics are installed and continuity verified.

12. Compressed air system for switches has been installed and is operational.

13. Gas exhaust system has been installed and is operational.

14. Crane hoists have been installed and are operational.

15. Ground bus is installed, connected and tested.

16. The fiber optic cables for the network tuning and safety are installed and connected to the patch panel and tested through the patch panels.

17. Grounding enclosure for high voltage cables is installed.

18. All high voltage cables are installed and tested.

19. All high voltage cables have connected to the amplifier.

20. Capacitor bay / laser bay wall has been sealed and fire-block has been installed in and around cable enclosure.

E. This milestone will denote Beneficial Occupancy and the beginning of sole-occupancy of Capacitor Bay 1 by LLNL. Access to the bays will be required by the Infrastructure Contractors for coordination for the completion of punch list. All of the infrastructure construction and installation of utilities is complete and statically tested. The area is 
operating at a cleanliness level of Class 100,000 and is temperature stable to 68 degrees +/__ degree Fahrenheit. The following has been done:

1. All 480/208/120 volt power is installed, checked out, and operational.

2. All doors have been installed and are operational (manually lockable with electric lock hardware installed but not yet automatically operable).

3. The area is broom clean.

4. All wall openings have been sealed.

5. Mezzanine steel is installed.

6. All lighting is installed and operational.

7. All Fire protection is installed and operational.

8. All infrastructure installation of power conditioning module equipment including the shells and control racks has been completed.

9. The shrapnel shields are permanently installed.

10. All control racks and wireways are installed with power supplies connected and the cooling operating in the balanced mode.

11. All control cables, AC power cables and fiber optics are installed and continuity verified.

12. Compressed air system for switches has been installed and is operational.

13. Gas exhaust system has been installed and is operational.

14. Crane hoists have been installed and are operational.

15. Ground bus is installed, connected and tested.

16. The fiber optic cables for the network tuning and safety are installed and connected to the patch panel and tested through the patch panels.

17. Grounding enclosure for high voltage cables is installed.

18. All high voltage cables are installed and tested.

19. All high voltage cables have connected to the amplifier.

20. Capacitor bay / laser bay wall has been sealed and fire-block has been installed in and around cable enclosure.

F. This milestone will denote Beneficial Occupancy and the beginning of sole-occupancy of Capacitor Bay 2 by LLNL. Access to the bays will be required by the Infrastructure Contractors for coordination for the completion of punch list. All of the infrastructure construction and installation of utilities is complete and statically tested. The area is operating at a cleanliness level of Class 100,000 and is temperature stable to 68 degrees

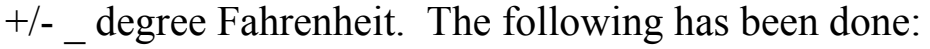

1. All 480/208/120 volt power is installed, checked out, and operational.

2. All doors have been installed and are operational (manually lockable with electric lock hardware installed but not yet automatically operable).

3. The area is broom clean.

4. All wall openings have been sealed.

5. Mezzanine steel is installed.

6. All lighting is installed and operational.

7. All Fire protection is installed and operational.

8. All infrastructure installation of power conditioning module equipment including the shells and control racks has been completed. 


\section{Appendix C to Scope of Work for IMI Services}

9. The shrapnel shields are permanently installed.

10. All control racks and wireways are installed with power supplies connected and the cooling operating in the balanced mode.

11. All control cables, AC power cables and fiber optics are installed and continuity verified.

12. Compressed air system for switches has been installed and is operational.

13. Gas exhaust system has been installed and is operational.

14. Crane hoists have been installed and are operational.

15. Ground bus is installed, connected and tested.

16. The fiber optic cables for the network tuning and safety are installed and connected to the patch panel and tested through the patch panels.

17. Grounding enclosure for high voltage cables is installed.

18. All high voltage cables are installed and tested.

19. All high voltage cables have connected to the amplifier.

20. Capacitor bay / laser bay wall has been sealed and fire-block has been installed in and around cable enclosure.

G. This milestone will denote Beneficial Occupancy and the beginning of sole-occupancy of Laser Bay 1 by LLNL. Access to the bays will be required by the Infrastructure Contractors for coordination for the punch list. All of the infrastructure construction and installation of utilities is complete and statically tested. Refer to separate milestones for the system operation of argon, nitrogen, and vacuum. The area meets Class 100,000 and temperature stable at 68 degrees $+/$ _ $_{-}$degree Fahrenheit. The following has been done:

1. All 480/208/120 volt power is installed, checked out, and operable.

2. All doors have been installed and are operational (manually lockable with electric lock hardware installed).

3. The area is cleaned and operating at Class 100,000.

4. All wall openings have been sealed

5. "House" compressed air system has been installed and is operational.

6. All lighting is installed and operational.

7. All Fire protection is installed and operational.

8. All electronics racks are installed powered, and connected on the field side of the terminal blocks, manually cooled, and grounded.

9. All cable trays and wireways are installed.

10. All control cables, AC power wiring, and fiber optics are installed and continuity verified.

11. Ground Bus is installed and connected.

12. Chilled Water System is installed and operational in the automatic mode.

13. All necessary power, lighting, sprinklers are installed and activated.

14. All walkways, ladders and stairs are installed.

15. The $\mathrm{T} \& \mathrm{H}$ path from the $\mathrm{OAB}$ is clear for all LRU installation.

16. $\mathrm{T} \& \mathrm{H}$ path from $\mathrm{OAB}$ to area below amplifier is clear of obstructions that might prevent insertion of slab or flashlamp LRUs.

17. The nitrogen supply system will be pressure tested and equipment will be manually checked. The automatic controls are not complete and need to be loop-checked, functionally tested, and started up. 
18. The argon supply system will be pressure tested and equipment will be manually checked. The automatic controls are not complete and need to be loop-checked, functionally tested, and started up.

19. The vacuum system plant will be pressure tested and equipment will be manually checked. The automatic controls are not complete and need to be loop-checked, functionally tested, and started up.

20. The tempered water supply system will be operational in the manual mode. The system will have been pressure tested and equipment will be manually checked. The automatic controls are not complete and need to be loop-checked, functionally tested, and started up.

21. The vessels are temporarily filled with a clean, non-hazardous gas.

22. All video cables installed to LRUs

23. All ethernet cables installed and tested

24. AC power installed up to LRUs

25. All catwalks installed, cleaned, and verified to cleanliness specified.

26. Elevator \#2 adjacent to Laser Bay available and tested.

27. All ghost baffles are installed and aligned.

28. Amplifier Subsystem status is:

a. All FAUs installed (in a temperature-stable bay) and aligned to precision specified in ICD.

b. Pulsed power cables are installed between capacitor modules and amplifier. They are connected and tested in amplifier Big-T connectors.

c. FAUs hi-potted to $30 \mathrm{kV}$ relative to each other and facility ground.

d. Cable tray and grounding enclosures installed and connected to all conductors in the vicinity of the amplifier pulsed power cables.

e. Flashlamp cooling system installed and static pressured tested only.

f. Slab cavity purge system installed and static pressure tested only.

g. Surface and NVR contamination levels characterized and verified in FAUs and adjoining enclosures and met the levels required.

h. Amplifier enclosures joined to mating interstage enclosures.

i. Amplifier and mating enclosures purged with nitrogen and maintained at positive pressure.

29. PEPC Subsystem status is:

a. Electrical power distributed to SPG racks locations.

b. Cooling water distributed and terminated near the locations of SPG racks.

c. Seismic tie-downs installed for SPG racks.

d. Kinematic mount wiring and pneumatics actuator installed and tested.

e. SPG cable support structure installed.

f. SPG cables routed including all cable trays and excess SPG cable on spools.

g. PPG racks installed above periscope.

h. Electrical power distributed to PPG racks .

i. Cooling water distributed and connected to PPG Racks- leak checked.

j. Seismic tie-downs installed for PPG racks.

k. PPG cables routed (including all cable trays).

1. Control and Diagnostics (C and D) Cable trays installed.

m. All cables pulled and checked for continuity. 
n. C\&D racks installed, cables pulled and verified, wired, powered, and grounded.

o. Structure-mounted kinematics installed and are not final aligned.

p. Kinematic actuator control system installed and tested.

q. Foreline vacuum system installed and verified.

r. Vibration isolation for foreline pumps installed.

s. Seismic restraints for all equipment installed.

t. Cylinder process gas system installed and verified.

u. The junction boxes are installed and conduit installed. The bulkhead is installed at the Periscope.

v. Gas filled enclosures status from LM1 to SF1 and from SF2 to SF3 is:

- Pressure-tested with a clean gas; and

- All ghost beam baffles installed.

w. The vacuum enclosures will vacuum leak TSF-1 to TSF-2 and TSF-3 and TSF-4.

30. LM1 structure/enclosure status is:

a. LM1 Beam Enclosures installed and final aligned.

b. Light source mounting plates installed and aligned.

c. Docking plate installed and final aligned.

d. Kinematic mounts installed and are not final aligned.

e. Docking receivers installed and are not final aligned.

f. Kinematic mount wiring and pneumatics actuator installed and tested.

g. Precision cleaned and verified.

h. Pressurization test completed.

31. Periscope structure status is:

a. Periscope structure installed and final aligned.

b. Light source enclosure installed and final aligned.

c. Docking plate installed and final aligned .

d. Kinematic mounts installed and are final aligned.

e. Docking receivers installed and final aligned.

f. Kinematic mount wiring and pneumatics actuator installed and tested.

g. Precision cleaned and verified.

32. CSF and TSF status is:

a. All center and end vessels installed and final aligned.

b. All roughing and vacuum lines installed.

c. All turbo pumps installed.

33. End Vessels

a. Kinematic mounts installed and are not final aligned

b. Docking plates installed and aligned

c. Docking receivers installed and aligned

34. Center Vessels

a. Kinematic mounts installed and are not final aligned

b. Removable cover plate installed

c. Temporary covers on all center vessel vacuum interfaces

d. Vacuum window ports attached on bottom of center vessels

35. Main aisle floor and LB1 slab will be level to spec (per ICD).

36. Main aisle floor and LB1 slab will be epoxy painted in full.

37. All walls are prepped and painted. 
38. Areas under laser clear of obstructions (per agreed-upon zones) for LBTS installation.

39. Utilities available at LM1, SF1-4, MA, PA, and periscope; 120V, $30 \mathrm{amp}$.

40. HVAC grilles installed and leveled in laser bay floor.

41. All T\&H LB2 and OAB corridor stayout zones must be clear.

42. LM1, SF1-4, MA, PA, and periscope ready for LRU installation

a. LRU Kinematic mounts aligned and control panels installed.

b. T\&H docking receivers aligned.

c. Positive pressure on beamline.

43. LBTS available for PAM/ILS installation.

44. Main ailseway from PAMMA/MOR aisleway to SY must be clear of obstructions (per ICD).

45. Main aisle floor and LB slab will be epoxy painted.

46. LB1 bridge crane available for $\mathrm{T} \& \mathrm{H} 10 \%$ of the time .

47. Walls in main aisle completed and painted.

48. TSF Vessels and PASS structure aligned and ready for LRU (PAM/IPS/PABST) installation.

49. Utilities available at PASS, PAMMA, LM1 for side loading skid compressed air for $(\mathrm{T} \& \mathrm{H})$ air bear map, and 120V, 30 Amp power.

50. Utilities (temporary power) $120 \mathrm{~V}, 30 \mathrm{~A}$ on top of CSF and TSF center vessels, and air for positive pressure in CSF and TSF vessels.

51. Catwalks or scaffolding installed around CSF and TSF vessels.

52. Main aisle from OAB corridor/loading dock accessible for PAM, ISP, PCU, PABST delivery to PAMMA and Tower delivery to drop off point (only need a short designated period of time).

53. Weekend /off shift access to main aisle to OAB is available with scheduling.

54. All T\&H LB1 stayout zones between SF3 and SY are clean.

H. This milestone will denote Beneficial Occupancy and the beginning of sole-occupancy of Laser Bay 2 by LLNL. Access to the bays will be required by the Infrastructure Contractors for coordination for the punch list. All of the infrastructure construction and installation of utilities is complete and statically tested. Refer to separate milestones for the system operation of argon, nitrogen, and vacuum. The area meets Class 100,000 and temperature stable at 68 degrees +/_ _ degree Fahrenheit. The following has been done:

1. All 480/208/120 volt power is installed, checked out, and operable.

2. All doors have been installed and are operational (manually lockable with electric lock hardware installed).

3. The area is cleaned and operating at Class 100,000.

4. All wall openings have been sealed

5. "House" compressed air system has been installed and is operational.

6. All lighting is installed and operational.

7. All Fire protection is installed and operational.

8. All electronics racks are installed powered, and connected on the field side of the terminal blocks, manually cooled, and grounded.

9. All cable trays and wireways are installed.

10. All control cables, AC power wiring, and fiber optics are installed and continuity verified. 
11. Ground Bus is installed and connected.

12. Chilled Water System is installed and operational in the automatic mode.

13. All necessary power, lighting, sprinklers are installed and activated.

14. All walkways, ladders and stairs are installed.

15. The $\mathrm{T} \& \mathrm{H}$ path from the $\mathrm{OAB}$ is clear for all LRU installation.

16. $\mathrm{T} \& \mathrm{H}$ path from $\mathrm{OAB}$ to area below amplifier is clear of obstructions that might prevent insertion of slab or flashlamp LRUs.

17. The nitrogen supply system will be pressure tested and equipment will be manually checked. The automatic controls are not complete and need to be loop-checked, functionally tested, and started up.

18. The argon supply system will be pressure tested and equipment will be manually checked. The automatic controls are not complete and need to be loop-checked, functionally tested, and started up.

19. The vacuum system plant will be pressure tested and equipment will be manually checked. The automatic controls are not complete and need to be loop-checked, functionally tested, and started up.

20. The tempered water supply system will be operational in the manual mode. The system will have been pressure tested and equipment will be manually checked. The automatic controls are not complete and need to be loop-checked, functionally tested, and started up.

21. The vessels are filled with a clean, non-hazardous gas.

22. All video cables installed to LRUs

23. All ethernet cables installed and tested

24. AC power installed up to LRUs

25. All catwalks installed, cleaned, and verified to cleanliness specified.

26. Elevator \#2 adjacent to Laser Bay available and tested.

27. All ghost baffles are installed and aligned.

28. Amplifier Subsystem status is:

a. All FAUs installed (in a temperature-stable bay) and aligned to precision specified in ICD.

b. Pulsed power cables are installed between capacitor modules and amplifier. They are connected and tested in amplifier Big-T connectors.

c. FAUs hi-potted to $30 \mathrm{kV}$ relative to each other and facility ground.

d. Cable tray and grounding enclosures installed and connected to all conductors in the vicinity of the amplifier pulsed power cables.

e. Flashlamp cooling system installed and static pressured tested only.

f. Slab cavity purge system installed and static pressure tested only.

g. Surface and NVR contamination levels characterized and verified in FAUs and adjoining enclosures and met the levels required.

h. Amplifier enclosures joined to mating interstage enclosures.

i. Amplifier and mating enclosures purged with nitrogen and maintained at positive pressure.

29. PEPC Subsystem status is:

a. Electrical power distributed to SPG racks locations.

b. Cooling water distributed and terminated near the locations of SPG racks.

c. Seismic tie-downs installed for SPG racks. 
d. Kinematic mount wiring and pneumatics actuator installed and tested.

e. SPG cable support structure installed.

f. SPG cables routed including all cable trays and excess SPG cable on spools.

g. PPG racks installed above periscope.

h. Electrical power distributed to PPG racks .

i. Cooling water distributed and connected to PPG Racks- leak checked.

j. Seismic tie-downs installed for PPG racks.

k. PPG cables routed (including all cable trays).

1. Control and Diagnostics (C and D) Cable trays installed.

m. All cables pulled and checked for continuity.

n. C\&D racks installed, cables pulled and verified, wired, powered, and grounded.

o. Structure-mounted kinematics installed and are not final aligned.

p. Kinematic actuator control system installed and tested.

q. Foreline vacuum system installed and verified.

r. Vibration isolation for foreline pumps installed.

s. Seismic restraints for all equipment installed.

t. Cylinder process gas system installed and verified.

u. The junction boxes are installed and conduit installed. The bulkhead is installed at the Periscope.

v. Gas filled enclosures status from LM1 to SF1 and from SF2 to SF3 is:

- Pressure-tested with a clean gas; and

- All ghost beam baffles installed.

w. The vacuum enclosures will vacuum leak TSF-1 to TSF-2 and TSF-3 and TSF-4.

30. LM1 structure/enclosure status is:

a. LM1 Beam Enclosures installed and final aligned.

b. Light source mounting plates installed and aligned.

c. Docking plate installed and final aligned.

d. Kinematic mounts installed and are not final aligned.

e. Docking receivers installed and final aligned.

f. Kinematic mount wiring and pneumatics actuator installed and tested.

g. Precision cleaned and verified.

h. Pressurization test completed.

31. Periscope structure status is:

a. Periscope structure installed and final aligned.

b. Light source enclosure installed and final aligned.

c. Docking plate installed and final aligned .

d. Kinematic mounts installed and are final aligned.

e. Docking receivers installed and final aligned.

f. Kinematic mount wiring and pneumatics actuator installed and tested.

g. Precision cleaned and verified.

32. CSF and TSF status is:

a. All center and end vessels installed and final aligned.

b. All roughing and vacuum lines installed.

c. All turbo pumps installed.

33. End Vessels

a. Kinematic mounts installed and are aligned 
b. Docking plates installed and aligned

c. Docking receivers installed and aligned

34. Center Vessels

a. Kinematic mounts installed and are aligned

b. Removable cover plate installed

c. Temporary covers on all center vessel vacuum interfaces

d. Vacuum window ports attached on bottom of center vessels

35. Main aisle floor and LB2 slab will be level to spec (per ICD).

36. Main aisle floor and LB2 slab will be epoxy painted in full.

37. All walls are prepped and painted.

38. Power/Utilities routed to LBT charging stations in OAB corridor.

39. Areas under laser clear of obstructions (per agreed upon zones) for LBTS installation.

40. Nitrogen purge gas ready/available in $\mathrm{OAB}$ corridor.

41. Utilities available at LM1, SF1-4, MA, PA, and periscope; 120V, $30 \mathrm{amp}$.

42. HVAC grilles installed and leveled in laser bay floor.

43. All T\&H LB2 and OAB corridor stayout zones must be clear.

44. LM1, SF1-4, MA, PA, and periscope ready for LRU installation

d. LRU Kinematic mounts aligned and control panels installed.

e. T\&H docking receivers aligned.

f. Positive pressure on beamline.

45. LBTS available for PAM/ILS installation.

46. Utilities (power, off gas) routed to LBT charging station in LB2.

47. Main ailseway from PAMMA/MOR aisleway to SY must be clear of obstructions (per ICD).

48. PAM/MOR aisleway to be clear of obstructions.

49. Main aisle floor and LB2 slab will be epoxy painted.

50. LB2 bridge crane available for T \& $\mathrm{H} 10 \%$ of the time .

51. Walls in main aisle completed and painted.

52. TSF Vessels and PASS structure aligned and ready for LRU (PAM/IPS/PABST) installation.

53. PAMMA ready to accept PAMs.

54. Utilities available at PASS, PAMMA, LM1 for side loading skid compressed air for $(\mathrm{T} \& \mathrm{H})$ air bear map, and 120V, $30 \mathrm{Amp}$ power.

55. Utilities (temporary power) $120 \mathrm{~V}, 30 \mathrm{~A}$ on top of CSF and TSF center vessels, and air for positive pressure in CSF and TSF vessels.

56. Catwalks or scaffolding installed around CSF and TSF vessels.

57. Main aisle from OAB corridor/loading dock accessible for PAM, ISP, PCU, PABST delivery to PAMMA and Tower delivery to drop off point (only need a short designated period of time).

58. Weekend /off shift access to main aisle to OAB is available with scheduling.

59. All T\&H LB2 stayout zones between SF3 and SY are clean.

I. This milestone will denote Beneficial Occupancy and the beginning of sole-occupancy of Switchyard 1 by LLNL. Access to the bays will be required for the coordination for the punch list. All of the infrastructure construction and installation of utilities is complete. Refer to separate milestones for the system operation of argon, nitrogen, and vacuum. 
The area meets Class 100,000 and temperature stable at 68 degrees +/_ _ degree

Fahrenheit. The following has been done:

1. All 480/208/120 VAC is installed, checked out, and operational.

2. All doors have been installed and are operational (manually lockable with electric lock hardware installed)

3. The area is Class 100,000 clean.

4. All wall openings have been sealed.

5. "House" compressed air system has been installed and is operational.

6. The grating and handrails are installed.

7. All lighting is installed and operational

8. All Fire protection is installed and operational

9. All electronics racks are installed, powered, and connected on the field side of the terminal blocks, manually cooled, and grounded.

10. All conventional cable trays and wireways are installed.

11. All control cables, AC power wiring, and fiber optics are installed and continuity verified.

12. Ground bus is installed and verified.

13. Chilled Water System will be installed and operational in the automatic mode for the air handling systems and in the manual mode for the rest of the systems.

14. The elevators and hoist are operational.

15. The nitrogen, vacuum, tempered water, and argon systems will be pressure tested and equipment will be manually checked. The automatic controls are not complete and need to be loop-checked, functionally tested, and started up.

16. The beam tubes are under slight positive pressure.

17. The tempered water system is operational.

18. The roving pick-off enclosure is installed including:

a. Cleaned to final specifications

b. Pressure tested

c. Lighting installed

d. Utilities and racks installed

e. Internal mounting rack is installed

f. The access door is locked and tagged for access.

19. Precision Diagnostics Trombone installed.

20. Beam enclosure installed.

21. The PDS mounting pates will be installed and aligned.

22. Alignment of all the equipment to $+/$ - om standard equipment.

23. The IOM stands are installed and aligned.

J. This milestone will denote Beneficial Occupancy and the beginning of sole-occupancy of Switchyard 2 by LLNL. Access to the bays will be required for the coordination for the punch list. All of the infrastructure construction and installation of utilities is complete. Refer to separate milestones for the system operation of argon, nitrogen, and vacuum. The area meets Class 100,000 and temperature stable at 68 degrees +/__ degree Fahrenheit. The following has been done:

1. All 480/208/120 VAC is installed, checked out, and operational. 


\section{Appendix C to Scope of Work for IMI Services}

2. All doors have been installed and are operational (manually lockable with electric lock hardware installed)

3. The area is Class 100,000 clean.

4. All wall openings have been sealed.

5. "House" compressed air system has been installed and is operational.

6. The grating and handrails are installed.

7. All lighting is installed and operational

8. All Fire protection is installed and operational

9. All electronics racks are installed, powered, and connected on the field side of the terminal blocks, manually cooled, and grounded.

10. All conventional cable trays and wireways are installed.

11. All control cables, AC power wiring, and fiber optics are installed and continuity verified.

12. Ground bus is installed and verified.

13. Chilled Water System will be installed and operational in the automatic mode for the air handling systems and in the manual mode for the rest of the systems.

14. The elevators and hoist are operational.

15. The nitrogen, vacuum, tempered water, and argon systems will be pressure tested and equipment will be manually checked. The automatic controls are not complete and need to be loop-checked, functionally tested, and started up.

16. The beam tubes are under slight positive pressure.

17. The tempered water system is operational.

18. The roving pick-off enclosure is installed including:

a. Cleaned to final specifications

b. Pressure tested

c. Lighting installed

d. Utilities and racks installed

e. Internal mounting rack is installed

f. The access door is locked and tagged for access.

19. Precision Diagnostics Trombone installed.

20. Precision Diagnostics beam enclosures are installed and cleaned to meet the specifications.

21. The PDS mounting plates will be installed and aligned.

22. Alignment of all the equipment to $+/$ - om standard equipment.

23. The IOM stands are installed and aligned.

24. The 3 omega tank is installed, connected, and cleaned.

25. The monorails are installed and aligned.

K. This milestone will denote Beneficial Occupancy and the beginning of sole-occupancy of Target Bay by LLNL. Access to the bays will be required for the coordination for the punch list. All of the infrastructure construction and installation of utilities is complete and statically checked. All equipment installation, alignment, checkout, and final cleaning by infrastructure subcontractor(s) has been completed. Refer to separate milestones for the system operation of argon, nitrogen, and vacuum. The area is at Class 100,000 and temperature stable at 68 degrees +/_ _ degree Fahrenheit. Area is turned over 
to the Project for Special Equipment installation, activation, and operation. The

following has been done:

1. Beam path installed with performance check and cleanliness.

2. All 480/208/120 VAC is installed, checked out, and operational.

3. All doors have been installed and are operational (manually lockable with electric lock hardware installed).

4. The area is Class 100,000 clean.

5. All wall penetrations have been sealed.

6. Room finishes have been complete.

7. "House" compressed air system has been installed and is operational.

8. The mezzanine steel and catwalks are installed and cleaned including lamps, ladders, and handrails.

9. All lighting is installed and operational.

10. All fire protection is installed and operational.

11. The mirror support structures are installed.

12. All cable trays and wireways are installed.

13. All control cables, AC power cables and fiber optics are installed and verified.

14. Ground bus is installed and verified.

15. Chilled Water System is installed and operational in the automatic mode for the air handlers.

16. The nitrogen, vacuum, and argon systems will be pressure tested and equipment will be manually tested. The automatic controls are not complete and need to be loopchecked, functionally tested, and started up.

17. IOM handling equipment is installed.

18. Installed CCRS Stands.

19. The CCRS modules are installed and rough aligned.

20. The beam tubes and support structures are installed.

21. Target Chamber service system.

22. The kinematic mounts will be installed with initial alignment only.

23. The calimometer spools and isolation valves and the wedges.

24. The helium system is installed and statically tested.

25 . The diagnostic vacuum system will be installed and statically tested.

26. The liquid nitrogen system will be installed and statically tested.

27. The EPS System is installed and operational.

28 . The clean compressed air system needs to be installed and fully open.

29. The first wall is installed and aligned.

30. The FOA cooling is installed and statically tested.

31. The house LCW is installed and fully operational

32. The tempered water will be installed and local flow control is operational.

33. Punch list work is ongoing.

34. No life/safety systems activated.

35. No ATSs on systems.

36. The 480 volt power is wired to the disconnect switches.

37. Gas exhaust system has been installed and is operational.

38. Crane hoists have been installed and are operational.

39. The shrapnel shields are in place. 


\section{Appendix C to Scope of Work for IMI Services}

40. The PCS Initial Occupancy is complete.

L. The PAMMA is ready for equipment installation, activation and initial testing. The Infrastructure activities associated with CSP-9 are complete. This includes:

1. Room lighting is complete and operational.

2. Fire protection is complete within the area but has not been activated.

3. Emergency lighting provided.

4. Cleanrooms activated and tested to IES Specification. Certifying Class 1000 in outer room and Class 100 in inner rooms

5. LCW \& CW Supply and Return. Provided and tested

6. Racks, cables, and cable trays to support the distribution of the ICCS the ISS networks will be installed between the MOR, PAMMA and Control Room only.

7. Nitrogen gas available from an alternate source.

8. AC Power routed in the facility operational and tested

9. Provision for access, on a scheduled basis, for delivery of hardware and equipment through access doors provided

M. The MOR is ready for equipment installation, activation and initial testing. The Infrastructure activities associated with CSP-9 are complete. This includes:

1. A ceiling system is installed.

2. The MOR overhead area lighting (fluorescent) is installed and operational.

3. The MOR overhead spot lighting (halogen) is installed and operational.

4. The Emergency Paging system is installed in the MOR.

5. The MOR overhead fire sprinkler system is operational.

6. The Room is maintained in a level one clean construction protocol clean condition throughout the following activities.

7. The HVAC system to floor interface has been installed.

8. The Fiber ductbank trays have been installed.

9. The Fiber ductbank support structure, has been installed.

10. The computer floor, stanchions, have been installed.

11. The computer floor, ground plane and stringers, has been installed.

12. The computer floor has been grounded and tested to ILS specification (see requirements note).

13. The AC filters and conduits have been installed.

14. The computer cables have been installed.

15. The computer floor, floor tiles have been installed.

16. The computer floor, insulation sheets have been installed.

17. The computer floor, chimneys have been installed.

18. The rack enclosures have been installed and grounding verified.

19. The control console/enclosure have been installed.

20. The HVAC system has been installed and is operational.

21. Interior unique electronics enclosure ventilation system has been installed.

22. The PZ fiber tray in the MOR have been installed.

23. Verification of MOR Positive Pressurization has been provided 
24. Test PZ Fiber Ducting to PAMMA, LB2 and LB1 to ILS specification (see requirements note)

25. Test and balance both of the MOR HVAC systems to ILS specification (see requirements note) 


\section{LASER BAY INTERSTAGE ENCLOSURES}

\section{PART 1 GENERAL}

\subsection{DESCRIPTION}

A. The purpose of this specification is to define minimum requirements for the installation and alignment of the following components:

1. Interstage Docking Frames (ISDFs)

2. $\quad$ Laser Bay Interstage Enclosures (LBIEs)

3. Laser Bay Interstage Enclosure (LBIE) Bellows

4. Interstage Docking Frame (ISDF) Rupture Panels

5. Laser Bay Interstage Enclosure (LBIE) Gaskets

B. Laser Bay Interstage Enclosures (LBIEs) and Interstage Docking Frame (ISDFs) are enclosures that provide a precision cleaned and pressurized environment for the laser beam as it travels within the Laser Bays towards the Target Chamber. Inside surface conditions in terms of particulate and nonvolatile residue (NVR) levels result from cleanliness requirements needed to protect optical surfaces from laser-induced damage. As discussed in Sections 15892 and 15895, all the ISDFs, LBIEs, LBIE Bellows, and ISDF Rupture Panels will be cleaned to Level 83-A/10 per MIL-STD-1246C and will not exceed Level 100 after installation and alignment. The ISDFs are attached to the Spatial Filter (SF) End Vessels and provide access for bottom loading of the line-replaceable units (LRUs) that contain the SF lenses. Both the ISDFs and LBIEs will be pressurized with gas to prevent an in-flow of gas from the external environment into their precision cleaned interiors. LBIEs and LBIE Bellows are mounted and attached to the Laser Mirror 1 structures (LM1), Periscopes, Main Amplifiers (MA), Power Amplifiers (PA), Roving Mirror Diagnostic Enclosure (RMDE), and ISDFs attached to the SF End Vessels. For the ISDFs and LBIEs between LM1 and SF3, nitrogen gas provides the pressurized interior environment, while the ISDFs and LBIEs between the SF4 and RMDE have a pressurized interior environment of argon gas. The LBIEs and LBIE Bellows are bundle-wide enclosures and the ISDFs are cluster-wide enclosures that are divided into bundle partitions and have ISDF Rupture Panels attached to their top surface.

\subsection{QUALITY CONTROL AND QUALITY ASSURANCE}

A. General quality control and quality assurance requirements shall be per Section 01400 .

B. Definitions of quality control and quality assurance shall be per Section 01010 .

C. The subcontractor inspector shall perform the following:

1. Inspect rigging and attachment points for compliance to the University approved rigging diagram and plan. 
2. Inspect each installed LBIE and ISDF and other related components for compliance to Part 3.0 of this Section, Section 01625, Section 15892, Section 15895, and the respective drawings. This includes monitoring the Cleanroom Protocol Level per Section 01625, the airborne cleanliness level per Sections 01625 and 15892, and the surface cleanliness level per Sections 15892 and 15895.

3. The subcontractor precision measurement surveyor shall perform a survey of the each installed component to verify compliance with Section 15897, this Section, and the drawings.

4. All welds shall be visually inspected for complete fusion, correct size, and correct contour per drawing.

D. The subcontractor shall institute the following hold points and work shall not proceed beyond these points without written release by the University:

\section{(The following list of hold points needs to be evaluated for possible pruning)}

1. Installation of first bundle of LBIEs and LBIE Bellows between LM1 and MA.

2. Installation of first bundle of LBIEs, LBIE Bellows, and ISDFs between MA and SF1.

3. Installation of first bundle of LBIEs, LBIE Bellows, and ISDFs between SF2 and Periscope.

4. Installation of first bundle of LBIEs and LBIE Bellows between Periscope and PA.

5. Installation of first bundle of LBIEs, LBIE Bellows, and ISDFs between PA and SF3.

6. Installation of first bundle of LBIEs, LBIE Bellows, and ISDFs between SF4 and Switchyard Wall.

7. Installation of first bundle of LBIEs in Switchyard Wall.

8. Installation of first cluster of LBIEs and LBIE Bellows between LM1 and MA.

9. Installation of first cluster of LBIEs, LBIE Bellows, and ISDFs between MA and SF1.

10. Installation of first cluster of LBIEs, LBIE Bellows, and ISDFs between SF2 and Periscope.

11. Installation of first cluster of LBIEs and LBIE Bellows between Periscope and PA.

12. Installation of first cluster of LBIEs, LBIE Bellows, and ISDFs between PA and SF3.

13. Installation of first cluster of LBIEs, LBIE Bellows, and ISDFs between SF4 and Switchyard Wall.

14. Installation of first cluster of LBIEs in Switchyard Wall.

15. Installation of fourth cluster of LBIEs and LBIE Bellows between LM1 and MA.

16. Installation of fourth cluster of LBIEs, LBIE Bellows, and ISDFs between MA and SF1.

17. Installation of fourth cluster of LBIEs, LBIE Bellows, and ISDFs between SF2 and Periscope.

18. Installation of fourth cluster of LBIEs and LBIE Bellows between Periscope and PA.

19. Installation of fourth cluster of LBIEs, LBIE Bellows, and ISDFs between PA and SF3.

20. Installation of fourth cluster of LBIEs, LBIE Bellows, and ISDFs between SF4 and Switchyard Wall.

21. Installation of fourth cluster of LBIEs in Switchyard Wall. 
22. In-situ cleaning of first cluster of LBIEs in Switchyard Wall (see Section 15997).

23. In-situ cleaning of fourth cluster of LBIEs in Switchyard Wall (see Section 15997).

24. Installation of first cluster of ISDF Rupture Panels.

25. Installation of fourth cluster of ISDF Rupture Panels.

E. The subcontractor shall provide the opportunity for the University to witness the following activities:

1. Initial lifting and setting of LBIEs, LBIE Bellows, ISDFs, and ISDF Rupture Panels to be installed.

2. Setting and Alignment of LBIEs and ISDFs.

3. As-installed Survey of LBIEs and ISDFs.

4. Clean connection procedure for LBIEs, LBIE Bellows, ISDFs, and ISDF Rupture Panels.

5. In-situ cleaning of LBIEs in Switchyard Wall.

6. Surface cleanliness verification.

\subsection{DELIVERY, STORAGE AND HANDLING}

A. The subcontractor shall obtain LBIEs, LBIE Bellows, ISDFs, ISDF Rupture Panels, and other associated Government Furnished Equipment (GFE) items from NIF Production Control at the designated on-site location and shall transport the GFE to the Laser Bays for installation.

B. The subcontractor shall examine all GFE before transporting from the on-site location to the erection location and give written notice to the University about any deficiency which would be detrimental for proper and timely installation of GFE.

C. LBIEs, LBIE Bellows, ISDFs, and ISDF Rupture Panels have been precision cleaned and are furnished in a precision cleaned condition (Level 83-A/10 per MIL-STD-1246C), except for the LBIEs that will be in-situ cleaned as discussed in Section 15997. Associated GFE items will have been precision cleaned where indicated in the Infrastructure drawing/GFE list in section 01015; the balance of GFE items has been gross cleaned. The subcontractor shall implement the cleanliness protocol requirements per Section 01625, will implement clean connections in accordance with Section 15892, and will implement any additional cleanliness and cleaning requirements identified under Parts 2.0 and 3.0 of this Section.

D. The subcontractor shall be responsible for all transport, handling and rigging operations and equipment as discussed in Sections 01015 and 15896.

E. The subcontractor shall not weld any attachments to the GFE equipment except where specified herein or the drawings.

F. Puncture-proof and cleanliness covers are installed on various openings of the LBIEs, LBIE Bellows, ISDFs, and ISDF Rupture Panels to maintain the internal and some external surfaces in a precision cleaned state. The subcontractor shall remove those covers 
as discussed in Part 3 and Section 15892. After removing the covers, the surface cleanliness level of the precision cleaned GFE can be determined according to the requirements of Sections 15892 and 15895.

\section{PART 2 PRODUCTS}

\subsection{GOVERNMENT FURNISHED EQUIPMENT (GFE)}

A. The University shall supply the GFE components listed in Section 01015 which include, but are not limited to, the following major components:

1. Interstage Enclosure LM1 to MA

2. Interstage Enclosure MA to SF1

3. Interstage Enclosure SF2 to Periscope

4. Interstage Enclosure Periscope to PA

5. Interstage Enclosure PA to Bellows

6. Interstage Enclosure Bellows to SF3

7. Interstage Enclosures SF4 to Bellows

8. Interstage Enclosures Wall Extension

9. Interstage Enclosures Wall

10. SF1 Interstage Docking Frame

11. SF2 Interstage Docking Frame

12. SF3 Interstage Docking Frame

13. SF4 Interstage Docking Frame

14. Interstage Enclosure Bellows

15. Interstage Enclosure SF4 Bellows

16. Rupture Panels

17. SF3 Ghost Glass Tower Assembly

B. LBIEs, LBIE Bellows, ISDFs, and LBIE Gaskets were fabricated in accordance with detailed fabrication drawings and specifications.

C. LBIEs, LBIE Bellows, ISDFs, and seals have been precision cleaned and are furnished in a precision cleaned condition (Level 83-A/10 per MIL-STD-1246C). The subcontractor shall ensure protection of precision cleaned surfaces throughout handling and placement of all GFE. Precision cleaned surfaces include all internal vacuum beamtube surfaces, all internal pressurized enclosure surfaces, sealing surfaces at the vacuum boundary, sealing surfaces at the pressurized boundary, interior sides of the rupture panels, and interior sides of covers. Sections 01625,15892 , and 15895 provide specific cleaning and protocol requirements.

D. For the ISDFs, the bottom bundle openings are covered with permanent LRU covers and seals that are furnished as GFE. For the ISDFs, the front and back openings are protected with ULO polyethylene sheets and a puncture-proof plate installed by others. For the ISDFs, the top openings are covered with Rupture Panel Covers that will be replaced with 


\section{Appendix C to Scope of Work for IMI Services}

the Rupture Panels. The inner surface of the Rupture Panels is protected with ULO polyethylene sheets and a puncture-proof plate installed by others.

E. For the LBIEs and LBIE Bellows, except those that will be in-situ cleaned as discussed in Section 15997, the front and back openings are protected with ULO polyethylene sheets and a puncture-proof plate installed by others. For the LBIEs with ports, the ports are covered with port covers and seals.

F. The subcontractor shall ensure protection of precision cleaned surfaces throughout handling and placement of all GFE, as applicable. The subcontractor shall not remove ULO polyethylene sheets or puncture-proof plates from the ISDFs, LBIEs, or LBIE Bellows until the appropriate requirements of Section 01625, Section 15892, Section 15895, and Parts 2 and 3 of this Section are satisfied.

\subsection{SUBCONTRACTOR FURNISHED MATERIALS}

A. The subcontractor shall fabricate and supply all the materials shown on each drawing except those identified as GFE in the Infrastructure drawing/GFE list in Section 01015 and unless otherwise specified.

B. Materials provided by the subcontractor shall meet the requirements listed on the drawings and related specifications. Materials provided by the subcontractor shall be delivered to the Laser Bays and maintained as a minimum in a gross clean condition in accordance with Sections 01625, 15892, and 15895.

\section{PART 3 EXECUTION}

\subsection{PREREQUISITES \& EXAMINATION}

A. The subcontractor shall perform following work as prerequisites before installation of LBIEs, LBIE Bellows, and ISDFs.

1. Install Main Amplifier and Power Amplifier Trusses, including the Catwalk Supports per Section 15992

2. Install Main Amplifier and Power Amplifier FAU Busses with temporary covers (aluminum plate) on LBIE sides of Main Amplifier and Power Amplifier End Isolators per Section 15992

3. Maintain precision clean condition of LM1 with temporary covers (ULO polyethylene sheets with puncture-proof layer) on LBIE side of LM1

4. In-situ clean Periscope and install temporary covers (ULO polyethylene sheets with puncture-proof layer) on LBIE sides of Periscope per Section 15994

5. Maintain precision clean condition of Spatial Filter End Vessels (SF1, SF2, SF3, and SF4) with temporary covers (ULO polyethylene sheets with puncture-proof layer) on LBIE side of Spatial Filter End Vessels per Section 15993 
B. Before starting work, the The subcontractor shall examine underlying and adjoining work for damaged or other apparent conditions that may be masked or made inaccessible by installation of LBIEs, LBIE Bellows, ISDFs, and associated items.

C. Before installing the LBIEs, LBIE Bellows, and ISDFs, the subcontractor shall examine and evaluate interfacing equipment for proper geometry, location, and orientation, as specified on the drawings. The subcontractor shall report to the University immediately for apparent deviations or other conditions that may impede proper installation of the assemblies. Affected work shall not commence until notified to do so in writing by the University.

D. Before installing the LBIEs, LBIE Bellows, and ISDFs, the subcontractor shall examine and evaluate temporary covers (typically ULO polyethylene sheets with puncture-proof layer) for an conditions that deviate from the precision cleaned conditions (Level 83-A/10 per MIL-STD-1246C) of the components before installation. These temporary covers shall be in an undamaged condition on the LM1, Periscope, Main Amplifier End Isolators, Power Amplifier End Isolators, and Spatial Filter End Vessels (SF1, SF2, SF3, and SF4). The Main and Power Amplifier End Isolators have aluminum temporary covers. In addition, the temporary covers shall be in an undamaged condition on LBIE GFE components received by the subcontractor. These GFE components include the ISDFs with the LRU covers and gaskets as well as the Rupture Panel Covers and gaskets installed, the LBIEs with port covers and gaskets installed (except the LBIEs that are insitu cleaned per Section 15997), the LBIE Bellows with gaskets installed, the Rupture Panels, and the LBIEs with SF3 ghost mitigation hardware installed. The subcontractor shall report to the University immediately any conditions that may affect the clean installation of components. Affected work shall not commence until notified to do so in writing by the University.

\subsection{PREPARATION}

A. The subcontractor shall prepare an Installation Sequence and Procedure, a Clean Installation Procedure, and an In-Situ Cleaning Procedure and each Procedure shall include a checklist that sets forth a full description of the task to be performed, installation sequence, and list of work documents to be used in accomplishing the task checklist. The subcontractor is responsible for collecting necessary working documents, including but not limited to, drawings, specifications, and reference documents necessary for installation.

B. Before installation of specific LBIEs, LBIE Bellows, and ISDFs, the conditions near the installation shall satisfy the requirements of Sections $01625,15892,15895$, and 15894, as appropriate.

C. Before installation of specific LBIEs, LBIE Bellows, and ISDFs, the access to the locations of installation shall be evaluated in accordance with Part 3.03 of this Section.

D. For access into LBIEs and ISDFs, the requirements of Section 15893 shall be followed. To enter the LBIEs and ISDFs or to have personnel access on top of the LBIEs and ISDFs, 


\section{Appendix C to Scope of Work for IMI Services}

the subcontractor shall evaluate the effects of personnel and equipment loads on the LBIEs and ISDFs. Additional support and scaffolding may be required for personnel access inside and on top of the LBIEs and ISDFs. The evaluation of personnel and equipment loads shall be submitted to the University for review and acceptance. The LBIE Bellows do not have provisions for personnel access.

E. The subcontractor shall submit Welding Procedure Specification for LBIEs installed with welding for review and acceptance by the University. The Specification shall satisfy appropriate AWS requirements and requirements of Section 05120 as well as Part 3.04 of this Section.

F. The subcontractor shall submit Alignment / Survey Plan and Procedure for ISDFs and for LBIEs installed in Switchyard Wall. This Procedure will be reviewed for acceptance by the University and shall satisfy the appropriate requirements of Section 15897. The alignment tolerance in NIF global coordinates for LBIE components is $\pm 1 \mathrm{~mm}$. The LBIE Bellows shall be installed by subcontractor with a minimum of $25 \mathrm{~mm}$. of compression.

G. The subcontractor shall submit Leak Checking Procedure for review and acceptance by the University. This Procedure shall satisfy appropriate requirements of Section 15122 . The LBIEs, LBIE Bellows, and ISDFs between the LM1 and SF1 and between the SF2 and SF3 have a design pressure of 12" W.G. (3 KiloPascal). The LBIEs, LBIE Bellows, and ISDFs between the SF4 and RMDE have a design pressure of 4" W.G. (1 KiloPascal).

\subsection{MATERIAL HANDLING AND RIGGING}

A. LBIEs, LBIE Bellows, and ISDFs shall be lifted using Nylon strings at lift points defined in the drawings or lift plans developed by the GFE fabricators. No single point lifts shall be performed on the LBIEs, LBIE Bellows, and ISDFs. Handling and lifting features for the LBIEs and LBIE Bellows will be provided by the GFE fabricators. These features shall be examined and evaluated by the subcontractor before installation of the components. The subcontractor shall notify the University in writing of any deviations from GFE fabricator-defined lifting and handling features and shall not commence with deviation unless notified in writing by the University.

B. The subcontractor shall exercise care when handling and installing the Rupture Panels. The subcontractor shall notify the University in writing of any damage to the Rupture Panels that are considered by the University to have vulnerable components. In their installed condition, the Rupture Panels will have protection from protective screens on standoffs.

\subsection{WELDING}

A. Welding shall comply with the requirements of AWS D1.6, Section 05120, and the following:

Welding Process: Welds on the external surface shall be of the Gas Tungsten Arc Welding GTAW or Gas Metal Arc Welding (GMAW) processes. All weld joints on the internal 


\section{Appendix C to Scope of Work for IMI Services}

surfaces shall be performed with the GTAW process. Alternative processes require approval in writing from the University.

Joint Preparation: Before welding, joints shall be cleaned of all foreign materials such as oil, grease, paint, dust, and oxides or sulfides. Cleaning shall remove all visible evidence of contamination, including all stains and discoloration of the surfaces.

Distortion Control: Weld procedures and fixtures shall be selected to control distortion within dimensional limits bounded by University drawings. Copper chill bar (backing bar) is recommended for flat seams to minimize distortion and maintain flatness of finished panels. The procedure utilized to control distortion shall be submitted to the University for information.

Weld Procedure Specification (WPS): A WPS is required for each weld process including the combination of wire filler type, base metal type, and size to be used in the construction. Weld procedures shall conform to AWS D1.6 Annex F (no pre-qualified procedures may be used) or the equivalent form per ASME Boiler and Pressure Vessel Code (B\&PVC) Section IX. If ASME Boiler and Pressure Vessel Code is used, the Essential, Supplementary, and Nonessential Variables are required. WPSs shall be submitted in writing to the University for acceptance.

Procedure Qualification Record (PQR): A PQR is required for each Weld Procedure Specification. Each PQR shall be prepared in accordance with AWS D1.6 or the equivalent form per ASME B\&PVC Section IX, and signed by a certified or qualified weld inspector. Each PQR shall indicate the specific inspection criteria (by paragraph number) from the code used to evaluate the weld samples. PQRs shall be submitted in writing to the University for acceptance.

Welder Performance Qualification (WPQ) Test Record: A WPQ is required for each welder or welding operator covering the utilized welding processes. Each WPQ shall be prepared in accordance with AWS D1.6 or the equivalent form per ASME B\&PVC Section IX. Qualified welders shall perform all welding and WPQs shall be submitted to the University in writing for acceptance.

Weld symbols: Weld symbols on sketches and drawings shall be interpreted in accordance with AWS A2.4. Any conflicts or questions related to application or interpretation of weld symbols should be directed to the University in writing for disposition and clarification.

Weld Quality and Acceptance Criteria: Weld joints shall be free of cracks, crevices, or incomplete fusion. Limits of porosity shall be determined using inspection criteria defined in AWS D1.6. Internal welds shall have: smooth transition with parent material without rough edges along bead (maximum peak to valley height $0.76 \mathrm{~mm}$ ), no undercut, no splatter, and no discoloration from oxidation. Weld finish shall be smooth to enable final cleaning processes and cleanliness verification.

Weld Filler Metal: Electrodes and filler wire for welds shall be of type 308 stainless steel and procured under the applicable ASME BPVC Section II or AWS specification. The 


\section{Appendix C to Scope of Work for IMI Services}

certified material test reports (CMTRs) shall be submitted to the University for all weld filler metal for information.

B. Weld inspections shall comply with the requirements of AWS D1.6 and the following:

Weld Inspection: Welding activities and all completed welds shall be visually inspected in accordance with AWS D1.6 or weld joints shall blend into the adjacent base metal in gradual smooth curves using inspection acceptance criteria delineated in AWS D1.6. Additional inspection requirements specified on the drawings shall also be implemented.

Weld Inspectors: Weld Inspectors shall be qualified and certified in accordance with AWS QC-1 or other industry sanctioned inspector qualification program applicable to weld inspection. The subcontractor shall maintain records that attest to the active status of qualified or certified weld inspectors. Program practices and inspector qualification and certification documentation shall be submitted in writing to the University for acceptance prior to start of welding.

\subsection{INSTALLATION PROCEDURE AND SEQUENCE}

All LBIEs, LBIE Bellows, ISDFs, and associated items shall be installed in accordance with drawings. This Section provides additional requirements to be implemented in conjunction with the drawings. However, except where identified as "mandatory" or dictated by physical configuration, the procedure and sequence provided in this Section is a recommendation. The actual sequence to be implemented is to be determined by the subcontractor as reflected in the submitted Installation Sequence and Procedure.

For ease of installation of components, the subcontractor shall establish a HEPA controlled cleanroom for subassembly of precision cleaned components in the Laser Bays. This Subassembly Cleanroom shall satisfy the requirements of Sections 01500 and 01625 and within the Subassembly Cleanroom, the applicable requirements of Parts 3.01, 3.02, and 3.03 of this Section shall also be satisfied.

The gaskets for the LBIEs, LBIE Bellows, and ISDFs will be installed next to the light shields prior to the subcontractor receiving the GFE components. These gaskets are discussed in Section 15107 and they shall be protected during lifting, handling, and installation activities by the subcontractor. If the gaskets become detached or damaged from the LBIEs, LBIE Bellows, and ISDFs, the subcontractor shall notify the University in writing per Section 01560. To position the gaskets on the LBIEs, LBIE Bellows, and ISDFs, University-approved adhesive as defined on the drawings can be used.

The fasteners for the LBIEs, LBIE Bellows, and ISDFs are defined in the drawings. The subcontractor shall use fasteners that satisfy the requirements of Section 15062 and the drawings.

The following is a recommended Installation Sequence for LBIEs, LBIE Bellows, and ISDFs on a per bundle basis:

A. LM1 to Main Amplifier (Installation Drawing AAA97-111181) 
1. In Laser Bay, remove LM1 Outriggers on LBIE side of LM1 if access to the installation location needs to be increased

2. In Subassembly Cleanroom, remove temporary covers from LM1 to MA LBIE and from LBIE Bellows and attach a LBIE with bolts and nuts to a LBIE Bellows

3. In Subassembly Cleanroom, package LBIE/LBIE Bellows Subassembly with temporary covers on open ends of Subassembly

4. In Laser Bay, place LBIE/LBIE Bellows Subassembly with temporary covers between LM1 and the Main Amplifier from below or above to verify handling clearances

5. In Laser Bay, install LBIE/LBIE Bellows Subassembly between LM1 and the Main Amplifier from below or above according to Part 2.03 of Section 15892

a. In Laser Bay, install LBIE/LBIE Bellows Subassembly with bolts to tapped holes in Main Amplifier End Isolator

b. In Laser Bay, uncompress LBIE Bellows

c. In Laser Bay, install LBIE/LBIE Bellows Subassembly with bolts to tapped holes in LM1

6. In Laser Bay, install LM1 Outriggers on LBIE side of LM1 if previously removed

B. Main Amplifier to SF1 (Installation Drawing AAA97-111182)

1. In Laser Bay, place SF1 ISDF with temporary covers between SF1 End Vessel and the Main Amplifier from below or above to verify handling clearances

2. In Laser Bay, remove Rupture Panel Covers and establish clean HEPA flow through openings in the ISDF with a portable clean-air supply system according to Part 2.02C of Section 15892

3. In Laser Bay, install ISDF Subassembly between SF1 End Vessel and the Main Amplifier from below or above

a. In Laser Bay, remove "guillotine" of inner temporary covers and install ISDF with exterior bolts and nuts to SF1 end vessel according to Part 2.03 of Section 15892 and using the 3 survey features on the ISDF and a "best-fit" process to the SF1 end vessel as described in Section 15897

b. In Laser Bay, complete installation of ISDF with interior bolts and nuts to interior of SF1 end vessel according to Part 2.02C of Section 15892. For the interior bolts, the access requirements of Section 15893 shall be satisfied. If the LRU Covers need to be removed, the requirements in the drawings and in Section 15893 shall be satisfied.

c. In Laser Bay, package Main Amplifier side of ISDF with temporary covers

4. In Laser Bay, remove portable clean-air supply systems from ISDF and install Rupture Panel Covers with nuts on welded studs according to Part 2.02C of Section 15892

5. In Subassembly Cleanroom, remove temporary covers from MA to SF1 LBIE and from LBIE Bellows and attach a LBIE Bellows with bolts and nuts to SF1 side of a LBIE

6. In Subassembly Cleanroom, package LBIE/LBIE Bellows Subassembly with temporary covers on open ends of Subassembly 


\section{Appendix C to Scope of Work for IMI Services}

7. In Laser Bay, place LBIE/LBIE Bellows Subassembly with temporary covers between SF1 End Vessel and the Main Amplifier only from below to verify handling clearances

8. In Laser Bay, install LBIE/LBIE Bellows Subassembly between SF1 End Vessel and the Main Amplifier only from below according to Part 2.03 of Section 15892

a. In Laser Bay, install LBIE/LBIE Bellows Subassembly with bolts to tapped holes in Main Amplifier End Isolator

b. In Laser Bay, install LBIE/LBIE Bellows Subassembly with shims, bolts, and nuts to Main Amplifier Catwalk Supports

c. In Laser Bay, uncompress LBIE Bellows

d. In Laser Bay, install LBIE/LBIE Bellows Subassembly with bolts and nuts to installed ISDF

9. In Laser Bay, install ISDF Rupture Panel only from above according to Part 2.03 of Section 15892

a. Remove Rupture Panel Covers

b. In Laser Bay, install ISDF Rupture Panel, Standoff, and Safety Screen with nuts to welded studs on top of ISDF

10. After LBIEs, LBIE Bellows, and ISDFs installed between LM1 and SF1 Vacuum Covers, Leak Checking can be performed between LM1 and SF1 according to Section 15122 to a design pressure of 12" W.G. (3 KiloPascal)

C. SF2 to Periscope (Installation Drawing AAA97-111187)

1. In Laser Bay, place SF2 ISDF with temporary covers between SF2 End Vessel and the Periscope from below or above to verify handling clearances

2. In Laser Bay, remove Rupture Panel Covers and establish clean HEPA flow through openings in the ISDF with a portable clean-air supply system according to Part $2.02 \mathrm{C}$ of Section 15892

3. In Laser Bay, install ISDF between SF2 End Vessel and the Periscope from below or above

a. In Laser Bay, remove "guillotine" of inner temporary covers and install ISDF with exterior bolts and nuts to SF2 end vessel according to Part 2.03 of Section 15892 and using the 3 survey features on the ISDF and a "best-fit" process to the SF2 end vessel as described in Section 15897

b. In Laser Bay, complete installation of ISDF with interior bolts and nuts to interior of SF2 end vessel according to Part 2.02C of Section 15892. For the interior bolts, the access requirements of Section 15893 shall be satisfied. If the LRU covers need to be removed, the requirements in the drawings and in Section 15893 shall be satisfied.

c. In Laser Bay, package Periscope side of ISDF with temporary covers

4. In Laser Bay, remove portable clean-air supply systems from ISDF and install Rupture Panel Covers with nuts on welded studs according to Part 2.02C of Section 15892

5. In Subassembly Cleanroom, remove temporary covers from SF2 to Periscope LBIE and from LBIE Bellows and attach a LBIE Bellows with bolts and nuts to Periscope side of a LBIE 
6. In Subassembly Cleanroom, package LBIE/LBIE Bellows Subassembly with temporary covers on open ends of Subassembly

7. In Laser Bay, place LBIE/LBIE Bellows Subassembly with temporary covers between SF2 End Vessel and the Periscope from below or above to verify handling clearances

8. In Laser Bay, install LBIE/LBIE Bellows Subassembly between SF2 End Vessel and the Periscope from below or above according to Part 2.03 of Section 15892

a. In Laser Bay, install LBIE/LBIE Bellows Subassembly with bolts to tapped holes in Periscope

b. In Laser Bay, uncompress LBIE Bellows

c. In Laser Bay, install LBIE/LBIE Bellows Subassembly with bolts and nuts to installed ISDF

9. In Laser Bay, install ISDF Rupture Panel only from above according to Part 2.03 of Section 15892

a. Remove Rupture Panel Covers

b. In Laser Bay, install ISDF Rupture Panel, Standoff, and Safety Screen with nuts to welded studs on top of ISDF

D. Periscope to Power Amplifier (Installation Drawing AAA97-111189)

1. In Subassembly Cleanroom, remove temporary covers from Periscope to PA LBIE and from LBIE Bellows and attach a LBIE with bolts and nuts to a LBIE Bellows

2. In Subassembly Cleanroom, package LBIE/LBIE Bellows Subassembly with temporary covers on open ends of Subassembly

3. In Laser Bay, place LBIE/LBIE Bellows Subassembly with temporary covers between Periscope and the Power Amplifier only from above to verify handling clearances

4. In Laser Bay, install LBIE/LBIE Bellows Subassembly between Periscope and the Power Amplifier only from above according to Part 2.03 of Section 15892

a. In Laser Bay, install LBIE/LBIE Bellows Subassembly with bolts to tapped holes in Power Amplifier End Isolator

b. In Laser Bay, uncompress LBIE Bellows

c. In Laser Bay, install LBIE/LBIE Bellows Subassembly with bolts to tapped holes in Periscope

E. Power Amplifier to SF3 (Installation Drawing AAA97-111191)

1. In Laser Bay, place SF3 ISDF with temporary covers between SF3 End Vessel and the Power Amplifier from below or above to verify handling clearances

2. In Laser Bay, remove Rupture Panel Covers and establish clean HEPA flow through openings in the ISDF with a portable clean-air supply system according to Part $2.02 \mathrm{C}$ of Section 15892

3. In Laser Bay, install ISDF Subassembly between SF3 End Vessel and the Power Amplifier from below or above

a. In Laser Bay, remove "guillotine" of inner temporary covers and install ISDF with exterior bolts and nuts to SF3 end vessel according to Part 2.03 of Section 15892 and using the 3 survey features on the ISDF and a "best-fit" process to the 
SF3 end vessel as described in Section 15897

b. In Laser Bay, complete installation of ISDF with interior bolts and nuts to interior of SF3 end vessel according to Part 2.02C of Section 15892. For the interior bolts, the access requirements of Section 15893 shall be satisfied. If the LRU Covers need to be removed, the requirements in the drawings and in Section 15893 shall be satisfied.

c. In Laser Bay, package Power Amplifier side of ISDF with temporary covers

4. In Laser Bay, remove portable clean-air supply systems from ISDF and install Rupture Panel Covers with nuts on welded studs according to Part 2.02C of Section 15892

5. In Subassembly Cleanroom, remove temporary covers from Bellows to SF3 LBIE and from LBIE Bellows and attach a LBIE Bellows with bolts and nuts to Bellows side of a LBIE

6. In Subassembly Cleanroom, package LBIE/LBIE Bellows Subassembly with temporary covers on open ends of Subassembly

7. In Laser Bay, place PA to Bellows LBIE with temporary covers between SF3 End Vessel and the Power Amplifier only from below to verify handling clearances

8. In Laser Bay, install PA to Bellows LBIE to the Power Amplifier only from below according to Part 2.03 of Section 15892

a. In Laser Bay, install PA to Bellows LBIE with bolts to tapped holes in Power Amplifier End Isolator

b. In Laser Bay, install PA to Bellows LBIE with shims, bolts, and nuts to Power Amplifier Catwalk Supports

c. SF3 Ghost Glass Tower Assemblies are installed in the PA to Bellows LBIE prior to the subcontractor receiving the PA to Bellows LBIE. The requirements of Section 15893 and Part 3.02 of Section 15892 shall be satisfied if the subcontractor must access these Assemblies. Written approval from the University is required before accessing the Tower Assemblies.

9. In Laser Bay, place LBIE/LBIE Bellows Subassembly with temporary covers between SF3 End Vessel and the Power Amplifier from below or above to verify handling clearances

10. In Laser Bay, install LBIE/LBIE Bellows Subassembly between SF3 End Vessel and the Power Amplifier from below or above according to Part 2.03 of Section 15892

a. In Laser Bay, install LBIE/LBIE Bellows Subassembly with bolts and nuts to installed PA to Bellows LBIE

b. In Laser Bay, uncompress LBIE Bellows

c. In Laser Bay, install LBIE/LBIE Bellows Subassembly with bolts and nuts to installed ISDF

d. SF3 Ghost Glass Tower Assemblies are installed in the LBIE/LBIE Bellows Subassembly prior to the subcontractor receiving the Bellows to SF3 LBIE. The requirements of Section 15893 and Part 3.02 of Section 15892 shall be satisfied if the subcontractor must access these Assemblies. Written approval from the University is required before accessing the Tower Assemblies.

11. In Laser Bay, install ISDF Rupture Panel only from above according to Part 2.03 of Section 15892

a. Remove Rupture Panel Covers 


\section{Appendix C to Scope of Work for IMI Services}

b. In Laser Bay, install ISDF Rupture Panel, Standoff, and Safety Screen with nuts to welded studs on top of ISDF

12. After LBIEs, LBIE Bellows, and ISDFs installed between SF2 Vacuum Covers and SF3 Vacuum Covers, Leak Checking can be performed between SF2 and SF3 according to Section 15122 to a design pressure of 12" W.G. (3 KiloPascal)

F. SF4 to Roving Mirror Diagnostic Enclosure (Installation Drawing AAA97-111193)

1. In Laser Bay, place SF4 ISDF with temporary covers between SF4 End Vessel and the Switchyard Wall from below or above to verify handling clearances

2. In Laser Bay, remove Rupture Panel Covers and establish clean HEPA flow through openings in the ISDF with a portable clean-air supply system according to Part $2.02 \mathrm{C}$ of Section 15892

3. In Laser Bay, install ISDF between SF4 End Vessel and the Switchyard Wall from below or above

a. In Laser Bay, remove "guillotine" of inner temporary covers and install ISDF with exterior bolts and nuts to SF4 end vessel according to Part 2.03 of Section 15892 and using the 3 survey features on the ISDF and a "best-fit" process to the SF4 end vessel as described in Section 15897

b. In Laser Bay, complete installation of ISDF with interior bolts and nuts to interior of SF4 end vessel according to Part 2.02C of Section 15892. For the interior bolts, the access requirements of Section 15893 shall be satisfied. If the LRU covers need to be removed, the requirements in the drawings and in Section 15893 shall be satisfied.

c. In Laser Bay, package Switchyard Wall side of ISDF with temporary covers

4. In Laser Bay, remove portable clean-air supply systems from ISDF and install Rupture Panel Covers with nuts on welded studs according to Part 2.02C of Section 15892

5. In Laser Bay, place Wall LBIE (not precision cleaned) through hole in Switchyard Wall from below due to space constraints above structures at end of Laser Bays

6. In Laser Bay, temporarily support with bolts and nuts in the LBIE Supports the Wall LBIE in cluster opening of Switchyard Wall in order to perform survey of location of Wall LBIE

7. In Laser Bay, survey location of Wall LBIE using survey locations on Wall LBIE as described in Section 15897

8. In Laser Bay, field weld LBIE Supports and Anchor Plate for Wall LBIE to embedment plates in cluster opening in Switchyard Wall according to requirements in Section 05120 and Part 3.04 of this Section

9. In Laser Bay, field weld Wall LBIE to Supports and Anchor Plate according to requirements in Section 05120 and Part 3.04 of this Section

10. In Laser Bay, attach temporary covers over Laser Bay side of Wall LBIE

11. In Switchyard, field weld Switchyard side of Wall LBIE to Roving Mirror Diagnostic Enclosure (RMDE) Plate according to requirements in Section 05120 and Part 3.04 of this Section. Section 15997 provides the requirements for the installation of the RMDE Plate 
12. In Switchyard, in-situ precision clean from temporary covers on Laser Bay side of Wall Extension LBIE to temporary covers on RMDE. Sections 15894 and 15997 provide the requirements for the in-situ precision cleaning of the RMDE and the Wall LBIE

13. In Subassembly Cleanroom, remove temporary covers from Switchyard side of Wall Extension LBIE and install dielectric to Wall Extension LBIE

14. In Subassembly Cleanroom, remove temporary covers from SF4 to Bellows LBIE and from LBIE Bellows and attach a LBIE Bellows with bolts and nuts to Switchyard Wall side of a LBIE

15. In Subassembly Cleanroom, package LBIE/LBIE Bellows and Wall Extension LBIE Subassemblies with temporary covers on open ends of Subassemblies

16. In Laser Bay, place Wall Extension LBIE Subassembly with temporary covers between SF4 End Vessel and the Switchyard Wall only from below to verify handling clearances

17. In Laser Bay, install Wall Extension LBIE Subassembly between SF4 End Vessel and the Switchyard Wall only from below according to Part 2.03 of Section 15892

a. In Laser Bay, install Wall Extension LBIE Subassembly with bolts and nuts to installed Wall LBIE

18. In Laser Bay, place LBIE/LBIE Bellows Subassembly with temporary covers between SF4 End Vessel and the Switchyard Wall only from below to verify handling clearances

19. In Laser Bay, install LBIE/LBIE Bellows Subassembly between SF4 End Vessel and the Switchyard Wall only from below according to Part 2.03 of Section 15892

a. In Laser Bay, install LBIE/LBIE Bellows Subassembly with bolts and nuts to installed ISDF

b. In Laser Bay, uncompress LBIE Bellows

c. In Laser Bay, install LBIE/LBIE Bellows Subassembly with bolts and nuts to installed Wall Extension LBIE

20. In Laser Bay, install 2-hour rated Fire Sealant between Wall Extension LBIE and opening in Switchyard Wall

21. In Laser Bay, install ISDF Rupture Panel only from above according to Part 2.03 of Section 15892

a. Remove Rupture Panel Covers

b. In Laser Bay, install ISDF Rupture Panel, Standoff, and Safety Screen with nuts to welded studs on top of ISDF

22. After LBIEs, LBIE Bellows, ISDFs, and RMDE installed between SF4 Vacuum Covers and Switchyard Isolation Valves, Leak Checking (on a cluster basis) can be performed between SF4 and Switchyard Isolation Valves according to Section 15122 to a design pressure of 4" W.G. (1 KiloPascal) 


\section{SPATIAL FILTER VACUUM VESSEL ENCLOSURES}

\section{PART 1 GENERAL}

\subsection{DESCRIPTION}

A. The purpose of this specification is to define minimum requirements for transport, lifting, assembly, installation, and vacuum leak testing of the following items in accordance with the drawings (AAA97-111148 and AAA97-111149):

1. CSF \& TSF beam tubes

2. CSF \& TSF beam tube supports

3. TSF center vessel extension tubes

4. CSF/TSF center vessel bottom port bellows and kinematic mount tops

5. $\mathrm{CSF} / \mathrm{TSF}$ vacuum and purge connector tube assemblies

6. High vacuum valves

7. CSF \& TSF end vessel vacuum blank-off plates

8. Ghost mitigation hardware inside CSF \& TSF vessels and beam enclosures

B. Beam tubes consist of circular and rectangular tube sections that contain the light between the center and end vessels of the spatial filter vacuum vessels. Beam tubes are connected at the vessels and constrained axially at the end vessels. They attach at the center vessels with beam connector tube assemblies which include a bellows expansion section.

C. The requirements and sequence of work is typical for each independent vacuum bundle. Both CSF and TSF spatial filters consist of end vessels, center vessel, and interconnecting beam tube bundles, columns and connecting tubes. Each vessel is composed of six independent volumes, therefore, the completed spatial filter installation of one cluster includes six independent volumes from one end vessel to the other end vessel. Thus, four clusters of spatial filters results in 24 independent CSF vacuum bundle volumes and 24 independent TSF vacuum bundle volumes.

D. Each CSF vacuum bundle volume is approximately 40,000 liters. Each TSF vacuum bundle volume is approximately 93,000 liters

\subsection{QUALITY ASSURANCE}

A. General Quality Control and Quality Assurance requirements shall be per Section 01400.

B. Definitions of Quality Control and Quality Assurance shall be per Section 01010.

C. The subcontractor's QC inspector shall perform the following:

1. Inspect rigging and attachment for compliance to the University approved rigging diagram and plan. 
2. Inspect each installed beam tube supports, beam tube Column, Vacuum Valves, and other related assemblies for compliance to part 3.0 of this section and the respective drawings.

3. The subcontractor's University approved precision measurement surveyor shall perform a survey of the each installed component to verify compliance with Section 15897, this section and the drawings.

4. All welds shall be visually inspected for complete fusion, correct type, size and contour per the drawing.

5. Surface cleanliness validation of the interior of surfaces of vessels and beam enclosures shall be performed and documented on a "Validation Certificate" per Section TBD. [Procedures for this validation remain to be defined.]

D. The subcontractor shall institute the following hold points; work shall not proceed beyond this point without written release by the University:

1. Placement and installation of first article CSF or TSF center vessel bottom bellows/kinematic mount top assemblies.

2. First in-vessel work inside a clean vessel enclosure.

3. Initial lifting, placement and clean connection installation of first article beam tube column assembly to the TSF end vessel with internal hardware connections.

4. Lifting, placement and clean connection installation of first article beam tube bundle assembly to the CSF end vessel.

5. University shall be notified 10 days in advance of the first bundle to be vacuum leak tested.

E. The subcontractor shall provide the opportunity for the University to witness the following activities:

1. Lifting, setting and clean connection installation of each beam tube and vacuum/purge connector tube installation.

2. In-vessel work required for installation of kinematic mount bellows and ghost mitigation hardware.

3. Vacuum leak testing of each CSF and TSF vacuum bundle volume.

\subsection{DELIVERY, STORAGE AND HANDLING}

A. The subcontractor shall obtain all GFE items (beam tubes, center vessel extension tubes, vacuum valves etc.) as identified in infrastructure GFE list from NIF production control at the designated on-site location and transport to Laser Bay for installation.

B. The subcontractor shall examine all Government Furnished Equipment (GFE) before transporting from the on-site location to the erection location. The subcontractor shall give written notice to the University of any deficiency or condition that impede installation (see Section 15895).

C. The subcontractor shall implement the cleanliness requirements per section 15895 with regard to these items and any additional cleanliness and cleaning requirements identified 


\section{Appendix C to Scope of Work for IMI Services}

under parts 2.0 and 3.0 of this section. The subcontractor shall also implement section 01625 Construction Cleanliness Protocol.

D. The subcontractor shall be responsible for all transport, handling and rigging operations and equipment as discuss in Sections 01015, 15896 and 01620.

E. The subcontractor shall not weld any attachment to the GFE equipment except where specified herein or the drawings.

F. Covers are installed on various openings of each vessel and beam tube to maintain the internal and some external surfaces in a precision cleaned state. The subcontractor shall remove these covers just before attaching the adjacent component.

G. Beam enclosure tubes shall be lifted using lifting attachment points shown on the drawings. Beam tubes may be lifted with nylon strings at two lift points, spaced apart at least $1 / 3$ of the length of the beam tubes. Single point lifts shall NOT be performed on the beam tubes.

\section{PART 2 PRODUCTS}

\subsection{GOVERNMENT FURNISHED EQUIPMENT (GFE)}

A. The University will provide all the items identified as GFE in the infrastructure drawing/GFE list of section 01015, which includes, but not limited to following major components.

1. CSF \& TSF beam tube bundles and columns, circular and rectangular sections, precision cleaned and packaged by University.

2. TSF center vessel extension tubes precision cleaned and packaged by University.

3. CSF \& TSF center vessel bottom port bellows and kinematic mount tops precision cleaned and packaged by University.

4. CSF \& TSF vacuum and purge connector tube assemblies with bellows precision cleaned and packaged by University.

5. CSF \& TSF end vessel vacuum blank-off plates precision cleaned and packaged by University.

6. Ghost mitigation hardware inside CSF \& TSF vessels and beam enclosures precision cleaned and packaged by University.

B. In addition to the GFE identified in Section 01015, the University will provide following components for use by the subcontractor at its discretion:

1. Bellows compression tools, quantity 2 .

2.

C. Each CSF and TSF Vessel has been installed and aligned on concrete pedestals by the CSP-13 subcontractor; refer to CSF Vessel Installation (AAA99-107876) and TSF Vessel Installation (AAA99-108039). 
D. See Concrete Pedestals drawing (AAA97-103454) and Laser Bay Concrete Pedestal Structure Technical Specification NIF-5000930 for details on the concrete pedestals.

\subsection{SUBCONTRACTOR FURNISHED MATERIALS}

A. The subcontractor shall provide all the materials shown on each drawing except those identified as GFE in the Infrastructure GFE list of Section 01015.

B. CSF beam tube support structures and supports (AAA99-107876) [verify with CV]

C. TSF beam tube support structures and supports (AAA98-101147) [verify with CV]

D. The following valves shall be procured and furnished by the subcontractor in accordance with Section 15261 and the drawings.

1. High vacuum gate valves, size 10 ", quantity 48 .

2. Roughing vacuum gate valves, size 8 ", quantity 48 .

3. Roughing vacuum inline valves, size 1", quantity 48.

4. Purge/vent vacuum gate valves, size 3", quantity 48 .

E. Materials provided by the subcontractor shall meet the requirements listed on the drawing and related specifications. Materials provided by the subcontractor shall be delivered to the Laser Bay and maintained as a minimum in clean condition consistent with the requirements in Section 15895.

\section{PART 3 EXECUTION}

\subsection{PREREQUISITES \& EXAMINATION}

A. Before starting work, the subcontractor shall examine underlying and adjoining work for damage or other apparent deleterious conditions that may be masked or made inaccessible by installation of the beam tube assemblies and associated items. The subcontractor shall report any damage or conditions that impact installation to the University.

B. Before installing the beam tube assemblies and other associated items examine interfacing items for proper geometry, location, and orientation as specified on the drawings. The subcontractor shall also examine the previously installed \& aligned vessels, tower support table assemblies to assure the vessel precision cleanliness barriers have not been breached and there is no other apparent damage. The subcontractor shall report to the University immediately for apparent deviations or other conditions that may impede proper installation of the assemblies. Do not commence affected work until notified to do so in writing by the University.

C. The subcontractor shall prepare an installation procedure, which shall include an installation and inspection checklist, a full description of the task to be performed, installation sequence, QA hold and witness points, and a listing of the work documents to be used. The procedure shall also include survey/alignment actions necessary to fulfill 
Section 15897. The subcontractor is responsible for collecting the necessary working documents including but not limited to drawings, specifications and reference documents necessary for installation

\subsection{INSTALLATION SEQUENCE AND DESCRIPTION}

The beam tube assemblies, vacuum/purge connector tube assemblies, vacuum valves and other associated items shall be installed in accordance with drawing AAA97-111148 \& AAA97-111149. This article provides additional details of the work to be performed in conjunction with the drawings and other related sections. Except where identified as "mandatory" or dictated by physical configuration, the sequence below is provided to facilitate the description of the work and to assist the subcontractor in understanding the relationship and fit-up assumptions between components. The drawing references are for guidance. The actual installation sequence planned by the subcontractor shall be submitted for University approval prior to execution.

A. CSF \& TSF End Vessel Vacuum Blank-off Plate Covers:

1. Vacuum blank-off plate covers shall be installed at each end vessel $1 \times 4$ vertical column at the LRU mounting location, side furthest from the center vessel.

2. Some vacuum blank-off plate covers have been pre-installed by the University. There are a total of 192 vacuum blank-off plate covers. The following vessels have pre-installed vacuum blank-off plate covers:

$\begin{array}{lll}\text { Vessel } & \text { Vessel quantity } & \text { Cover quantity } \\ \text { SF1 } & \text { TBD } & \text { TBD } \times 12 \\ \text { SF2 } & \text { TBD } & \text { TBD } \times 12 \\ \text { SF3 } & \text { TBD } & \text { TBD } \times 12 \\ \text { SF4 } & \text { TBD } & \text { TBD } \times 12\end{array}$

3. Install vacuum covers not pre-installed by University. The subcontractor shall prepare and submit an installation procedure for installing the vacuum covers for University approval.

4. Care must be taken by the subcontractor to maintain the cleanliness of the precision cleaned vessels and covers consistent with the requirements of Section 15894.

B. CSF \& TSF Beam Tube Mounting Structure and Supports:

1. Install the CSF beam tube mounting structure in accordance with drawing AAA99107876.

2. Install the TSF beam tube supports \#2 through \#7 in accordance with drawing AAA98-101147.

3. Install the Unistrut beam connecting tube supports for supporting the center vessel beam connecting tube assemblies in accordance with drawing AAA99-116070. The 


\section{Appendix C to Scope of Work for IMI Services}

subcontractor shall install the Unistrut supports following CSP-14 subcontractor's installation of the catwalk structures and as required during beam tube connection installation rather than installing all of the Unistrut supports prior to starting beam tube installations. Detailed coordination of work is required with CSP - 14 subcontractor per Section 01039.

C. CSF Beam Tubes

1. The beam tube installation shall be performed in an equivalent class 5,000 or better environment and consistent with the clean connection requirements of Section 15893 and work in clean enclosures requirements of Section 15894. An equivalent local clean environment may be proposed and submitted by the subcontractor in accordance with the following:

a. Establishing a temporary subassembly cleanroom around the installation area.

b. Providing a positive air pressure inside the vessel or beam tube and appropriate HEPA air flow through the vessel or beam tubes openings.

c. Minimize the time the vessel and beam tubes are opened to the environment.

d. Do not remove protective covers when the environment is greater than class 10,000 .

2. The subcontractor shall receive from the University the SF1 and SF2 beam tube subassemblies with ghost mitigation and gasket hardware pre-installed, precision cleaned and double wrapped.

a. Establish scaffolding and/or utilize man-lifts as necessary to facilitate connection and safe installation of equipment.

b. Install SF1 and SF2 beam tubes per the University drawings and accepted installation procedure. Vessel entry is not required for this assembly.

c. The vacuum valves should be pre-installed on the tube assemblies in a local cleanroom prior to installing the tube assemblies to the CSF center vessel. Clean covers shall be placed over the open side of the valve and double wrapped.

d. Install CSF beam connecting tube assemblies per the University accepted installation procedure. The University will provide two bellows compression tools. Before installing the tube assembly the bellows shall be compressed as necessary to facilitate insertion of the part between center vessel and beam tube bundle. The subcontractor furnished vacuum O-rings shall be installed at the end of each connecting tube.

D. TSF Beam Tubes

1. The beam tube installation shall be performed in an equivalent class 5,000 or better environment and consistent with the clean connection requirements of Section 15893 and work in clean enclosures requirements of Section 15894. An equivalent local clean environment may be proposed and submitted by the subcontractor as discussed in paragraph 3.02.C1.

2. The subcontractor shall receive from the University the SF3 and SF4 beam tube subassemblies with ghost mitigation and gasket hardware pre-installed, precision cleaned and double wrapped. 
3. Plan and execute installation of ghost mitigation features in SF3 and SF4 end vessels in conjunction with installing the rectangular straight beam tubes to the end vessels. Vessel entry is required to attach the ghost features and the rectangular straight beam tubes to the end vessel (see paragraph 3.03).

4. The subcontractor may consider pre-connecting the rectangular straight and the rectangular tapered beam tubes in a local clean room and placing both tube assemblies in one operation. If performed separately the rectangular straight beam tube would require temporary support and the clearance between tubes for bolting the flanges is extremely limited. Special tooling and bolting hardware features shall be evaluated and submitted by the subcontractor where necessary to facilitate installation.

5. The subcontractor may consider pre-connecting the rectangular straight, rectangular tapered and both circular beam tubes in a local clean room and placing all beam tube assemblies in one operation. This placement will require special rigging fixtures and procedures but may facilitate make-up and bolting of flanged connections where clearances are limited.

6. Install TSF rectangular straight beam tubes per the University accepted installation procedure. Vessel entry is required (see paragraph 3.03).

NOTICE: There are two SF4 rectangular straight beam tubes, AAA97-103531, SF-4, Rectangular Straight, \#1, and AAA97-103532, SF-4, Rectangular Straight, \#2. The difference in the two beam tubes is one has a right-hand and the other a left-hand $0.12^{\mathrm{O}}$ taper on the flange that mounts to the SF4 vessel. Refer to the installation drawing for the correct beam tube location and details.

7. Install the TSF rectangular tapered beam tubes per the University accepted installation procedure.

8. Install the TSF circular beam tubes per the University accepted installation procedure.

9. The vacuum valves should be pre-installed on the tube assemblies in a local cleanroom prior to installing the tube assemblies to the TSF center vessel. Clean covers shall be placed over the open side of the valve and double wrapped.

10. Install TSF beam connecting tube assemblies per the University accepted installation procedure. The University will provide two bellows compression tools. Before installing the tube assembly the bellows shall be compressed as necessary to facilitate insertion of the part between center vessel and beam tube bundle. The subcontractor furnished vacuum O-rings shall be installed at the end of each connecting tube.

E. Install center vessel kinematic mount bellows assembly in the round and rectangular kinematic mount bottom ports. Perform work activities inside the CSF \& TSF center vessels in accordance with the section 3.03 for the vessel entry requirements.

1. Establish a cleanroom work zone above the center vessel bundle. Establish HEPA ventilation flow from the clean work zone through the internal vessel bundle space by removing a blank flange cover or temporary poly cover from a bottom port flange.

2. Remove the center vessel top plate cover to gain access into the vessel bundle space. Maintain the cover in a precision clean state for later closure of the vessel bundle space. Place a clean room ladder into the vessel space to facilitate access. 


\section{Appendix C to Scope of Work for IMI Services}

3. The subcontractor shall receive from the University the kinematic mount bellows assemblies with related gasket and bolting hardware, precision cleaned and double wrapped.

4. Remove the temporary bellows port covers and wipe clean all surfaces near and around the port location. HEPA air flow shall be exiting the port opening due to ventilation established in paragraph 1 above. Wipe all surfaces in the direction of the port opening and utilize the exiting air to remove any particles and dispose of cleanroom whiper.

5. Install the kinematic mount bellows assembly and kinematic mount tops per the drawings.

6. Plan and execute installation of kinematic mount bellows in conjunction with installing the center vessel extension tubes. Work on kinematic mount bellows should be performed prior to installation of extension tubes to prevent particle contamination of the extension tubes. If extension tubes are previously installed, temporary precision clean covers shall be placed over the internal port openings during kinematic mount bellows installation or any related work activities inside the center vessel.

F. Install the TSF center vessel extension tubes on the underside of the TSF center vessel. The extension tubes consist of the following for each vessel bundle: $1 \omega$ Alignment Spool, $1 \omega$ Diagnostic Spool, and 2 Injection Spools.

1. The extension tube installation shall be performed in an equivalent class 10,000 or better environment and consistent with the clean connection requirements of Section 15893 and work in clean enclosures requirements of Section 15894. An equivalent local clean environment may be proposed and submitted by the subcontractor as discussed in paragraph 3.02.C1.

2. The subcontractor shall receive from the University the extension tube subassemblies with related gasket and bolting hardware, precision cleaned and double wrapped.

3. Plan and execute installation of extension tubes in conjunction with installing the kinematic mount bellows.

G. Install Ghost Mitigation features inside the end vessels. Perform work activities inside the CSF \& TSF end vessels in accordance with the section 3.03 for the vessel entry requirements.

1. Plan and execute installation of ghost mitigation features in the end vessels in conjunction with installing the rectangular straight beam tubes to the end vessels.

Vessel entry is required to attach the ghost features and the rectangular straight beam tubes to the end vessel (see paragraph 3.03).

2. The subcontractor shall receive from the University the ghost mitigation subassemblies with related bolting hardware, precision cleaned and double wrapped.

3. Install the ghost mitigation equipment per the drawings.

H. Vacuum Leak Testing 
1. The subcontractor shall vacuum leak test each independent vacuum bundle from end vessel to end vessel (SF1 to SF2 for CSF and SF3 to SF4 for TSF) in accordance with the requirements of the Section 15121.

2. It is recommended that the subcontractor perform preliminary vacuum leak testing of smaller bundle volumes prior to final end vessel to end vessel bundle leak testing to confirm proper installation of the smaller subassemblies. Reasonable smaller volumes may include the following: a) each end vessel through circular beam tube segment, b) center vessel with kinematic bellows and extension tubes. Final bundle leak testing would follow installation of the beam connecting tubes attached to the center vessel.

3. The University shall be notified 10 days in advance of the first bundle to be vacuum tested.

\subsection{ENTRY INSIDE THE VESSEL}

A. End vessel entry is required to attach the ghost mitigation features and the rectangular straight beam tubes to the end vessels. Vessel entry shall be made through the bottom manport opening and HEPA flow established through the top manport opening. The vessel interior is precision cleaned to a level 83 particulate cleanliness per MIL-STD-1246 and the subcontractor shall be responsible for maintaining the vessel in a precision cleaned condition during entry inside the vessel and following exit from the vessel.

1. Initial assembly of some vessels utilizes a manport cover, AAA99-102950 (obsolete), with Gask-o-seal gasket which will not adequately vacuum seal the vessel manports.

2. Correct assembly of vessel requires a manport cover-grove, AAA99-116071, with oring seal as shown on End Vessel Assembly drawing AAA 99-101675.

3. The subcontractor shall inspect each vessel manport cover and determine by part number which cover is installed on the manport. The manport cover with Gask-o-seal shall be replaced with the manport cover-grove, AAA99-116071, with o-ring.

4. The subcontractor shall receive from the University the replacement manport covergrove, AAA99-116071, with o-ring for installation on the manport opening following completion of entry inside the vessel and closure of the manport.

5. The obsolete manport cover, AAA99-102950, shall be returned to the University for rework.

B. Center vessel entry is required to install the kinematic bellows. Vessel entry shall be made through the top vacuum cover opening and HEPA flow established through the top opening by use of temporary cleanroom above the vessel and removal or a bottom port blank cover. The vessel interior is precision cleaned to a level 83 particulate cleanliness per MIL-STD-1246 and the subcontractor shall be responsible for maintaining the vessel in a precision cleaned condition during entry inside the vessel and following exit from the vessel.

C. Working inside the vessel is defined as a confined space and work shall be performed in accordance with the Section 15893. HEPA flow shall be established through the vessel interior space. The subcontractor shall submit a procedure for working in a confined space and for maintaining the vessel precision cleanliness level. 


\subsection{WELDING}

A. Unless otherwise specified welding shall be performed in accordance with the AWS D1.1 and performed by qualified welders. Unless otherwise specified all structural material and welds are of low carbon steel and weld material shall be selected in accordance with AWS D1.1.

B. Welding process shall be Gas Tungsten-Arc Welding (GTAW), Flux Cored-Arc Welding (FCAW) or Gas Metal-Arc Welding (GMAW).

C. Weld Procedure Specification and Welder Qualification Reports shall be submitted to the University for information.

D. Cleanliness shall be maintained in welding areas. All stubs and other foreign or expanded material shall be removed from the structure.

E. Weld symbols on sketches and drawings shall be interpreted in accordance with AWS A2.4. Any conflicts or questions related to application or interpretation of weld symbols shall be directed to the University for disposition and clarification.

\subsection{ALIGNMENT AND SURVEY}

A. Alignment and surveying shall be performed in accordance with Section 15897.

B. Beam Tube Enclosure Position

1. The position of beam tube enclosures between end vessel and center vessel is dictated by the machined tolerances in the mating parts.

2. Centering pins are provided at the top and bottom beam tube flanges to facilitate alignment of flanged connections. The beam tube support hardware shall be adjusted to align beam tubes plumb with end vessel face and mating beam tube flange.

3. The subcontractor shall measure and record the actual beam tube column centerline position relative to the nominal beam tube centerline between end vessel and center vessel. A deviation of greater than $20 \mathrm{~mm}$ at the circular beam tube flange adjacent to the beam connecting tubes is not permissible. The subcontractor shall report any deviations greater than $20 \mathrm{~mm}$ for review and resolution by the University.

\subsection{GASKETS AND SEALS}

A. All gaskets and seals provided by the subcontractor shall be in accordance with the drawings and Section 15107.

B. All gaskets and seals provided by the subcontractor shall precision cleaned per Section 15895. 


\subsection{PAINTING}

A. Touch-up painted scratched or otherwise exposed previously painted surfaces, and paint subcontractor installed welds and adjacent surfaces per Section 09900. 


\section{MAIN AMPLIFIER AND POWER AMPLIFIER}

\section{PART 1 GENERAL}

\subsection{DESCRIPTION}

A. The purpose of this specification is to define minimum requirements for transport, handling, lifting, installation, and alignment of Main Amplifier (MA) and Power Amplifier (PA) assemblies identified in drawings (AAA98-100655 \& AAA98-100653). There are four Amplifier assemblies in this construction package, two each in Laser Bays 1 and 2.

B. Each Laser Bay has two Power Amplifier and two Main Amplifier cluster. Each cluster consists of a steel structure that supports six Frame Assembly Unit (FAU) buses on a system of seven trusses. The trusses are supported on concrete pedestals. The two MA clusters have some of the concrete pedestals in common, as do the two PA clusters. The clusters can be treated independently and installed in parallel if enough resources (manpower, preload equipment etc.) are available. Three rows of 12-inch channel truss ties are provided at the top of the trusses, one row at the $-\mathrm{Z}$ end and two at the $+\mathrm{Z}$ end. The two rows of truss ties at the $+Z$ end are used to support grating for an access platform to the top of Amplifiers. The row at the $-Z$ end and one of the rows at the $+Z$ end support the outer housing of the Amplifier End Isolator. The tops of the trusses located at the $+X$ side and the $-\mathrm{X}$ side are tied to the concrete walls of the pedestals by welding bracket plates to embedded plates in the pedestal. Match drilling and bolting them to pre-welded bracket plates on the trusses using high strength bolts and a tie plate.

C. The Main Amplifier and Power Amplifier assemblies have been assembled \& disassembled at the fabricator's shop. The University recommends that the subcontractor consult with the fabricator to take advantage of this experience. The fabricator can be contacted at:

Hogan Manufacturing

Esclalon, CA

(209) 838-7323

\subsection{QUALITY CONTROL AND QUALITY ASSURANCE}

A. For definitions of Quality Control and Quality Assurance shall be per Section 01010.

B. General Quality Control and Quality Assurance requirements shall be per Section 01400 .

C. The subcontractor QC Inspectors shall perform the following:

1. Inspect rigging and attachment for compliance to the University-approved rigging and handling procedure. 


\section{Appendix C to Scope of Work for IMI Services}

2. Visually inspect all welds for correct type, complete fusion, correct size and correct contour per the drawing.

3. Inspect installation of the Amplifier Assembly for compliance to the drawing and Part 3.0 of this Section as delineated in the subcontractor's approved installation sequence and procedures.

4. The subcontractor's University-approved precision measurement surveyor shall perform survey of the installed Amplifier Assemblies to verify compliance with Section 15897, this Section, and related drawings.

D. The subcontractor shall institute the following Hold Points; work shall not proceed beyond this point without written release by the University:

1. Subsequent to scribing and prior to welding steel plate to pedestal embedment plates for review of placement locations.

2. Before field drilling the Truss ties to concrete wall.

3. After all Buses are tied and installed in place, but before adding top structure to verify the buses alignment.

E. The subcontractor shall provide the opportunity for the University to witness the following activities:

1. Initial lifting and setting of major Amplifier Assembly section to be installed.

2. Welding to Pedestal embedment plates.

3. Field drilling of Truss ties.

\subsection{DELIVERY, STORAGE AND HANDLING}

A. The subcontractor shall obtain Main Amplifier and Power Amplifier assembly sections and other associated GFE items as denoted in section 01015 from NIF Production Control at the designated on-site location and transport to Laser Bay for Installation.

B. The subcontractor shall examine all Government Furnished Equipment (GFE) before transporting from the on-site location to the erection location. The subcontractor shall give written notice to the University of any deficiency or condition that could impede proper or timely installation (see Section 15895).

C. The subcontractor shall implement the cleanliness requirements per section 15895 with regard to these items and any additional cleanliness and cleaning requirements identified under parts 2.0 and 3.0 of this section. The subcontractor shall also implement section 01625 Cleanroom Cleanliness Protocol.

D. The subcontractor shall be responsible for all transport, handling and rigging operations and equipment as delineated in Sections 01015 and 15896.

E. The subcontractor shall not weld or otherwise permanently attach to the GFE equipment except where specified herein or on the drawings. 
F. Retrieval of Transporter (loaded with Amplifier assembly) from storage area:

The subcontractor shall implement the following steps in order to remove a loaded Amplifier from storage. This task is accomplished by using the following list of GFE available from the University: Two Air Pallets, Two Air Pallet Drive Units, a $900 \mathrm{cfm}$ air supply, and One Straddle Lift. All personnel that will operate this GFE shall receive prior training on operation of the equipment. Do not expose the Transporter for more than 8 continuous hours to environment outside $20+/-5.0{ }^{0} \mathrm{C}$.

1. Locate a Transporter that is identified as "Loaded".

2. Drive the Air Bearing Pallets under the desired Transporter.

3. Connect main air supply to the Transporter.

4. Connect each Air Pallet Air supply

5. Connect the drive unit air supply.

6. Inflate the Air Bearings by opening the control valve.

Note: It might be necessary to shim the Air Bearing so that they are snug against the Transporter before inflating the bearings to preclude parts of the Transporter from dragging on the ground during movement.

7. Drive the Transporter into the main isle.

8. Drive the Transporter out of the building and deflate the air bearings on the exterior pad.

9. Remove the Air Bearings from the Transporter.

10. Remove the four lifting fixture covers from the Transporter (drawing AAA98-101903 or AAA98-101901, item 15).

11. Drive Straddle Lift over the Transporter centering the Straddle lift over the Transporter within +/- $25 \mathrm{~mm}$ (1").

Note: Leave Air Bearings under the Transporter but disconnect the drive units and drive Straddle Lift over Transporter and use Air Bearings with the drive units attached on the ends to position the Transporter under the Straddle Lift.

12. Lower Straddle Lift Lifting bars into receivers of Transporter (drawing AAA9810193 or AAA98-101901).

13. Place the Lifting Pins (drawing AAA98-101903 or AAA98-101901, item 32) through Transporter and Straddle Lift securing the load to the lift.

14. Using a qualified operator place the Straddle Lift in "Low Speed Operation" set idle speed and drive the Straddle Lift and Transporter to the receiving area at the NIF LTAB.

15. Lower Transporter to the landing pad outside the LTAB/OAB corridor and remove the Lifting Pins (drawing AAA98-101903 or AAA98-101901, item 32) from Transporter.

Note: The landing pad shall be a surface that is flat within $5 \mathrm{~mm}$ and level within 1-_ ${ }^{0}$ with a surface that is free of cracks and joints and capable of supporting $34,000 \mathrm{~kg}$.

16. Replace items removed in step10.

G. Movement of Transporter (loaded with Amplifier assembly) into NIF LTAB: 
The following steps are required to move a loaded Amplifier Transporter from the receiving area at the NIF LTAB to the parked area ready to unload into the structure. This task is accomplished by using the following list of GFE available from the University: Tow Air Pallets, Two Air Pallet Drive Units and One Straddle Lift. All personnel that will operate GFE must be properly trained for the operation of that equipment. One overhead crane in the LTAB building and one $900 \mathrm{cfm}$ or lager air compressor will also be required. Do not expose the Transporter for more than 8 hours to environment outside $20+/-5.0{ }^{0} \mathrm{C}$.

1. If required a high-pressure wash may be completed prior to entry into the LTAB.

2. Drive Air Bearing under desired Transporter.

3. Connect main air supply to Transporter.

4. Connect each air pallet air supply.

5. Attach drive unit to each end of the Transporter.

6. Connect drive unit air supply.

7. Inflate air bearing by opening the control valve.

8. Drive Transporter into LTAB/OAB Corridor through double doors.

Note: The Transporter will be stenciled as to which end should be pointed toward Target Chamber Center. When off-loading the Transporter outside of the building Transporters that are going into Laser Bay 1 should have the stencil facing towards the exterior door on the corridor. Transporters going in Laser Bay 2 should have the stenciling facing away from the exterior door. This will ensure proper orientation when the parts are off-loaded in the Laser Bay.

9. Drive Transporter down the LTAB Corridor approximately following the paths shown in Figure 2.

10. Park Transporter next to the corresponding off-load location. The Transporter should be approximately centered to the concrete pedestal.

\section{PART 2 PRODUCTS}

\subsection{GOVERNMENT FURNISHED EQUIPMENT (GFE)}

A. The University will provide the Amplifier Assemblies and associated components identified as GFE in Infrastructure drawing/GFE list of Section 01015.

B. The Main Amplifier and Power Amplifier are to be constructed on concrete pedestals provided by the University. The concrete pedestals are shown on drawing (AAA9713453-0B) and AAA97-103456-0B.

C. In addition to GFE identified in Section 01015, the University will provide the following items for use by the subcontractor at its discretion.

1. Hamar Laser Level

2. Euclid Alignment Laser

3. Tie rod removal

4. Concrete Blocks

5. Transporter

6. Two air pallets and two air pallet drive units 
7. $900 \mathrm{cfm}$ air supply

8. Straddle lift

9. Scaffold as required

\subsection{SUBCONTRACTOR FURNISHED MATERIAL AND EQUIPMENT}

A. The subcontractor shall provide the items in the Infrastructure drawing/GFE list of Section 01015 not identified as GFE ("non-GFE").

B. Material and equipment provided by the subcontractor shall be maintained in a cleaned condition consistent with the requirements in Section 15895.

\section{PART 3 EXECUTION}

\subsection{PREREQUISITES AND EXAMINATION}

A. Before starting work the subcontractor shall examine underlying and adjoining work for damage or other apparent deleterious conditions that may be masked or made inaccessible by installation of the Main Amplifier and Power Amplifier Assemblies and associated items. The subcontractor shall report any damage or conditions that impact installation to the University.

B. Before installing assemblies examine and survey interfacing embedment plates for proper geometry, location and orientation, as defined on the Amplifier Pedestal drawing (AAA97-103453-0B, AAA97-103456-0B, and Laser Bay Concrete Pedestal Structure Specification NIF-5000930).

C. Prior to start erection of the Amplifier support steel, embedded plates shall be surveyed to determine the positions of the support box girders in relation to the existing embedded plates. Each of the embedded plates is provided with two quarter inch diameter holes to permit setting of accurate survey instruments. Mark the locations of the girder attachment points on the embedded plates.

D. The subcontractor shall immediately report to the University in writing any apparent deviations or other conditions that may impede proper installation of the assemblies. Do not commence affected work until notified to do so in writing by the University.

E. The subcontractor shall prepare an installation procedure, which shall include an installation, and inspection checklist, a full description of the task to be performed, installation sequence, QA hold and witness points, and a listing of the work documents to be used. The subcontractor is responsible for collecting necessary working documents including but not limited to drawings, specifications and reference documents necessary for installation. 


\subsection{INSTALLATION SPECIFICS:}

The Main Amplifier and Power Amplifier Assemblies and associated items shall be installed in accordance with drawings (AAA98-100655 for Main Amplifier, AAA98100653 for Power Amplifier Truss and Rail, AAA-99-111936 for Power Amplifier FAU, and AAA99-111937 for Power Amplifier Super Structure). The following sections provide additional requirements to be implemented in conjunction with the drawing. However, except where identified as "mandatory" or dictated by physical configuration, the sequence provided is a recommendation, and the drawing references are for guidance. The actual sequence to be implemented is to be determined by the subcontractor as reflected in the submitted installation sequence and procedures.

\subsection{LOWER SUPERSTRUCTURE INSTALLATION}

The Lower superstructure provides supports to bundled Power Condition System (PCS) cables and Nitrogen cooling ductwork. The Lower superstructure and associated items shall be installed in accordance with drawing AAA99-111937.

A. Box Girders:

1. Box girders with the stud weld plates (saddle plates with studs) loosely attached to the bottoms of the girders shall be lifted into place. Shim to raise the tops of the girder to appropriate levels.

2. The tops of the girders are provided with stud weld plates to facilitate connection of the Amplifier support trusses. Two of the studs at each end shall be selected to mount survey instruments to determine the location of the girders as shown on Drawing AAA98-100655 for the Main Amplifier and AAA98-1009653 for the Power Amplifier.

3. Align the girders per Section 15897. Tack weld the stud plates under the box girder to embedded plates.

4. Lift the box girders up and out of the way to permit structural welding of the weld stud plates to the embedded plates. Insert shims between underside of box girder and stud weld plates as required to raise the top of girder in accordance with Section 15897.

B. Amplifier Support Trusses:

1. Truss assemblies are provided with holes for 3-inch diameter pins. Each truss requires a pair of connector angles at each end. Plates with bonded neoprene sheets are sandwiched between the angles and the sides of the truss bottom chord members.

2. The connector angles, the plates with neoprene and the truss bottom chord members are provided with holes for 3-inch diameter pins. Insert the pins through the connector angles, the plates with bonded neoprene sheets and the truss bottom chord members.

3. Use nuts over the threaded ends of the pins at each end to secure the pins in place. Care should be taken to locate the pins to have same projection of the pins on each side before the end nuts are put on. 


\section{Appendix C to Scope of Work for IMI Services}

4. The trusses with pins and connector angles are placed on top of the support girders. There are two U-shaped stud weld plates per truss, one on each side of truss welded on the box girder.

5. The connector angles are provided with holes in the horizontal legs to permit attachment of the trusses to the box girder weld stud plates. The studs are attached to trusses by means of a connector nut at top and a leveling nut below the connector angle leg.

6. The leveling nut permits adjustment of the level of the top of erected trusses. Horizontal slotted holes in the $\mathrm{Z}$ direction in the connector angle legs, permit adjustment of the truss location in the $\mathrm{Z}$ direction.

7. Tie the tops of trusses together with the 10-inch channels (AAA97-111244) using high strength bolts to connect to the 12-inch channel pieces (AAA97-111247, Item 8) welded on top of the trusses.

8. One row of truss ties is provided at the '- $Z$ ' end and two rows of truss ties are provided at the ' $+Z$ ' end. The trusses are set and aligned using survey features on each end at top of trusses (see Drawing AAA98-100655 for the Main Amplifier and AAA98-1009653 for the Power Amplifier).

9. Align the end locations of the trusses to position in accordance with Section 15897. Insert packing shims under the leveling nuts at the truss bottoms. Similarly insert packing shims between the vertical legs of the u-shaped weld stud plates and the ends of the connector angles to secure truss location in the $\mathrm{Z}$ direction.

C. Attachment of Amplifier Support Trusses to Concrete:

1. Embedded plates are provided on the sides of the vertical concrete walls at the $+X$ and $-\mathrm{X}$ sides of each cluster of trusses. The centerlines of the embedded plates are at the same level as the top of the truss top chord members.

2. The top chord members of the trusses nearest the concrete walls are provided with horizontal connector plates (AAA97-111247, Item 7) with a 1-9/16 inch diameter holes for one and one-half inch diameter high strength bolts.

3. Weld horizontal connector plates to the embedded plates in the concrete walls. Drill a 1-9/16-inch diameter hole at 8 inches from the truss connector plate bolt hole and tie the two plates together with match drilled 3/8-inch thick strap plates using two 1-1/2 inch diameter high strength bolts.

4. Drilling of holes in the connector plates welded to embedded plates shall be done after alignment of the trusses is finally confirmed. The trusses are set and aligned using survey features on each end at the top of the trusses (see Drawing AAA98100655 for the Main Amplifier and AAA98-1009653 for the Power Amplifier).

5. Align the end locations of the trusses in accordance with Section 15897.

D. Grating and Ladders:

Grating and Ladders shall be installed in accordance with drawings (PA) AAA97-1088340B and (MA) AAA97-109024-0B. 


\subsection{INSTALLATION AND ALIGNMENT OF RAILS}

A. Preloading of Structure:

1. The entire truss system for one cluster shall be preloaded to the full weight of populated FAUs. Each truss will be load tested to $125 \%$ of the preload.

2. Three concrete blocks shall be moved under each truss. A total of 21 concrete blocks are required per cluster. Each truss shall be connected to the concrete blocks with load cells and a hydraulic pump. The truss will then be remotely loaded to $125 \%$ of the specified preload value TBD.

3. After successful load testing, each truss shall be connected to the concrete blocks with load cells and a chain fall. Using the chain falls and load cells the cluster will be loaded to the proper weight TBD distribution for a fully populated amplifier cluster. (Need Drawing Number)

B. Scaffold Installation:

1. Scaffold shall be supplied and installed as required by the subcontractor.

2. Scaffold shall be installed over the concrete block to allow working at the top of the trusses. The working surface of the scaffold shall be $36+/-6$ inches below the top of the trusses.

C. Rails Installation:

1. Install the rails and rough align the rails or template in the $X$ and $Z$ directions to \pm 2.0 $\mathrm{mm}$ relative to NIF Global. (Note: The spacing between the sections of each rail ( $\mathrm{Z}$ direction) must be maintained to within $\pm 0.125 \mathrm{~mm}$ [see Drawings AAA98-100655 for the Main Amplifier and AAA99-111936 for the Power Amplifier]. This is to ensure that the amplifier will match the boltholes in the rails.

2. Use the Euclid alignment laser fixtures Drawing (AAA98-110397 \& AAA99$100218)$ to align the rails in the $X$ direction. Remove the rails or template and match drill and tap the trusses for the rail tie-down bolts. Reinstall the rails and install the rail tie down bolts (see Drawings AAA98-100655 for the Main Amplifier and AAA99-111936 for the Power Amplifier).

D. Rail Precision Alignment:

1. A Hamar laser level fixture (GFE) (drawing AAA98-115002) will be installed in one corner and its receivers will be installed in the other three corners of a cluster. Survey will use the laser tracker and set each of the four targets to a set height above the rails (height to be agreed on by both amplifier and survey).

2. These targets will become the masters for leveling the rails. This will set the vertical $\mathrm{Y}$ position of the rails. Note that the laser tracker will have to be positioned at or above the rail height to provide visibility to the targets.

3. Use the Euclid alignment laser fixtures (GFE) (drawings AAA98-110397 and AAA99-100218) to align the rails in the X direction. Survey will set the Euclid targets in the proper location at each end of the truss. As the rails are moved in the horizontal X direction the vertical Y direction will be checked. 
4. Required accuracy of the installed rails for $\mathrm{X}$ and $\mathrm{Y}$ is $\pm 0.625 \mathrm{~mm}$ (includes all errors i.e. survey, placement and measured) in relation to NIF global co-ordinates. Required accuracy of the installed rails in $\mathrm{Z}$ is $\pm 1.5 \mathrm{~mm}$ (includes all errors i.e. survey, placement and measured) in relation to NIF global co-ordinates.

5. Survey will provide scribe lines for the $Z$ position of the AMP rail. Scribed lines shall be on the inside of the " $C$ " channel on the top of the truss. The scribe line is only required on the target end of the truss. When the entire cluster has been aligned survey will check the alignment of each rail using the laser tracker. That data will be checked against the Euclid and Hamar data to determine if the rails are within the alignment specification. When the alignment is correct the scaffolding and loads are removed and moved to the next cluster for alignment.

\subsection{INSTALLATION OF MAIN AMPLIFIER (MA) AND POWER AMPLIFIER (PA) BUSES}

The Amplifier Buses are assembled and aligned in the B381 Amplifier Assembly Area. Once the buses are completed they are picked up using a strongback and placed into a purpose built Transporter (also know as container). The Transporters are then placed into storage or ready for pick-up to be installed in NIF. Buses will be retrieved from storage first. Once all buses have been retrieved from storage they will be picked up from the Assembly Area directly.

A. FAU Bus Installation:

The following sequence prepares the Bus for removal from the Transporter according to drawings (AAA98-10193 and AAA98-10901). The overhead crane in the LTAB building will be required.

1. Remove Item 15 from Transporter (quantity 4)

2. Unlatch Items $27 \& 29$ (quantity 4) retaining Item 9

3. Using four Carr-Lane Lifting pins (CL-8-LFP-1.00) or equal lift item 9 off.

4. Unlatch Items $27 \& 29(4 x)$ retaining Item 10

5. Using four Carr-Lane Lifting pins (CL-8-LFP-1.00) or equal, remove item 10. Items may be stacked to conserve space.

6. Repeat Steps $4 \& 5$ for remaining panel. Items may be stacked to conserve space.

7. Using two Carr-Lane Lifting pins (CL-8-LFP-1.00) secure item 8 before unlatching.

8. Unlatch Items $27 \& 29$ (quantity 6) retaining Item 8 and remove panel. Items may be stacked to conserve space.

9. Repeat steps $7 \& 8$ for remaining Item 8 panel. Items may be stacked to conserve space.

10. With the Main Air Supply Valves Closed (see Figure 3) open all airbag valves.

11. Open Vent Valve and let the system vent until the pressure gage reads zero psi.

12. Disconnect the Amplifier Bus Purge System.

13. Loosen Strongback-retaining bolt (item 15, AAA98-101901 or item 12, AAA98101903

14. The following steps are required to install the bus onto the MA or PA structure. The overhead crane in the LTAB building will be required. 
15. Remove the truss ties AAA97-111244 from the space where the bus is being placed. Do not remove the ties from the adjoining trusses.

16. Attach a 25-ton Crosby Shackle to the Strongback Lifting Point (see AAA98-102057 or AAA98-102058)

17. Using the LTAB main hoist lift the Strongback and Bus from the Transporter and place in the structure. (See AAA98-100665 or AAA98-100663 for travel paths and details)

18. Bus should be centered on the rail within $+/-2 \mathrm{~mm}$ in $\mathrm{Z}$.

19. A safety drain wire should be installed that connects the installed bus to building ground. This connection should be clearly marked and visible so that it can be removed for high potential (hi-pot) testing and after pulsed power cable installation.

20. An audible continuity checker should be used to inform the installer if the electrical insulation integrity if violated during the installation process.

21. Connect a purge gas system to the bus to maintain a 3-5 inches of $\mathrm{H} 2 \mathrm{O}$ positive pressure in the bus with ULPA filtered N2 or ULPA and carbon filtered air. The purge gas shall have a relative humidity of less than $60 \%$.

22. The following steps are required to remove the Strongback from the bus. This task is accomplished by using the following list of Government Furnished Equipment (GFE) available from the Amplifier Group (WBS 1.3.2.6): Tie rod removal tool and necessary training required to operate the tool. All personnel that will operate any GFE must be properly trained for the operation of that equipment.

23. See Detail C of AAA98-102057. Remove item 13 and one item 5 twenty times.

24. See Detail D of AAA98-102057. Remove item 15 and one item 5 four times.

25. Lift Strongback from bus and replace in Transporter. Tighten Strongback-retaining bolt Item 15, AAA98-101901.

26. See Detail C of AAA98-102057. Remove remaining item 5. Loosen item 14 and remove Tie Rod (item 4) with supplied removal tool. Replace items removed from step 23.

27. See Detail D of AAA98-102057. Remove the bottom item 15 from the threaded rod (item 6). Remove rod from item 7 and replace items from step 24. Remove the End Isolator bracket (item 7) from the End Isolator by loosening items 10, 11, and 16. Replace bolts on loose bracket.

28. Place loose items from steps $26 \& 27$ into sturdy boxes or buckets and place inside transporter. (Items 4-7 and 10-16). The installation subcontractor shall create a check list that identifies all loose parts and verifies that they are in the Transporter. The checklist shall be part of the written procedures submitted for LLNL approval prior to the start of work.

29. Seismic tie plates are installed between adjacent FAU bus Top Plates and between the out board $(+\mathrm{X}$ and $-\mathrm{X})$ Top Plates and the concrete support pedestals. Embedded plates are provided on the sides of the vertical concrete walls at the $+\mathrm{X}$ and $-\mathrm{X}$ sides of each cluster of trusses. The centerlines of the embedded plates are at the same level as the top of the FAU top plate. The seismic ties for the Top Plate nearest the concrete walls are provided by horizontal connector plates with 1-9/16 inch diameter holes for one and one-half inch diameter high strength bolts. Weld horizontal connector plates to embedded plates in concrete walls. Drill 1-9/16-inch diameter hole at 8 inches from the Top Plate seismic tie bolt hole and tie the two plates together with $3 / 8$-inch thick 
strap plates using two 1-1/2 inch diameter high strength bolts. Install the Top Plate to Top Plate seismic ties.

B. Reassembly of Transporter:

It is very important to reassemble the Transporter with the installation panels in the original positions. Ensure that the stencils match for each panel position (see drawing ??? for more information). The following sequence applies to both MA Transporter (AAA98101903) and the PA Transporter (AAA98-101901).

1. Using two Carr-Lane Lifting pins (CL-8-LFP-1.00) lift item 8 into position on Transporter. Secure with six latches (items 27 \& 29)

2. Repeat step 1 for remaining panel

3. Using four Carr-Lane Lifting pins (CL-8-LFP-1.00) lift item 10 into position on Transporter. Secure with four latches (items $27 \& 29$ )

4. Repeat step 3 for remaining panel

5. Using four Carr-Lane Lifting pins (CL-8-LFP-1.00) lift item 9 into position on Transporter. Secure with four latches (items 27 \& 29)

6. Replace Item 15 and secure with item $32(4 \mathrm{x})$

C. Return of Transporter to Storage Facility:

Once the bus has been delivered to the Laser Bay the Transporter should be returned to the Storage Facility.

1. Mark Transporter traveler as "UNLOADED"

2. Move unloaded transporter to an open position in the Storage Facility.

\subsection{COMPLETION OF FAU BUS INSTALLATION}

A. Installation of End Isolators:

The following steps are required to complete the installation of the End Isolators that are attached to the Bus ends. This can occur in parallel with the above sections (Reassembly of Transporter and Return of Transporter to Storage Facility) depending upon availability of Crane.

1. Support weight of the End Isolator using overhead crane and lug attachment points at the top of the End Isolator

2. Remove the transport clamps

3. Attach the End Isolator to $\mathrm{C}-$ Channel with appropriate amount of shimming (bolted connection)

4. With stabilizer bracket assemblies (AAA99-108922) attached to the End Isolator use proper thickness shim to place attachment plate against header beam.

5. Tack weld attachment plate to header beam

6. Unbolt stabilizer bracket weldment from the End Isolator and attachment plate 
7. Use continuous fillet weld along both vertical edges of the attachment plate to attach it to the header beam.

All the areas of structural steel where paint is removed to facilitate welding and areas damaged in installation and erection shall be touch-up painted in accordance with Section 09900.

8. Bolt stabilizer bracket weldment and appropriate thickness shim to attachment plate and the End Isolator.

B. Installation of Docking Blocks:

1. Docking blocks shall be installed in accordance with drawings (AAA96-106156) and AAA96-109154). The docking blocks are serialized and each has a specific location.

2. Bolts shall be torqued to specified value on the respective drawings or per manufacturer's specification.

C. Mapping of FAU Location:

1. LLNL Survey will map the entire cluster of docking block survey features. Record this data and compare to the map of the FAUs from assembly in building 381 . This is a hold point quality check to assure the bus has maintained alignment.

D. Hi-Pot Test of FAU

1. Hi-pot test each installed bus to the truss structure in accordance with Section 16966 (after removing the safety drain wire). Maintain electrical isolation of the FAU enclosure from all surrounding structures in all subsequent steps.

E. Installation of Temporary Bus Ground

1. After each bus has passed the hi-pot, replace the safety drain wire connecting the FAU bus to building ground Protection of Top of FAUs.

2. After all 6 FAU buses in a cluster have been installed, cover the entire cluster and top of the FAUs with plastic and build a wood floor over the entire cluster. This provides protection to the FAUs during assembly of the super structure. It provides an area to walk on over the FAUs. Temporary decking shall contact the amplifier busses at specified locations only. These bearing locations on the Big Ts are defined in Figure 4.

\subsection{UPPER SUPERSTRUCTURE INSTALLATION}

A. Upper superstructure provides supports to bundled Power Condition System (PCS) cables and Nitrogen cooling ductwork. The super-structure of each cluster consists of support vertical frames at the $+\mathrm{X}$ and the $-\mathrm{X}$ sides that are connected together by horizontal frame modules. The super-structure for each cluster has a cable ramp on the $\mathrm{X}$ side away from the Laser Bay centerline. The ramp supports the PCS cables running from the Capacitor Bay to the Amplifier. The support vertical frames are attached to the top of the concrete pedestals using stud weld plates welded to embedded plates in the concrete and bolted to 


\section{Appendix C to Scope of Work for IMI Services}

the base plates of the vertical frames. The horizontal frames are erection bolted initially to the vertical support frames and to the adjacent horizontal frames and then a structural weld connection is made at all joints with erection bolts. The PCS cable ramp frames are initially tack-welded to the vertical frames and then structurally welded. Diagonal brace members are provided in the $\mathrm{X}$ direction with bolted connections.

B. The Upper superstructure and associated items shall be installed in accordance with drawing AAA99-111937. The following steps must be followed to install the upper superstructure.

1. Survey the locations of the embedded plates, on top of the pedestal walls provided for attachment of the support vertical frames of the super-structure.

2. Mark the locations of the centerlines of the vertical columns.

3. Vertical frames with loosely attached weld stud plates shall be lifted into place.

4. Adjust the frame locations to the marked locations on the embedded plates.

5. Tack weld stud plates to the embedded plates.

6. Remove the vertical frames out of the way to permit structural welding of the weld stud plates to the embedded plates.

7. Erect the vertical frames in place by bolting the bases to the weld stud plates.

8. Erect the horizontal frames starting from one end to the other end and hold these frames in place by means of erection bolts as shown on the drawings.

9. After erection of all the members in the proper position, weld all the joints between the frames to make a rigid frame structure.

10. Install the diagonal brace members in the $\mathrm{X}$ direction by welding the gusset plates to the WT 12 web and using high strength bolts between the gusset plates and the connector plates of the TS 8X8 member at the bottom.

11. At the top, the brace member cap plate is to be loosely bolted to horizontal plate with boltholes pre-welded to the underside of the horizontal frame member. An initial gap of one-quarter inch is left between the cap plate and the connector plate. This gap is to be filled with shim plates after the completion of erection of all the PCS cables and Nitrogen cooling ductwork.

12. Tighten the high strength bolts with the turn of the nut method in accordance with the AISC Manual.

\subsection{ALIGNMENT AND SURVEYING}

A. The Main Amplifier and Power Amplifier Assembly shall be aligned consistent with the coordinates and tolerances specified in Section 15897 unless otherwise specified specifically in this section. Location of the PSFs shall be as indicated on the University supplied coordinate table.

\subsection{PAINTING}

A. Touch-up all painted surfaces that have been scratched during the assembly process and paint external weld and adjacent surfaces per Section 09900. 


\subsection{CLEANING}

A. The subcontractor shall clean and wipe down structure to remove any installation debris. The finished structure shall be visibly clean per MIL-STD-1246C. 


\section{ROVING MIRROR DIAGNOSTICS ENCLOSURE (RMDE)}

\section{PART 1 GENERAL}

\subsection{DESCRIPTION}

A. The purpose of this specification is to define minimum requirements for fabrication, transport, handling, lifting, assembly, cleaning and alignment of RMDE assemblies including Lower/Upper Rails and Studs as identified on the drawing.

B. There are a total of two RMDE, one in each Switchyard in the LTAB. The RMDE is part of the Switchyard Enclosures where optical devices are used for transferring the laser beam through a path that leads towards the Target Chamber. Inside surface conditions are subject to cleanliness requirements needed to protect optical surfaces from laser damage. The RMDE will be filled with argon gas at a slight positive pressure. The RMDE is a section of the beam enclosure located between SF4 and LM4 mirrors. The primary purpose of the RMDE is to serve as a beam enclosure pressure boundary and housing for the Roving Mirror Diagnostic assembly system components that move within a controlled environment.

\subsection{QUALITY CONTROL}

A. General Quality Control and Quality Assurance Requirements shall be per Section 01400.

B. Definitions of Quality Control and QC Inspectors shall be per Section 01010.

C. The subcontractor and QC Inspectors shall perform the following:

1. Inspect rigging, attachment and handling for compliance to the approved rigging diagram and plan.

2. Inspect installed RMDE assembly for compliance to the drawing and Part 3.0 of this Section, as delineated in the subcontractor's approved installation sequence and procedures.

3. The subcontractor's University approved precision measurement surveyor shall perform survey of the installed RMDE assembly including welded studs, alignment plate, guide rails and tube assemblies to verify compliance with Section 15897, this Section and related drawings.

4. All welds shall be visually inspected for correct type, complete fusion, correct size and correct contour per drawing. The drawing will specify the type of additional weld inspection if required for each welded stud.

5. Visually inspect pre-weld surface preparation. After welding of studs they shall be inspected for alignment and perpendicularity as specified in the drawing. Visual 
inspection shall always be employed in addition to any other inspection methods specified in the drawings.

6. Final Cleaning and Surface Inspection shall be performed to assure that clean components yield a visibly clean surface (Level 300 per MIL-STD-1246C) and shall remove all oil, grease, fluids and other organic compounds from the surface (Applies to section 3.03).

D. The subcontractor shall institute the following Hold Points; work shall not proceed beyond this point without written release by the University:

1. Complete erection of floor subassemblies

2. Rail mounting stud installation

3. All welding completed

4. Complete precision cleaning

E. The subcontractor shall provide the opportunity for the University to witness the following activities:

1. Initial lifting and setting of RMDE Assembly to be installed.

2. Welding

3. Contractor precision survey

4. Leak testing

5. Precision cleaning

6. Gate valve installation

7. Optic mount installation

\subsection{WELDING REQUIREMENTS}

A. Welding shall comply with the requirements of AWS D1.1. (Structural Welding CodeSteel and AWS D1.6 (Structural Welding Code-Stainless Steel). Field welding shall be as designated on the drawings. The subcontractor shall be particularly aware of the weld details on interior of the RMDE. Weld surface finish requirements shall be met to permit subsequent precision cleaning processes (see section $2.03, \mathrm{~F}$ ).

B. Welding Process: All weld joints on the internal surfaces shall be performed with the GTAW process or as designated on drawings. In limited areas subcontractor may propose specific GMAW processes as a substitute for GTAW. Use of GMAW processes is subject to University approval. GMAW process must demonstrate finished weld area properties to be equal to a GTAW process. The plasma-arc process may be substituted for GTAW without pre-approval.

C. Joint Preparation: Before welding, joints shall be cleaned of all foreign materials such as oil, grease, paint, dust, and oxides or sulfides resulting from chemical reaction of the surface. Cleaning shall remove all visible evidence of contamination, including all stains and discoloration of the surfaces. 


\section{Appendix C to Scope of Work for IMI Services}

D. Distortion: Weld procedures and fixtures shall be selected to control distortion within dimensional limits bounded by University drawings. Copper chill bar (backing bar) is recommended for flat seams to minimize distortion and maintain flatness of finished panels. The procedure utilized to control distortion shall be submitted to the University for information.

E. Welding Procedure Specification (WPS): A WPS is required for each weld process, combination of wire filler and base metal type and size to be used in the construction of the Product. Weld procedures shall conform to AWS D1.1 Appendix E (no pre-qualified procedures may be used) or ASME Boiler and Pressure Vessel Code (BPVC) Section IX. WPSs shall be submitted to the University for acceptance.

F. Procedure Qualification Record (PQR): A PQR is required for each Weld Procedure Specification. Each PQR shall be prepared in accordance with AWS D1.1 or ASME BPVC Section IX as required and signed by a qualified weld inspector. PQR shall indicate the specific inspection criteria (by paragraph number) from the code used to evaluate the weld samples. PQRs shall be submitted to the University for information.

G. Welder Performance Qualification (WPQ) Test Record: A WPQ is required for each welder or welding operator covering the utilized welding processes. Each WPQ shall be prepared in accordance with AWS D1.1 or ASME BPVC Section IX as required. Qualified welders shall perform all welding. WPQs shall be submitted to the University for information.

H. Weld Symbols: Weld symbols on sketches and drawings shall be interpreted in accordance with AWS A2.4. Any conflicts or questions related to application or interpretation of weld symbols should be directed to the University for disposition and clarification.

I. Weld Quality and Acceptance Criteria: Weld joints shall be free of cracks, crevices or incomplete fusion. Limits of porosity shall be determined using inspection criteria defined in AWS D1.1. Internal welds shall have smooth transition with parent material, without rough edges along bead (maximum peak to valley height $.762 \mathrm{~mm}$ ), no undercut, free of splatter and no discoloration from oxidation. Weld finish shall be smooth, enabling final cleaning processes and cleanliness verification.

J. Tooling Techniques for Stud Welding from TRW should be used as a general approach to various tooling techniques when using standard Nelson Equipment. (Need to include weld contact angular tolerance allowed by TRW standards) (applies to section 3.03)

\subsection{DELIVERY, STORAGE AND HANDLING}

A. The subcontractor shall examine all Government Furnished Equipment (GFE) before transporting from the on-site location to the erection location. The subcontractor shall give written notice to the University of any deficiency or condition that impede installation (see Section 15895). 
B. The subcontractor shall be responsible for all transport, handling and rigging operations and equipment as discussed in Sections 01015 and 01620.

C. The subcontractor shall design and supply certified lifting fixtures or other equipment necessary to install the RMDE assemblies including Lower/Upper Rails and Studs. These can include, but not be limited to strap, hoist, booms, strong backs, wire rope slings etc.

D. The subcontractor shall implement the cleanliness requirements per section 15895 with regard to these items and any additional cleanliness and cleaning requirements identified under parts 2.0 and 3.0 of this section. The subcontractor shall also implement Section 01625 Construction Cleanliness Protocol.

E. RMDE components and subassemblies shall be protected during subsequent assembly, packaging, or shipping operations to prevent contamination or scoring. Type of protection selected shall not leave residues, which can contaminate an equivalent vacuum system.

F. It is assumed that the elevator in the Diagnostics Building is not scheduled to be available during the period of RMDE erection. Also, access through the SY by way of the jib cranes is also severely restricted due to existing structural steel. The platform Elevation $9.172 \mathrm{~m}$ and $1.651 \mathrm{~m}$ will be complete prior to RMDE erection. Thus overhead crane/hoist access is expected to be limited or impractical.

G. The subcontractor shall not weld or otherwise permanently attach to the GFE equipment except where specified herein or on the drawings.

H. Rigging and material handling shall preserve the integrity of the precision cleaning packaging and bagging. Precision cleaned GFE will be triple bagged (at a minimum).

I. The RMDE will be precision cleaned prior to installation of the optic mount hardware per drawing AAA98-111673. Material movement sequencing shall be planned by the subcontractor to meet the objectives of "clean installation" of this hardware. Outer packaging/bagging or temporary covers shall not be removed prior to handling the assembly within the portable cleanroom/gowning vestibule. Material handling and rigging from that point on shall employ cleaned and prepared equipment, dollies, rails, hoists, etc. to avoid introduction of contaminants into the pre-cleaned RMDE.

J. Since the RMDE interior is not a cleanroom area employing downflow ventilation or comparable means of particulate control and flushing, it is imperative to minimize contaminant generation rather than relying on conventional laminar flow means of contaminant transport and removal.

K. Small parts hand carried will not have any special provisions for material handling or rigging. Larger parts or subassemblies shall have a means of attachment exposed for use (e.g., lifting lugs, lifting eyes, etc.) without violating the packaging integrity.

L. Equipment, tools, supplies, etc. shall be properly prepared for transfer into the RMDE via the vestibule. See Section 01625. Tenting or similar means of masking/segregation shall be applied to limit contaminating precleaned areas not requiring access. 


\section{PART 2 PRODUCTS}

\subsection{GOVERNMENT FURNISHED EQUIPMENT (GFE)}

A. The University will supply the RMDE assemblies and associated components identified as GFE in the Infrastructure drawing/GFE list of Section 01015 including but not limited to following major items:

1. Upper Rail Plate Assembly \& Fasteners

2. Upper PM Frames Rail Assembly (4 ft.) \& Fasteners

(AAA98-112710)

3. Upper Calorimeter Rail Assembly (4 ft.) \& Fasteners

(AAA98-112700)

4. Upper PM Frames Rail Assembly (10 ft.) \& Fasteners

(AAA98-112720)

5. Upper Calorimeter Rail Assembly (10 ft.) \& Fasteners

(AAA98-112705)

6. Lower Rail Plate Adjustment Assembly \& Fasteners

(AAA98-112725)

7. Lower Rail Assembly Mounting Tubes, Rails \& Fasteners

(AAA98-112730)

8. Optic Frame Assembly

(AAA98-112750)

9. Switchyard Gate Valve Assemblies

B. In addition to GFE identified in the Infrastructure drawing/GFE list of Section 01015, the University will provide the following fixtures for use by the subcontractor at its discretion.

1. Alignment Fixture (applies to section 3.03)

\subsection{SUBCONTRACTOR FURNISHED MATERIALS AND EQUIPMENT}

The subcontractor shall provide the items in the Infrastructure drawing/GFE list of Section 01015 not identified as GFE ("non-GFE"). Material provided by the subcontractor shall meet the requirements listed on the drawings and related specifications. Material and equipment provided by the subcontractor shall be delivered to the LTAB and maintained as a minimum in a clean condition consistent with the requirements in Section 15895. In addition to the items identified as non-GFE in Section 01015, the subcontractor shall provide the following:

A. Stud, Full Threaded Base (M12 X 53 mm carbon steel), Steel Stud Shims (6.35 mm thick. $\& 50.8 \mathrm{~mm}$ diameter) as required for assembly. (applies to Section 3.03)

B. Intumescent Fireproofing

1. The subcontractor shall provide fireproofing of all structural steel and components structurally connecting the RMDE to the concrete wall (AAA98-106391).

2. Fire proofing materials shall be per PPG Industries Pitt-Char XP.

3. Surface preparation, priming, application equipment, application and procedures shall be in compliance with the latest revision of the Pitt-Char XP Fire Protective Coating Manual issued to certified Pitt-Char XP Coating applicators. In the event of conflict with this specification, the manual shall control. 
4. The contract for application of fire protection includes surface preparation, priming of surface, cleaning of primed surfaces, application of fire protection, and paint topcoat unless otherwise stated.

5. The contractor shall furnish all labor, equipment, and materials required for all phases of the work subject to the methods specified throughout the completion of this work. This shall include delivery to and from the site of all contractor-furnished labor, materials, and equipment.

6. Contractor and Applicator must be a currently Certified Pitt-Char XP Fire Protective Coating contractor and applicator.

7. Thickness to be $15 \mathrm{~mm}$, or as otherwise certified by an independent testing service to provide a 2 hour rating on the specific steel sections to be protected.

8. Sherwin-Williams "Nova White" topcoat shall be applied to fireproofed structural steel only (not to RMDE assemblies). [per specification applied to Switchyard Structural steel, NIF-5001534, Section 3.06. Sherwin Williams "Polane HS Enamel \#F63 W 56" (Gloss White)].

C. Temporary Covers

1. Temporary covers shall be installed on RMDE openings to cover and seal all openings until precision cleaning has been completed.

2. Temporary covers may be removed to attach auxiliary systems piping or ducting only after such piping or ducting has been precision cleaned and flushed.

3. Alternate temporary cover removal sequencing may be implemented by the subcontractor to coordinate between CSP-14, CSP-16 and CSP-19 and is subject to University approval.

4. Large temporary covers shall be designed for internal positive pressure of $750 \mathrm{~Pa}$.

D. Lighting

1. All Material shall be per NIF Component Engineering Number N6210-15769.

- M. Canty Model HYL80, 80 Watt light

- NEMA 4 Housing

- 316L stainless steel wetted material

- $25.4 \mathrm{~mm}$ NPT mounting connection

- Wide Beam light pipe option

2. Installation instructions shall be per J.M. Canty. Inc. requirements.

3. Wiring required from lighting unit to an available power junction box.

E. Expansion Joint

Expansion joint shall meet the following requirements:

1. Large full perimeter expansion joints shall be by:

DISTRIBUTOR:

Lamons Power Engineering

189 Arthur Road 


\title{
Appendix C to Scope of Work for IMI Services
}

\author{
Martinez, CA 94553
}

Tel: $925-313-9080$

MANUFACTURER:

Holz Rubber Style 941, FEP 160

$0.762 \mathrm{~mm}$ thick fluoroelastomer, with 304 stainless steel retaining bars

Gortex Teflon joint gasket with $38.1 \mathrm{~mm}$ wide retaining bars

2. Overall dimensions to be per drawing AAA98-106399.

3. Design Conditions:

- Maximum pressure $76.2 \mathrm{~mm} \mathrm{H}_{2} \mathrm{O}$

- Maximum temperature $100{ }^{\circ} \mathrm{C}$

- Maximum periodic Compression movement: $6 \mathrm{~mm}$

- Maximum periodic Extension movement: $6 \mathrm{~mm}$

- Maximum periodic Lateral offset movement: $6 \mathrm{~mm}$

- Maximum one time Compression/Extension movement (e.g. seismic): $41 \mathrm{~mm}$

- Maximum one time Lateral offset movement (e.g. seismic): 9 mm

- Maximum initial installation offset (lateral-horizontal or lateral, axial): $13 \mathrm{~mm}$

4. Expansion joint shall be cleaned to Level 100 or better Wipeable to Level 70 or better. Bake-out per MEL99-004. Expansion joints shall be double bagged for shipping.

5. Stainless steel threaded fasteners shall be supplied and installed by the subcontractor.

6. External debris shield to be installed over the expansion joint to protect against foreign object damage to expansion joint. Debris shield shall be removable to allow service access.

7. Shield material may be aluminum or stainless steel solid sheet stock, perforated, or expanded metal. Perforations or expanded screen openings shall be sized to prevent debris larger than $3 \mathrm{~mm}$ from passing through.

8. Method of attaching debris shield should not, in and of itself, generatedebris, which may settle on expansion joint material and subject such material to potential damage. Shield material may be attached to structure on the 9.162 meter platform or the spaceframe TS members.

\section{F. Ventilation System}

1. An air purge system shall be installed to supply pressurized filtered air at the outboard end of the RMDE, exhausting out the personnel access door, or other existing ports at the inboard end of the RMDE. Unit shall be installed over the RMDE in a manner which does not impede access to existing structure, decking, existing utilities, etc. Doors and access panels to be accessible from existing decking. Location shall be approximately as shown on AAA98-106390.

2. An air purge system shall meet following requirements:

- Minimum Flow Rate: 1000 scfm@ 2 in WG

- Fan Motor shall be totally enclosed and water proof (TEFC type)

- Fan and motor shall be installed with anti-vibration mounts

- Airborne Molecular Contamination (AMC) control, Gas-Phase Contamination Filtration: Hoechst-Celanese AQF GPR Series, 24"x24"x12" or similar 
- Particulate Filtration: Gore ULPA DuraNET filtration media

3. The subcontractor shall be responsible for installation including connection to local electrical supply (115/208 VAC single phase), local switch, and indicator light.

4. The subcontractor shall submit for manufacturer information data for the unit supplied. Information shall include motor data, fan performance data, filter data and performance.

5. All duct materials up to the ventilation unit, including upstream of valves, closures, or other means of seal, must be stainless steel (2B finish or better for stainless sheet interior surfaces). Cleanliness shall be to Level 70 at start up. Seal materials to be baked Teflon, Viton, or silicone rubber in accordance with MEL99-004.

6. All nonmetallic ventilation system components downstream from the closure or valve shall be shielded from scattered laser light exposure emanating from within the RMDE.

7. Ventilation system shall include a manually operated valve, blank, closure, or other means of maintaining a leak tight seal when unit is not in use. Fan is to be locally activated by lockable manual control located near the entry door. Fan operation and power status shall be indicated in the vicinity of the access door with a labeled indicator light or similar means.

8. Ventilation system routing shall be subcontractor routed, but shall not impede or interfere with other adjacent equipment or utilities.

G. Viewports

1. After precision cleaning and just prior to completion of CSP-16 activities in the respective Switchyard, the glass lens included as part of the drawing (AAA98-106438 and AAA98-106452) subassemblies shall be replaced with :

Melles Griot P/N 02 WBK 001

2. The interior face of the lens assembly shall be cleaned to MEL98-010 or MIL-STD1246C Level 70, A/10., prior to installation at each location.

3. The subcontractor to protect glass and its respective optical properties. Glass surfaces and optical coatings shall not be scratched, nicked, or otherwise degraded or damaged in any other manner.

4. Viewport flange bolts shall be torqued to manufacturer's specifications.

H. Doors

The subcontractor shall supply and install doors per following requirements to fit access opening dimensions shown on drawing (AAA98-106390).

1. There are two doors required (One for RH opening and one for LH opening). Both the doors are mirror image to each other.

2. Doors configuration shall be rectangular outward opening, gas-tight. Radiused or mitered corners may be acceptable.

3. Rough opening shall be per drawing (AAA98-106390). Finished size shall be maximum allowed for rough opening width and height, with allowance for build-up 


\section{Appendix C to Scope of Work for IMI Services}

at floor threshold to allow jamb hardware to clear floor structure. Sill height to be kept to minimum achievable. Height not to exceed $152.4 \mathrm{~mm}$ above surrounding floor level.

4. Material exposed to interior side shall be stainless steel (2B finish or better for sheet) or clear anodized, bare aluminum may be an alternative.

- Surfaces not exposed to the interior may employ stainless steel, aluminum (clear anodized or bare), or carbon steel finished with approved coating per specification NIF 5001534, Section 3.06 (Sherwin Williams "Polane HS Enamel \# F63 W 56" (Gloss White).

- All exterior surfaces or surface finishes shall be non-particulating.

5. Hinges shall be stainless steel with 90 degree minimum swing located on door exterior.

6. Frame/Jamb shall be welded to exterior carbon steel structure members. Interior jamb and or joints shall be complete stainless steel cladding over existing carbon steel structural members. Interior Jamb detailing shall provide pressure tight seal at all seams. Stainless steel sheet, where used, shall be 2B finish. Other material shall be finished to 1.6 micrometer $(63 \mu)$ RMS or better.

7. Hardware shall meet following requirements:

- Latching handles shall be installed on outside only (enclosed space is to be designated for confined space entry only).

- Lockable quick acting latches shall be used.

- Locking system to be compatible with standard lockout/tagout hardware (e.g. Padlock hasp and/or multiple padlock lockout device, $7.144 \mathrm{~mm}$ minimum padlock shackle diameter).

- Most lubricants are prohibited for interior hardware. Lubricants shall be limited to vacuum-type greases, Krytox, Braycote, etc. Any lubricants to be used must be baked out in accordance with MEL99-004.

8. Door seals to be pressure-tight for up to $750 \mathrm{~Pa}$ of argon and/or air.

- Knife edge or compression seal.

- Seal material to be silicon rubber or Viton. Either material must be baked per MEL99-004. Silicone rubber shall meet requirements of Section 15107.

9. Ambient temperature range from (4.4 to 32.2 degrees $C)$. Interior to be air $(40 \%<$ $\mathrm{RH}<60 \%$ ) and/or $>80 \%$ pure argon (inert) at the same range of temperature and humidity.

10. Possible Vendors shall be one of the following:

- Freeman Marine Equipment, Inc.

28336 Hunter Creek Road

Gold Beach, OR 97444

- Waltz \& Krenzer, Inc.

90 Forest Avenue

P.O. Box 382

Locust Valley, NY 11560

11. Interior seams between jambs and RMDE space frame cladding assemblies shall be fully seal welded per drawing and this specification.

I. Floor 
1. Floor grating shall be aluminum 2 inch $\times 3 / 16$ " bar, with 4" x 1-3/16" spacing, McNichols GAL-200 or equivalent.

2. Floor grating shall be designed for a minimum floor loading of $14.4 \mathrm{kPa}\left(300 \mathrm{lb} / \mathrm{ft}^{2}\right)$ at $1.83 \mathrm{~m}$ (6 foot) span.

3. Design assumes that the specified aluminum floor grating will be pre-cleaned prior to final insulation. This sequence, while not mandatory, assumes that in-situ precision cleaning of grating and areas below it will be impractical.

\subsection{MATERIAL REQUIREMENTS}

\section{A. Weld Filler Metal}

1. Electrodes and filler wire for welds shall be of type 308 stainless steel, procured under the applicable ASME BPVC Section II specification.

2. The certified material test reports (CMTRs) shall be submitted to the University for all weld filler metal for information.

\section{B. Base Material}

1. The base materials shall be comprised of type 304L stainless steel, which meets the mechanical requirements of type 304 .

2. The material shall conform to the University's drawing requirements and shall comply with ASTM or ASME BPVC Section II specifications. CMTRs shall be submitted to the University for all base metals.

C. Cutting Fluids

1. Unless explicitly approved by the University, the subcontractor shall use only those cutting/cooling fluids listed in MEL98-001 to ensure that the enclosure material can be cleaned to required levels.

2. The cutting/cooling fluids used shall be submitted to the University for information.

D. Tool Materials

1. Tools used on stainless steel for contouring (forming) and weld prep shall be clean of all foreign material. Tools may include stainless steel brush, file, burr, or chisel; forming dies and machine cutting tools.

2. Abrasive cutting and grinding wheels are acceptable for use on stainless steel only if they are used exclusively on stainless steel and not contaminated with other material. Abrasive polishing compounds shall not be used.

E. Covering Materials

The following are acceptable covering materials for storage, handling, covering and packaging of shop fabricated items. Other materials proposed by the subcontractor shall be submitted for University approval prior to use. Other than polyethylene, plastic 


\section{Appendix C to Scope of Work for IMI Services}

sheeting shall not be used for protective interleaving material during storage or packaging of the Product.

1. Brown paper or polyethylene sheeting shall be used for protective interleaving material during storage.

2. Plywood, exterior grade, shall be used for end covering during packaging and shipment.

3. Nylon, polyethylene sheeting or shrink-wrap shall be used to wrap the cleaned product in preparation for shipment and delivery.

\section{F. Surface Finishes}

1. Sheet material shall be cold rolled stainless steel with a $2 B$ finish, or as specified on the respective drawings. Structural shapes, plates, and bars shall be standard stainless steel material hot rolled, annealed and pickled or extruded as designated on respective drawing.

2. All internal surfaces, as designated on subassembly drawings, shall be free of weld discoloration and have a 1.6 micro-meter RMS finish or better, except for welded surfaces, which shall satisfy the welding requirements paragraph 1.08 .

3. All seal surfaces shall be free of dirt, grit, dust and any other contaminants that would prevent a good seal. Machining or polishing marks shall run parallel to the long direction of the seal. Seal surfaces shall be protected during subsequent assembly, packaging, or shipping operations to prevent contamination or scoring. Exterior surfaces that are not sealing surfaces shall be maintained in the as procured material condition, including free of gouges and dents.

\section{G. Forming}

1. Cracking and other failure or damage resulting from brake forming is not acceptable.

2. Plastic materials shall not be used, nor otherwise be in contact with the sheet at worked surfaces, during forming of the interior sheet surface of the Product.

H. All shop fabricated material Cleaning and Handling

1. Remove all tape, inks and other residue using Acetone or Methyl Ethyl Ketone and a clean room approved wiper.

2. The Product shall then be thoroughly washed to yield a visibly clean surface, free of dirt, oil, grease, cutting fluids and other foreign materials, utilizing a 3\% solution of Brulyn 1990GD and distilled or de-ionized hot ( $>54.4$ o C) water.

3. The cleaning solution shall be applied by slow moving passes of pressurized spray $(7.03 \mathrm{~kg} / \mathrm{cm} 2$ minimum), and then similarly slowly rinsed at least three times with hot distilled/de-ionized water.

4. The rinsing shall be followed by air drying (if blown air is used, it shall be oil free and HEPA filtered). Subsequent handling operations shall maintain product cleanliness through packaging. The subcontractor's cleaning and handling procedures shall be submitted to the University for acceptance. 


\section{Packaging and Shipping}

1. The Product shall be packaged in such a manner that it may be shipped or stored without damage to surfaces, protrusions, extended structures, welds, and structural integrity.

2. The subcontractor shall select shipping coverings and materials. Selection criteria shall be consistent with Section $2.04 \mathrm{E}$ for covering materials, maintaining compliance to dimensional and the "visibly clean" requirements. The subcontractor's packaging procedure shall be submitted to the University for information.

\section{PART 3 EXECUTION}

\subsection{PREREQUISITES AND EXAMINATION}

A. Before starting work the subcontractor shall examine underlying and adjoining work for damaged or other apparent conditions that may be masked or made inaccessible by installation of the RMDE assemblies and associated items.

B. Before installing the RMDE assemblies and associated items subcontractor shall examine and survey interfacing embedment plates for proper geometry, location and orientation as specified on the drawings.

C. The subcontractor shall immediately report to the University in writing any apparent deviations or other conditions that may impede proper installation of the assemblies. Do not commence affected work until notified to do so in writing by the University.

D. The subcontractor shall prepare an installation procedure, which shall include an installation and inspection checklist, a full description of the tasks to be performed, installation sequence, QA hold and witness points, and a listing of the work documents to be used. The procedure shall also include survey/alignment actions necessary to fulfill Section 15897. The subcontractor is responsible for collecting the necessary working documents including but not limited to drawings, specifications and reference documents necessary for installation.

\subsection{INSTALLATION SEQUENCE}

The RMDE assemblies and associated items shall be installed in accordance with drawing AAA98-106390 and associated drawings. The following sections (3.02 through 3.16) provides additional details of the work in conjunction with drawings. Except where identified as "mandatory" or dictated by physical configuration, the sequence below is provided to facilitate description of the work, to assist the subcontractor in understanding the relationship and fit-up assumptions between components. The drawing references are for guidance. The actual installation sequence planned by the subcontractor is to be submitted for University approval prior to execution.

A. The subcontractor shall submit installation sequence for approval including but not limited to the following items: 


\section{Appendix C to Scope of Work for IMI Services}

1. Install Roving mirror Diagnostic Enclosure (RMDE) floor subassemblies

2. Install Roving Mirror Assembly track (lower/upper rails and studs)

3. Line concrete with stainless steel sheet

4. Install wall and ceiling subassemblies

5. Seal weld subassemblies

6. Seal weld between stainless steel sheet and bundle tubes

7. Locate and install Switchyard-side RMDE wall

8. Install expansion joint

9. Precision clean enclosure

10. Install pre-cleaned floor grating

11. Install gate valve

12. Install and precision align optic mount assemblies

B. The vertical beam tube connection must be located relative to the beam line (centered over PM3) and thus controls the floor assembly location. Consequently, floor subassembly AAA98-106433 must be surveyed and installed first. Continue installing floor subassemblies by building out from this initial subassembly. Subassemblies are butted to the preceding subassembly. U-shaped flanges on SY sides of subassemblies must be match fitted for later seal welds. Field cut-to-fit strips may be used to fill/splice gaps where field tolerances result in mismatch.

C. End walls are rigged in and temporarily secured in place. Final end wall fit up requires adjoining ceiling panels to be installed.

D. Ceiling subassembly panel installation is next in the assembly sequence. The viewport in drawing (AAA98-106426) must be aligned over the vertical beam centerline (over the PM3 mirror). Once this assembly is located and welded to the supporting structure, adjacent ceiling subassemblies may be fitted up and welded to the overhead structure. Continue installing ceiling subassemblies by building out from initial subassembly. Ushaped flanges on SY sides of subassemblies must be match fitted for later seal welds. Field cut-to-fit strips may be used to fill/splice gaps where field tolerances result in mismatch.

E. End walls may now be final fitted to mate with floor and ceiling assemblies. U-shaped flanges on sides of SY subassemblies must be match fitted to adjoining sections on floor and ceiling assemblies.

F. Rail mounting studs are to be surveyed and installed.

G. Flanged concrete wall sheets (AAA98-106446 and AAA98-106447) are to be installed over the rail-mounting studs. Brake-formed flanges on the wall sheets shall be fitted to the floor, ceiling, and end walls for best possible fit and eventual seal welding. Install GFE adjustment plates (see Section 3.03) to secure sheets to wall and effect a pressure seal. Sheets shall be tacked to adjacent embedded plates wherever possible. 
H. Wall sheets (AAA98-111448) are to be installed for best fit-up to other sheets. Additional small sheets, strips may be cut to fit and lap welded over any gaps resulting from field fitup.

I. End walls shall be welded to supporting structure, shimming if required. All assemblies shall now be seal welded as required.

J. Install cladding and pedestal assemblies per drawing (AAA98-106392). Pedestals are to be located relative to beam references (TCC or other references defined by NIF precision survey) as shown on drawing (AAA98-106392). Splice pieces may be cut to fit as required to join pieces or make up for field as-built tolerances and maintain pressure boundary integrity.

K. Install expansion joint studs onto U-shaped channel.

L. Rig, survey and install major subassemblies shown on drawing (AAA98-106392). Gate valve interface assemblies to be surveyed and installed to match bundle centerlines (to be defined by NIF Precision Survey).

M. Mate and seal to the Laser Bay beam enclosures in concrete wall penetration.

N. Install main access door.

O. Install gate-valve interface assembly, expansion joints, temporary covers, and associated hardware.

P. Leak check.

Q. Precision clean.

R. Install expansion joint light shielding over interior expansion joint.

S. Install optic mount hardware using clean installation procedures.

T. Install gate valve using clean connection procedures.

\subsection{LOWER/UPPER RAILS AND STUDS ASSEMBLY SEQUENCE}

A. Stud Installation (drawing AAA98-112899)

There are two sets of full threaded Carbon Steel Studs (M12 X 53mm) to be welded in an identical manner to the Switchyard 1 and 2 embedded steel plates. Both the upper and lower sets consist of 54 studs welded in-groups of 3 to the embedded steel plates located on the switchyard walls.

A survey of the embedded steel plates installed into the concrete face of the switchyard walls have shown that the plates vary in their $\mathrm{z}$ axis position by as much as 1.5 " and slope as much as $2^{\circ}$ from the NIF Global X-Y plane. Therefore the following procedures are suggested as a means to assure that the RMDE support studs are installed accurately. 
1. The studs shall be welded to the embedded plates using the ANSI/AWS D1.1, structural-welding code for steel, section 7.

2. All studs shall be located on the steel plates at the X-Y locations (NIF Global Coordinates) indicated on drawing AAA98-112899 sheet 2.

3. The studs shall be mounted perpendicular to the NIF global X and Y plane (parallel to $\mathrm{Z}$ axis). The TRW manual of "Tooling Techniques for Stud Welding" under section II Methods of Insuring Perpendicularity section offers several suggestions on techniques for maintaining perpendicularity with respect to a global plane in welding of studs.

4. A surface area of $50.8 \mathrm{~mm}$ diameter is called out on drawing \# AAA98-112899 sheet 1 as the required sealing area around each stud. This sealing area surface of the enclosure liner shall be perpendicular across this diameter to the stud to within + or 0.30 o to assure proper seating of the stud extender " $O$ " ring and a sealed contact between the stud extender and the enclosure skin. The exposed surface area of any shim used to adjust the $\mathrm{z}$ axis position at each stud location shall meet these same specifications.

5. In order to maintain the locations of each welded stud over the entire length of the assembly, the uppermost stud of position 1t (top embedded plate), the uppermost stud of position $1 \mathrm{~b}$ (bottom embedded plate), the uppermost stud of position 18t (top embedded plate) and the uppermost stud of position $18 \mathrm{~b}$ (bottom embedded plate) shall be designated as reference studs. These referenced studs shall be surveyed, marked, and used as the benchmarks for all other stud locations. The surveyed referenced studs shall be within + or $-3 \mathrm{~mm}$ of their NIF global coordinate X-Y locations as called out on drawing \# AAA98-112899 Sheet 2.

6. For each welded stud, the locations called out on drawing \# AAA98-112899 Sheet 2 for each switchyard shall be maintained to within + or $-1 \mathrm{~mm}$ (in both $\mathrm{X}$ and $\mathrm{Y}$ coordinates) with respect to the surveyed reference stud locations over the entire length of the enclosure for both sets of studs.

7. The top stud in each 3-stud pattern can be located and welded in the proper location based on the survey from the reference studs determined above. The other 2 studs in the pattern can then be located and aligned from the upper stud using an alignment template supplied by the University.

8. All installed studs can be the same length $(>$ or $=53 \mathrm{~mm})$.

9. After welding all studs shall be resurveyed to ensure that the tolerance and location that are called out on Drawings AAA98-112899 and this document have been met.

B. Enclosure Skin Installation

1. The point of intersection of each stud centerline and the outer surface of any required shim shall lie on the NIF Global coordinates plane (within + or $-6.35 \mathrm{~mm}$ ). Note: This requirement allows the vendor to use standard size $(6.35 \mathrm{~mm}$ thick) shims to meet this specification for each stud location.

2. At this point the shims can be installed on the studs and the enclosure skin mounted per procedure AAAA

C. Adjustment Plates Installation 
1. The stud extender, sealing 'O' ring, jam nut, and adjustment lug shall be installed on all stud locations as shown in Drawing AAA98-112895. The stud extender shall be torqued in place. The stud extender shall seal against the enclosure skin.

2. The upper (AAA98-112710) and lower (AAA98-112730) adjustment plate assemblies can now be installed. They are to be mounted onto the three adjustment lugs and attached with the Button Head Cap Screws, and Spherical Washers per the assembly drawings. (May want to insert a suggested assembly sequence here)

3. Both the upper and lower adjustment plates shall be surveyed and aligned such that the top two corners and the bottom right corner on the front surface of each adjustment plate are coplanar to the NIF coordinates global plane defined by $\mathrm{Z}=$ TBD within + or $-1 \mathrm{~mm}$. The stud adjuster lugs, locking nuts, button head cap screws, and spherical washers can be used to maneuver the plates in all dimensions to the specified location.

4. After all the adjustment plates have been allowed all jam nuts should be torqued.

D. Upper PM and Calorimeter Rails Installation

1. Install the upper PM Frames Rail and Upper Calorimeter Rail Assemblies and related hardware for the four (4) foot sections and the ten (10) foot sections as shown in AAA98-12700, AAA98-112705, AAA98-112720, AAA98-112725, and upper rail assembly drawing.

2. Start assembly on the end closest to the drive motor end of the RMDE and work towards the middle of the NIF chamber.

3. Both rails shall be aligned to within + or $-0.5 \mathrm{~mm}$ in both horizontal (NIF Global X coordinate) and vertical (NIF Global Y coordinate) for straightness and parallelism over the entire length. The upper rails shall also be parallel to the lower Thomson Rails over the entire length of the enclosure to a tolerance of + or $-0.5 \mathrm{~mm}$.

4. Torque all fasteners.

E. Lower PM and Calorimeter Rails Installation

1. The lower rail adjustment brackets (AAA98-112732) can be installed onto all the lower adjustment plates (AAA98-112731). The lower rail adjustment brackets have two (2) adjustment set screws used in the alignment of the lower rail tubes. All fasteners are to be torque in place.

2. Install the sections of the PM and calorimeter horizontal drive tubes and Thomson Rails (Drawings AAA98-112762, AAA98-112765, AAA98-112767, AAA98112770, and AAA98-112773) on the Lower Rail Plate Adjustment Assembly (AAA98-112730). Refer to overall lower rail assembly drawing for proper placement of short sections of drive tubes and rails.

3. Alignment of the Horizontal Drive Tubes and Thomson Rails shall be within + or $0.5 \mathrm{~mm}$ in both horizontal (NIF Global X coordinate) and vertical (NIF Global Y coordinate) straightness and parallelism over their entire length. They shall also be parallel to the upper guide rails over the entire length of the enclosure to a tolerance of + or $-0.5 \mathrm{~mm}$.

F. Precision Alignment 
1. A Euclid alignment laser (manufacture) can be used to align the rails in the $X$ direction and also in the $\mathrm{Y}$ direction. Required accuracy of the installed rails for $\mathrm{X}$ and $\mathrm{Y}$ is $+/-$ $0.5 \mathrm{~mm}$ ( includes all errors i.e. survey, placement and measured) in relation to NIF global co-ordinates. Alignment and survey shall be performed in accordance with the drawing and the Section 15897.

\subsection{OPTIC MOUNT VERTICAL SUPPORT ASSEMBLY INSTALLATION}

A. Following installation specifics apply to drawings (AAA98-106392 and AAA98-106409).

1. During erection of the vertical posts (AAA98-106409) as part of assembly drawing (AAA98-106392), the posts must be shimmed tight between the pedestals following vertical positioning to the feature locations shown in drawing (AAA98-106392).

2. To achieve a tight fit between the upper and lower pedestal base plates, it is suggested that following determination of the proper shim arrangement to achieve required vertical positioning, the upper and lower pedestal assemblies be jacked apart slightly. Jacking should be sufficient to result in snug fit-up or slight compressive preload on the vertical posts. Jacking shall not cause any permanent deformation in the spaceframe beams however.

3. Alternately, the vertical posts can be chilled below ambient temperature and allowed to "grow" sufficiently to fill the remaining gaps to the shims.

4. Any process used to install the posts shall not produce or result in any permanent deformation or deflection in the spaceframe structure following release of jacks or return to ambient temperature. Contractor shall determine the appropriate jacking load/displacement or chill temperature to result in a snug fit without inducing preload stresses in the structural members.

\subsection{OPTIC MOUNT INSTALLATION}

GFE assemblies will be delivered precision cleaned. Installation must be performed under cleanroom protocol (see Section 3.12 and Section 01625).

A. The optic mount structure assemblies are also referred to here as the Kinematic Mounting Structure (KMS). The related hardware and installation are documented on drawing (AAA98-111673).

B. CAUTION: The KMS system employs a unique "six-strut" support system. The KMS assembly is NOT stable unless all six support struts are installed or additional temporary support is provided.

C. Lubricants of any kind are not permitted for use with KMS system hardware.

D. KMS rigging equipment may be temporarily supported using the bolt holes above each KMS installation position.

E. Spanner wrenches are to be used to adjust the struts. Strut collars and rod ends are preloaded or clamped to achieve zero play. Thus, adjustments will require higher effort than typically expected with turnbuckle hardware. 
F. Although to a large extent, strut adjustments produce uncoupled motion, the adjustment sequence should be selected to minimize iterations due to potential cross coupling. The suggested adjustment sequence is as follows:

1. Adjust vertical strut to attain proper elevation.

2. Adjust "X-direction" struts to attain proper $x$ translational location.

3. Adjust "X-direction" struts by equal increments in opposing directions to attain proper plumb in the "roll" direction.

4. Adjust "Z-direction" struts to attain proper $\mathrm{z}$ direction translational location.

5. Adjust the two mid-level "Z-direction" struts by equal increments in opposing directions to attain proper orientation in the "yaw" direction.

6. Adjust the top "Z-direction" strut to attain the proper plumb in the "pitch" direction.

7. Recheck (and adjust if necessary) locations.

G. Shim material, if required, must be from 304 or 316 stainless steel sheet stock and precleaned to precision levels.

H. HEPA filtered exhaust vacuums may be required to remove particulate locally generated during installation operations.

\subsection{FIELD INSTALLED WELDED STUDS}

Expansion Joint Studs

A. Prior to installation, spacing shall be verified with hole pattern of the contractor-supplied expansion joint, ordered per vendor control drawing (AAA98-106399).

B. Stud welding WPSs and WPQs shall be prepared and submitted for approval.

C. Surfaces to which studs will be welded must be prepared in accordance with stud manufacturer's specifications. Existing welds where studs are to install must be ground prior to stud installation. Any unforeseen surface irregularities, which may affect sealing, must be corrected prior stud installation.

D. Studs shall be installed perpendicular to the working surface.

\subsection{ANCHOR BOLTS}

A. Anchor bolts shall be 304 or 316 stainless steel unless otherwise specified on the RMDE drawings or NIF Quality Standards.

B. Anchor bolts specified on the drawings shall be installed per the manufacturer's specifications.

\subsection{BOLTED FLANGE GASKET CONNECTION}

A. Gasket shall be centered such that gasket will seat outside of light shield lip at closure. 


\section{Appendix C to Scope of Work for IMI Services}

B. Gasket shall not rest on sealing edge of the light shield lip nor be located in a manner which will place gasket material at risk of exposure to interior laser light.

C. Flange bolts/nuts shall be torqued to specified value on the respective drawing or per manufacturer's specification in order to achieve a pressure tight seal.

\subsection{FLANGED OPENINGS}

A. Gaskets shall be positioned over openings so that interior edge will be shielded from the interior by the built-in lip. Gasket shall not be compressed or crushed by the lip.

B. M6 studs/bolts shall be tightened so that the gasket is compressed and the cover plates are in contact with the light shielding lip, if applicable, or a maximum.

C. Prior to assembly, surfaces contacting gaskets sealing surfaces shall be gross cleaned to MIL-STD-1246C level 500 or better.

D. Gaskets shall be installed in a manner to allow precision cleaning of all interior exposed surfaces.

\subsection{LEAK TESTING}

A. Thru-bolts used on temporary covers may be sealed with a temporarily applied sealing compound, gaskets, or gasketed washers during the pressure testing process. The selected means of sealing must be readily removable by the precision cleaning processes dictated under Section 3.10, Precision Cleaning.

\subsection{GROSS CLEANING}

Gross cleaning processes shall achieve Level 500, as defined in MIL-STD-1246C. The following procedures have been shown to produce satisfactory results and maybe used without further process qualification. The subcontractor is free to develop and qualify other comparable processes to achieve the same final results with respect to particulate and NVR contamination removal. Other precision cleaning processes must be submitted for University review and acceptance prior to use.

A. Gross cleaning processes shall be performed in accordance with or demonstrated to produce conditions essentially equivalent or exceeds the required contamination (subject to University's approval) to those resulting from the following MELs:

1. MEL98-004: Cleaning of 300/400 Series Stainless Steel Components.

2. MEL98-011: Gross High-Pressure Water Wash for NIF Components.

B. All seal surfaces shall be free of dirt, grit, dust and other contaminants that would prevent a good seal. Machining or polishing marks shall run parallel to the long direction of the seal. Sealed surfaces shall be protected during subsequent assembly, packaging, or shipping operations to prevent contamination or scoring. Exterior surfaces that are not sealing surfaces shall be maintained in the as procured material conditions. 
C. Effluent from fluid based cleaning processes shall be handled in accordance with the subcontractor effluent handling plan. The subcontractor is responsible for effluent disposal. Effluent shall be contained and may not be allowed to freely flow out of the enclosure or otherwise pose risks of affecting other structure, equipment, or personal outside of the enclosure. Temporary covers and closures shall be installed as required. Drainage connections and Sump pumps may be utilized for effluent control with prior University approval of the subcontractor effluent handling plan.

D. The procedure shall yield a visibly gross clean surface (Level 500 per MIL-STD-1246C) for external surfaces and shall remove gross levels of oil, grease, cutting fluids and other organic compounds from surface.

\subsection{PRECISION CLEANING}

Precision cleaning processes shall achieve Level 70 - A/10, as defined in MIL-STD1246C. The following procedures have been shown to produce satisfactory results and maybe used without further process qualification. The subcontractor is free to develop and qualify other comparable processes to achieve the same final results with respect to particulate and NVR contamination removal. Other precision cleaning processes must be submitted for University review and acceptance prior to use.

A. Precision cleaning processes shall be performed in accordance with or demonstrated to produce conditions essentially equivalent or exceed the required contamination (subject to University's approval) to those resulting from the following specifications:

3. MEL99-004 High Temperature Atmospheric Bake-out to Remove Volatile Organics for NIF.

4. MEL98-008 Precision High-Pressure Water Wash of NIF Components.

5. MEL98-010 Precision Surface Wiping for NIF Components.

6. MEL98-012 Surface Cleanliness Validation by NIF Components.

7. MEL98-015 Non-Volatile Residue (NVR) Validation for Components.

8. MIL-STD-1246C Level 70 for particulate contamination and A/10 for NVR contamination.

B. Prior to initiating precision cleaning, clean filtered air purge shall be established. Purge air shall meet the minimum requirements per Fed-Spec-209E Class 100.

C. Adequate filtered purge ventilation must be established prior performing any cleaning operations involving solvents or other fume generating material or fluids, or any other similar processes. Quantity and type of forced ventilation shall, at a minimum, employ the installed RMDE filtration and ventilation system (Section 2.02-F). Based on the processes used during construction and cleaning, ventilation requirements may not to be met by the permanently installed unit. The subcontractor shall determine if additional or alternate forced air ventilation is required and its sufficiency for the expected hazards.

D. Cleaning or other operations involving solvents or alcohol mixtures (IPA) must employ appropriate forced air ventilation. Unimpeded personnel egress must be made available 


\section{Appendix C to Scope of Work for IMI Services}

out of the RMDE through the full sized main personnel entry door unless work is performed under Confined Space Entry controls.

E. Cleaning or other operations involving other connected enclosures accessed via the RMDE may require designating the local space as a Confined Space based on personnel egress considerations. Volumes and workspaces judged to represent difficult personnel egress are likely to require classification as a Confined Space. The subcontractor shall be responsible for designating confined spaces based on in-progress configuration and cleaning processes employed. In such instances, the contractor shall develop and/or implement formal training, procedures, and controls for Confined Space Entry in accordance with the NIF Construction Safety Program.

F. A temporary gowning area or cleanroom must be established outside the personnel access door to control introduction of contaminants into the RMDE. The growing area shall include sufficient laminar airflow and/or other means to maintain a Class 100 environment. An air shower and sticky mat (or equivalent) shall also be provided as part of this temporary area, and must be used by personnel entering the RMDE during precision cleaning (see Section 01625).

G. The temporary cleanroom shall also allow for use as a cleanroom for preparing equipment and assemblies for subsequent clean installation.

H. Contamination control protocol training shall be established for all contractor personnel authorized to enter the RMDE during after precision cleaning. Personnel shall practice contamination control protocol for entry and work in the RMDE during and following precision cleaning.

I. The RMDE is designated as a Protocol Level 4 area. Entry and work protocol shall be in compliance with MEL98-014 and Section 01625 for preparation, gowning, entry, and work in a cleanroom. Entry and exit areas shall be identified for used during entry and exit.

J. Equipment, tools, supplies, materials, etc., shall be cleaned and prepared for transfer into the RMDE in the vestibule.

\subsection{CLEANLINESS VALIDATION}

A. Cleanliness validation requirements shall be in accordance with following documents:

1. MEL98-012 Surface Cleanliness Validation by Swiping for NIF Components.

2. MEL98-015 Non-Volatile Residue (NVR) Validation for NIF Components.

\subsection{CONFINED SPACE ACTIVITIES}

A. The RMDE includes a full sized entry door to allow unimpeded personnel egress. When erection is nearly complete and permanent and temporary covers are installed, forced air ventilation will be required, and the RMDE may require classification as "Confined Space". In particular, operations involving welding, grinding, introduction of solvents, etc. 
following this stage of construction shall require appropriate forced air ventilation, fume extractors, etc. compatible with and suitable for the materials used, products generated, and operations being performed.

B. For related requirements during cleaning operations, refer to Section above on Gross and Precision Cleaning.

C. Other enclosures (LB Enclosures) attached to the RMDE which require access through the RMDE may be treated separately. Connected dead end spaces which present difficult personnel egress, and for which airflow may be restricted, may require classification as Confined Space Entry, depending on the subcontractor's erection/installation sequence, work procedures, safety plan, and Job Hazards Analysis.

D. Connected spaces so designated as Confined Space will require the subcontractor to implement Confined Space Entry procedures and training in compliance with the NIF Construction Safety Program and applicable regulations in order to permit personnel access.

E. Administrative procedures must be prepared, reviewed, and approved prior to commencement of work within the enclosure.

F. Work in confined space shall comply with the requirements of Section 15893.

\subsection{ALIGNMENT AND SURVEY}

A. Alignment and surveying of RMDE assemblies shall be performed in accordance with drawing (AAA98-106392 and AAA98-111673) and Section 15897.

B. Elevation of viewport assembly shall be in accordance with drawing (AAA98-106391).

C. Location of vertical viewport shall be in accordance with drawing (AAA98-106391).

D. Unless otherwise specified on the drawing, all dimensions and tolerances shall be applicable at a temperature of 20 degrees $\mathrm{C},+/-1.11$ degrees $\mathrm{C}$.

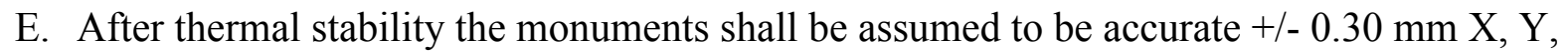
$Z$. The subcontractor shall use these values in calculating the total uncertainty in the coordinates of the installed hardware.

F. Alignment specifics for KMS:

1. "Rough" alignment is necessary to align the KMS assemblies within the necessary tolerances to permit subsequent "precision" alignment using a survey LRU.

2. "Rough" alignment shall locate features on each KMS according to locations and tolerances shown on AAA98-111673 (other survey drawing???).

3. Locations of the features can be surveyed in absolute coordinates relative to TCC in order to verify global locations and tolerances required on drawing (AAA98-111673). 


\section{Appendix C to Scope of Work for IMI Services}

4. Plumb and planarity of the front faces of all KMS units (AAA98-106410 and AAA98-106411) may be verified using separate means independent of the location survey data.

5. "Final" or precision alignment will require use of a survey LRU and will not be performed as part of this work scope.

\subsection{PAINTING}

A. Touch-up paint applies to structural steel only, not to RMDE stainless steel assemblies. Top coat with Sherwin-William "Nova White" per specification applied to Switchyard Structural steel NIF-5001534, Sec 3.06 Sherwin Williams" Polane HS Enamel \#63W56" (Gloss White).

1. Any Exterior painted surface shall meet the requirements of Switchyard Structural Steel Specification \# NIF-5001534, and Section 09900 for Touch-up \& patch existing finishes.

B. Cleaning and Section 01625 for Construction Cleanliness Protocol. 


\section{PERISCOPE}

\section{PART 1 GENERAL}

\subsection{DESCRIPTION}

A. The purpose of this specification is to define minimum requirements for assembly, cleaning, and alignment of the Periscope Assembly identified on General Arrangement Drawing 16-GA-00-10. There are two Periscope Assemblies in this construction package, one in Laser Bay 1 and one in Laser Bay 2

\subsection{QUALITY CONTROL AND QUALITY ASSURANCE}

A. Definitions of Quality Control and Quality Assurance shall be per Section 01010.

B. General Quality Control and Quality Assurance requirements shall be per Section 01400.

C. The Subcontractor QC Inspectors shall perform the following:

1. Inspect rigging and attachment for compliance to the approved rigging diagram and plan.

2. Inspect installed Periscope Assembly for compliance to Part 3.0 of this Section and the drawings respectively as delineated in the Subcontractor's approved installation sequence and procedures.

D. The Subcontractor shall institute the following Hold Points; work shall not proceed beyond these points without written release by the University (see Section 14000):

1. Before precision cleaning of the periscope assembly begins.

E. The Subcontractor shall provide the opportunity for the University to witness the following activities:

1. Precision survey alignment of the first kinematic mounts.

2. Precision cleaning of the first Periscope Assembly.

\subsection{DELIVERY, STORAGE AND HANDLING}

A. Subcontractor shall obtain Periscope Assembly components and other Government Furnished Equipment (GFE) from NIF Production Control at the designated on-site location and transport to Laser Bay for Installation. Reference Section 01015, paragraph 1.06 for the GFE list.

B. Subcontractor shall examine all Government Furnished Equipment (GFE) before transporting from the on-site location to the erection location. Subcontractor shall give 
written notice to the University of any deficiency or condition that may be pertinent (see Section 15895, part 2).

C. Periscope Assembly components shall be cleaned of loose dirt and debris before entering the laser bays. The subcontractor shall implement the cleanliness requirements per section 15895, Product Cleanliness and Cleaning with regard to these items and any additional cleanliness and cleaning requirements identified under parts 2.0 and 3.0 of this section. Subcontractor shall also implement section 01625 Construction Cleanliness Protocol.

D. Subcontractor shall be responsible for all transport, handling and rigging operations and equipment as discussed in Sections 01015 and 15896.

E. Subcontractor shall not weld or otherwise permanently attach to the GFE equipment except where specified herein or on the drawings.

\section{PART 2 PRODUCTS}

\subsection{GOVERNMENT FURNISHED EQUIPMENT (GFE)}

The University will supply the Periscope Assemblies as shown on AAA97-100583-OA located in the laser bay and additional components identified as GFE in Section 01015, paragraph 1.06 .

In addition to the GFE listed on AAA drawings in Section 01015, additional miscellaneous items will be supplied by the University. Application of these items to the assembly procedure is described in Section 3 of this specification.

1. Cover plates for pressure testing (See Section 3.05)

2. Pre-packaged caulking, caulking applicators, and caulking mixers

3. Viewing windows for the Periscope structure (See Section 3.06)

4. Custom survey alignment tools required for kinematic mount alignment (See Section 3.03).

\subsection{SUBCONTRACTOR FURNISHED MATERIAL AND EQUIPMENT}

5. The Subcontractor shall supply all materials required to complete the work identified in this specification, less the components identified as GFE in Section 01015, paragraph 1.06 .

6. The Subcontractor shall supply rigging and handling equipment required to move the Periscope components from the LLNL storage area and assembly the components in the Laser Bay (except the GFE supplied overhead crane in the laser bay). The rigging and handling equipment shall be consistent with the requirements of 15896 .

7. Material and equipment provided by the Subcontractor shall be maintained in a cleaned condition consistent with the requirements in Section 15895.

8. Survey equipment used to meet the installation requirements called out in this specification shall be consistent with the requirements called out in Section 15897. 


\section{PART 3 EXECUTION}

\subsection{PREREQUISITES AND EXAMINATION}

A. Before starting work the Subcontractor shall examine underlying and adjoining work for damage or other apparent deleterious conditions that may be masked or made inaccessible by installation of the Periscope Assemblies and associated items. The subcontractor shall report any damage or conditions that impact installation to the University.

B. Before installing assemblies examine interfacing items for proper geometry, location and orientation as defined on AAA97-100582. Promptly report to the University in writing any apparent deviations or other conditions that may impede proper installation of the assemblies. Do not commence affected work until notified to do so in writing by the University.

C. The Subcontractor shall prepare an installation procedure (or procedures), including checklist setting forth a full description of the task to be performed, installation sequence, QA hold points, and listing the work documents to be used by the Subcontractor in accomplishing the task checklist. The procedure shall include installation of periscope structures, survey alignment, precision cleaning, and pressure testing the enclosure. The Subcontractor is responsible for collecting the necessary working documents including but not limited to drawings, specifications and reference documents necessary for installation.

\subsection{INSTALLATION; GENERAL}

A. The University will provide the Subcontractor with the structure shown in AAA97-100583 already installed in Laser Bays 1 and 2. The Subcontractor is responsible for conducting subtasks in the following order:

1. Install and survey align kinematic mounts inside the Periscope enclosure (Section 3.03).

2. Install top and side panels, and bottom covers (Section 3.04).

3. Preliminary leak test (Section 3.05).

4. Precision clean surfaces inside the Periscope (Section 3.06).

5. Install internal wiring and pneumatic lines, and cover plates (Section 3.07).

6. Final leak test (Section 3.08).

7. Install LM3 light source support assemblies (Section 3.09).

The following sections provide additional requirements to be implemented with each subtask, and a suggested sequence. Except where identified as "shall", or dictated by physical configuration, the sequence provided is a recommendation, and the drawing references are for guidance. The actual sequence planned by the Subcontractor is to be submitted for University approval prior to execution. 


\subsection{KINEMATIC MOUNT INSTALLATION AND ALIGNMENT SPECIFICS}

This task begins with the Periscope Assembly installed in the laser bays as shown in AAA97-100583. The Subcontractor is responsible for installing and aligning components as described below. An overall view of kinematic mount installation is provided on AAA98-104850, with applicable views and details called out below.

The sequence described below was selected to clarify the tasks, and may not represent the most efficient order of installation. The sequence planned by the Subcontractor shall submitted in an installation plan for University approval.

A. Install the LM2 Lower Kinematic Mount Interface Kit.

1. Bolt the LM2 Lower Kinematic Interface Kit, AAA97-109802, on the LM2 Array Frame as shown in AAA98-104850. Install all items except items 7 and 8 on AAA97109802. Items 7 and 8 will be installed after the periscope is precision cleaned.

2. Measure the location of the two $1 / 4$ " diameter survey-tooling features on the Lower Kinematic Interface Assembly using a mounted SMR (Subcontractor supplied). These points are named on AAA97-100587. Compare to the coordinates and tolerances specified in Section 15897.

3. Adjust the Tie Rods, item 1 on AAA97-109802, to obtain the correct $\mathrm{x}$ and $\mathrm{y}$ locations, and $\mathrm{z}$ rotational orientation, relative to global coordinates. Reduce or increase the thickness of the Interface Plate Shim, item 6, or obtain the correct $\mathrm{z}$ location and rotation about y. Verify tolerances are within those specified in Section 15897.

4. Torque hex nuts, item 12 of AAA97-109802, as specified on AAA98-104850.

5. Repeat for all twelve locations of this assembly in a Laser Bay.

B. Install the LM2 Upper Kinematic Mount Interface Kit:

1. Bolt the Upper Kinematic Interface Kit, AAA97-109801, onto the LM2 Array Frame as shown in AAA98-104850. Install all items, including the interface pins, item 7 of AA97-109801.

2. Using the pin survey tool supplied by the University as GFE, measure the location of the pins named on drawing AAA97-100587. Compare to the coordinates and tolerances specified in Section 15897.

3. Adjust the Tie Rods, item 3, of the Upper Kinematic Interface Kit to obtain the correct $x$ locations and $z$ rotational orientation relative to global coordinates. Adjust the location of individual pins to obtain the correct $\mathrm{x}$ and $\mathrm{z}$ location. Verify tolerances are within those specified in Section 15897.

4. Torque hex nuts, item 12, as specified on AAA98-104850.

5. Repeat for all 12 locations of this assembly in each laser bay.

C. Install the LM2 Electrical Interface Kit:

1. Install the LM2 Electrical Interface Kit, AAA97-113673, onto the LM2 Array Frame in locations shown in AAA98-104850. 
2. Align the pins on the Electrical Interface Kit, item 5, to the dimensions shown on view zz of AAA98-104850. This can be done without the use of survey alignment tools (these points are not named on a survey alignment drawing).

3. Repeat for all 24 locations in each laser bay.

D. Install the LM3/Pol Lower Kinematic Interface Kit:

1. Bolt the LM3/Pol Lower Kinematic Interface Kit, AAA98-110428, to an Array Frame Module as shown in AAA98-104850. Install all items except items 9 and 10, the Lower Kinematic Mount Assemblies, of AAA98-110428.

2. Measure the location of the two 1/4" diameter survey tooling features on the LM3/Pol Lower Kinematic Interface Assembly using a mounted SMR (Subcontractor supplied). These survey points are named on AAA97-100587. Compare to the locations and tolerances specified in Section 15897.

3. Adjust the pucks, item 2, of the Lower Kinematic Interface Kit to obtain the correct $z$ and $y$ locations, and $x$ rotational orientation, relative to global coordinates. Reduce or increase the thickness of the Interface Plate Shim, item 6 , or obtain the correct $x$ location and rotation about $\mathrm{y}$. Verify tolerances are within those specified in Section 15897.

4. Tighten fasteners, item 4, as specified on AAA98-104850.

5. Repeat for all 120 locations of this assembly in each laser bay.

E. Install the LM3/Pol Top Kinematic Mount Interface Kit:

1. Install the LM3/Pol Top Kinematic Interface Kit, AAA98-104856, onto the Array Frame Modules at the locations shown in AAA98-104850.

2. Using the pin survey tool supplied by the University as GFE, measure the location of the pins named on drawing AAA97-100587. Compare to the coordinates and tolerances specified in Section 15897.

3. Adjust the pins to obtain correct $\mathrm{x}$ and $\mathrm{z}$ locations and $\mathrm{y}$ rotational orientation relative to global coordinates using the oversized holes. Adjust the shim thickness, item 5 of AAA98-104856, to obtain the correct $\mathrm{z}$ location. Verify tolerances are within those specified in Section 15897.

4. Torque hex nuts, item 7, as specified on AAA98-104850.

5. Repeat steps 1 through 4 for all 72 locations of AAA98-104856 in the laser bay.

6. Repeat steps 1 through 4 for the 24 Top Kinematic Mount Single A Kits, AAA99107070, and the 24 Top Kinematic Mount Single B Kits, AAA99-107071, in each laser bay.

F. Install the LM3/Pol Electrical Interface Assembly:

1. Place the LM3/Pol Electrical Interface Assembly-Flat, AAA98-110445, on the LM3 Array Frame Modules as shown in AAA98-104850. At this time the wiring harness, item 5 on AAA98-110445, is not installed. It will be installed after the Periscope structure is precision cleaned. 


\section{Appendix C to Scope of Work for IMI Services}

2. Measure the distance from the Wiring Harness Alignment Pins, item 1 on AAA98110445, to the pins on the LM3/Pol Top Kinematic Mount Interface Kits installed in task E above. This does not require survey alignment tools, and these points are not named on a survey alignment drawing. Move the Electrical Interface Assemblies until the locations and tolerances relative to LM3/Pol Top Kinematic Mount pins is as shown on view tbd, AAA98-104850.

3. Repeat steps 1 and 2 above for all 24 locations of the LM3/Pol Electrical Interface Assembly-Flat in each laser bay.

4. Place the LM3/Pol Electrical Interface Assembly-Double, AAA98-110438, onto the LM3 Array Frame Modules as shown in AAA98-104850. At this time the wiring harness, item 5 on AAA98-110438, is not installed. It will be installed after the Periscope structure is precision cleaned.

5. Measure the distance from the Wiring Harness Alignment Pins, item 1 on AAA98110438 , to the pins on the LM3/Pol Top Kinematic Mount Interface Kits installed in task E above. This does not require survey alignment tools, and these points are not named on a survey alignment drawing. Move the Electrical Interface Assemblies until the locations and tolerances relative to LM3/Pol Top Kinematic Mount pins is as shown on view tbd, AAA98-104850.

6. Repeat for all 72 locations of the LM3/Pol Electrical Interface Assembly-Double in each laser bay.

7. Place LM3/Pol Electrical Interface Assembly-Single, AAA99-110545, onto the LM3 Array Frame Modules as shown in AAA98-104850. At this time the wiring harness, item 5 on AAA99-110545, is not installed. It will be installed after the Periscope structure is precision cleaned.

8. Measure the distance from the Wiring Harness Alignment Pins, item 1 on AAA98110545, to the pins on the LM3/Pol Top Kinematic Mount Interface Kits installed in task E above. This does not require survey alignment tools, and these points are not named on a survey alignment drawing. Move the Electrical Interface Assemblies until the locations and tolerances relative to LM3/Pol Top Kinematic Mount pins is as shown on view tbd, AAA98-104850.

9. Repeat step 8 for all 24 locations of the LM3/Pol Electrical Interface Assembly-Single.

G. Install the PEPC Lower Kinematic Mount Assemblies:

1. Bolt the PEPC Lower Kinematic Mount Assy, AAA99-106420, onto the PEPC Array Frame as shown in AAA98-104850.

2. Measure the location of item 2 of AAA99-106420 using the survey tool supplied by the University as GFE. These points are named on AAA99-100587. Compare to the coordinates and tolerances specified in Section 15897.

3. Adjust the Lower Kinematic Mount using item 8 on AAA99-106420 for $\mathrm{x}$ adjustment, and adjust the threads on item 2 for adjustment in $\mathrm{z}$ and rotation about $\mathrm{y}$. Verify tolerances are within those specified in Section 15897.

4. Verify tolerances are within those specified in Section 15897.

5. Repeat steps 1 through 4 for 24 locations in each laser bay.

H. Install Cable \& Pneumatic Line Tie Down Points 
1. Drill and tap holes spaced along the bottom of the Array Frame Modules as shown in AAA97-100585.

2. Bolt cable and pneumatic line tie downs, item tbd on AAA97-100585, into the tapped holes.

\subsection{PERISCOPE TOP AND SIDE PANEL INSTALLATION}

Panel installation described in this section establishes much of the Periscope boundary required for leak testing. The gas sealing boundary between bolt up joints is facilitated using a caulking prepared by the University and supplied as GFE. No substitute for this caulking, referred to as LPU-1, is acceptable. Caulking specifications are described in Section TBD.

A. LM2 Array Frame Panels

1. Apply LPU-1 around the bolt pattern of the LM2 Array Frame that interfaces with the LM2 Back Panel Assembly, AAA87-100515. Lift the LM2 Back Panel Assembly to the bolt patter on the LM2 Array Frame Module and bolt as shown on AAA97100585.

2. Apply LPU-1 inside the bolt pattern on the LM2 Array Frame for the LM2 Top Enclosure \#1, AAA97-100526. Lift the LM2 Top Enclosure \#1 to the mating flange on the LM2 Array Frame and bolt as shown on AAA97-100585.

3. Apply LPU-1 inside the bolt pattern on the LM2 Array Frame for the LM2 Top Enclosure \#2, AAA97-100527. Lift the LM2 Top Enclosure \#2 to the mating flange on the LM2 Array Frame and bolt as shown on AAA97-100585.

4. Repeat for each of twelve LM2 Back Panel Assemblies, Top Enclosure \#1 and Top Enclosure \#2 per laser bay.

B. Install PEPC Array Frame Panels and PEPC Ball Grabber Assembly

1. Apply LPU-1 inside the bolt pattern on the PEPC Array Frame that holds the PEPC Top Enclosure \#1, AAA97-100524, on the PEPC Array Frame. Lift PEPC Top Enclosure \#1 to the mating flange on the PEPC Array Frame, and bolt to the torque specified on AAA97-100585.

2. Apply LPU-1 inside the bolt pattern on the PEPC Array Frame that holds the PEPC Top Enclosure \#2, AAA97-100525, on the PEPC Array Frame. Lift PEPC Top Enclosure \#2 to the mating flange on the PEPC Array Frame, and bolt to the torque specified on AAA97-100585.

3. Bolt the PEPC Ball Grabber Mounting Bracket, AAA97-112323, to threaded holes on the PEPC Array Frame beam using the six slotted holes on items 1 and 2 of that drawing. See AAA97-100585 for installation details. Align the holes on top of the PEPC Top Enclosure to the corresponding threaded holes on the PEPC Ball Grabber Mounting Bracket, but do not bolt the top of the PEPC Ball Grabber Mounting Bracket to the PEPC Top Enclosure at this time.

4. Bolt the PEPC Ball Grabber Assembly, AAA97-109105, into the PEPC Ball Grabber Mounting Bracket. 
5. Using the pin survey tool supplied by the University as GFE for the PEPC Ball Grabber Assembly, measure the $\mathrm{x}, \mathrm{y}$, and $\mathrm{z}$ location of the ball grabber as called out on drawing AAA99-100586. These survey points are named on AAA97-100587. Compare to the coordinates and tolerances specified in Section 15897.

6. Adjust the $\mathrm{x}, \mathrm{y}$, and $\mathrm{z}$ location of the PEPC Ball Grabber using items 14 and 25 on AAA97-109105. Verify tolerances are within those specified in Section 15897.

7. Install the Cover Plate, AAA99-112122, and Cover Plate Gasket, AAA99-112132, as shown in AAA97-100585.

8. Repeat steps 1-7 for all locations of the PEPC Ball Grabber shown on AAA97100585.

C. Install the Array Frame Module Top Enclosures

1. Apply LPU-1 inside the bolt pattern on the Array Frame Module that supports Top Enclosure \#1, AAA97-100528. Lift Top Enclosure \#1 to the mating flange on the Array Frame Module, and bolt to the torque specifications on AAA97-100585.

2. Repeat step 1 to install Top Enclosures \#2, \#3, \#4, \#5, \#6, and \#7, drawings AAA97100529, AAA97-100530, AAA97-100531, AAA97-100532, and AAA97-100533, and AAA97-100551, respectively, on the Array Frame Module.

3. Repeat steps 1 and 2 for all Top Enclosures in a laser bay.

D. Install the Middle Enclosure Assembly

1. Apply LPU-1 inside the bolt pattern that supports the Middle Lower Enclosure Assembly, AAA97-100512.

2. Bolt the Lower Middle Enclosure Assembly to it's supporting structures, and torque the bolts as specified on AAA97-100583.

3. Repeat steps 1 and 2 for the Middle Upper Enclosure Assembly, AAA97-100513.

E. Install and Align Bottom Enclosures

1. Loosely bolt the LM2 Bottom Enclosure, AAA97-100516, along with the o-ring, AAA97-100583, onto the LM2 Array Frame.

2. Bolt three Docking Receivers, AAA98-111082, into the three $100 \mathrm{~mm}$ diameter counter-bored holes on the bottom enclosure. Measure the location of the LM2 Bottom Enclosure relative to the coordinates and tolerances specified in Section 15897 using the University supplied survey sphere indicated by datum A on AAA98-111082. These survey points are named on AAA97-100586.

3. Nudge the LM2 Bottom Enclosure in $\mathrm{x}, \mathrm{z}$, and rotation about $\mathrm{y}$ with a mallet until alignment in these axis are consistent with Section 15897. Torque the bolts on the LM2 Bottom Enclosure to the specifications on AAA97-100585, and verify alignment in $\mathrm{x}, \mathrm{y}$, and rotation about $\mathrm{y}$.

4. Place (Subcontractor supplied) shims under the Docking Receivers. The shims shall be sized to locate each receiver in y consistent with the coordinates and tolerances of Section 15897.

5. Measure the location of the two $13.2 \mathrm{~mm}$ diameter holes counter-bored into the bottom of the LM2 Bottom Enclosure using a standard 1.5" diameter survey sphere 
(Subcontractor supplied). Magnets have already been glued in by the University to hold the sphere. Record in the appropriate column in Section 15897. These reference points are used during laser operation.

6. Repeat steps 1 through 3 for the PEPC Bottom Enclosure, AAA97-100518, and the Periscope Bottom Enclosure, AAA97-100517. Repeat for all the bottom enclosure locations in Laser Bay 1 and 2.

\subsection{PRELIMINARY LEAK TEST}

A. General Leak Test Requirements

During laser operation the Periscope will contain a clean gas at standard temperature, and up to 12 inches of water $(2.98 \mathrm{kPa})$ over pressure relative to the laser bay. To limit leakage, the Periscope enclosure is limited to no more than $12 \mathrm{cfm}$ per laser bay at maximum overpressure.

The periscope structure within a laser bay is comprised of twelve separate gas tight compartments, referred to as bundles. The average leak rate of each compartment shall be measured, and the average leak rate shall be no more than $1 \mathrm{cfm}$. Open apertures in the structure are to be covered using cover plates provided as GFE by the University. These cover plates were fabricated by the Periscope manufacturer, and AAA drawings are not available.

1. Leak Test Preparation

Cover plates are provided by the Univesity to cover open ports of the Periscope during preliminary leak testing. The Subcontractor shall install the cover plates prior to leak test. The PEPC and Array Frame Module cover plates cover large horizontal openings that connect to laser beam tubes during laser operation. The Bottom Cover Plates cover bottom openings in the Periscope, where clean cover plates will be placed later in this contract. Fasteners for the cover plates are provided by the University. Before bolting the cover plates into place, the contractor shall apply LPU-1 caulking inside the bolt pattern to facilitate a pressure seal.

\begin{tabular}{|l|c|}
\hline \multicolumn{1}{|c|}{ University Supplied Items } & Quantity \\
\hline PEPC Array Frame Cover Plate & 1 \\
\hline PEPC Bottom Cover Plate & 2 \\
\hline Array Frame Module Cover Plate & 1 \\
\hline LM2 Bottom Cover Plate & 2 \\
\hline Array Frame Module Bottom Cover Plate & 10 \\
\hline Array Frame Module Top Enclosure Port Covers & 16 \\
\hline Electrical Feed-through Covers & 12 \\
\hline
\end{tabular}




\section{Appendix C to Scope of Work for IMI Services}

Certain bolt joints require LPU-1 caulking to provide a gas seal prior to leak test. The caulking shall be applied by removing one bolt at a time, applying caulking between the bolt shaft and the adjacent structure to form a gas seal gasket, and re-applying torque before the caulking hardens. These bolt joints are identified below:

a. Each bolt fastening the Middle Upper Enclosure, AAA97-100513, and the Middle Lower Enclosure, AAA97-100512. There are fourteen of each Enclosure panel per laser bay (see Detail E, 100583).

b. Each bolt fastening the Lower Left Hand Side Beam Assembly, AAA97-100545, the Lower Right Hand Side Beam Assembly, AAA97-100519, and the Lower Inboard Beam Assembly, AAA97-100511, to either the PEPC Array Frame, the LM2 Array Frame or the PEPC Array Frame. There are fourteen Beam Assemblies per laser bay (see Detail E and L, AAA97-100583 for example).

c. Each bolt fastening Array Frame Modules 1, 2, \& 3, AAA97-100505, AAA97100506, and AAA97-100507 to the PEPC Array Frame. There are fourteen of these interfaces per laser bay (see Detail K, AAA97-100583). Only bolts inside the enclosure need be removed and caulked.

d. Each bolt on top of the Array Frame Modules 1, 2, \& 3, AAA97-100505, AAA97-100506, and AAA97-100507 fastening the Array Frame Modules to each other. There are four of these interfaces per laser bay (see Detail J, AAA97100583). Only bolts inside the enclosure need be removed and caulked.

2. Leak Test Procedure

Each of the twelve Periscope compartments (modules) in a laser bay shall be individually leak tested. The test shall be conducted in accordance with Section 6.5.3 of ANSI/ASME N510(1980) for testing of air treatment systems. The specification defines a leak rate test using the pressure decay method. All equipment required for this test shall be provided by the Subcontractor.

The Subcontractor shall apply an overpressure of 12 inches of water to a prepared Periscope module (bundle) using a suitable pressurizing fan. The Subcontractor shall measure the ambient temperature and the pressure fall rate after shutting off the air supply valve. The rate of fall shall be defined as

$$
\text { LeakRate }=\frac{\Delta \mathrm{P}}{\Delta \mathrm{t}} \frac{V}{\rho R T}
$$

Where $\Delta \mathrm{p}=$ pressure drop

$\Delta \mathrm{t}=$ time duration

$\mathrm{V}=$ enclosed volume

$\rho=$ air density

$\mathrm{T}=$ ambient temperature

$\mathrm{R}=$ gas constant for air.

If a bundle of the Periscope enclosure fails to meet the requirements of Part A of this Section, the Subcontractor shall identify the source of the leaks, apply LPU-1 caulking to 
the leaking joint (on the outside surfaces of the Periscope structure where possible), and re-test.

\subsection{PRECISION CLEANING}

The Periscope Assembly shall be cleaned in place to establish a particulate and nonvolatile residue on its inner surfaces consistent with the clean laser enclosures it will interface with. Enclosures the Periscope interfaces with have been cleaned to Level 83$\mathrm{A} / 10$, as defined in MIL-STD-1246C.

A. Cleaning Process

High-pressure water spray wash, followed by high-pressure spray rinse and a drying cycle, has proven to meet the Level 83-A/10 requirement in previous applications. One University approved procedure using this method is documented in MEL98-008-OA. The contractor shall propose a procedure with similar content for university approval, documenting the process parameters and verification methods. Enclosure cover plates provided by the University to facilitate pressure testing may be used by the contractor to establish physical boundaries around the periscope openings during precision cleaning.

B. Establishing a Clean Zone

The Subcontractor has the option of establishing the entire area between concrete walls underneath the periscope (see AAA97-100501) as a clean zone from which to clean the Periscope, or confining the clean zone to the vicinity of a single Periscope gas enclosure module (bundle). For purposes of work description in this specification, it is assumed the Subcontractor will establish the entire area between concrete support walls as a clean zone.

The clean zone established by the Subcontractor should be consistent with the cleanliness protocol called out for Level 4 cleanliness as defined in Section 01625. The zone shall also contain the following features:

1. Plastic sheet barriers erected between the concrete walls supporting the Periscope structure to isolate the clean work area underneath the Periscope from the surroundings, including coverage of gaps in the concrete. The Subcontractor may propose temporary structures attached to the concrete wall for University approval.

2. Continuous supply of clean, filtered supply air to the clean zone to eliminate dust ingress.

3. A controlled entry buffer zone between the clean zone and outside work area to serve as a changing station and clean parts entry.

4. Temporary (possibly raised) floor covering underneath the Periscope with drainage to collect water run off from the high-pressure spray and rinse.

5. A supply of clean high-pressure water for precision cleaning, and a source of clean heated air for drying.

6. A drain tank with sufficient capacity to support the cleaning operation.

7. Temporary scaffolding to allow man access in close proximity to Periscope internal surfaces at various levels. Precision cleaning is expected to begin at the top of the structure and progress downward. 


\section{Appendix C to Scope of Work for IMI Services}

8. Portable lighting sufficient to support the cleaning operation.

Space external to the clean zone will be made available to support utilities and services (pumps, tanks, etc.) best provided from outside the clean zone. The University will respond to the Subcontractors needs for utility space as they are identified.

C. Post Cleaning

As each enclosure module (bundle) of the Periscope is cleaned and dried:

1. Remove the two GFE supplied cover plates from the large square openings of the PEPC and LM2 Array Frame and replace them with double layers of ultra-low outgas polyethylene sheet (supplied by Subcontractor).

2. Remove the sixteen GFE supplied cover plates from the ports on the Top Enclosures \#2, \#3, \#4, and \#5, and install GFE supplied glass windows, NIF part number N666016882, and mounting flange, AAA97-100541, taking care to maintain a high level of cleanliness on the glass. After installation, tape a layer of ultra-low outgas polyethylene sheet over the flange to serve as a dust cover.

3. Remove the GFE supplied PEPC and LM2 Bottom Cover Plates, and replace them with a layer of ultra-low outgas polyethylene sheet taped to the bottom of the Periscope.

4. Remove the GFE supplied Electrical Feed-through Covers and replace them with ultra-low outgas polyethylene sheet taped over the opening to the outside of the Periscope.

5. Move the GFE supplied cover plates to the next bundle requiring cleaning.

After six bundle sections (a cluster) of the periscope enclosure have been cleaned, the contractor may proceed with installation of pre-cleaned enclosure components. The clean room under the Periscope structure is to remain intact while these components are being installed.

\subsection{CLEAN COMPONENT INSTALLATION}

Final installation of pre-cleaned GFE inside the Periscope enclosure constitutes the last task before the local clean area can be decommissioned. Pre-cleaned GFE includes pneumatic actuators and lines, wiring, and a removable bottom cover plate.

Pre-cleaned GFE components will arrive triple bagged. The first bag is removed prior to entering the clean area changing station. The second bag is removed in the changing station, and the third bag is removed just prior to component installation.

Remove the plastic sheet taped to the bottom plates below one precision cleaned module (bundle) of the Array Frame Module and LM2 Array Frame. Erect local scaffolding up into the enclosure to provide access to the LM3/Polarizer and LM2 Electrical Interface Assemblies bolted to the top of the Periscope structure.

A. Electrical Feed-through Installation 
1. Bolt the Harness Assembly, item 5 of AAA99-109545, into the bottom of the Mounting Plate, item 2. This mounting plate is at the top of the Periscope structure, as shown in AAA97-100585 Insert the electrical feed-though, item 4, into the MS Connector Mounting Plate and tighten the sealing nut from outside the Periscope enclosure.

2. Bolt the Harness Assembly, item 5 of AAA98-110438, into the bottom of Mounting Plate, item 2. Insert two electrical feed-thoughs, item 4, into the MS Connector Mounting Plate and tighten the sealing nut from outside the Periscope enclosure. Repeat for all three Harness Assemblies per bundle, as shown on AAA97-100585

3. Bolt the Harness Assembly, item 5 of AAA98-110445, into the bottom of Mounting Plate, item 2. There is one of these at the bottom of the Periscope structure, as shown on AAA97-100585. Insert the electrical feed-though, item 4, into the MS Connector Mounting Plate and tighten the sealing nut from outside the Periscope enclosure.

\section{B. Kinematic Mount Component Installation}

1. Bolt and torque a left and right hand Lower Kinematic Mount Assembly, items 8 and 10 of AAA98-110428, onto the shim plates, item 6, of the LM3/Polarizer Lower Kinematic Interface Kit. This unit comes with a pre-attached limit switch and connector. Repeat for all ten LM3/Polarizer Lower Kinematic Interface Kits within a bundle enclosure.

2. Bolt and torque a left and right hand Lower Kinematic Mount Assembly, AAA97109802, onto the shim plates, item zz, of the LM2 Lower Kinematic Interface Kit. Repeat for the two LM2 Lower Kinematic Interface Kits within a bundle enclosure.

3. Install the pneumatic lines for the LM3/Polarizer and LM2 actuators as shown on Section BB and yy of Periscope General Arrangement AAA98-104850.

\section{LM3/LM2/Polarizer Wiring Harness Installation}

1. Install Loading Sensor and Seismic Sensor, both LEA99-134252, as shown on AAA98-104850 in each of the five locations of the Lower Kinematic Mounts for the left side of the LM3/Polarizer. Repeat for the right side.

2. Install Loading Sensor and Seismic Sensor, both LEA99-134252, as shown on AAA98-104850 in locations of the LM2 left and right hand side Lower Kinematic Mounts.

3. Install one left and one right LM2/LM3 Sensor Interface, LEA99-135142 and LEA99135242, respectively, as shown in the Periscope General Arrangement AAA98104850. Insert the electrical feed-though into the LM2 Electrical Interface Kit, AAA97-113675, and tighten the sealing nut from outside the Periscope enclosure.

4. Install and route the cable harness as shown on view yy of AAA98-104850, distributing pin plugs to the loading sensor, seismic sensor, and actuator switches at the five locations of the LM3/Polarizer Lower Kinematic Mounts on the left side. Repeat for the right side. Use teflon cable ties, AAA98-104850, to secure the harness to tie down points on the Array Frame Module.

5. Mate connectors and conduct an electrical continuity check of the circuits.

D. Universal Cover Installation 
1. Lift a Universal Cover, AAA98-116726, to the opening of a LM2 Bottom Enclosure plate installed at the bottom of the LM2 Array Frame as shown on AAA97-100585. Using a suitable tool, retract the spring-loaded pins in the Universal Cover, and press the cover against the gas-sealing surface. Extend the pins to hold the Universal Cover in place.

2. Repeat step 1 for the fourteen Universal Cover locations under a bundle: two for the LM2 Array Frame, two for the PEPC Array Frame, and ten for the Array Frame Module.

\subsection{FINAL LEAK TEST}

A. Leak Test Requirements

At this point in the Periscope assembly sequence, all operations inside the clean enclosure are complete and the Periscope enclosure forms a complete gas sealed enclosure except for the large rectangular openings on the $-z$ side of the PEPC Array Frame and the $+z$ side of the Array Frame Modules.

Because so many additional gas seal components have been added prior to precision cleaning the periscope, and because the precision cleaning process itself can effect the gas seals, it is necessary to conduct a final leak test. The test requirements are identical to those listed in Section 3.05, Part A.

B. Leak Test Preparation

The number of University supplied cover plates required to conduct the test is reduced to two for the final leak test: the PECP Array Frame Cover Plate, and the Module Array Frame Cover Plate. These plates must be precision cleaned prior to installation, and maintained clean as each bundle is tested. The University supplied caulking can applied to these two plates to implement a gas seal.

C. Pressure Test Procedure

The procedure described in Section 3.05, Part C applies.

\subsection{LM3 LIGHT SOURCE SUPPORT STRUCTURE INSTALLATION}

The last major task of Periscope installation is to install and align the LM3 Light Source Support Assembly illustrated on AAA97-100546 (item numbers below are from this assembly drawing). There is one such assembly per bundle, or twelve per laser bay, located on top of the LM2 Array Frame. The assembly is subdivided into the steps below for one bundle, and shall be repeated for every bundle in a laser bay.

The LM3 Light Source Support Assembly AAA97-100546 references Light Source Beam Tube Assemblies, items 3, 4, 5, and 6. These beam tubes and support hardware are not to be installed by the Subcontractor.

A. Install Light Source Support Structures

1. Locate the LM3 Light Source Support Stand Frame, item 1, on top of the LM2 Array Frame Module. Bolt the frame feet into the pre-drilled tapped holes. 
2. Locate the LM3 Light Source Tube Stand Assembly, item 2, on top of the Array Frame Module. Bolt the Tube Stand Assembly into the pre-drilled holes on the Array Frame Module.

3. Bolt a Foot Bracket, item 12, into the pre-drilled holes on the Array Frame as shown on AAA97-100546.

4. Bolt a Middle Bracket, item 10, onto the Foot Bracket to form a receiver for the Light Source Plate.

B. Pre-assemble the LM3 Light Source Support Plate

1. Bolt six Light Source Foot Mounts, item 27, into the backside of the Light Source Support Plate.

2. Install the threaded rod, item 28, and leveling feet, item 29, into the six Light Source Foot Mounts.

3. Bolt four Lower Spool Assemblies, item 8, into the bottom four locations of the LM3 Light Source Support Plate.

4. Bolt eight Spool Assemblies, item 7, into the remaining 12 locations of the LM3 Light Source Support Plate.

C. Install and Align the LM3 Light Source Support Plate

1. Set the LM3 Light Source Support Plate against the welded tabs of the Support Stand Frame, item 1.

2. Bolt the two Corner Brackets, item 11, to the welded tabs of the Support Stand Frame to capture the Support Plate.

3. Bolt five Middle Brackets, item 10, to the five middle bracket locations on the Support Stand Frame.

4. Install 1.5" diameter SMR survey targets (Subcontractor supplied) into the counterbored locations on the $-\mathrm{z}$ side of the Light Source Support Plate. Using the leveling screws on the plate, survey align the plate consistent with the coordinates and tolerances called out in Section 15897.

5. Thread the unused leveling screws out against the stops on the Light Source Support Stand to induce a stabilizing force on the Light Source Support Plate. 


\section{LASER MIRROR - 1 (LM-1)}

\section{PART 1 GENERAL}

\subsection{DESCRIPTION}

The purpose of this specification is to define minimum requirements for transport, lifting, setting, and alignment of Light Source Plate assemblies as identified in the drawing. The subcontractor shall install these Light Source Plate assemblies to the previously installed (by CSP-13 subcontractor) LM-1 assemblies in Laser Bays 1 \& 2

\subsection{QUALITY CONTROL AND QUALITY ASSURANCE}

A. General QC and QA Requirements shall be per Section 01400.

B. Definitions of QC and QA shall be per Section 01010.

C. The subcontractor and QC Inspectors shall perform the following:

1. Inspect rigging and attachment for compliance to the University approved rigging diagram and plan.

2. Inspect installed Light Source Plate assemblies for compliance to Part 3.0 of this Section and the drawings respectively as delineated in the subcontractor's approved installation sequence and procedures.

3. The subcontractor's University approved precision measurement surveyor shall perform survey of the installed Light Source Plate assemblies to verify compliance with Section 15897, this section, and related drawings.

D. The subcontractor shall institute the following hold points; work shall not proceed beyond this point without written release by the University:

1. Placement and installation of first Light Source Plate assembly.

E. The subcontractor shall provide the opportunity for the University to witness the following activities:

1. Initial lifting and setting of first Light Source Plate assembly to be installed.

\subsection{DELIVERY, STORAGE AND HANDLING}

A. The subcontractor shall obtain Light Source Plate assemblies and other associated Government Furnished Equipment (GFE) as denoted in section 01015 from NIF Production Control at the designated on-site location and transport to the Laser Bay for Installation. 
B. The subcontractor shall examine all GFE before transporting from the on-site location to the erection location in accordance with Section 15895 and shall give written notice on any deficiency detrimental for proper and timely installation of work to the University.

C. Light Source Plate assemblies will be furnished in a cleaned condition where so indicated in the Infrastructure drawing/GFE list provided in Section 01015. The subcontractor shall implement the cleanliness and cleaning requirements of Sections 01625 and 15895, and any additional cleanliness and cleaning requirements identified under parts 2.0 and 3.0 of this section.

D. The subcontractor shall be responsible for all transport, rigging, and handling operations and equipment as discussed in Sections 01015, 01620 and 15896.

E. The subcontractor shall not weld to the GFE except where specified herein or the drawings.

\section{PART 2 PRODUCTS}

\subsection{GOVERNMENT FURNISHED EQUIPMENT (GFE)}

A. The University shall supply the Light Source Plate assemblies and associated GFE listed in Section 01015, which includes but is not limited to the followings major components:

\section{Light Source Plate Assembly}

B. LM-1 assemblies has been installed and aligned on the concrete pedestals by CSP-13 subcontractor (see installation drawing AAA99-108113).

\subsection{SUBCONTRACTOR FURNISHED MATERIAL AND EQUIPMENT}

A. The subcontractor shall fabricate and supply all the material shown on each drawing except those identified as GFE in Section 01015.

B. Material provided by the subcontractor shall meet the requirements listed on the drawings and related specifications. Material and equipment provided by the subcontractor shall be delivered to the Laser Bays and cleaned in accordance with Section 15895.

\section{PART 3 EXECUTION}

\subsection{PREREQUISITES AND EXAMINATION}

A. Before starting work, the subcontractor shall examine underlying and adjoining work for damaged or other apparent deleterious conditions that may be masked or made inaccessible by installation of the Light Source Plate assemblies and associated items. 


\section{Appendix C to Scope of Work for IMI Services}

B. Before installing Light Source Plate assemblies, the subcontractor shall examine and survey interfacing components for proper geometry, location and orientation, as defined on the drawing. The subcontractor shall report to the University immediately for apparent deviations or other conditions that may impede proper installation of the Light Source Plate assemblies. Do not commence affected work until notified to do so in writing by the University.

\subsection{PREPARATION}

The subcontractor shall prepare installation procedure, which shall include an installation and inspection checklist, a full description of the task to be performed, installation sequence, QA hold and witness points and listing of the work documents to be used. The procedure shall also include survey/alignment actions necessary to fulfil requirements of this sections and Section 15897. The subcontractor is responsible for collecting necessary working documents including but not limited to drawings, specifications, and reference documents necessary for installation.

\subsection{INSTALLATION SPECIFICS}

The Light Source Plate assemblies and associated items shall be installed in accordance with drawing. The following paragraph provides additional requirements to be implemented in conjunction with the drawing. However, except where identified as "mandatory" or dictated by physical configuration, the sequence provided is a recommendation. The actual installation sequence and procedure shall be determined by the subcontractor and submitted for the University approval prior to execution.

A. Installation and alignment of Light Source Plate Assemblies:

1. Light Source Plate assemblies shall be installed to the previously installed (by CSP-13 subcontractor) LM-1 assembly in accordance with drawing.

2. Install 1.5" diameter SMR survey targets (subcontractor supplied) into the counterbored locations on the $-Z$ side of the Light Source Support Plate. Using the leveling screws on the plate, survey and align the plate consistent with the coordinates and tolerances called out in the Section 15897.

3. Thread the unused leveling screws out against the stops on the Light Source Support Stand to include a stabilizing fore on the Light Source Support Plate. 


\section{SWITCHYARD ENCLOSURES}

\section{PART 1 GENERAL}

\subsection{DESCRIPTION}

A. The purpose of this specification is to define minimum requirements for the installation and alignment of the Switchyard Enclosures.

B. Switchyard Enclosures are enclosures that provide a precision cleaned and pressurized environment for the laser beam as it travels within the Switchyard towards the Target Chamber. Inside surface conditions in terms of particulate and nonvolatile residue (NVR) levels result from cleanliness requirements needed to protect optical surfaces from laserinduced damage. As discussed in Section 15895, all of the Switchyard Enclosure hardware will be cleaned to Level 83-A/10 per MIL-STD-1246C and will not exceed Level 100 after installation and alignment. The Switchyard Enclosures are attached to the Roving Mirror Diagnostic Enclosure (RMDE) Gate Valves at one end and connected to the through Target Wall Enclosures on the other. The Switchyard Enclosures will be pressurized with argon gas to prevent an in-flow of gas from the external environment into their precision cleaned interiors.

\subsection{QUALITY CONTROL AND QUALITY ASSURANCE}

A. General QC and QA requirements shall be per Section 01400.

B. Definitions of QC and QA shall be per Section 01010.

C. The subcontractor and QC Inspectors shall perform the following:

1. Inspect rigging and attachment points for compliance to the University approved rigging diagram and plan.

2. Inspect each installed Switchyard Enclosure and other related components for compliance to Part 3.0 of this Section, Section 01625, Section 15895, and the respective drawings. This includes monitoring the Clean Construction Protocol Level per Section 01625, the airborne cleanliness level per Sections 01625 and 15895, and the surface cleanliness level per Section 15895.

3. The Subcontractor precision measurement surveyor shall perform a survey of the each installed component to verify compliance with Section 15897, this Section, and the drawings.

4. All welds shall be visually inspected for complete fusion, correct size, and correct contour per drawing.

D. Subcontractor shall institute the following hold points and work shall not proceed beyond these points without written release by the University:

1. Installation of first bundle Enclosure. 


\section{Appendix C to Scope of Work for IMI Services}

2. Installation of first through Target Wall Enclosure.

3. Installation of first Enclosure Intersection Joint.

4. Installation of first complete Enclosure run.

E. Subcontractor shall provide the opportunity for the University to witness the following activities:

1. Initial lifting and setting of Switchyard Enclosures to be installed.

2. Setting and Alignment of Switchyard Enclosures, as applicable.

3. As-installed Survey of Switchyard Enclosures, as applicable.

4. Clean connection procedure for Switchyard Enclosures and enclosure hardware.

5. In-situ cleaning of through Target Wall Enclosure.

6. Surface cleanliness verification, as applicable.

\subsection{DELIVERY, STORAGE AND HANDLING}

A. Subcontractor shall obtain Switchyard Enclosures, and other associated Government Furnished Equipment (GFE) items from NIF Production Control at the designated on-site location and shall transport the GFE to the Laser Bays for installation.

B. Subcontractor shall examine all GFE before transporting from the on-site location to the erection location and give written notice to the University about any deficiency which would be detrimental for proper and timely installation of GFE.

C. Switchyard Enclosures have been precision cleaned and are furnished in a precision cleaned condition (Level 83-A/10 per MIL-STD-1246C), except for the through Target Wall Enclosures that will be in-situ cleaned as discussed in Section 15894. Associated GFE items will have been gross cleaned or precision cleaned as required by the University. The Subcontractor shall implement the cleanliness protocol requirements per Section 01625, will implement clean connections in accordance with Section 15895, and will implement any additional cleanliness and cleaning requirements identified under Parts 2.0 and 3.0 of this Section.

D. Subcontractor shall be responsible for all transport, handling and rigging operations and equipment as discussed in Sections 01015 and 15896.

E. Subcontractor shall not weld any attachments to the GFE equipment except where specified herein or the drawings.

F. Puncture-proof and cleanliness covers are installed on various openings of the Switchyard Enclosures to maintain the internal and some external surfaces in a precision cleaned state. Subcontractor shall remove those covers as discussed in Section 15895. After removing the covers, the surface cleanliness level of the precision cleaned GFE can be determined according to the requirements of Section 15895. 


\section{PART 2 PRODUCTS}

\subsection{GOVERNMENT FURNISHED EQUIPMENT (GFE)}

A. The University shall supply the GFE components listed in Section 01015.

B. Switchyard Enclosures and seals were fabricated in accordance with detailed fabrication drawings and specifications.

C. Switchyard Enclosures and seals have been precision cleaned and are furnished in a precision cleaned condition (Level 83-A/10 per MIL-STD-1246C). Subcontractor shall ensure protection of precision cleaned surfaces throughout handling and placement of all GFE. Precision cleaned surfaces include all internal vacuum beamtube surfaces, all internal pressurized enclosure surfaces, sealing surfaces at the vacuum boundary, sealing surfaces at the pressurized boundary, interior sides of the rupture panels, and interior sides of covers. Sections 01625 and 15895 provides specific cleaning and protocol requirements.

D. The Switchyard Enclosure, except those that will be in-situ cleaned as discussed in Section 15894, openings are protected with ULO polyethylene sheets and a punctureproof plate installed by others.

E. Subcontractor shall ensure protection of precision cleaned surfaces throughout handling and placement of all GFE, as applicable. Subcontractor shall not remove ULO polyethylene sheets or puncture-proof plates from the Switchyard Enclosure until the appropriate requirements of Section 01625, Section 15895, and Parts 2 and 3 of this Section are satisfied.

\subsection{SUBCONTRACTOR FURNISHED MATERIALS}

A. Subcontractor shall fabricate and supply all the materials shown on each drawing except those listed in the GFE list in Section 01015 and unless otherwise specified. It is the responsibility of the Subcontractor to compare each item shown on the drawings with the GFE list in order to determine the items supplied under this subcontract.

B. Materials provided by the Subcontractor shall meet the requirements listed on the drawings and related specifications. Materials provided by the Subcontractor shall be delivered to the Laser Bays and maintained as a minimum in a gross clean condition in accordance with Sections 01625 and 15895.

\section{PART 3 EXECUTION}

\subsection{PREREQUISITES AND EXAMINATION}

A. Before starting work, the Subcontractor shall examine underlying and adjoining work for damaged or other apparent conditions that may be masked or made inaccessible by installation of Switchyard Enclosures and associated items. 


\section{Appendix C to Scope of Work for IMI Services}

B. Before installing the Switchyard Enclosures, Subcontractor shall examine and evaluate interfacing equipment for proper geometry, location, and orientation, as specified on the drawings. Subcontractor shall report to the University immediately for apparent deviations or other conditions that may impede proper installation of the assemblies. Affected work shall not commence until notified to do so in writing by the University.

C. Before installing the Switchyard Enclosures, Subcontractor shall examine and evaluate temporary covers (typically ULO polyethylene sheets with puncture-proof layer) for an conditions that deviate from the precision cleaned conditions (Level 83-A/10 per MILSTD-1246C) of the components before installation. In addition, the temporary covers shall be in an undamaged condition on Switchyard Enclosure GFE components received by the Subcontractor. Subcontractor shall report to the University immediately any conditions that may affect the clean installation of components. Affected work shall not commence until notified to do so in writing by the University.

\subsection{PREPARATION}

A. Subcontractor shall prepare an Installation Sequence and Procedure, a Clean Installation Procedure, and an In-Situ Cleaning Procedure and each Procedure shall include a checklist that sets forth a full description of the task to be performed, installation sequence, and list of work documents to be used in accomplishing the task checklist. Subcontractor is responsible for collecting necessary working documents, including but not limited to, drawings, specifications, and reference documents necessary for installation.

B. Before installation of specific Switchyard Enclosures the conditions near the installation shall satisfy the requirements of Sections 01625,15895 , and 15894, as appropriate.

C. Subcontractor shall submit Welding Procedure Specification for Enclosure Mounts installed with welding for review and acceptance by the University. The Specification shall satisfy appropriate AWS requirements and requirements of Sections 05120 and 15141 as well as Part 3.04 of this Section.

D. Subcontractor shall submit Alignment / Survey Plan and Procedure for Switchyard Enclosures. This Procedure will be reviewed for acceptance by the University and shall satisfy the appropriate requirements of Section 15897. The alignment tolerance in NIF global coordinates for Switchyard Enclosures components is $\pm 1 \mathrm{~mm}$. The Switchyard Enclosure Bellows shall be installed by Subcontractor with a minimum of $25 \mathrm{~mm}$. of compression.

E. Subcontractor shall submit Leak Checking Procedure for review and acceptance by the University. This Procedure shall satisfy appropriate requirements of Section 15122 . The Switchyard Enclosures have a design pressure of 2" W.G. (0.5 KiloPascal)

\subsection{MATERIAL HANDLING AND RIGGING}

A. Subcontractor shall submit a Rigging Diagram and Lifting Plan for all items under one ton and a specific rigging and lifting plan for each item one ton or over. Specific access limitations and handling routes shall be considered per Section 15896. 
B. Switchyard Enclosures shall be lifted using Nylon strings at lift points defined in the drawings or lift plans developed by the GFE fabricators. No single point lifts shall be performed on the Switchyard Enclosures. Handling and lifting features for the Switchyard Enclosures will be provided by the GFE fabricators. These features shall be examined and evaluated by the Subcontractor before installation of the components. Subcontractor shall notify the University in writing of any deviations from GFE fabricator-defined lifting and handling features and shall not commence with deviation unless notified in writing by the University.

\subsection{WELDING}

A. Welding shall comply with the requirements of AWS D1.1, AWS D1.6, and the following:

Welding Process: Welds on the external surface shall be of the Gas Tungsten Arc Welding GTAW or Gas Metal Arc Welding (GMAW) processes. All weld joints on the internal surfaces shall be performed with the GTAW process. Alternative processes require approval in writing from the University.

Joint Preparation: Before welding, joints shall be cleaned of all foreign materials such as oil, grease, paint, dust, and oxides or sulfides. Cleaning shall remove all visible evidence of contamination, including all stains and discoloration of the surfaces.

Distortion Control: Weld procedures and fixtures shall be selected to control distortion within dimensional limits bounded by University drawings. Copper chill bar (backing bar) is recommended for flat seams to minimize distortion and maintain flatness of finished panels. The procedure utilized to control distortion shall be submitted to the University for information.

Weld Procedure Specification (WPS): A WPS is required for each weld process including the combination of wire filler type, base metal type, and size to be used in the construction. Weld procedures shall conform to AWS D1.6 Annex F (no pre-qualified procedures may be used) or the equivalent form per ASME Boiler and Pressure Vessel Code (B\&PVC) Section IX. If ASME Boiler and Pressure Vessel Code is used, the Essential, Supplementary, and Nonessential Variables are required. WPSs shall be submitted in writing to the University for acceptance.

Procedure Qualification Record (PQR): A PQR is required for each Weld Procedure Specification. Each PQR shall be prepared in accordance with AWS D1.6 or the equivalent form per ASME B\&PVC Section IX, and signed by a certified or qualified weld inspector. Each $\mathrm{PQR}$ shall indicate the specific inspection criteria (by paragraph number) from the code used to evaluate the weld samples. PQRs shall be submitted in writing to the University for acceptance.

Welder Performance Qualification (WPQ) Test Record: A WPQ is required for each welder or welding operator covering the utilized welding processes. Each WPQ shall be prepared in accordance with AWS D1.6 or the equivalent form per ASME B\&PVC Section IX. Qualified welders shall perform all welding and WPQs shall be submitted to the University in writing for acceptance. 


\section{Appendix C to Scope of Work for IMI Services}

Weld symbols: Weld symbols on sketches and drawings shall be interpreted in accordance with AWS A2.4. Any conflicts or questions related to application or interpretation of weld symbols should be directed to the University in writing for disposition and clarification.

Weld Quality and Acceptance Criteria: Weld joints shall be free of cracks, crevices, or incomplete fusion. Limits of porosity shall be determined using inspection criteria defined in AWS D1.6. Internal welds shall have: smooth transition with parent material without rough edges along bead (maximum peak to valley height $0.76 \mathrm{~mm}$ ), no undercut, no splatter, and no discoloration from oxidation. Weld finish shall be smooth to enable final cleaning processes and cleanliness verification.

Weld Filler Metal: Electrodes and filler wire for welds shall be of type 308 stainless steel and procured under the applicable ASME BPVC Section II or AWS specification. The certified material test reports (CMTRs) shall be submitted to the University for all weld filler metal for information.

B. Weld inspections shall comply with the requirements of AWS D1.6 and the following:

Weld Inspection: Welding activities and all completed welds shall be visually inspected in accordance with AWS D1.6 or weld joints shall blend into the adjacent base metal in gradual smooth curves using inspection acceptance criteria delineated in AWS D1.6. Additional inspection requirements specified on the drawings shall also be implemented.

Weld Inspectors: Weld Inspectors shall be qualified and certified in accordance with AWS QC-1 or other industry sanctioned inspector qualification program applicable to weld inspection. The Subcontractor shall maintain records that attest to the active status of qualified or certified weld inspectors. Program practices and inspector qualification and certification documentation shall be submitted in writing to the University for acceptance prior to start of welding.

\subsection{INSTALLATION PROCEDURE AND SEQUENCE}

All Switchyard Enclosure and associated items shall be installed in accordance with drawings. This Section provides additional requirements to be implemented in conjunction with the drawings. However, except where identified as "mandatory" or dictated by physical configuration, the procedure and sequence provided in this Section is a recommendation. The actual sequence to be implemented is to be determined by the Subcontractor as reflected in the submitted Installation Sequence and Procedure.

For ease of installation of components, Subcontractor shall establish a HEPA controlled cleanroom for subassembly of precision cleaned components in the Laser Bays. This Subassembly Cleanroom shall satisfy the requirements of Section 01625 and within the Subassembly Cleanroom, the applicable requirements of Parts 3.01, 3.02, and 3.03 of this Section shall also be satisfied.

The gaskets for the Switchyard Enclosures will be installed next to the light shields prior to the Subcontractor receiving the GFE components. These gaskets are defined in Section 


\section{Appendix C to Scope of Work for IMI Services}

15107 and they shall be protected during lifting, handling, and installation activities by the Subcontractor. If the gaskets become detached or damaged from the Switchyard Enclosures the Subcontractor shall notify the University in writing. To position the gaskets on the Switchyard Enclosures University-approved adhesive as defined on the drawings can be used.

The fasteners for the Switchyard Enclosures are defined in the drawings. The Subcontractor shall use fasteners that satisfy the requirements of Section 15062 and the drawings.

\subsection{ALIGNMENT AND SURVEYING}

The switchyard Enclosures and its components shall be aligned consistent with the coordinates and tolerances specified in Section 15897 unless otherwise specified specifically in this section.

\subsection{CLEANING}

A. The Subcontractor shall clean and wipe down Switchyard Enclosures and its components to remove any installation debris. The finished structure shall be visibly clean per MILSTD-1246C.

B. The Subcontractor shall meet the requirements of Section 15895 for Product Cleaning and Cleanliness and Section 01625 for Clean Construction Protocol. 


\section{PRECISION DIAGNOSTIC SYSTEM (PDS)}

\section{PART 1 GENERAL}

\subsection{DESCRIPTION}

The purpose of this specification is to define the minimum requirements for transport, lifting, installation and alignment of the two Precision Diagnostic System (PDS) assemblies in this construction package that are identified in drawing AAA98-113700 for Switchyard \#2 and AAA98-113701 for Switchyard \#1. These are located at the 0'-0" level in each Switchyard. The two differ somewhat in their configuration.

\subsection{RELATED SECTIONS}

A. Section 01010 - Administrative Requirements

B. Section 01015 - Scope of Work

C. Section 01300 - Submittals

D. Section 01400 - Quality Control and Quality Assurance

E. Section 01620 - Product Receipt, Storage, and Protection

F. Section 01625 - Clean Construction Protocol

G. Section 09900 - Painting

H. Section 15122 - Pressure Leak Testing

I. Section 15895 - Product Cleaning and Cleanliness

J. Section 15896 - Rigging and Handling

K. Section 15897 - Surveying and Alignment

\subsection{REFERENCES}

The following codes and standards form a part of this specification to the extent specified herein. Codes and standards invoked on the drawings shall also apply. The latest version of these documents issued as of the date of Request for Quotation shall apply, unless otherwise specified. The Seller shall be responsible for identifying conflicts or contradictions found between this specification and the following documents and notifying the University Technical Representative in writing for resolution.

American Society of Mechanical Engineers (ASME)

Boiler and Pressure Vessel Code (B\&PVC) 
Section II Material Specifications

Section IX Welding and Brazing Qualification

B31.1 Power Piping

American Society for Testing and Materials (ASTM)

E $498 \quad$ Gas Analyzer in the Tracer Probe Mode

American Welding Society (AWS)

A2.4 Symbols for Welding and Nondestructive Testing

D1.6 Structural Welding Code - Stainless Steel

B2.1 Specification for Welding Procedure and Performance

Qualification

QC-1 Standards for AWS Certification of Welding Inspectors

American National Standards Institute (ANSI)

ANSI/ASQC C1 General Requirements for a Quality Program

American Society for Nondestructive Testing (ASNT)

SNT-TC-1A Personnel Qualification and Certification in Nondestructive

Testing

International Standards Organization

ISO $9000 \quad$ Quality System Standards

Military Standards

Mil-Std-1246 Product Cleanliness Levels and Contamination Control

Program

Mechanical Engineering Livermore (MEL)

MEL98-006 High Temperature Vacuum Bake-out to Remove Volatile

Organics for NIF

MEL98-008

MEL98-009

Precision High-Pressure Water Wash for NIF Components

MEL98-010

Precision Ultrasonic Cleaning for NIF Components

MEL98-012

Precision Surface Wiping for NIF Components

Surface Cleanliness Validation by Swiping for NIF

Components

MEL98-014

Handling of Components for NIF and Guidelines for

Creating and Maintaining Clean Areas

MEL98-015

Non-Volatile Residue Validation for NIF Components

Switchyard Structure Specification

Document No: NIF 5001534

\subsection{CODES \& STANDARDS}

The following codes and standards form a part of this specification to the extent specified herein. Codes and standards invoked on the drawings shall also apply. 
American Welding Society (AWS)

AWS D1.1 Structural Welding Code - Steel

AWS D1.2 Structural Welding Code - Aluminum

AWS D10.4 Welding of Austenitic Chromium Nickel Steel

\subsection{SUBMITTALS}

Submit the following documents to the University in accordance with Section 01300:
A. Rigging and handling procedures, for acceptance before use
B. Installation sequence and procedure, for acceptance before use
C. Welding Procedure Specification
D. Weld inspection records
E. Welder Qualification Reports
F. Alignment / survey plan \& procedure, for acceptance before use
G. Alignment Survey results

\subsection{QUALITY CONTROL AND QUALITY ASSURANCE}

D. General QC and QA requirements shall be per Section 01400.

E. Definitions of QC and QA shall be per Section 01010.

F. The subcontractor and QC Inspectors shall perform the following:

1. Inspect rigging and attachment for compliance to the University approved rigging diagram and plan.

2. All welds performed by subcontractor shall be visually inspected for correct type, complete fusion, correct size, and correct contour per drawing. For all structures that must contain argon, welds shall be inspected for sealing against a pressure greater than four inches of water.

3. Inspect installed PDSs in each switchyard for compliance to Part 3.0 of this Section and the drawings respectively as delineated in the subcontractor's approved installation sequence and procedures.

4. The subcontractor's precision surveyor shall perform survey of the installed PDS assembly to verify compliance with Section 15897, this section, and related drawings.

D. There are four Hold Points to be instituted by the subcontractor. The first of these occurs after completion of the alignment in a dirty environment and is for the purpose of allowing 
off-site cleaning of the three mirror mount carriages that were used during alignment. The duration of this Hold Point is 5 working days. The remaining three Hold Points occur during the installation of the LM7, LM8, and LM10 mirror station enclosures and are for the purpose of LLNL performing functional tests of the carriages within these enclosures. These Hold Points will occur within a clean area and will be two hours in duration.

E. The subcontractor shall provide the opportunity for the University to witness the following activities:

1. Alignment of the $3 \omega$ Diagnostic Focal Plane Diagnostic Chamber.

2. Installation and alignment of the PM7 mirror mount assembly in SY1.

\subsection{DELIVERY, STORAGE AND HANDLING}

A. The subcontractor shall obtain PDS assemblies and other associated Government Furnished Equipment (GFE) as denoted in section 01015 from NIF Production Control at the designated on-site location and transport these assemblies to the appropriate Switchyard for installation.

B. The subcontractor shall examine all GFE before transporting it from the on-site location to the erection location in accordance with Section 15895 and shall give written notice to the University of any deficiency detrimental to the proper and timely performance of the work.

C. A Portion of the PDS assemblies have been gross cleaned and a portion have been precision cleaned as indicated in the Infrastructure drawing/GFE list provided in Section 01015. The level of cleanliness is dependent upon the sequence of installation. The subcontractor shall implement the cleanliness and cleaning requirements of Sections 01625 and 15895, and any additional cleanliness and cleaning requirements identified under parts 2.0 and 3.0 of this section.

D. The subcontractor shall be responsible for all transport, rigging, and handling operations and equipment as discussed in Sections 01015, 01620 and 15896.

E. The subcontractor shall not weld to the GFE except where specified herein on the drawings.

\section{PART 2 PRODUCTS}

\subsection{GOVERNMENT FURNISHED EQUIPMENT (GFE)}

A. The University will supply the PDS assemblies and associated components identified as Government Furnished Equipment (GFE) in the Infrastructure drawing/GFE list of the Section 01015.

1. The following will be supplied gross cleaned (see Appendix A for definition) 


\section{Appendix C to Scope of Work for IMI Services}
a. PM7, PM8, PM9/PL1, and PM10 support frames with attached LRU carriages
b. IOM frame for SY \#2,
c. Beam dump stands (3) and beam dump for SY \#1, and
d. Trombone enclosure frame subassemblies for SY \#2.

2. The following will be supplied precision cleaned internally and sealed against external contamination. (See Appendix A, MEL98-004, MEL98-008 and MEL81-001627 for stainless steel, and MEL98-003 for aluminum)
a. Beam Tube Assembly AAA99-115200 for Switchyard \#1
b. Beam Tube Assembly AAA98-113706 for Switchyard \#2
c. PM10 enclosures,
d. Horizontal beam enclosures between the Trombone and PM10,
e. Horizontal beam enclosures between the PM10 mirror enclosure and the PM7 mirror enclosure,
f.PM7 mirror enclosures,
g. Horizontal beam enclosures between the PM7 mirror enclosures and the PM9/PL1 mirror/lens enclosures,
h. PM8 mirror enclosures,
i. PM9/PL1 mirror/lens enclosures,
j. Vertical beam enclosures (between the Roving Mirror Enclosure and the Trombone),
k. All bellows joining the beam enclosures to the mirror enclosures

3. The following will be cleaned in situ after installation and alignment (see MEL98-010) and sealed against external contamination:
a. upper surface of the PM7 mounts, including hardware,
b. upper surface of the PM8 mounts, including hardware,
c. upper surface of the PM9 mounts, including hardware,
d. upper surface of the PM10 mounts including hardware,
e. upper surface of the PL1 mounts. 
4. The following will be removed from the Switchyard, precision cleaned, (see Appendix A, MEL98-004, MEL98-008 and MEL81-001627) re-installed in a clean environment upon their respective mounts, and the assemblies protected against external contamination prior to the installation of their respective enclosures :

\section{a. PM10 LRU carriages, \\ b. PM7 LRU carriages, \\ c. PM8 LRU carriages.}

There will be a Hold Point of 5 working days while these items are precision cleaned.

B. Special tooling is required to install and align the $3 \omega$ Focal Plane Diagnostic Chamber and the transport optics associated with the Precision Diagnostics System (PDS). There are four lifting fixtures for the $3 \omega$ Focal Plane Diagnostic Chamber, three Optics Mount Installation Fixtures (OMIF), two Beam Dump Alignment Fixtures, and an Integrated Optics Module (IOM) Alignment Fixture. A portable motor controller is required to drive the motors of the PM7, PM8, and PM10 carriages. Also required are 2 electronic levels capable of reading to $5 \mu$ radians.

Four lifting fixtures, two located at each end of the $3 \omega$ Focal Plane Diagnostic Chamber, will be used in conjunction with subcontractor-supplied jacks, to position and align this Chamber.

Optics Mount Installation Fixtures (OMIF) will be available for use in the installation and alignment process in both Switchyards \#2 and \#1. The fixtures consist of a platform upon which are mounted a set of 4 spherically mounted retro-reflectors, an attachment point (5/8"-11, " long stud) for a theodolite, and an attachment point for the Euclid that is not used by the contractor. Each of the retro-reflectors is used as a Precision Survey Feature (PSF) to identify an exact point within a Switchyard. These five items are located on the top of a plate which has the same thickness as used in the Line Replaceable Units (LRU) for which they are surrogates. On its lower surface are mounted kinematic sockets identical to those used on the LRUs. There are two versions of the OMIF: OMIF1 and OMIF2 (AAA99-115400 and AAA99-115402, respectively). The OMIF1 is used at positions PM6 - PM8 and the OMIF2 for PM9, PM10, and PL1. The PSFs are located at a known distance in $\mathrm{x}, \mathrm{y}$ and $\mathrm{z}$ from the center of the mirror. The OMIFs are weighted to have approximately the same weight as the LRUs that will be in place.

The PL3 Alignment Fixtures are used only in Switchyard \#1. The forward PL3 Alignment Fixture (AAA99-115139) and rear PL3 Alignment Fixture (AAA99-11518) is used to locate the position of the PL3 lens. As shown in these drawings, it has provision for the mounting of either cross hairs or PSFs.

An IOM Alignment Fixture (AAA99-115428) is required only for switchyard \#2. It is mounted to the IOM test stand during the installation and alignment of the test stand. 
As shown in AAA99-115428, it has four mounts for PSFs on the side that faces the PM7 position (the negative z-side of the Fixture). A through hole is provided with provision for mounting a 50/50 beam splitting pellicle parallel to the interface between the IOM Alignment Fixture and the test stand. This fixture is necessary in order to establish the position of the IOM test stand with respect to the optical axis of the diagnostic chamber

Shims, machined to the proper dimensions in the horizontal plane but oversize in the vertical plane, will be furnished for the $3 \omega$ Focal Plane Diagnostic Chamber. They will be inserted under each leg of the Chamber after alignment has established the correct vertical dimension and the shims have been machined to that dimension.

Shim packs for use under the legs of the support frames for PM3-PM10, the IOM mount, and the PL3 mounts will be furnished. The pack will be constituted so that it is possible with the use of the pack to meet the tolerances for the vertical location and levelness of these support stands.

A motor controller will be furnished to drive the motors for the belts of PM10, PM7 and PM8. The controller weighs less than 35 pounds and has the cables necessary to connect to the mains and to the local connectors.

\subsection{SUBCONTRACTOR FURNISHED MATERIAL AND EQUIPMENT}

A. The subcontractor shall provide the items in the Infrastructure drawing/GFE list of the Section 01015 not identified as GFE ("non-GFE").

B. The Subcontractor shall supply all the material identified on each drawing as subcontractor Furnished Material (SFM). These materials are restricted to generic fasteners, and construction materials, including welding supplies.

C. Material provided by the subcontractor shall meet the requirements listed on the drawings and related specifications. Material and equipment provided by the subcontractor shall be delivered to the Switchyard and maintained in a cleaned condition consistent with Section 15895 .

\section{PART 3 EXECUTION}

\subsection{PREREQUISITES AND EXAMINATION}

1. Before starting work, the subcontractor shall examine underlying and adjoining work for damage or other apparent deleterious conditions that may be masked or made inaccessible by installation of the PDS assemblies and associated items. The subcontractor shall report to the University any damage or conditions that impact installation.

B. Before installing assemblies, the subcontractor shall examine and survey the assembly mounting pads for location and orientation, as defined in the drawings AAA97-115170 for Switchyard \#1, AAA97-106179 for Switchyard \#2 and Switchyard Structure Specification 
(NIF-5001534). Promptly report to the University in writing any apparent deviations or other conditions that may impede proper installation of the assemblies. Do not commence affected work until notified to do so in writing by the University.

C. The subcontractor shall prepare an installation procedure, which shall include an installation and inspection checklist, a full description of the task to be performed, installation sequence, QA hold and witness points, and a listing of the work documents to be used. The procedure shall also include survey/alignment actions necessary to fulfill Section 15897. The subcontractor is responsible for collecting the necessary working documents including but not limited to drawings, specifications, and reference documents necessary for installation.

\subsection{INSTALLATION; GENERAL}

A. The PDS assemblies and associated items shall be installed in accordance with the drawing. The following subparts provide additional requirements to be implemented in conjunction with the drawing. However, except where identified as "mandatory" or dictated by physical configuration, the sequence provided is a recommendation. The actual sequence to be implemented is to be determined by the subcontractor as reflected in the submitted installation sequence and procedures.

B. There are two types of coordinates used in this Specification: absolute and relative. Absolute coordinates are referenced to the NIF global coordinate system, with the origin being taken as Target Chamber Center (TCC). These are used for the location of only one Precision Survey Feature (PFS) in each switchyard. In SY \#2 this reference is located on the most negative-z end of the $3 \omega$ Focal Plane Diagnostic Chamber. All other PSFs in SY \#2 are referenced to this one. In SY \#1, this reference is the SMR located directly above the kinematic ball which mates with the cone socket (PSF PM-1-07-MS1).

C. Prior to the $3 \omega$ Focal Plane Diagnostic Chamber being moved from Beamlet into Switchyard \#2, the same optical axis that was established for Beamlet was verified by mounting cross hairs onto the external flanges of the front and rear enclosures and centering these on the Beamlet alignment beam. Since the beam dump and large mirror were removed from the vessel, a line of sight was established through the two sets of cross hairs. The vacuum vessel was not separated for the move to a storage location. Prior to the move, locating pins were placed into the flanged joint at the point of separation of the two halves of the vessel and at the end enclosures. This maintained indexing during moving from Beamlet into and when the vessel was moved from storage and installed in Switchyard \#2.

D. The laser beam enclosures will not be in place for the PDS beam lines. All of the installation and initial alignment will be carried out in a dirty environment. Alignment assemblies, which are surrogates for the optical assemblies, will be used in place of the high value actual optical assemblies. 


\section{Appendix C to Scope of Work for IMI Services}

E. All mirror and lens kinematic sockets will be set at the midpoint of their range of adjustment, leveled with respect to a set of set-up rails that are perpendicular with respect to the gravity vector, and tightened to their mounting plates before delivery as GFE.

F. In Switchyard \#2, the origin for the installation of the PDS is considered to be PSF PL-200-MS1 mounted upon the most z-negative end of the $3 \omega$ Focal Plane Diagnostics Chamber. The chamber was placed into Switchyard \#2 during construction. The current placement is not the final location of the chamber.

G. In Switchyard \#1, the origin for installation of the PDS is considered to be PSF PM-1-07MS1 mounted on the OMIF on the PM7 kinematic ball locations.

H. The support frames for PM7, PM8, and PM10 will be supplied to the subcontractor with the rails, belt, drive mechanism, LRU carriage seismic restraints, temporary motor power receptacle, and hard stop mounted to the support frame. The mirror carriages will be mounted upon the rails and fixed at the position at which they would be withdrawn for change, e.g. at the end of the rails opposite the hard stop. This placement is done to provide the best possible balance of the unit when suspended from the lifting mechanism that is employed to put the assembly in place.

I. All LRUs have a seismic restraint mechanism that prevents the LRU from separating from the carriage upon which it rests in the event of an earthquake. Because of the undefined vertical and horizontal relationship that exist between the LRU plate and the carriage prior to installation and alignment, this restraint must be adjusted. This is accomplished by shimming for vertical adjustment from the carriage and positioning in slots in the horizontal plane after the OMIF has been positioned to the coordinates specified in the ACD.

J. All LRUs have a robotic-type electrical connector on the LRU plate that mates in a vertical direction to a corresponding receptacle on the carriage. Due to the undefined relationship in the horizontal and vertical planes that exists between the LRU plate and the carriage prior to installation and alignment, this receptacle must be adjusted in the horizontal plane and vertical direction after the OMIF has been positioned to the coordinates specified in the ACD

$\mathrm{K}$. In the installation procedures given below, reference is made to using jackscrews mounted at each corner of the support frame. It is desirable to use only three of these four for the actual position adjustment of the frame, the fourth being used only to stabilize that corner during fastening to the space frame. It is apparent that the center of gravity of the frame being installed must fall within the triangle formed by the three adjusting points. The appropriate three jackscrews to use at each location are given on the Alignment Control Drawing (ACD), drawing AAA99-115183 for Switchyard \#1 and AAA99-103607 for Switchyard \#2, along with the dimensions of the Precision Survey Features (PSF) with respect to the origin of the NIF global coordinate system.

L. Each support frame for PM7s, PM8s, PM10s, PM9/PL1s, PL3 and the IOM has a rectangular flange welded to the lower extremity of each leg. Each of these plates has 
three clearance holes for tie-down fasteners and one threaded hole for a jackscrew. Associated with each of these flanges is a plate, below the flange, from which three threaded studs protrude and pass through the clearance holes in the flange. This lower plate is the plate against which the jackscrews push and to which the flanges will be locked. It will be welded to the mounting plates on the space frame after the support frame is installed and aligned.

\subsection{OVERVIEW OF THE INSTALLATION AND ALIGNMENT}

A. Switchyard \#2

1. Establish the absolute location with respect to NIF global of one end of the $3 \omega$ Focal Plane Diagnostic Chamber by surveying,

2. Place the Trombone support beam at the proper location.

3. By surveying, align the optical axis of the Chamber to be parallel to the NIF z-axis and to be at the proper height,

4. Place PM7 mount into position by surveying, and align, referenced to the absolute Chamber position,

5. Place the IOM mount in position by surveying, and align, referenced to the absolute Chamber position and its optical axis,

6. Mount the elements of the Trombone Enclosure onto their supporting girder. Weld the elements together to form a continuous enclosure. Leak check the assembly. Passivate the enclosure.

7. Install and align PM10 mount by surveying referenced to the absolute Chamber location.

8. Install the PM8 mount by surveying referenced to the absolute Chamber position.

9. Install the PM9 mount by surveying referenced to the absolute Chamber position.

10. Install and align the PL1 mount by surveying referenced to the absolute Chamber location.

11. Remove all OMIFs and all carriages. Precision clean all carriages.

12. Re-install carriages, install enclosures and leak check.

B. Switchyard \#1

1. Install the PM7 to NIF global coordinates by surveying.

2. Place the PM3 withdrawal enclosure support beam at the proper location. 


\section{Appendix C to Scope of Work for IMI Services}

3. Place the PL3 Alignment Fixture in position by surveying referenced to the absolute position of PM7,

4. Construct the PM3 Withdrawal Enclosure and passivate.

5. Install and align PL3 and the beam dump by surveying referenced to the absolute position of PM7

6. Install and align PM10 by surveying referenced to the absolute position of PM7.

7. Install the PM8 by surveying referenced to PM7.

8. Install the PM9 by surveying referenced to PM7.

9. Install and align the PL1 by surveying referenced to PM7.

10. Install and align the PL1 mount by surveying referenced to the absolute Chamber location.

11. Remove all OMIFs and all carriages. Precision clean all carriages

12. Re-install carriages, install enclosures and leak check.

\subsection{INSTALLATION SPECIFICS: SWITCHYARD \#2}

A. Install and Align the $3 \omega$ Focal Plane Diagnostic Chamber

1. The Focal Plane Diagnostic Chamber will be in place in Switchyard \#2 at the commencement of this construction package but will not have been aligned. Fasten lifting fixtures to each end of the Chamber and install the Subcontractor-furnished jacks.

2. The optical axis of the Chamber can be aligned to the $x, y$ and z-axes of the Target Chamber Center (TCC) global coordinate system using the PSFs that are located on each end of the Chamber and that are centered on the Chamber optical axis. These are designated PSF PL-2-00-MS1 for the one located on the most negative $\mathrm{z}$ end of the Chamber and PSF PL-2-00-MS2 is the designation for the one at the most positive $\mathrm{z}$ end.

3. The most z-negative end of the Chamber will be aligned so that PSF PL-2-00-MS1 has $\mathrm{x}, \mathrm{y}$, and $\mathrm{z}$ coordinates that are within $\pm 1.0 \mathrm{~mm}$ of the NIF global coordinates specified on the Alignment Control Drawing (ACD). The most positive-z end will then be aligned so that the $\mathrm{x}$ and $\mathrm{y}$-coordinates of PSF PL-2-00-MS2 are identical to within $\pm 0.2 \mathrm{~mm}$ of the coordinates of the $\mathrm{x}$ and $\mathrm{y}$-coordinates of PSF PL-2-00-MS1.

B. Place and Align the 30-inch Trombone Support Beam 
1. The 30-inch box beam that supports the trombone enclosure must be put in place prior to proceeding with the remainder of the installation of the PDS within Switchyard \#2. The location of this beam is referenced to PSF PL-2-00-MS1.

2. Place four Precision Survey Features (PSFs) onto the top surface of the box beam, as close to the edges as possible. These PSFs are located as follows:

a. $186 \mathrm{~mm}$ from the East end, going westerly, on the North edge of the beam: PB-201-MS1

b. $186 \mathrm{~mm}$ from the East end, going westerly, on the South edge of the beam: PB-201-MS2

c. $168 \mathrm{~mm}$ from the West end, going easterly, on the North edge of the beam: PB-201-MS3

d. $168 \mathrm{~mm}$ from the West end, going easterly, on the South edge of the beam: PB-201-MS4

3. Position the box beam until the dimensions from PSF PB-2-01-MS1 and PB-2-01-MS3 to PSF PL-2-00-MS1 (mounted on the $3 \omega$ Chamber) are within $\pm 1.0 \mathrm{~mm}$ in $\mathrm{x}, \mathrm{y}$ and $\mathrm{z}$, to those shown in the ACD (AAA99-103607).

C. Install the PM7 Support Frame

1. The kinematic ball mounts upon which the PM7 mirror Line Replaceable Unit (LRU) rests are attached to the top of a wheeled carriage that rests upon a set of rails. The carriage has two grooved wheels riding on one rail and one non-grooved wheel riding on the other rail. The rails are mounted upon a support frame that is, in turn, fastened to the structural steel of the Switchyard. The rails are used only for removal and replacement of the PM7 mirror, which is in an inaccessible location.

2. Place the support frame for the PM7 mirror, which has the LRU carriage attached to it, onto the switchyard frame support pads indicated in AAA97-106179. Be sure that the frame is oriented correctly. This is done by ensuring that the frame leg with an "A2" stamped upon it rests upon the pad indicated as "A2" in the drawing. Remove the lashings holding the LRU carriage to the support frame. Place an Optics Mount Installation Fixture (OMIF1) upon the kinematic balls of the LRU carriage.

3. Connect the motor controller output cable to the mating connector (AAA99-103901) and drive the carriage in the negative z-direction until the limit switch turns off power to the motor. This places the carriage against a hard stop that defines the position at which the Optics Mount Installation Fixture (OMIF1) will be aligned.

4. CAUTION: When the carriage is driven against the hard stop, there is approximately 300 pounds of tension in the drive belt. A temporary belt guard is supplied. This must be placed over the belt during the remainder of the installation and alignment process. It must be removed prior to the installation of the PM7 enclosure. 


\section{Appendix C to Scope of Work for IMI Services}

5. Locate the support frame and LRU carriage combination relative to PSF PL-2-00-MS1 (mounted on the $3 \omega$ Chamber) to within $\pm 1.0 \mathrm{~mm}$ in $\mathrm{x}$, $\mathrm{y}$ and $\mathrm{z}$, as shown in the ACD (AAA99-103607). This is accomplished by placing four PSFs (PM-2-07-MS1 - PM2-07-MS4) onto the OMIF1. The PSF PM-2-07-MS1 is used to establish the location in $\mathrm{x}, \mathrm{y}$, and $\mathrm{z}$ of the OMIF1 relative to PSF PL-2-00-MS1. The PSF PM-2-07-MS2 is used in conjunction with PSF PM-2-07-MS1 to control rotation about the y-axis. The coordinates of PSF PM-2-07-MS2 are measured relative to that of PSF PM-2-07-MS1. Rotation about the $\mathrm{x}$ and $\mathrm{z}$-axes is set by leveling the OMIF2 with respect to the normal to gravity.

6. Adjustment in the horizontal plane and in rotation about the vertical (y) axis is accomplished by moving the frame, which is resting on the rounded ends of three of the jackscrews. Adjust the frame until PSF PM-2-07-MS1 is at the $\mathrm{x}$ and $\mathrm{z}$ coordinates, relative to PSF PL-2-00-MS1, specified in the ACD, within $\pm 1.0 \mathrm{~mm}$, and PSF PM-2-07-MS2 is located at the measured $\mathrm{x}$-coordinate of PSF PM-2-07-MS1, within $\pm 0.5 \mathrm{~mm}$.

7. The support frame is adjusted in the vertical direction and in rotation about the two horizontal axes by use of the jackscrews provided at each of three corners on the inside of the frame (see AAA99-103901). These jackscrews have a pitch of $3 \mathrm{~mm}$ and a center to center distance of approximately 1 meter. They are adjusted until the PSF PM-2-07-MS1 is at the nominal y-position, relative to PSF PL-2-00-MS1, that is specified in the ACD, within $\pm 1.0 \mathrm{~mm}$. Level the OMIF2 in the $\mathrm{x}$ and $\mathrm{z}$-direction so that the y-coordinates of PSF PM207MS2 and PM207MS4 are within $\pm 1.0 \mathrm{~mm}$ of the y-coordinate of PSF PM-2-07-MS1. Check the y-position of PSF PM-2-07-MS1 and, if necessary, re-adjust the jackscrews and re-level the OMIF1.

8. Lower the fourth jackscrew to lightly make contact with the stud plate. Install the selected $\operatorname{shim}(\mathrm{s})$. Fix the support frame to the stud plates by tightening the mounting bolts against the jackscrews. Tightening torque is as recommended. Weld the stud plates to the switchyard mounting pads as shown in AAA99-103901.

9. Measure the distance between each of the corner flanges on the support stand and the lower stud plates upon which the jackscrews rest. Select a shim(s) from the shim pack available that will provide a vertical location of the OMIF1 that is within the 1-mm tolerance.

10. Recheck all measurements to ensure that the PSFs indicated are located with respect to PSF PL-2-00-MS1 to within the tolerances indicated. If any PSF is outside of the allowable tolerances reposition the frame until it is within the tolerances allowed.

D. Align the PM7 Mirror Mount

1. After attaching the support frame to the space frame, level the OMIF1 in the $x$ and zdirection to a deviation of less than $30 \mu$ radians from the normal to the local gravity vector. This is accomplished by loosening the jam nuts on the balls on the kinematic 
plate that mate to the kinematic sockets on the OMIF1, and threading the balls into or out of their mating threads.

2. Adjust the OMIF1 in the y-direction (height), using the threads on the ball kinematics, until PSF PM-2-07-MS1 is within $\pm 0.3 \mathrm{~mm}$ of the y-distance between it and PSF PL-2$00-\mathrm{MS} 1$, that is specified in the ACD. Assure that the OMIF1 is level to $30 \mu$ radians.

3. The proper $\mathrm{x}$-coordinate of PSF PM-2-07-MS1 is established by adjusting that kinematic ball, mounted upon the top plate of the support frame, which mates with the cone receptacle. The orientation of the kinematic sockets, which consist of a cone, a vgroove and a flat, is such that the v-groove is parallel to the NIF $\mathrm{x}$-axis. The OMIF1 is adjusted in the $\mathrm{x}$-direction by loosening the attachment of the cone kinematic ball and then sliding the ball and OMIF1 in the x-direction until the PSF PM-2-07-MS1 is at the absolute $\mathrm{x}$-coordinate specified in the ACD, to within $\pm 0.3 \mathrm{~mm}$.

4. If the z-coordinate of PSF PM-2-07-MS2 differs more than $\pm 0.1 \mathrm{~mm}$ from that of PSF PM-2-07-MS1, it will be necessary to adjust OMIF1 in rotation about the y-axis. If such is the case, loosen the kinematic ball that mates with the v-groove. Adjust the OMIF1 in rotation about the vertical axis until the x-coordinate of PSF PM-2-07-MS2 is within $0.1 \mathrm{~mm}$ of the measured x-coordinate of PSF PM-2-07-MS1. Re-check the $\mathrm{y}$ coordinate of PSF PM-2-07-MS1 and the level of the OMIF1 and, if not correct, all other measurements must be re-checked and the OMIF1 re-leveled.

5. Set the position of PSF PM-2-07-MS1 in the z-direction, relative to PSF PL-2-00-MS1, to the nominal coordinate determined from the ACD, to a tolerance of $\pm 0.3 \mathrm{~mm}$. This is accomplished by changing the position of the hard stop that positions the carriage at the correct position. See AAA99-103901 for the location of this adjustment.

6. Measure the vertical distance between the hook of the LRU seismic restraint that is mounted on the underside of the OMIF1 and the mounting plate for the latch portion of the restraint that is located on the upper face of the support stand. Subtract TBD mm from this measured distance and machine a spacer that corresponds to AAA99-103901, with the 'TBD' dimension on this drawing defined as the result obtained when the subtraction was performed. Install the latch portion of the restraint onto the support stand with the spacer between the hook and the stand. Adjust the hook in the horizontal plane until it engages properly with the latch on the OMIF1.

7. The robotic-type electrical receptacle mounted on the LRU plate must be adjusted in the horizontal plane and vertical direction to mate properly with the connector on the OMIF1. Loosen the screws that retain the receptacle in the horizontal position and place it under the connector. Loosen the screws that retain the receptacle in the vertical direction and bring the receptacle up to the connector until there is a $3 \mathrm{~mm}, \pm 0.5 \mathrm{~mm}$, gap between the mounting flanges of each, completely around their periphery. The body of the connector will center the receptacle properly as the receptacle is brought to within $3 \mathrm{~mm}$. Tighten all mounting screws to the torque specified. Remove the OMIF1. 


\section{Appendix C to Scope of Work for IMI Services}

\section{E. Install the IOM Support Frame}

1. Place the IOM support frame onto the switchyard mounting pads indicated in AAA97106179 , verifying that the leg marked "B2" is on the pad designated "B2" in AAA99103607. Mount the IOM Alignment Fixture (AAA99-115428) on the support frame and place the four PSFs (PM-2-00-MS1 - PM-2-00-MS4) into their magnetic sockets. The PM-2-00-MS1 PSF is used to establish the $\mathrm{x}, \mathrm{y}$, and z-coordinates of the IOM Alignment Fixture, relative to PSF PL-2-00-MS1. The PM-2-00-MS4 PSF is used in conjunction with PSF PM-2-00-MS1 to measure rotation about the z-axis. Rotation about the $\mathrm{x}$ and $\mathrm{y}$-axes is controlled by establishing the Alignment Fixture to be perpendicular to the axis passing through the crosshairs on each end of the $3 \omega$ Chamber. This axis is within $3 \mu$ radians of the NIF z-axis, based upon the tolerance used in aligning the Chamber. The coordinates of PSF PM-2-00-MS4 are measured relative to those of PSF PM-2-00-MS1.

2. Adjust the frame in $\mathrm{x}$ and $\mathrm{z}$ until measurement of PSF PM-2-00-MS1 indicates that it is within $\pm 1.0 \mathrm{~mm}$ in $\mathrm{x}$ and $\mathrm{z}$ of its nominal position relative to the measured coordinates of PSF PL-2-00-MS1, as determined from the ACD (AAA99-103607). While maintaining PSF PM-2-00-MS1 as fixed as is possible, rotate the frame about the vertical axis until the $\mathrm{z}$-coordinate of PSF PM-2-00-MS2 is within $\pm 1.0 \mathrm{~mm}$ of the measured z-coordinate of PSF PM-2-00-MS1.

3. Vertical adjustment and adjustment for rotation about the $\mathrm{x}$ and $\mathrm{z}$-axes is accomplished by using the designated three jackscrews provided at the corners of the support stand. These jackscrews have a pitch of $0.8 \mathrm{~mm}$ and a center to center distance of approximately 1 meter. Adjust the frame in the y-direction until measurement of PSF PM-2-00-MS1 is within $\pm 0.5 \mathrm{~mm}$ of the measured y-coordinate of PSF PL-2-00-MS1 as installed. Level the frame, using as a measuring surface the top of the IOM Alignment Fixture, so that the IOM Alignment Fixture is perpendicular to the local gravity vector to within $\pm 100 \mu$ radians along the $\mathrm{x}$ and $\mathrm{z}$-axes.

4. Lower the fourth jackscrew to lightly make contact with the mounting pad. Install the selected shims and fix the support frame to the stud plates by tightening the mounting bolts to pull against the jackscrews. Tightening torque is as recommended. Weld the stud plates to the switchyard mounting pads as shown in AAA99-103908. Verify that the y-distance from PSF PM-2-00-MS1 to PSF PM-2-00-MS1 is within $\pm 0.3 \mathrm{~mm}$ of that given in the ACD. If it is not, it will be necessary to re-shim the mount.

5. Measure the distance between each of the flanges on the lower extremity of the support frame legs and the stud plate against which the jackscrews rest. Select a shim(s) from those available that will provide a vertical location of the Alignment Fixture that is within the above tolerance. If the tolerance cannot be met with the shims available, it will be necessary to make special shims complying with the $\mathrm{x}$ and $\mathrm{z}$-dimensions shown in AAA99-103607.

6. Recheck all measurements to ensure that the PSFs indicated are located with respect to PSF PL-2-00-MS1 to within the tolerances indicated. If any PSF is outside of the 
allowable tolerance, the frame must be repositioned so as to be within the tolerances specified.

\section{E. Align the IOM Test Frame}

- The z-position of PSF PM-2-00-MS1 must be at the distance in the negative-z direction relative to PSF PL-2-00-MS1 that is indicated by the ACD, to within $\pm 0.3 \mathrm{~mm}$. The plane defined by the PSFs PM-2-00-MS1, PM-2-00-MS2, and PM-2-00-MS4 must be within 50 $\mu$ radians of being perpendicular to the optical axis that is established by the cross hairs mounted in each end of the $3 \omega$ Focal Plane Diagnostic Chamber.

- The perpendicularity to the Chamber optical axis can be measured and adjusted by using, for example, an autocollimator mounted at the PM7 position. The optical axis of the autocollimator is set by aligning the visual axis of the instrument onto the two cross hairs mounted on the ends of the Chamber. Perpendicularity to the optical axis is obtained by observing the back-reflection from the pellicle mounted in the center of the IOM Alignment Fixture.

- Adjustment of translation in the $\mathrm{x}$ and $\mathrm{z}$-direction is provided by an arrangement of jackscrews lying in that plane. Rotational adjustment about the y-axis is accomplished by using the built-in rotational alignment feature. All other adjustments are carried out using the jackscrews on the base of the mount. It should not be necessary to disturb these after the installation process. If it is necessary to adjust them, the sequence of installation must be repeated.

\section{F. Install and Align the Trombone Mirror Enclosure}

1. The Trombone Enclosure is constructed of 11 separate modules, seven of which are identical. These are fabricated off-site, supplied as GFE, and assembled into a continuous, gas-tight enclosure in the switchyard. Each enclosure has rail mounts welded into it. Although intended for other a different purpose, these will be used to align the enclosure sections to the support beam upon which they rest and to each other. The Trombone Enclosure top assembly drawing is AAA99-103630.

2. Each module is fabricated with a floor of $6 \mathrm{~mm}$ stainless steel. The top, with one exception, is fabricated from internally welded stainless sheet and, in general, the side in the most positive $\mathrm{x}$-direction is covered with internally welded stainless sheet. The side in the most negative $\mathrm{x}$-direction is left open to facilitate later (subsequent to CSP 19) equipment installation. The ends of the modules are open so that when assembled and welded together in the switchyard they form a continuous, tunnel-like enclosure.

3. Installation starts with the placement of the Mirror Junction Enclosure (AAA99103630), the module locate at the most $\mathrm{z}$-negative end of the 30-inch steel support box beam that runs the length of the Trombone and provides support for all the modules. Do not put the side panels on the most positive $\mathrm{x}$-side in place. 


\section{Appendix C to Scope of Work for IMI Services}

4. The Mirror Junction Enclosure is used as the starting point for the installation of the Trombone Enclosure. This enclosure is adjusted in $\mathrm{z}$ by manually pushing it along the box girder upon which it rests. It is adjusted in $\mathrm{x}$, and rotation about the y-axis, by using the jackscrews provided at each corner of the enclosure. These jackscrews push against either side of the box girder and can be used to fasten the enclosure laterally when the proper position is attained. There is no need to adjust the enclosure in the vertical direction.

5. In the Mirror Junction Enclosure, bolt PSF PM-2-06-MS1 onto the most z-negative rail mount on the positive $\mathrm{x}$ - side, being careful to align its base to the rail mount. Note that PSF PM-2-06-MS1 and PM-2-06-MS2 are physically identical, the different names being used to distinguish the different locations. Do the same for PSF PM2-06MS2 at the most z-positive rail mount on that same side. Position PSF PM-2-06-MS1 so that its $\mathrm{x}$ and $\mathrm{z}$-coordinates are within $\pm 0.3 \mathrm{~mm}$ of their nominal location with respect to PSF PL-2-00-MS1, as given in the ACD. Using the jackscrews, rotate the enclosure about the vertical axis until the X-coordinate of PSF PM-2-06-MS2 is within $\pm 0.1 \mathrm{~mm}$ of the $\mathrm{x}$-coordinate of PSF PM-2-06-MS1. Ensure that PSF PM-2-06-MS1 is still accurate to within $\pm 0.3 \mathrm{~mm}$ with respect to PL2-00-MS1. Tighten the jackscrews so that the enclosure is firmly fixed laterally. Install the clamps that fix the enclosure to the box girder in the vertical direction, shimming where required, directly beneath the clamp, to prevent distortion of the enclosure if the box girder is warped at that location. Remove PSFs PM-2-06-MS1 and PM-2-06-MS2.

6. Place a Standard Enclosure upon the box girder and butt it up to the Mirror Junction Enclosure. This is followed by four more Standard Enclosures, each pushed tightly against the previous enclosure. The Glove Box Enclosure is now put in place on the box girder and butted tightly against the adjacent Standard Enclosure. The remaining enclosures, including the Motor Enclosure, are put in place, being careful to pack them as tightly as possible toward the negative z-direction.

7. In the Motor Enclosure, bolt PSF PM-2-06-MS3 (which is physically identical to PM2-06-MS1) onto the most $\mathrm{z}$-negative rail mount on the positive $\mathrm{x}$ - side, being careful to align its base to the rail mount. Do the same for PSF PM-2-06-MS4 (which is physically identical to PM-2-06-MS1) at the most z-positive rail mount on that same side. Position PSF PM-2-06-MS3 so that its $x$ and $z$-coordinates are within $\pm 0.3 \mathrm{~mm}$ of their nominal location with respect to PSF PL-2-00-MS1, as given in the ACD. Using the jackscrews, rotate the enclosure about the vertical axis until the $x$-coordinate of PSF PM-2-06-MS4 is within $\pm 0.1 \mathrm{~mm}$ of the $\mathrm{x}$-coordinate of PSF PM-2-06-MS1. Ensure that PSF PM-2-06-MS3 is still accurate to within $\pm 0.3 \mathrm{~mm}$ with respect to PL200 -MS1, using the dimensions from the ACD. Tighten the jackscrews so that the enclosure is firmly fixed laterally. Install the clamps that fix the enclosure to the box girder in the vertical direction, shimming where required, directly beneath the clamp, to prevent distortion of the enclosure if the box girder is warped at that location. Remove PSFs PM-2-06-MS3 and PM-2-06-MS4.

8. Place a string line on the center of the most $\mathrm{z}$-negative and $\mathrm{x}$-positive rail mounting hole in the Mirror Junction Enclosure and stretch it to the corresponding more $\mathrm{x}$ - 
positive mounting hole in the Motor Enclosure. Pull the string line taut and fix it in place.

9. Adjust the positions of all the enclosures between the Motor Enclosure and the Mirror Junction Enclosure so that their more x-positive mounting holes are centered on the string line to within $\pm 1.0 \mathrm{~mm}$. Tighten all the jackscrews. Weld the enclosures into a single gas tight enclosure following the weld descriptions and notes provided. Clamp the completed enclosure to the box girder to control vertical motion, shimming where required, directly beneath the clamp, to prevent distortion of the enclosure if the box girder is warped at that location.

10. In order to leak check the enclosure, it is necessary to install all of the enclosure panels that are missing from the completed enclosure. These are delineated in the drawings. Install the temporary covers for the openings on the top and side of the Mirror Junction Enclosure. All of these side panels and covers are furnished with gaskets attached and with a set of the proper fasteners.

11. Pressure leak test the enclosure for leakage as described in 3.09. The trombone enclosure is the Zone 1 referred to in this section.

12. Remove the source of air from the vertical enclosure and re-install the blanking plate covering the port.

13. Subsequent to successfully leak checking the enclosure, remove all of the panels that were installed to facilitate leak checking and return them to the area from which they were obtained.

14. Passivate the completed enclosure, following the procedure given in Appendix B.

\section{G.Install the PM10 Mirror Support Frame}

1. The kinematic ball mounts upon which the PM10 mirror Line Replaceable Unit (LRU) rests are attached to a four-position indexing mechanism. This mechanism indexes and locks the PM10 to face toward the PM7, toward the Trombone, or face in the positive z-direction, which is the position for retracting PM10 from the beam line between PM6 and PM7. The carriage is supplied with the indexing mechanism oriented so that if a mirror were mounted it would face in the PM7 direction. This indexing mechanism is mounted to the top of a wheeled carriage that rests upon a set of rails that run in the $\mathrm{z}$ direction. The carriage has two grooved wheels riding on one rail and one nongrooved wheel riding on the other rail. The rails are mounted upon a support frame that is, in turn, fastened to the structural steel of the Switchyard. The rails are used for withdrawal of the PM10 mirror from the beam line when a system beam is directed to the $1 \omega$ Diagnostics Table and also when it is necessary to replace the PM10 mirror.

2. Place the support frame for the PM10 mirror, which has the LRU carriage attached, onto the switchyard frame support pads indicated in AAA97-106179. Be sure that the frame is oriented correctly. This is done by ensuring that the frame leg with "C2" 
stamped upon it rests upon the pad indicated as "C2". Remove the lashings holding the LRU carriage to the support frame. Mount the OMIF2 upon the kinematic balls of the LRU carriage and four PSFs (PM-2-10-MS1 - PM-2-10-MS4) onto the OMIF2. When delivered to the switchyard, the indexing mechanism is locked at the middle position, which means that the OMIF2 PSF pattern is orthogonal to the coordinate system defined by the beam line from the Chamber to PM7, and from PM7 to PM6.

3. Connect the portable motor controller output cable to the mating connector (AAA99103901) and drive the carriage in the negative $\mathrm{z}$-direction until the limit switch turns off power to the motor. This places the carriage against a hard stop that defines the position at which the Optics Mount Installation Fixture (OMIF2) will be aligned. The hard stop has been pre-set at its nominal location.

4. CAUTION: When the carriage is driven against the hard stop, there is approximately 300 pounds of tension in the drive belt. A temporary belt guard is supplied. This must be placed over the belt during the remainder of the installation and alignment process. It must be removed prior to the installation of the PM10 enclosure.

5. The PSF PM-2-10-MS1 is used to establish the location in $\mathrm{x}, \mathrm{y}$, and $\mathrm{z}$ of the OMIF2, and thus the support frame and LRU carriage combination, relative to PSF PL-2-00MS1. Locate PSF PM-2-10-MS1 to within $\pm 1.0 \mathrm{~mm}$ in $\mathrm{x}, \mathrm{y}$ and $\mathrm{z}$, of the distance from PSF PL-2-00-MS1 (mounted on the Chamber) shown in the ACD (AAA99-103607). The PSF PM-2-10-MS4 is used in conjunction with PSF PM-2-10-MS1 to control rotation about the $\mathrm{x}$ and $\mathrm{y}$-axes, and PSF PM-2-10-MS2 is used in conjunction with PM-2-10-MS1 to control rotation about the z-axis. The coordinates of both PSF PM-210-MS2 and PSF PM-2-10-MS4 are measured relative to those of PSF PM-2-10-MS1.

6. Adjustment in the horizontal plane and in rotation about the vertical axis is accomplished by moving the frame, which is resting on the rounded ends of three of the jackscrews. Adjust the frame until PSF PM-2-10-MS1 is at the $\mathrm{x}$ and $\mathrm{z}-$ coordinates, relative to PSF PL-2-00-MS1, specified in the ACD, within $\pm 1.0 \mathrm{~mm}$, and PSF PM-2-10-MS4 is located at the measured x-coordinate of PSF PM-2-10-MS1, within $\pm 0.5 \mathrm{~mm}$.

7. The support frame is adjusted in the vertical direction and in rotation about the two horizontal axes by use of the jackscrews provided at each of three corners on the inside of the frame (see AAA99-103901). These jackscrews have a pitch of $3 \mathrm{~mm}$ and a center to center distance of approximately 1 meter. They are adjusted until PSF PM-2$10-\mathrm{MS} 1$ is at the nominal y-position, relative to PSF PL-2-00-MS1, that is specified in the ACD, within $\pm 1.0 \mathrm{~mm}$. Level the OMIF2 in the $\mathrm{x}$ and $\mathrm{z}$-direction so that the $\mathrm{y}-$ coordinates of PSF PM-210-MS2 and PM-2-10-MS4 are within $\pm 1.0 \mathrm{~mm}$ of the $y-$ coordinate of PM-2-10-MS1. Check the y-position of PSF PM-2-10-MS1 and, if necessary, re-adjust the jackscrews and re-level the OMIF2.

8. Lower the fourth jackscrew to lightly make contact with the stud plate. Install the selected shim(s). Fix the support frame to the stud plates by tightening the mounting 
bolts against the jackscrews. Tightening torque is as shown. Weld the stud plates to the switchyard mounting pads as shown in AAA99-103901.

9. Measure the distance between each of the corner flanges on the support stand and the lower stud plates upon which the jackscrews rest. Select a shim(s) from the shim pack available that will provide a vertical location of the OMIF2 that is within this tolerance.

10. Recheck all measurements to ensure that the PSFs indicated are located with respect to PSF PL-2-00-MS1 to within the tolerances indicated. If any PSF is outside of the allowable tolerance, the frame must be repositioned so as to be within the tolerance allowed.

\section{H.Align the PM10 Mirror Mount}

1. Prior to being delivered, the PM10 carriage was set up so that an OMIF2 placed on its kinematic pattern was parallel to the set-up carriage rails to within $15 \mu$ radians. This was accomplished by rotating the plate, to which the kinematic balls are mounted, about the axis of mirror rotation so that the line joining the centers of PM-2-10-MS1 and PM-2-10-MS4 is parallel to within $15 \mu$ radians to the rail upon which the grooved wheels ride.

2. Place rail spreaders at either end of the PM10 carriage. There should be one of these hooked over each end of the rail that is in the more negative $\mathrm{x}$-direction. The adjustable end of the rail spreader should be engaged against the side of the rail support of the other rail. Loosen the mounting for the more positive-x rail. Adjust the rail spreaders until PM-2-10-MS1 is within $\pm 0.3 \mathrm{~mm}$ of the $\mathrm{x}$-distance between it and PSF PL-2-00-MS1 that is specified in the ACD, and the x-coordinate of PM-2-10-MS4 is within $\pm 0.1 \mathrm{~mm}$ of the $\mathrm{x}$-coordinate of PM-2-10-MS1.

3. Adjust the OMIF2 at PM10 in the y-direction (height) until PSF PM-2-10-MS1 is within $\pm 0.3 \mathrm{~mm}$ of the $\mathrm{y}$-distance between it and PSF PL-2-00-MS1 that is specified in the ACD. Assure that the OMIF2 is level to within $30 \mu$ radians of the normal to the local gravity vector. These criteria are accomplished by placing shims, from the shim pack provided, between the rail supports and the rails. Do not use the screw adjustment of the kinematic balls for height or lateral adjustment! Check that the xdimensions of the two measured PSFs are still within tolerance and correct the alignment if they are not. Fasten the rails to the rail mounts and re-check all dimensions, correcting where required.

4. The z-position of the PM10 mount is set by adjusting the z-position of the hard stop against which the carriage is driven by the belt drive. The distance from PSF PM-210 -MS1 to PSF PL-2-00-MS1 must be within $\pm 0.3 \mathrm{~mm}$ of that specified by the ACD.

5. Measure the vertical distance between the hook of the LRU seismic restraint that is mounted on the underside of OMIF2 and the mounting plate for the latch portion of the restraint that is located on the upper face of the support stand. Subtract 'TBD' mm from this measured distance and machine a spacer that corresponds to AAA99-103901, 
with the 'TBD' dimension on this drawing defined as the result obtained when the subtraction was performed. Install the latch portion of the restraint onto the support stand with the spacer between the hook and the stand. Adjust the hook in the horizontal plane until it engages properly with the latch on the OMIF2.

6. The robotic-type electrical receptacle mounted on the LRU plate must be adjusted in the horizontal plane and in the vertical direction to mate properly with the connector on OMIF2. Loosen the screws that retain the receptacle in the horizontal position and place it under the connector. Loosen the screws that retain the receptacle in the vertical direction and bring the receptacle up to the connector until there is a $3 \mathrm{~mm}, \pm 0.5 \mathrm{~mm}$, gap between the mounting flanges of each, completely around their periphery. The body of the connector will center the receptacle properly as the receptacle is brought to within $3 \mathrm{~mm}$. Tighten all mounting screws to the torque specified. Remove the OMIF2.

\section{Install the PM8 Mirror Support Frame}

1. The kinematic ball mounts upon which the PM8 mirror Line Replaceable Unit (LRU) rests are attached to the top of a wheeled carriage that rests upon a set of rails. The carriage has two grooved wheels riding on one rail and one non-grooved wheel riding on the other rail. The rails are mounted upon a support frame that is, in turn, fastened to the structural steel of the Switchyard. The rails are used only for removal and replacement of the PM8 mirror, which is in an inaccessible location.

2. Place the support frame for the PM8 mirror, which has the LRU carriage attached to it, onto the switchyard frame support pads indicated in AAA97-106179. Be sure that the frame is oriented correctly. This is done by ensuring that the frame leg with an "E2" stamped upon it rests upon the pad indicated as "E2". Remove the lashings holding the LRU carriage to the support frame. Mount an OMIF upon the kinematic balls of the LRU carriage.

3. Connect the portable motor controller output cable to the mating connector (item $\mathrm{X}$ of AAA99-103901) and drive the carriage in the negative $\mathrm{z}$-direction until the limit switch turns off power to the motor. This places the carriage against a hard stop that defines the position at which the Optics Mount Installation Fixture (OMIF1) will be aligned.

4. CAUTION: When the carriage is driven against the hard stop, there is approximately 300 pounds of tension in the drive belt. A temporary belt guard is supplied. This must be placed over the belt during the remainder of the installation and alignment process. It must be removed prior to the installation of the PM8 enclosure.

5. Locate the support frame and LRU carriage combination relative to PSF PL-2-00-MS1 (mounted on the Chamber) to within $\pm 1.0 \mathrm{~mm}$ in $\mathrm{x}, \mathrm{y}$ and $\mathrm{z}$, as shown in the ACD (AAA99-103607). This is accomplished by placing four PSFs (PM-2-08-MS1 - PM2-08-MS4) onto the OMIF1. The PSF PM-2-08-MS1 is used to establish the location in $\mathrm{x}, \mathrm{y}$, and $\mathrm{z}$ of the OMIF1 relative to PSF PL-2-00-MS1. The PSF PM-2-08-MS4 is 
used in conjunction with PSF PM-2-08-MS1 to control rotation about the $\mathrm{x}$-axis, and PSF PM-2-08-MS2 is used in conjunction with PSF PM-2-08-MS1 to control rotation about the z-axis. The coordinates of both PSF PM-2-08-MS2 and PSF PM-2-08-MS4 are measured relative to that of PSF PM-2-08-MS1.

6. Adjustment in the horizontal plane and in rotation about the vertical axis is accomplished by moving the frame, which is resting on the rounded ends of three of the jackscrews. Adjust the frame until PSF PM-2-08-MS1 is at the $\mathrm{x}$ and $\mathrm{z}$ coordinates, relative to PSF PL-2-00-MS1, specified in the ACD, within $\pm 1.0 \mathrm{~mm}$, and PSF PM-2-08-MS4 is located at the measured x-coordinate of PSF PM-2-08-MS1, within $\pm 0.5 \mathrm{~mm}$.

7. The support frame is adjusted in the vertical direction and in rotation about the two horizontal axes by use of the jackscrews provided at each of three corners on the inside of the frame (see AAA99-103901, item X). These jackscrews have a pitch of $3 \mathrm{~mm}$ and a center to center distance of approximately 1 meter. They are adjusted until the PSF PM-2-08-MS1 is at the nominal y-position, relative to PSF PL-2-00-MS1, that is specified in the ACD, within $\pm 1.0 \mathrm{~mm}$. Level the OMIF1 in the $\mathrm{x}$ and $\mathrm{z}$-direction so that it is within \pm 1.0 mradian of the normal to the local gravity vector. Check the $y-$ position of PSF PM-2-08-MS1 and, if necessary, re-adjust the jackscrews and re-level the OMIF1.

8. Lower the fourth jackscrew to lightly make contact with the stud plate. Install the selected $\operatorname{shim}(\mathrm{s})$. Fix the support frame to the stud plates by tightening the mounting bolts against the jackscrews. Tightening torque is as recommended. Weld the stud plates to the switchyard mounting pads as shown in AAA99-103901.

9. Measure the distance between each of the corner flanges on the support stand and the lower stud plates upon which the jackscrews rest. Select a shim(s) from the shim pack available that will provide a vertical location of the OMIF1 that is within this tolerance.

10. Recheck all measurements to ensure that the PSFs indicated are located with respect to PSF PL-2-00-MS1 to within the tolerances indicated. If any PSF is outside of the allowable tolerance, the frame must be repositioned so as to be within the tolerance allowed.

\section{J. Align the PM8 Mirror Mount}

1. After attaching the support frame to the space frame, level OMIF1 in the $x$ and zdirection to a deviation of less than $30 \mu$ radians from the normal to the local gravity vector. This is accomplished by loosening the jam nuts on the balls on the kinematic plate that mate to the kinematic sockets on the OMIF, and threading the balls into or out of their mating threads.

2. Adjust OMIF1 in the y-direction (height), using the same method, until PSF PM-2-08MS1 is within $\pm 0.3 \mathrm{~mm}$ of the measured y-coordinate of PL-2-00-MS1 specified by the ACD. Assure that OMIF1 is level to $30 \mu$ radians. The z-position of the mount is set 


\section{Appendix C to Scope of Work for IMI Services}

by adjusting the hard-stop on the carriage. The distance from PSF PM-2-10-MS1 to PSF PL-2-00-MS1 must be within $\pm 0.3 \mathrm{~mm}$ of that given in the ACD.

3. The proper x-coordinate of PSF PM-2-08-MS1 is established by adjusting that kinematic ball, mounted upon the top plate of the support frame, which mates with the cone receptacle. The orientation of the kinematic sockets, which consist of a cone, a vgroove and a flat, is such that the v-groove is parallel to the NIF x-axis. The OMIF1 is adjusted in the $\mathrm{x}$-direction by loosening the attachment of the cone kinematic ball. Slide the ball and OMIF1 in the x-direction until the PM-2-08-MS1 is at the relative distance from the measured $x$-coordinate of PSF PL-2-00-MS1 specified in the ACD, to within $\pm 0.3 \mathrm{~mm}$.

4. At this point, it may be necessary to adjust OMIF1 in rotation about the y-axis. If such is the case, loosen the kinematic ball that mates with the v-groove. Adjust the OMIF1 in rotation about the y-axis until the $\mathrm{x}$-coordinate of PM-2-08-MS2 is within $0.1 \mathrm{~mm}$ of the measured x-coordinate of PM-2-08-MS1. Re-check the y-coordinate of the PM-208-MS1 PSF and the level of OMIF1 and, if not correct, all other measurements must be re-checked and OMIF1 re-leveled.

5. Set the position of PM-2-08-MS1 in the $\mathrm{z}$-direction, relative to PL-2-00-MS1, to the nominal coordinate determined from the ACD, to a tolerance of $\pm 0.3 \mathrm{~mm}$. This is accomplished by changing the position of the hard stop that positions the carriage at the correct position. See AAA99-103901 for the location of this adjustment.

6. Measure the vertical distance between the hook of the LRU seismic restraint that is mounted on the underside of OMIF1 and the mounting plate for the latch portion of the restraint that is located on the upper face of the support stand. Subtract 'TBD' mm from this measured distance and machine a spacer. Install the latch portion of the restraint onto the support stand with the spacer between the hook and the stand. Adjust the hook in the horizontal plane until it engages properly with the latch on the OMIF1.

7. The robotic-type electrical receptacle mounted on the LRU plate must be adjusted in the horizontal plane and vertical direction to mate properly with the connector on OMIF1. Loosen the screws that retain the receptacle in the horizontal position and place it under the connector. Loosen the screws that retain the receptacle in the vertical direction and bring the receptacle up to the connector until there is a $3 \mathrm{~mm}, \pm 0.5 \mathrm{~mm}$, gap between the mounting flanges of each, completely around their periphery. The body of the connector will center the receptacle properly as the receptacle is brought to within $3 \mathrm{~mm}$. Tighten all mounting screws to the torque specified.

\section{K.Install and Align the PM9/PL1 Mirror and Lens Support Frame and Mount}

1. Place the support frame for the PM9/PL1 mirror/lens onto the switchyard frame support pads indicated in AAA97-106179. Be sure that the frame is oriented correctly. This is done by ensuring that the frame leg with an "F2" stamped upon it rests upon the pad indicated as "F2". This is a very large frame supporting two optics mounts.

Proper installation requires coordination with the alignment of two OMIFs. Mount an 
OMIF2 onto kinematic balls of the PM9 kinematic plate. Mount a PSF PL-2-01-MS1 and a PSF PL-2-01-MS2 at the locations shown.

2. Locate the support frame relative to PSF PL-2-00-MS1 (mounted on the Chamber) to within $\pm 1.0 \mathrm{~mm}$ in $\mathrm{x}, \mathrm{y}$ and $\mathrm{z}$, as shown in the ACD (AAA99-103607). This is accomplished by placing four PSFs (PM-2-09-MS1 - PM-2-09-MS4) onto the OMIF2 located on the PM9 kinematic balls. The PSF PM-2-09-MS1 is used to establish the location in $\mathrm{x}, \mathrm{y}$, and $\mathrm{z}$ of the PM9 OMIF2 relative to PSF PL-2-00-MS1. The PSF PL2-01-MS1 is used in conjunction with PSF PM-2-09-MS1 to control rotation about the $\mathrm{x}$ and $\mathrm{y}$-axis. The PSF PL-2-01-MS2 is used in conjunction with PM-2-09-MS1 to control rotation about the $\mathrm{z}$-axis.

3. Adjustment in the horizontal plane and in rotation about the vertical axis is accomplished by moving the frame, which is resting on the rounded ends of three of the eight jackscrews. Adjust the frame until PSF PM-2-09-MS1 is at the $\mathrm{x}$ and $\mathrm{z}$ coordinates, relative to PSF PL-2-00-MS1, specified in the ACD, within $\pm 1.0 \mathrm{~mm}$, and PSF PL-2-01-MS1 is at the $\mathrm{x}$ and z-coordinates, relative to PSF PL-2-00-MS1, specified in the ACD, within $\pm 1.0 \mathrm{~mm}$.3. The support frame is adjusted in the vertical direction and in rotation about the two horizontal axes by use of three of the eight jackscrews provided on the frame. The ones to use are indicated on the drawings. These jackscrews have a pitch of $3 \mathrm{~mm}$ and a center to center distance of approximately 1 meter. They are adjusted until PSFs PM-2-09-MS1, PL-2-01-MS1 and PSF PL-2-01-MS2 are all at the measured y-position relative to PSF PL-2-00-MS1, specified in the ACD, within $\pm 1.0 \mathrm{~mm} .3$. Level the OMIF2 in the $\mathrm{x}$ and $\mathrm{z}$-direction so that it is within \pm 1.0 mradian of the normal to the local gravity vector. Check the $y-$ position of PSF PM-2-09-MS1 and, if necessary, re-adjust the jackscrews and re-level the support frame.

4. Lower the remaining five jackscrews to lightly make contact with the stud plates. Install the selected shim(s). Fix the support frame to the stud plates by tightening the mounting bolts against the jackscrews. Tightening torque is as recommended. Weld the stud plates to the switchyard mounting pads as shown in AAA99-103901. Measure the distance between each of the flanges on the support stand and the lower stud plates upon which the jackscrews rest. Select a shim(s) from the shim pack available that will provide a vertical location of OMIF2 and the other two monuments that is within this tolerance.

5. Measure the vertical distance between the hook of the LRU seismic restraint that is mounted on the undersides of the OMIF2 and the mounting plates for the latch portions of the restraints that is located on the upper face of the support stand. Subtract 'TBD' $\mathrm{mm}$ from this measured distance and machine spacers. Install the latch portion of the restraints onto the support stands with the spacer between the hook and the stand. Adjust the hooks in the horizontal plane until it engages properly with the latch on the OMIF2.

6. The robotic-type electrical receptacle mounted on the LRU plate must be adjusted in the horizontal plane and vertical direction to mate properly with the connector on the 


\section{Appendix C to Scope of Work for IMI Services}

OMIF2. Loosen the screws that retain the receptacle in the horizontal position and place it under the connector. Loosen the screws that retain the receptacle in the vertical direction and bring the receptacle up to the connector until there is a $3 \mathrm{~mm}, \pm 0.5 \mathrm{~mm}$, gap between the mounting flanges of each, completely around their periphery. The body of the connector will center the receptacle properly as the receptacle is brought to within $3 \mathrm{~mm}$. Tighten all mounting screws to the torque specified.

\section{Remove and Precision Clean all Optics Carriages}

1. Connect the portable motor controller to the receptacle on the PM10 support frame. Move the PM10 carriage to the most positive-z location. Remove the PSFs and OMIF, if present. Remove the seismic restraints. Disconnect the portable motor controller from the PM10 support frame. Remove the carriage and precision clean it to level 50, the cleanliness being validated according to the procedures of MEL98-012 and MEL98-015, latest revision. It shall be packaged according to MEL99-014, latest revision and stored at a University-designated location.

2. Connect the portable motor controller to the receptacle on the PM7 support frame. Move the carriage to the most positive-z location. Remove the PSFs and OMIF, if present. Remove the seismic restraints. Disconnect the portable motor controller from the PM7 support frame. Remove the carriage and precision clean it to level 50, the cleanliness being validated according to the procedures of MEL98-012 and MEL98015, latest revision. It shall be packaged according to MEL99-014, latest revision and stored at a University-designated location.

3. Remove the IOM Alignment fixture from the IOM mount and place it into the designated GFE container at the designated location.

4. Connect the portable motor controller to the receptacle on the PM8 support frame. Move the carriage to the most positive-z location. Remove the PSFs and the OMIF1 and deposit them into the designated GFE containers at the designated locations. Remove the seismic restraints. Disconnect the portable motor controller from the PM7 support frame. Remove the carriage and precision clean it to level 50, the cleanliness being validated according to the procedures of MEL98-012 and MEL98-015, latest revision. It shall be packaged according to MEL99-014, latest revision and stored at a University-designated location.

5. Remove the PSFs and the OMIF2 from the PM9 location and deposit them into the designated GFE containers at the designated locations.

6. Remove the PSFs and the OMIF2 from the PL1 location and deposit them into the designated GFE containers at the designated locations.

\section{Install a Crosshair and Bellows on the Top of the Trombone Enclosure}

1. When delivered, the crosshair assembly will be precision cleaned internally and externally and packaged according to MEL99-014, latest revision. The bellows will be precision cleaned both internally and externally and packaged according to the 
same procedures. Internal cleanliness is maintained by blanking plates on both the top and bottom of these items. These plates are removed during installation. Note that the lower blanking plate of the crosshair has a gasket on the external surface.

2. The crosshair assembly must be installed in a clean area as described in MEL98-014, latest revision. Prior to installing the crosshair onto the upper surface of the trombone, the surface upon which the crosshair rests must be cleaned following the procedures given in MEL99-010, latest revision, and the cleanliness validated according to the procedures of MEL98-012 and MEL98-015, latest revision. Also, the area internal to the trombone, immediately below the fastener pattern, must be cleaned and validated according to the same procedures.

3. Remove the lower blanking plate, with attached gasket, from the crosshair and reserve it in a clean location close to hand. Note that there is also a gasket attached to the lower surface of the crosshair. Place the crosshair onto the trombone, aligning it with the fastener pattern on the top surface of the trombone. Place the previously removed blanking plate inside the trombone, with the gasket surface up. Align it with the fastener pattern, and install the fasteners indicated so that the trombone upper surface is sandwiched between the blanking plate and the crosshair, with gaskets on each side.

4. Within the clean area, remove the top blanking plate from the crosshair and one of the blanking plates, with gasket attached, from the bellows. Note that there is a gasket on the surface of the bellows and none on the upper surface of the crosshair. Mount the open end of the bellows onto the top of the crosshair and fasten it with the hardware indicated. Leave the upper blanking plate in place on the bellows.

N. Install the Vertical Beam Enclosure and Upper Bellows

1. The vertical beam enclosure connects the crosshair on top of the trombone to the roving mirror enclosure located on the next level up of the switchyard. The enclosure is composed of a duct-like assembly with an appendage housing a motorized shutter located at a right angle to its vertical axis. The enclosure is installed so that this appendage is located over the trombone. There are bellows located at the top and bottom of the enclosure to accommodate axial and longitudinal misalignment.

2. The beam enclosure is attached to a column of the switchyard steel by means of two horizontal arms that are pre-mounted to the enclosure assembly. To accomplish the installation, a set of four mounting holes must be correctly located, drilled and tapped into this column. It should be appreciated that the $200 \mathrm{~kg}$ weight of the enclosure is cantilevered from these arms and that the enclosure is installed in a location in which it is difficult to work. Neither the upper or lower bellows connecting the enclosure to the crosshair and roving mirror enclosure can support the weight of the enclosure. It is anticipated that a vertically adjustable clamping arrangement will be required to support the enclosure against the switchyard column while the mounting holes are being located. 


\section{Appendix C to Scope of Work for IMI Services}

3. When delivered, the vertical beam enclosure will have been precision cleaned internally and packaged according to MEL99-014, latest revision. It will be under 50 $\mathrm{mm}$ ( 2 inches) of $\mathrm{H}_{2} \mathrm{O}$ internal pressure. The internal cleanliness is maintained by blanking plates on both the top and bottom of the enclosure. These will be removed during installation. The upper bellows will be cleaned internally and externally and packaged according to MEL99-014, latest revision.

4. The enclosure must be installed in a clean area as described in MEL98-014, latest revision. Temporarily mount the vertical enclosure to a column in the orientation shown, taking care that it is suspended between $1 / 2$ and 1 inch above the lower bellows that was previously installed on top of the crosshair. Remove the cover on the 4-inch port indicated, located midway on the more positive z-side of the enclosure, remembering that the enclosure is under pressure. Quickly (within 5 seconds) fasten a source of clean, HEPA-filtered to class 10, dry air, regulated to a pressure no greater than $100 \mathrm{~mm}$ (4 inches) of $\mathrm{H}_{2} \mathrm{O}$, to the port.

5. Remove the lower blanking panel from the vertical enclosure. Remove the upper blanking panel from the bellows on the crosshair. Lower the enclosure until contact is just made with the bellows. Use the supplied fasteners indicated to attach the vertical enclosure and bellows. Measure the distance between the top flange (not including the blanking panel) of the enclosure and the sealing face located on the bottom of the roving mirror enclosure. Lower the enclosure until this distance is no greater than indicated.

6. The roving mirror enclosure, to which the vertical enclosure attaches, was precision cleaned earlier in the contract. It is under approximately $50 \mathrm{~mm}$ ( 2 inches) of $\mathrm{H}_{2} \mathrm{O}$ pressure. Remove the blanking plate from the flange that protrudes downward from the roving mirror enclosure. Remove the blanking panel from the top of the vertical enclosure. Note that the sealing gaskets for both of these are located on the blanking plates, not the flanges.

7. Remove both blanking plates from the bellows and insert the bellows into the gap between the roving mirror enclosure and the vertical beam enclosure. Be careful not to dislodge the gaskets on the upper and lower flanges of the bellows. It will probably be necessary to lower the vertical beam enclosure in order to accomplish this. Using the fasteners indicated and furnished with the bellows, fasten the upper bellows to both the roving mirror enclosure and the vertical beam tube.

8. Adjust the vertical beam tube until the upper and lower bellows have the same degree of compression (expansion). Transfer punch, drill, and tap the four mounting holes, shown, into a column and mount the vertical beam enclosure to this column.

9. Pressure test the vertical beam tube assembly for leakage as described in 3.09 .

10. While in a clean area, remove the source of clean air from the vertical enclosure and reinstall the blanking plate covering the port.

O. Install a Crosshair on the Side of the Trombone Enclosure 
1. When delivered, the crosshair assembly and the bellows will be precision cleaned internally and packaged according to MEL99-014, latest revision. Internal cleanliness is maintained by blanking plates on both sides of these items. These plates are removed during installation. Note that the one of the blanking plates of the crosshair has a gasket on the external surface.

2. The crosshair assembly must be installed in a clean area as described in MEL98-014, latest revision. Prior to installing the crosshair onto the vertical surface of the trombone, the surface upon which the crosshair rests must be cleaned following the procedures given in MEL99-010, latest revision, and the cleanliness validated according to the procedures of MEL98-012 and MEL98-015, latest revision. Also, the area internal to the trombone, immediately on the other side of the fastener pattern, must be cleaned and validated according to the same procedures.

3. Remove from the crosshair the blanking plate that has a gasket attached to the outer surface and reserve it in a clean location close to hand. Note that there is also a gasket attached to the flange of the crosshair. Place the crosshair onto the trombone, aligning it with the fastener pattern on the side of the trombone. Place the previously removed blanking plate inside the trombone, with the gasket surface toward the crosshair. Align it with the fastener pattern, and install the fasteners indicated, so that the trombone vertical surface is sandwiched between the blanking plate and the crosshair, with gaskets on each side.

\section{P. Install the PM10 Mirror Enclosure}

1. The PM10 mirror enclosure will be delivered with one bellows already attached to the enclosure at the point where the attachment of beam enclosures is to take place. This is located on the side that faces in the positive $\mathrm{x}$-direction. There are two additional openings in the enclosure. One is on the side facing in the positive $\mathrm{x}$-direction and the other on the side facing in the positive $\mathrm{z}$-direction. Both are closed with blanking plates.

2. The interior of the PM10 mirror enclosure and bellows are precision cleaned off site and packaged in accordance with MEL99-014, latest revision. The assembly will be furnished to the subcontractor in this condition. The enclosure must be installed in a clean area as described in MEL98-014, latest revision.

3. The top surface of the support frame must be precision cleaned by wiping, as described in MEL99-010, latest revision, prior to the installation of the enclosure that rests on top of the support frame. The surfaces that are to be cleaned are indicated. The clean environment must be at least class 100 . The surfaces shall be cleaned to level 50, as determined by MEL98-012 and MEL98-015, latest revisions.

4. A gasket to seal between the surface of the support frame and the PM10 mirror enclosure will be installed on the horizontal top surface of the support frame. This gasket is installed following the NIF procedures, using the materials indicated in this document. The gasket material and the double-backed tape that attaches it to the 


\section{Appendix C to Scope of Work for IMI Services}

support frame will be provided in bulk quantity to the subcontractor. They will be installed at the location indicated to the tolerances indicated.

5. Before installing the PM10 mirror enclosure, the PM10 carriage must be placed back upon its rails and tested for electrical functionality. The carriage will be delivered precision cleaned and packaged according to MEL99-014, latest revision. After placing the carriage onto its rails, a 4 hour Hold Point is instituted to provide LLNL personnel access to test and adjust, if necessary, the electrical interlocks.

6. Prior to removing the protective packaging from the bottom of the enclosure, remove the blanking plate from the $z$-facing side and install a source of clean, HEPA-filtered to class 10 , dry air, regulated to a pressure no greater than $10 \mathrm{~mm}(0.4$ inches $)$ of $\mathrm{H}_{2} \mathrm{O}$ above ambient. Remove the packaging and place the PM10 enclosure upon the support frame, taking great care to bring the enclosure directly downward, with no lateral motion, so as not to cause separation of the gasket and the double-backed tape. The reason for this concern is that the tape does not reach full cure strength for 48 hours, and it is desired not to impose a Hold Point to allow for increased curing time. Install the fasteners indicated at the locations shown. Leave the clean air source in place.

\section{Q. Install the Trombone to PM10 Beam Enclosure and Bellows}

1. This beam enclosure extends between the bellows on the side of the trombone and the bellows on the more $\mathrm{x}$-negative side of the PM10 enclosure. When delivered, the beam enclosure is precision cleaned internally and packaged according to MEL99-014, latest revision. Internal cleanliness of the enclosure is maintained by blanking plates mounted on each end. These plates are removed during installation. The beam enclosure must be installed within a clean area, as described in MEL98-014, latest revision, located at each end of the enclosure.

2. Increase the internal pressure of the PM10 enclosure to $50 \mathrm{~mm}$ ( 2 inches) of $\mathrm{H}_{2} \mathrm{O}$ above ambient. Temporarily support the beam enclosure at the height of the bellows located on the more negative x-side of PM10. Remove the blanking plate from the bellows of the PM10 enclosure, while maintaining flow through the enclosure. Remove the blanking plate from the end of the beam enclosure closer to the PM10 enclosure and connect the beam enclosure to the PM10 enclosure using the fasteners provided and indicated.

3. Adjust the supports for the beam enclosure so that it is aligned with the crosshair on the trombone and the bellows on PM10. Within the clean area, remove the remaining blanking plate from the crosshair and both of the blanking plates from the bellows, and the remaining blanking plate from the beam enclosure. Note that there is a gasket on the surface of the bellows and none on the surface of the crosshair. Mount the bellows between the crosshair and the beam tube. It may be necessary to compress the bellows mounted on the PM10 enclosure in order to accomplish this. Fasten the bellows to both the crosshair and beam enclosure with the hardware indicated. 
4. While in a clean area, remove the source of clean air from the PM10 enclosure and reinstall the blanking plate covering the port.

R. Install the PM7 Mirror Enclosure and Bellows

1. The PM7 mirror enclosure will be delivered with one bellows already attached to the enclosure at the point where the attachment of beam enclosures is to take place. This is located on the side that faces in the positive x-direction. There are two additional openings in the enclosure. One is on the side facing in the positive $\mathrm{x}$-direction and the other on the side facing in the positive z-direction. Both are closed with blanking plates.

2. The interior of the PM7 mirror enclosure and bellows are precision cleaned off site and packaged in accordance with MEL99-014, latest revision. The assembly will be furnished to the subcontractor in this condition. The enclosure must be installed in a clean area as described in MEL98-014, latest revision.

3. The top surface of the support frame must be precision cleaned by wiping, as described in MEL99-010, latest revision, prior to the installation of the enclosure that rests on top of the support frame. The surfaces that are to be cleaned are indicated. The clean environment must be at least class 100 . The surfaces shall be cleaned to level 50 , as determined by MEL98-012 and MEL98-015, latest revisions.

4. A gasket to seal between the surface of the support frame and the PM7 mirror enclosure will be installed on the horizontal top surface of the support frame. This gasket is installed following the NIF procedures, using the materials indicated in this document. The gasket material and the double-backed tape that attaches it to the support frame will be provided in bulk quantity to the subcontractor. They will be installed at the location indicated.

5. Before installing the PM7 mirror enclosure, the PM7 carriage must be placed back upon its rails and tested for electrical functionality. The carriage will be delivered precision cleaned and packaged according to MEL99-014, latest revision. After placing the carriage onto its rails, a 4 hour Hold Point is instituted to provide LLNL personnel access to test and adjust, if necessary, the electrical interlocks.

6. Prior to removing the protective packaging from the bottom of the enclosure, remove the blanking plate from the $\mathrm{z}$-facing side and install a source of clean, HEPA-filtered to class 10 , dry air, regulated to a pressure no greater than $10 \mathrm{~mm}(0.4$ inches $)$ of $\mathrm{H}_{2} \mathrm{O}$ above ambient. Remove the packaging and place the PM7 enclosure upon the support frame, taking great care to bring the enclosure directly downward, with no lateral motion, so as not to cause separation of the gasket and the double-backed tape. Install the fasteners indicated at the locations shown. Leave the clean air source in place.

S. Install the PM10 to PM7 Beam Enclosure and Bellows

1. This beam enclosure extends between the bellows on the more positive X-side of the PM10 enclosure and the bellows on the more $\mathrm{x}$-negative side of the PM7 enclosure. 


\section{Appendix C to Scope of Work for IMI Services}

When delivered, the beam enclosure is precision cleaned internally and packaged according to MEL99-014, latest revision. Internal cleanliness of the enclosure is maintained by blanking plates mounted on each end. These plates are removed during installation. The beam enclosure must be installed within a clean area, as described in MEL98-014, latest revision, located at each end of the enclosure.

2. Increase the internal pressure of the $\mathrm{PM} 7$ enclosure to $50 \mathrm{~mm}$ ( 2 inches) of $\mathrm{H}_{2} \mathrm{O}$ above ambient. Temporarily support the beam enclosure at the height of the bellows located on the more negative X-side of PM7. Remove the blanking plate from the bellows of the PM10 enclosure, while maintaining flow through the enclosure. Remove the blanking plate from the end of the beam enclosure closer to the PM7 enclosure and connect the beam enclosure to the PM7 enclosure using the fasteners provided and indicated.

3. Adjust the supports for the beam enclosure so that it is aligned with the crosshair on the trombone and the bellows on PM7. Within the clean area, remove both of the blanking plates from the bellows, and the remaining blanking plate from the beam enclosure. Note that there is a gasket on the surface of the bellows and none on the surface of the crosshair. Mount the bellows between the crosshair and the beam tube. It may be necessary to compress the bellows mounted on the PM7 enclosure in order to accomplish this. Fasten the bellows to both the crosshair and beam enclosure with the hardware indicated.

4. Pressure test the beam path from the trombone through the PM7 enclosure for leakage as described in 3.09 .

5. While in a clean area, remove the source of clean air from the PM7 enclosure and reinstall the blanking plate covering the port.

T. Install the PL1 Crosshair

1. When delivered, the crosshair assembly will be precision cleaned internally and packaged according to MEL99-014, latest revision. Internal cleanliness is maintained by blanking plates on both sides of these items. These plates are removed during installation.

2. The crosshair assembly must be installed in a clean area as described in MEL98-014, latest revision. Prior to installing the crosshair onto the support provided on the PM9/PL1 frame, the surface upon which the crosshair rests must be cleaned following the procedures given in MEL99-010, latest revision. The surfaces that are to be cleaned are indicated. The clean environment must be at least class 100 . The surfaces shall be cleaned to level 50, as determined by MEL98-012 and MEL98-015, latest revisions.

3. Remove from the crosshair the blanking plates. Place the crosshair onto the mount provided, aligning it with the fastener pattern and install the fasteners indicated.

U. Install the PM9/PL1 Mirror/Lens Enclosure and Bellows 
1. The PM9/PL1 mirror enclosure will be delivered with two bellows already attached to the enclosure at the points where the attachment of beam enclosures is to take place. These are located on the two sides that face in the negative $\mathrm{x}$-direction. There is a third opening in the enclosure on the side facing in the positive $\mathrm{x}$-direction that is closed with a blanking plate.

2. The interior of the PM9/PL1 mirror enclosure and bellows assembly is precision cleaned off- site and packaged in accordance with MEL99-014, latest revision. The assembly will be furnished to the subcontractor in this condition. The enclosure must be installed in a clean area as described in MEL98-014, latest revision.

3. The top surface of the support frame must be precision cleaned by wiping, as described in MEL99-010, latest revision, prior to the installation of the enclosure that rests on top of the support frame. The surfaces that are to be cleaned are indicated. The clean environment must be at least class 100 . The surfaces shall be cleaned to level 50 , as determined by MEL98-012 and MEL98-015, latest revisions.

4. A gasket to seal between the surface of the support frame and the PM9/PL1 mirror enclosure will be installed on the horizontal top surface of the support frame. This gasket is installed following the NIF procedures, using the materials indicated in this document. The gasket material and the double-backed tape that attaches it to the support frame will be provided in bulk quantity to the subcontractor. They will be installed at the location indicated to the tolerances indicated.

5. Prior to removing the protective packaging from the bottom of the enclosure, remove the blanking plate from the rightmost of the openings on the x-facing side. Install on that opening a source of clean, HEPA-filtered to class 10, dry air, regulated to a pressure no greater than $10 \mathrm{~mm}(0.4$ inches $)$ of $\mathrm{H}_{2} \mathrm{O}$ above ambient. Remove the packaging and place the PM9/PL1 enclosure upon the support frame, taking great care to bring the enclosure directly downward, with no lateral motion, so as not to cause separation of the gasket and the double-backed tape. The reason for this concern is that the tape does not reach full cure strength for 48 hours, and it is desired not to impose a Hold Point to allow for increased curing time. Install the fasteners indicated at the locations shown. Leave the clean air source in place.

\section{Install the PM7 to PM9/PL1 Beam Enclosure and Bellows}

1. This beam enclosure extends between the bellows on the more positive x-side of the PM7 enclosure and the bellows on the more X-negative side of the PM9/PL1 enclosure. When delivered, the beam enclosure is precision cleaned internally and packaged according to MEL99-014, latest revision. Internal cleanliness of the enclosure is maintained by blanking plates mounted on each end. These plates are removed during installation. The beam enclosure must be installed within a clean area, as described in MEL98-014, latest revision, located at each end of the enclosure.

2. Increase the internal pressure of the $\mathrm{PM} 7$ enclosure to $50 \mathrm{~mm}$ ( 2 inches) of $\mathrm{H}_{2} \mathrm{O}$ above ambient. Temporarily support the beam enclosure at the height of the bellows located 


\section{Appendix C to Scope of Work for IMI Services}

on the more negative X-side of PM7. Remove the blanking plate from the bellows of the PM10 enclosure, while maintaining flow through the enclosure. Remove the blanking plate from the end of the beam enclosure closer to the PM7 enclosure and connect the beam enclosure to the PM7 enclosure using the fasteners provided and indicated.

3. Adjust the supports for the beam enclosure so that it is aligned with the crosshair on the trombone and the bellows on PM7. Within the clean area, remove both of the blanking plates from the bellows, and the remaining blanking plate from the beam enclosure. Note that there is a gasket on the surface of the bellows and none on the surface of the crosshair. Mount the bellows between the crosshair and the beam tube. It may be necessary to compress the bellows mounted on the PM7 enclosure in order to accomplish this. Fasten the bellows to both the crosshair and beam enclosure with the hardware indicated. Leave the source of clean air attached to the PM7 mirror enclosure.

\section{W. Install the PM8 Mirror Enclosure and Bellows}

1. The PM8 mirror enclosure will be delivered with one bellows already attached to the enclosure at the point where the attachment of beam enclosures is to take place. This is located on the side that faces in the positive x-direction. There are two additional openings in the enclosure. One is on the side facing in the positive $x$-direction and the other on the side facing in the positive $\mathrm{z}$-direction. Both are closed with blanking plates.

2. The interior of the PM8 mirror enclosure and bellows are precision cleaned off site and packaged in accordance with MEL99-014, latest revision. The assembly will be furnished to the subcontractor in this condition. The enclosure must be installed in a clean area as described in MEL98-014, latest revision.

3. The top surface of the support frame must be precision cleaned by wiping, as described in MEL99-010, latest revision, prior to the installation of the enclosure that rests on top of the support frame. The surfaces that are to be cleaned are indicated. The clean environment must be at least class 100. The surfaces shall be cleaned to level 50, as determined by MEL98-012 and MEL98-015, latest revisions.

4. A gasket to seal between the surface of the support frame and the PM8 mirror enclosure will be installed on the horizontal top surface of the support frame. This gasket is installed following the NIF procedures, using the materials indicated in this document. The gasket material and the double-backed tape that attaches it to the support frame will be provided in bulk quantity to the subcontractor. They will be installed at the location indicated.

5. Before installing the PM8 mirror enclosure, the PM8 carriage must be placed back upon its rails and tested for electrical functionality. The carriage will be delivered precision cleaned and packaged according to MEL99-014, latest revision. After 
placing the carriage onto its rails, a 4 hour Hold Point is instituted to provide LLNL personnel access to test and adjust, if necessary, the electrical interlocks.

6. Prior to removing the protective packaging from the bottom of the enclosure, remove the blanking plate from the z-facing side and install a source of clean, HEPA-filtered to class 10 , dry air, regulated to a pressure no greater than $10 \mathrm{~mm}(0.4$ inches $)$ of $\mathrm{H}_{2} \mathrm{O}$ above ambient. Remove the packaging and place the PM8 enclosure upon the support frame, taking great care to bring the enclosure directly downward, with no lateral motion, so as not to cause separation of the gasket and the double-backed tape. Install the fasteners indicated at the locations shown. Leave the clean air source in place.

X. Install the PM8 to PM9/PL1 Beam Enclosure and Bellows

1. This beam enclosure extends between the bellows on the PM8 enclosure and the two sets of bellows on the more x-positive side of the PM9/PL1 enclosure. When delivered, the beam enclosure is precision cleaned internally and packaged according to MEL99-014, latest revision. Internal cleanliness of the enclosure is maintained by blanking plates mounted on each end. These plates are removed during installation. The beam enclosure must be installed within a clean area, as described in MEL98-014, latest revision, located at each end of the enclosure.

2. Increase the internal pressure of the PM8 enclosure to $50 \mathrm{~mm}$ ( 2 inches) of $\mathrm{H}_{2} \mathrm{O}$ above ambient. Temporarily support the beam enclosure at the height of the bellows located on the side of PM8. Remove the blanking plate from the bellows of the PM9/PL1 enclosure, while maintaining flow through the enclosure. Remove the blanking plate from the end of the beam enclosure closer to the PM8 enclosure and connect the beam enclosure to the PM8 enclosure using the fasteners provided and indicated.

3. Adjust the supports for the beam enclosure so that it is aligned with the crosshair on the trombone and the bellows on PM8. Within the clean area, remove both of the blanking plates from the bellows, and the remaining blanking plate from the beam enclosure. Note that there is a gasket on the surface of the bellows and none on the surface of the crosshair. Mount the bellows between the crosshair and the beam tube. It may be necessary to compress the bellows mounted on the PM8 enclosure in order to accomplish this. Fasten the bellows to both the crosshair and beam enclosure with the hardware indicated.

4. Pressure test the PM9/PL1, bellows, PM8, and beam enclosures for leakage as described in 3.09 .

5. While in a clean area, remove the source of clean air from the PM7 enclosure and reinstall the blanking plate covering the port.

\subsection{INSTALLATION SPECIFICS: SWITCHYARD \#1}

A. Install the PM7 Mirror Support Frame 
1. The kinematic ball mounts upon which the PM7 mirror Line Replaceable Unit (LRU) rests are attached to the top of a wheeled carriage that rests upon a set of rails. The carriage has two grooved wheels riding on one rail and one non-grooved wheel riding on the other rail. The rails are mounted upon a support frame that is, in turn, fastened to the structural steel of the Switchyard. The rails are used only for removal and replacement of the PM7 mirror, which is in an inaccessible location.

2. Place the support frame for the PM7 mirror, which has the LRU carriage attached to it, onto the switchyard frame support pads indicated in AAA99-115170. Be sure that the frame is oriented correctly. To this end, be sure that the frame leg with an "A1" stamped upon it rests upon the pad indicated as "A1" in AAA99-115183. Remove the lashings holding the LRU carriage to the support frame. Place the OMIF1 upon the kinematic balls of the LRU carriage.

3. Connect the motor controller output cable to the mating connector (item X of AAA99103901) and drive the carriage in the negative $\mathrm{z}$-direction until the limit switch turns off power to the motor. This places the carriage against a hard stop that defines the position at which the Optics Mount Installation Fixture (OMIF1) will be aligned.

4. CAUTION: When the carriage is driven against the hard stop, there is approximately 300 pounds of tension in the drive belt. A temporary belt guard is supplied. This must be placed over the belt during the remainder of the installation and alignment process. It must be removed prior to the installation of the PM7 enclosure.

5. Locate the support frame and LRU carriage combination at its absolute $x$ and $z-$ location (NIF global), to within $\pm 2.0 \mathrm{~mm}$, and at its absolute location in $\mathrm{y}$, to within $\pm 1.0 \mathrm{~mm}$, as shown in the ACD (AAA99-115183). This is accomplished by placing four PSFs (PM-1-07-MS1 - PM-1-07-MS4) onto the OMIF1. The PSF PM-1-07-MS1 is used to establish the absolute $\mathrm{x}, \mathrm{y}$, and z-location of the OMIF1. The PSF PM-1-07MS4 is used in conjunction with PM-1-07-MS1 to control rotation about the $\mathrm{x}$ and $\mathrm{y}-$ axes, and PM-1-07-MS2 is used in conjunction with PM-1-07-MS1 to control rotation about the z-axis. The coordinates of both PM-1-07-MS2 and PM-1-07-MS4 are measured relative to that of PM-1-07-MS1.

6. The support frame is adjusted in the vertical direction and in rotation about the two horizontal axes by use of the jackscrews provided at each of three corners on the inside of the frame (see AAA99-103901). These jackscrews have a pitch of $3 \mathrm{~mm}$ and a center to center distance of approximately 1 meter. They are adjusted until the PSF PM-1-07-MS1 is at the nominal absolute y-position specified in the ACD, within \pm 1.0 $\mathrm{mm}$. Level the OMIF1 in the $\mathrm{x}$ and $\mathrm{z}$-direction so that it is within \pm 1.0 mradian of the normal to the local gravity vector. Check the y-position of PSF PM-1-07-MS1 and, if necessary, re-adjust the jackscrews and re-level the OMIF1.

7. Adjustment in the horizontal plane and in rotation about the vertical axis is accomplished by moving the frame, which is resting on the rounded ends of three of the jackscrews. The frame will be adjusted until PM-1-07-MS1 is at the absolute $\mathrm{x}$ and 
Z-coordinates specified in the ACD, within $\pm 2.0 \mathrm{~mm}$, and PM-1-07-MS4 is located at the measured $\mathrm{x}$-coordinate of PM-1-07-MS1, within $\pm 0.5 \mathrm{~mm}$.

8. Measure the distance between each of the corner flanges on the support stand and the lower stud plates upon which the jackscrews rest. Select a shim(s) from the shim pack available that will provide a vertical location of the OMIF1 that is within this tolerance.

9. Fix the support frame to the space frame using the selected $\operatorname{shim}(\mathrm{s})$. Tightening torque is as recommended. Weld the stud plates to the switchyard mounting pads as shown in AAA99-103901.

\section{B. Align the PM7 Mirror Mount}

1. After attaching the support frame to the space frame, level the OMIF1 in the $x$ and $z-$ direction to a deviation of less than $30 \mu$ radians from the normal to the local gravity vector. This is accomplished by loosening the jam nuts on the balls on the kinematic plate that mate to the kinematic sockets on OMIF1, and threading the balls into or out of their mating threads.

2. Adjust the OMIF in the y-direction (height), using the same method, until PSF PM-107-MS1 is at the absolute y-coordinate indicated on the ADC (AAA99-115183), to within $\pm 0.3 \mathrm{~mm}$. Assure that OMIF1 is level to $30 \mu$ radians.

3. The proper x-coordinate, referenced to NIF global, of PSF PM-1-07-MS1 is established by adjusting that kinematic ball, mounted upon the top plate of the support frame, which mates with the cone receptacle. The orientation of the kinematic sockets, which consist of a cone, a v-groove and a flat, is such that the v-groove is parallel to the NIF $\mathrm{x}$-axis. The OMIF is adjusted in the $\mathrm{x}$-direction by loosening the attachment of the cone kinematic ball and then sliding the ball and OMIF1 in the x-direction until the PSF PM-1-07-MS1 is at the absolute $\mathrm{x}$-coordinate specified in the ACD, to within \pm 0.3 $\mathrm{mm}$.

4. At this point, it may be necessary to adjust OMIF1 in rotation about the y-axis. If such is the case, loosen the kinematic ball that mates with the v-groove. Adjust OMIF1 in rotation about the $y$-axis until the $\mathrm{x}$-coordinate of PM-1-07-MS2 is within $0.1 \mathrm{~mm}$ of the measured $\mathrm{x}$-coordinate of PM-1-07-MS1. Re-check the y-coordinate of the PSF PM-1-07-MS1 and the level of OMIF1 and, if not correct, all other measurements must be re-checked and OMIF1 re-leveled.

5. Set the position of PM-1-07-MS1 in the z-direction to the coordinate indicated by the ACD to a tolerance of $\pm 0.3 \mathrm{~mm}$. This is accomplished by changing the position of the hard stop that positions the carriage at the correct position. See AAA99-103901 for the location and operation of this adjustment.

6. Measure the vertical distance between the hook of the LRU seismic restraint that is mounted on the underside of OMIF1 and the mounting plate for the latch portion of the restraint that is located on the upper face of the support stand. Subtract 'TBD' mm 


\section{Appendix C to Scope of Work for IMI Services}

from this measured distance and machine a spacer that corresponds to AAA99-103901, with the 'TBD' dimension on this drawing defined as the result obtained when the subtraction was performed. Install the latch portion of the restraint onto the support stand with the spacer between the hook and the stand. Adjust the hook in the horizontal plane until it engages properly with the latch on the OMIF1.

7. The robotic-type electrical receptacle mounted on the LRU plate must be adjusted in the horizontal plane and vertical direction to mate properly with the connector on the OMIF1. Loosen the screws that retain the receptacle in the horizontal position and place it under the connector. Loosen the screws that retain the receptacle in the vertical direction and bring the receptacle up to the connector until there is a $3 \mathrm{~mm}, \pm 0.5 \mathrm{~mm}$, gap between the mounting flanges of each, completely around their periphery. The body of the connector will center the receptacle properly as the receptacle is brought to within $3 \mathrm{~mm}$. Tighten all mounting screws to the torque specified.

C. Place and Align the 30-inch PM3 Withdrawal Enclosure Support Beam

1. The 30-inch box beam that supports the PM3 Withdrawal Enclosure must be put in place prior to proceeding with the remainder of the installation of the PDS within Switchyard \#1. The location of this beam is referenced to PSF PM-1-07-MS1.

2. Place four Precision Survey Features (PSFs) onto the top surface of the box beam, as close to the edges as possible. These PSFs are located as follows:

a. TBD mm from the East end, going westerly, on the North edge of the beam: PB-101-MS1

b. TBD mm from the East end, going westerly, on the South edge of the beam: PB-101-MS2

c. TBD mm from the West end, going easterly, on the North edge of the beam: PB-101-MS3

d. TBD mm from the West end, going easterly, on the South edge of the beam: PB-101-MS4

3. Position the box beam until the dimensions from PSF PB-1-01-MS1 and PB-1-01-MS3 to PSF PM-1-07-MS1 (mounted on the $3 \omega$ Chamber) are within $\pm 1.0 \mathrm{~mm}$ in $\mathrm{x}, \mathrm{y}$ and $\mathrm{z}$, to those shown in the ACD (AAA99-103607).

D. Install the Beam Dump

1. Place the main support of the beam dump onto the switchyard mounting pads indicated in AAA99-115170, verifying that the leg marked "B1" is on the pad designated "B1" in AAA99-115183. Mount the PL3 lens drive assembly (item \#1 of AAA99-115179) onto the main support. Bolt the Front Beam Dump Alignment Fixture (AAA99115428) onto the PL3 lens drive assembly. Place four PSFs (PL-1-03-MS1 - PL-1-03MS4) into the magnetic sockets located on the most negative-z face of the Alignment Fixture. Note that the plane formed by these PSFs is not perpendicular to the NIF zaxis. The PL-1-03-MS1 PSF is used to establish the $\mathrm{x}, \mathrm{y}$, and z-location of one corner 
of the most negative-z end of the beam dump, relative to the PSF PM-1-07-MS1 located on the OMIF1 at PM7. The PL-1-03-MS2 PSF is used in conjunction with PL1-03-MS1 to measure rotation about the y-axis. The coordinates of both PL-1-03-MS2 and PL-1-03-MS4 are measured relative to that of PL-1-03-MS1.

2. Place the center and end stand assemblies of the beam dump onto the switchyard mounting pads indicated in AAA99-115170, verifying that the legs marked "H1" for the center stand and " $\mathrm{J} 1$ " for the end stand, are on the pads designated "H1" and "J1" in AAA99-115183.

3. The beam dump body is composed of two spatial filters (AAA99-115170). Install one of the spatial filters (item \# 2 of AAA99-115170) between the main support and the center stand assembly. Install, and tighten to the torque shown on AAA99-115170, all of the bolts joining the spatial filter to the main support. Install and tighten to the indicated torque all fasteners at the joint of the spatial filter and the center stand. Install the remaining spatial filter between the center stand and the end stand. The joint between this spatial filter and the end and center stands should have all fasteners installed to the proper torque. Fasten the Rear Beam Dump Alignment fixture to the end stand assembly.

4. Adjust the main support in $\mathrm{x}$ and $\mathrm{z}$ until measurement of PSF PL-1-03-MS1 indicates that it is within $\pm 1.0 \mathrm{~mm}$ of its relative position in $\mathrm{x}$ and $\mathrm{z}$ with respect to PM-1-07MS1, as given in the ACD (AAA99-115183).

5. Vertical adjustment and adjustment for rotation about the $\mathrm{x}$ and $\mathrm{z}$-axes is accomplished by using the designated three jackscrews provided at each the corners of the support stand. These jackscrews have a pitch of $3.0 \mathrm{~mm}$ and a center to center distance of approximately 1 meter. Adjust the frame in the y-direction until measurement of PSF PL-1-03-MS1 indicates that it is within $\pm 1.0 \mathrm{~mm}$ of the as-installed $\mathrm{y}$-coordinate of PSF PM-1-07-MS1. Level the frame, using as a measuring surface the top of the frame, so that the frame is perpendicular to the local gravity vector to within \pm 1.0 mradians along the $\mathrm{x}$ and $\mathrm{z}$-axes.

6. Lower the fourth jackscrew of the main support to lightly make contact with the stud plate. Install the selected shim(s). Fix the end stand assembly to the stud plates by tightening the mounting bolts against the jackscrews. Tightening torque is as shown. Do not weld the stud plates to the switchyard mounting pads.

7. Place a PSF (PL-1-03-MS5) in the center position provided on the Rear beam Dump alignment fixture. Adjust the end stand in $\mathrm{x}$ and $\mathrm{z}$ until measurement of PSF PL-1-03MS5 indicates that it is within $\pm 1.0 \mathrm{~mm}$ of its relative position in $\mathrm{x}$ and $\mathrm{z}$ with respect to PM-1-07-MS1, as given in the ACD (AAA99-115183).

8. Adjust the height of the end stand assembly, using the designated three jackscrews, until the y-coordinate of PSF PL-1-03-MS5 is within $1.0 \mathrm{~mm}$ of the y-coordinate of PM-1-07-MS1, as given in the ACD (AAA99-115183). 


\section{Appendix C to Scope of Work for IMI Services}

9. Lower the fourth jackscrew of the main, center, and end supports to lightly make contact with the stud plates. Measure the distance between each of the flanges on the lower extremity of each of the stand legs and the stud plate against which the jackscrews rest. Select a shim(s) from those available that will provide a vertical location of the beam dump alignment fixtures that are within the tolerances cited above. Install the selected shim(s). Fix the stand assemblies to their stud plates by tightening the mounting bolts against the jackscrews. Tightening torque is as shown. Weld the stud plates to the switchyard mounting pads as shown in AAA99-103901.

10. Verify that the coordinates of PSFs PL-1-03-MS1 and PL-1-03-MS5 are within the tolerances specified with respect to PSF PM-1-07-MS1 as given in the ACD. If they are not, it will be necessary to re-install the beam dump. If this is necessary, the sequence of installation must be repeated.

E. Install the PM3 Withdrawal Enclosure

1. An enclosure and rails substantially identical to the Trombone enclosure and rails in Switchyard \#2, with the exception of length, is installed in Switchyard \#1. Unlike the Trombone rails, the sole purpose of this assembly is to provide a method to remove mirror PM3. As is the case in Switchyard \#2, these mirrors are located in an inaccessible location and must be moved to a location from which they may be removed. The withdrawal enclosure and rails are installed for this sole purpose. Consequently, the alignment of these rails is critical only at the location at which PM3 rests and at the location where it will be removed / replaced.

2. The Withdrawal Enclosure is constructed of eight separate modules, five of which are identical. These are fabricated off-site and assembled into a continuous, gas-tight enclosure in Switchyard \#1. Each enclosure has rail mounts welded into it. The Withdrawal Enclosure assembly drawing is AAA99-103240.

3. Each module is fabricated with a floor of $6 \mathrm{~mm}$ stainless steel. The top, with one exception, is fabricated from stainless sheet and, in general, the side in the most negative $\mathrm{x}$-direction is covered with stainless sheet. The side in the most positive $\mathrm{x}$ direction is left open to facilitate later (post CSP 19) installation and alignment of the rails as well as installation of the belt and drive for the PM3 carriage. The ends of the modules are open so that when assembled and welded together in the switchyard they form a continuous, tunnel-like enclosure.

4. Installation starts with the placement of the Mirror Junction Enclosure (AAA99103585), the module in which the PM3 carriage is contained, onto the 30-inch steel box beam that is mounted to the Switchyard frame and that supports the Withdrawal Enclosure modules. This enclosure is adjusted in $\mathrm{z}$ by manually pushing it along the box girder upon which it rests. It is adjusted in $\mathrm{x}$, and rotation about the y-axis, by using the jackscrews provided at each corner of the enclosure. These jackscrews push against either side of the box girder and can be used to fasten the enclosure laterally when the proper position is attained. There is no need to adjust the enclosure in the 
vertical direction. Do not put in place the side panels on the most negative x-side of the enclosure.

5. In the Mirror Junction Enclosure, bolt PSF PM-1-06-MS1 onto the most z-negative rail mount on the positive $\mathrm{x}$ - side, being careful to align its base to the rail mount. Note that PSF PM-1-06-MS1 and PM-1-06-MS2 are physically identical to each other and to PM-2-06-MS1, the different names being used to distinguish different locations. Do the same for PSF PM1-06-MS2 at the most z-positive rail mount on that same side. Position PSF PM1-06-MS1 so that its $\mathrm{x}$ and $\mathrm{z}$-coordinates are within $\pm 0.3 \mathrm{~mm}$ of their nominal location with respect to PSF PM-1-07-MS1, as given in the ACD. Using the jackscrews, rotate the enclosure about the vertical axis until the x-coordinate of PSF PM-1-06-MS2 is within $\pm 0.1 \mathrm{~mm}$ of the $\mathrm{x}$-coordinate of PSF PM-1-06-MS1. Ensure that PSF PM-1-06-MS1 is still accurate to within $\pm 0.3 \mathrm{~mm}$ with respect to PM-1-07MS1. Tighten the jackscrews so that the enclosure is firmly fixed laterally. Install the clamps that fix the enclosure to the box girder in the vertical direction, shimming where required, directly beneath the clamp, to prevent distortion of the enclosure if the box girder is warped at that location. Remove PSFs PM-1-06-MS1 and PM1-06-MS2.

6. Place a Standard Enclosure upon the box girder and butt it up to the Mirror Junction Enclosure. This is followed by four more Standard Enclosures, each pushed tightly against the previous enclosure.

7. The Glove Box Enclosure is now put in place on the box girder and butted tightly against the adjacent Standard Enclosure. The remaining Motor Enclosure is put in place, being careful to all of the enclosures as tightly as possible toward the negative $\mathrm{z}$ direction.

8. In the Motor Enclosure, bolt PSF PM-1-06-MS3 (which is physically identical to PSF PM-1-06-MS1) onto the most z-negative rail mount on the positive $\mathrm{x}$ - side, being careful to align its base to the rail mount. Do the same for PSF PM-1-06-MS4 (which is physically identical to PSF PM-1-06-MS1) at the most z-positive rail mount on that same side. Position PSF PM-1-05-MS5 MS3 so that its $\mathrm{x}$ and $\mathrm{z}$-coordinates are within $\pm 0.3 \mathrm{~mm}$ of their nominal location with respect to PSF PM-1-07-MS1, as given in the ACD. Using the jackscrews, rotate the enclosure about the vertical axis until the $\mathrm{x}-$ coordinate of PSF PM-1-06-MS4 is within $\pm 0.1 \mathrm{~mm}$ of the $\mathrm{x}$-coordinate of PSF PM-106-MS3. Ensure that PSF PM-1-06-MS3 is still accurate to within $\pm 0.3 \mathrm{~mm}$ with respect to PM-1-07-MS1 of the distance indicated on the ACD. Tighten the jackscrews so that the enclosure is firmly fixed laterally. Install the clamps that fix the enclosure to the box girder in the vertical direction, shimming where required, directly beneath the clamp, to prevent distortion of the enclosure if the box girder is warped at that location. Remove PSFs PM-1-06-MS3 and PM-1-06-MS4.

9. Place a string line on the center of the most $\mathrm{z}$-negative and $\mathrm{x}$-negative rail mounting hole in the Mirror Junction Enclosure and stretch it to the corresponding more $\mathrm{x}-$ positive mounting hole in the Motor Enclosure. Pull the string line taut and fix it in place. 


\section{Appendix C to Scope of Work for IMI Services}

10. Adjust the positions of all the enclosures between the Motor Enclosure and the Mirror Junction Enclosure so that their more x-positive mounting holes are centered on the string to within $\pm 1.0 \mathrm{~mm}$. Tighten all the jackscrews. Weld the enclosures into a single gas tight enclosure following the weld descriptions and notes provided. Clamp the completed enclosure to the box girder to control vertical motion, shimming where required, directly beneath the clamp, to prevent distortion of the enclosure if the box girder is warped at that location.

11. In order to leak check the enclosure, it is necessary to install all of the enclosure panels that are missing from the completed enclosure. These are delineated in the drawings. Install the temporary covers for the openings on the top and side of the Mirror Junction Enclosure. All of these side panels and covers are furnished with gaskets attached and with a set of the proper fasteners.

12. Pressure leak test the enclosure following the procedures outlined in 3.09. The PM3 Withdrawal Enclosure is the Zone 1 referred to in this section.

13. Subsequent to successfully leak checking the enclosure, remove the panels that were installed to facilitate leak checking and return them to the area from which they were obtained.

14. Remove the source of air from the vertical enclosure and re-install the blanking plate covering the port.

15. Passivate the completed enclosure, following the procedures given in Appendix B.

F. Install the PM10 Mirror Support Frame

1. The kinematic ball mounts upon which the PM10 mirror Line Replaceable Unit (LRU) rests are attached to a four-position indexing mechanism. This mechanism indexes and locks the PM10 to face toward the PM7, toward the PM3, or toward PL2, which is the position for retracting PM10 from the beam line between PM3 and PM7. The carriage is supplied with the indexing mechanism oriented so that if a mirror were mounted it would face in the PM7 direction. This indexing mechanism is mounted to the top of a wheeled carriage that rests upon a set of rails that run in the z-direction. The carriage has two grooved wheels riding on one rail and one non-grooved wheel riding on the other rail. The rails are mounted upon a support frame that is, in turn, fastened to the structural steel of the Switchyard. The rails are used for withdrawal of the PM10 mirror from the beam line when a system beam is directed to the $1 \omega$ Diagnostics Table and also when it is necessary to replace the PM10 mirror.

2. Place the support frame for the PM10 mirror, which has the LRU carriage attached to it, onto the switchyard frame support pads indicated in AAA99-115170. Be sure that the frame is oriented correctly. This is done by ensuring that the frame leg with an "C1" stamped upon it rests upon the pad indicated as "C1" in AAA99-115183. Remove the lashings holding the LRU carriage to the support frame. Mount the OMIF2 upon the kinematic balls of the LRU carriage and PSFs onto the OMIF2. 
When delivered to the switchyard, the indexing mechanism is locked at the middle position, which means that the OMIF2 PSF pattern is nominally orthogonal to the coordinate system defined by the beam line from the Chamber to the center of PM7 and from PM7 to PM3.

3. Connect the motor controller output cable to the mating connector and drive the carriage in the negative z-direction until the limit switch turns off power to the motor. This places the carriage against a hard stop that defines the position at which the Optics Mount Installation Fixture (OMIF2) will be aligned.

4. CAUTION: When the carriage is driven against the hard stop, there is approximately 300 pounds of tension in the drive belt. A temporary belt guard is supplied. This must be placed over the belt during the remainder of the installation and alignment process. It must be removed prior to the installation of the PM10 enclosure.

5. The PSF PM-1-10-MS1 is used to establish the location in $\mathrm{x}, \mathrm{y}$, and $\mathrm{z}$ of the OMIF2, and thus the support frame and LRU carriage combination, relative to PSF PM-1-07MS1. Locate PSF PM-1-10-MS1 to within $\pm 1.0 \mathrm{~mm}$ in $\mathrm{x}, \mathrm{y}$ and $\mathrm{z}$, of the distance from PSF PM-1-07-MS1 (mounted on the Chamber) shown in the ACD (AAA99-103607). The PSF PM-1-10-MS4 is used in conjunction with PSF PM-1-10-MS1 to control rotation about the $\mathrm{x}$ and $\mathrm{y}$-axes, and PSF PM-1-10-MS2 is used in conjunction with PM-1-10-MS1 to control rotation about the z-axis. The coordinates of both PSF PM-110-MS2 and PSF PM-1-10-MS4 are measured relative to those of PSF PM-1-10-MS1.

6. The support frame is adjusted in the vertical direction and in rotation about the two horizontal axes by use of the jackscrews provided at each of three corners on the inside of the frame (see AAA99-103901, item X). These jackscrews have a pitch of $3 \mathrm{~mm}$ and a center to center distance of approximately 1 meter. They are adjusted until the PSF PM-1-10-MS1 is at the nominal y-position, relative to PSF PM-1-07-MS1, that is specified in the ACD, within $\pm 1.0 \mathrm{~mm}$. Level the OMIF2 in the $\mathrm{x}$ and z-direction so that it is within \pm 1.0 mradian of the normal to the local gravity vector. Check the $y-$ position of PSF PM-1-10-MS1 and, if necessary, re-adjust the jackscrews and re-level the OMIF2.

7. Adjustment in the horizontal plane and in rotation about the vertical axis is accomplished by moving the frame, which is resting on the rounded ends of three of the jackscrews. Adjust the frame until PSF PM-1-10-MS1 is at the $\mathrm{x}$ and $\mathrm{z}-$ coordinates, relative to PSF PM-1-07-MS1, specified in the ACD, within $\pm 1.0 \mathrm{~mm}$, and PSF PM-1-10-MS4 is located at the measured x-coordinate of PSF PM-1-10-MS1, within $\pm 0.5 \mathrm{~mm}$.

8. Measure the distance between each of the corner flanges on the support stand and the lower stud plates upon which the jackscrews rest. Select a shim(s) from the shim pack available that will provide a vertical location of the OMIF2 that is within this tolerance. 


\section{Appendix C to Scope of Work for IMI Services}

9. Lower the fourth jackscrew to lightly make contact with the stud plate. Install the selected shim(s). Fix the support frame to the stud plates by tightening the mounting bolts against the jackscrews. Tightening torque is as recommended. Weld the stud plates to the switchyard mounting pads as shown in AAA99-103901.

G. Align the PM10 Mirror Mount

1. Prior to being delivered, the PM10 carriage was set up so that an OMIF2 placed on its kinematic pattern was parallel to the set-up carriage rails to within $15 \mu$ radians. This was accomplished by rotating the plate, to which the kinematic balls are mounted, about the axis of mirror rotation so that the line joining the centers of PM-1-10-MS1 and PM-1-10-MS4 is parallel to within $15 \mu$ radians to the rail upon which the grooved wheels ride.

2. Place rail spreaders at either end of the PM10 carriage. There should be one of these hooked over each end of the rail that is in the more negative x-direction. The adjustable end of the rail spreader should be engaged against the side of the other rail. Loosen the mounting for the more positive-X rail. Adjust the rail spreaders until PM-1-10-MS1 is within $\pm 0.3 \mathrm{~mm}$ of the $\mathrm{x}$-distance between it and PSF PM-1-07-MS1 that is specified in the ACD, and the $\mathrm{x}$-coordinate of PM-1-10-MS4 is within $\pm 0.1 \mathrm{~mm}$ of the $\mathrm{x}$-coordinate of PM-1-10-MS1.

3. Adjust the OMIF2 at PM10 in the y-direction (height) until PSF PM-1-10-MS1 is within $\pm 0.3 \mathrm{~mm}$ of the y-distance between it and PSF PM-1-07-MS1 that is specified in the ACD. Assure that the OMIF2 is level to within $30 \mu$ radians of the normal to the local gravity vector. These criteria are accomplished by placing shims, from the shim pack provided, between the rail supports and the rails. Do not use the screw adjustment of the kinematic balls for height or lateral adjustment! Check that the xdimensions of the two measured PSFs are still within tolerance and correct the alignment if they are not. Fasten the rails to the rail mounts and re-check all dimensions, correcting where required.

4. The z-position of the mount is set by adjustment of the hard stop, against which the carriage is driven by its belt drive. The distance in the z-direction from PSF PM-1-10MS1 to PSF PM-1-07-MS1 must be within $\pm 0.3 \mathrm{~mm}$ of that given in the ACD.

5. Measure the vertical distance between the hook of the LRU seismic restraint that is mounted on the underside of OMIF2 and the mounting plate for the latch portion of the restraint that is located on the upper face of the support stand. Subtract 'TBD' mm from this measured distance and machine a spacer that corresponds to AAA99-103901, with the 'TBD' dimension on this drawing defined as the result obtained when the subtraction was performed. Install the latch portion of the restraint onto the support stand with the spacer between the hook and the stand. Adjust the hook in the horizontal plane until it engages properly with the latch on the OMIF2.

6. The robotic-type electrical receptacle mounted on the LRU plate must be adjusted in the horizontal plane and in the vertical direction to mate properly with the connector on 
OMIF2. Loosen the screws that retain the receptacle in the horizontal position and place it under the connector. Loosen the screws that retain the receptacle in the vertical direction and bring the receptacle up to the connector until there is a $3 \mathrm{~mm}, \pm 0.5 \mathrm{~mm}$, gap between the mounting flanges of each, completely around their periphery. The body of the connector will center the receptacle properly as the receptacle is brought to within $3 \mathrm{~mm}$. Tighten all mounting screws to the torque specified. Remove the OMIF2.

\section{H. Install the PM8 Mirror Support Frame}

1. The kinematic ball mounts upon which the PM8 mirror Line Replaceable Unit (LRU) rests are attached to the top of a wheeled carriage that rests upon a set of rails. The carriage has two grooved wheels riding on one rail and one non-grooved wheel riding on the other rail. The rails are mounted upon a support frame that is, in turn, fastened to the structural steel of the Switchyard. The rails are used only for removal and replacement of the PM8 mirror, which is in an inaccessible location.

2. Place the support frame for the PM8 mirror, which has the LRU carriage attached to it, onto the switchyard frame support pads indicated in AAA99-115170. Be sure that the frame is oriented correctly. This is done by ensuring that the frame leg with an "E1" stamped upon it rests upon the pad indicated as "E1". Remove the lashings holding the LRU carriage to the support frame. Mount an OMIF upon the kinematic balls of the LRU carriage.

3. Connect the portable motor controller output cable to the mating connector (item $\mathrm{X}$ of AAA99-103901) and drive the carriage in the negative z-direction until the limit switch turns off power to the motor. This places the carriage against a hard stop that defines the position at which the Optics Mount Installation Fixture (OMIF1) will be aligned.

4. CAUTION: When the carriage is driven against the hard stop, there is approximately 300 pounds of tension in the drive belt. A temporary belt guard is supplied. This must be placed over the belt during the remainder of the installation and alignment process. It must be removed prior to the installation of the PM8 enclosure.

5. Locate the support frame and LRU carriage combination relative to PSF PL-2-00-MS1 (mounted on the Chamber) to within $\pm 1.0 \mathrm{~mm}$ in $\mathrm{x}, \mathrm{y}$ and $\mathrm{z}$, as shown in the ACD (AAA99-103607). This is accomplished by placing four PSFs (PM-1-08-MS1 - PM1-08-MS4) onto the OMIF1. The PSF PM-1-08-MS1 is used to establish the location in $x, y$, and $z$ of the OMIF1 relative to PSF PM-1-07-MS1. The PSF PM-1-08-MS4 is used in conjunction with PSF PM-1-08-MS1 to control rotation about the $\mathrm{x}$ and $\mathrm{y}$-axes, and PSF PM-1-08-MS2 is used in conjunction with PSF PM-1-08-MS1 to control rotation about the z-axis. The coordinates of both PSF PM-1-08-MS2 and PSF PM-108-MS4 are measured relative to that of PSF PM-1-08-MS1.

6. The support frame is adjusted in the vertical direction and in rotation about the two horizontal axes by use of the jackscrews provided at each of three corners on the inside 


\section{Appendix C to Scope of Work for IMI Services}

of the frame (see AAA99-103901, item X). These jackscrews have a pitch of $3 \mathrm{~mm}$ and a center to center distance of approximately 1 meter. They are adjusted until the PSF PM-1-08-MS1 is at the nominal y-position, relative to PSF PM-1-07-MS1, that is specified in the ACD, within $\pm 1.0 \mathrm{~mm}$. Level the OMIF1 in the $\mathrm{x}$ and $\mathrm{z}$-direction so that it is within \pm 1.0 mradian of the normal to the local gravity vector. Check the $y$ position of PSF PM-1-08-MS1 and, if necessary, re-adjust the jackscrews and re-level the OMIF1.

7. Adjustment in the horizontal plane and in rotation about the vertical axis is accomplished by moving the frame, which is resting on the rounded ends of three of the jackscrews. Adjust the frame until PSF PM-1-08-MS1 is at the $\mathrm{x}$ and $\mathrm{z}-$ coordinates, relative to PSF PM-1-07-MS1, specified in the ACD, within $\pm 1.0 \mathrm{~mm}$, and PSF PM-1-08-MS4 is located at the measured $\mathrm{x}$-coordinate of PSF PM-1-08-MS1, within $\pm 0.5 \mathrm{~mm}$.

8. Measure the distance between each of the corner flanges on the support stand and the lower stud plates upon which the jackscrews rest. Select a shim(s) from the shim pack available that will provide a vertical location of the OMIF1 that is within this tolerance.

9. Lower the fourth jackscrew to lightly make contact with the stud plate. Install the selected shim(s). Fix the support frame to the stud plates by tightening the mounting bolts against the jackscrews. Tightening torque is as recommended. Weld the stud plates to the switchyard mounting pads as shown in AAA99-103901.

I. Align the PM8 Mirror Mount

1. After attaching the support frame to the space frame, level OMIF1 in the $x$ and zdirection to a deviation of less than $30 \mu$ radians from the normal to the local gravity vector. This is accomplished by loosening the jam nuts on the balls on the kinematic plate that mate to the kinematic sockets on the OMIF, and threading the balls into or out of their mating threads.

2. Adjust OMIF1 in the y-direction (height), using the same method, until PSF PM-1-08MS1 is within $\pm 0.3 \mathrm{~mm}$ of the measured y-coordinate of PM-1-07-MS1. Assure that OMIF1 is level to $30 \mu$ radians.

3. The proper x-coordinate of PSF PM-1-08-MS1 is established by adjusting that kinematic ball, mounted upon the top plate of the support frame, which mates with the cone receptacle. The orientation of the kinematic sockets, which consist of a cone, a vgroove and a flat, is such that the v-groove is parallel to the NIF x-axis. The OMIF1 is adjusted in the $\mathrm{x}$-direction by loosening the attachment of the cone kinematic ball and then sliding the ball and OMIF1 in the $\mathrm{x}$-direction until the PM-1-08-MS1 is at the absolute $\mathrm{x}$-coordinate specified in the ACD, to within $\pm 0.3 \mathrm{~mm}$.

4. At this point, it may be necessary to adjust OMIF1 in rotation about the y-axis. If such is the case, loosen the kinematic ball that mates with the v-groove. Adjust the OMIF1 in rotation about the y-axis until the $\mathrm{x}$-coordinate of PM-1-08-MS2 is within $0.1 \mathrm{~mm}$ of 
the measured x-coordinate of PM-1-08-MS1. Re-check the y-coordinate of the PM-108-MS1 PSF and the level of OMIF1 and, if not correct, all other measurements must be re-checked and OMIF1 re-leveled.

5. Set the position of PM-1-08-MS1 in the z-direction, relative to PM-1-07-MS1, to the nominal coordinate determined from the ACD, to a tolerance of $\pm 0.3 \mathrm{~mm}$. This is accomplished by changing the position of the hard stop that positions the carriage at the correct position. See AAA99-103901 for the location of this adjustment.

6. Measure the vertical distance between the hook of the LRU seismic restraint that is mounted on the underside of OMIF1 and the mounting plate for the latch portion of the restraint that is located on the upper face of the support stand. Subtract TBD mm from this measured distance and machine a spacer. Install the latch portion of the restraint onto the support stand with the spacer between the hook and the stand. Adjust the hook in the horizontal plane until it engages properly with the latch on the OMIF1.

7. The robotic-type electrical receptacle mounted on the LRU plate must be adjusted in the horizontal plane and vertical direction to mate properly with the connector on OMIF1. Loosen the screws that retain the receptacle in the horizontal position and place it under the connector. Loosen the screws that retain the receptacle in the vertical direction and bring the receptacle up to the connector until there is a $3 \mathrm{~mm}, \pm 0.5 \mathrm{~mm}$, gap between the mounting flanges of each, completely around their periphery. The body of the connector will center the receptacle properly as the receptacle is brought to within $3 \mathrm{~mm}$. Tighten all mounting screws to the torque specified.

J. Installation and Alignment of the PM9/PL1 Mirror and Lens Support Frame and Mount

1. Place the support frame for the PM9/PL1 mirror/lens onto the switchyard frame support pads indicated in AAA99-115170. Be sure that the frame is oriented correctly. This is done by ensuring that the frame leg with an "F2" stamped upon it rests upon the pad indicated as "F2". This is a very large frame supporting two optics mounts. Proper installation requires coordination with the alignment of two OMIFs. Mount an OMIF2 onto kinematic balls of the PM9 kinematic plate. Mount a PSF PL-1-01-MS1 and a PSF PL-1-01-MS2 at the locations shown.

2. Locate the support frame relative to PSF PL-2-00-MS1 (mounted on the Chamber) to within $\pm 1.0 \mathrm{~mm}$ in $\mathrm{x}, \mathrm{y}$ and $\mathrm{z}$, as shown in the ACD (AAA99-103607). This is accomplished by placing four PSFs (PM-1-09-MS1 - PM-1-09-MS4) onto the OMIF2 located on the PM9 kinematic balls. The PSF PM-1-09-MS1 is used to establish the location in $\mathrm{x}, \mathrm{y}$, and $\mathrm{z}$ of the PM9 OMIF2 relative to PSF PM-1-07-MS1. The PSF PL1-01-MS1 is used in conjunction with PSF PM-1-09-MS1 to control rotation about the $\mathrm{x}$ and $\mathrm{y}$-axis. The PSF PL-1-01-MS2 is used in conjunction with PM-1-09-MS1 to control rotation about the $\mathrm{z}$-axis.

3. Adjustment in the horizontal plane and in rotation about the vertical axis is accomplished by moving the frame, which is resting on the rounded ends of three of the eight jackscrews. Adjust the frame until PSF PM-1-09-MS1 is at the $\mathrm{x}$ and $\mathrm{z}-$ 


\section{Appendix C to Scope of Work for IMI Services}

coordinates, relative to PSF PM-1-07-MS1, specified in the ACD, within $\pm 1.0 \mathrm{~mm}$, and PSF PL-1-01-MS1 is at the $\mathrm{x}$ and z-coordinates, relative to PSF PM-1-07-MS1, specified in the ACD, within $\pm 1.0 \mathrm{~mm}$.3. The support frame is adjusted in the vertical direction and in rotation about the two horizontal axes by use of three of the eight jackscrews provided on the frame. The ones to use are indicated. These jackscrews have a pitch of $3 \mathrm{~mm}$ and a center to center distance of approximately 1 meter. They are adjusted until PSFs PM-1-09-MS1, PL-1-01-MS1 and PSF PL-1-01-MS2 are all at the measured y-position relative to PSF PM-1-07-MS1, specified in the ACD, within $\pm 1.0 \mathrm{~mm} .3$. Level the OMIF2 in the $\mathrm{x}$ and $\mathrm{z}$-direction so that it is within \pm 1.0 mradian of the normal to the local gravity vector. Check the y-position of PSF PM-1-09-MS1 and, if necessary, re-adjust the jackscrews and re-level the support frame.

4. Lower the remaining five jackscrews to lightly make contact with the stud plates. Install the selected shim(s). Fix the support frame to the stud plates by tightening the mounting bolts against the jackscrews. Tightening torque is as recommended. Weld the stud plates to the switchyard mounting pads as shown. Measure the distance between each of the flanges on the support stand and the lower stud plates upon which the jackscrews rest. Select a shim(s) from the shim pack available that will provide a vertical location of OMIF2 and the other two monuments that is within this tolerance.

5. Measure the vertical distance between the hook of the LRU seismic restraint that is mounted on the undersides of the OMIF2 and the mounting plates for the latch portions of the restraints that is located on the upper face of the support stand. Subtract 'TBD' $\mathrm{mm}$ from this measured distance and machine spacers. Install the latch portion of the restraints onto the support stands with the spacer between the hook and the stand. Adjust the hooks in the horizontal plane until it engages properly with the latch on the OMIF2.

6. The robotic-type electrical receptacle mounted on the LRU plate must be adjusted in the horizontal plane and vertical direction to mate properly with the connector on the OMIF2. Loosen the screws that retain the receptacle in the horizontal position and place it under the connector. Loosen the screws that retain the receptacle in the vertical direction and bring the receptacle up to the connector until there is a $3 \mathrm{~mm}, \pm 0.5 \mathrm{~mm}$, gap between the mounting flanges of each, completely around their periphery. The body of the connector will center the receptacle properly as the receptacle is brought to within $3 \mathrm{~mm}$. Tighten all mounting screws to the torque specified.

\section{K. Remove and Precision Clean all Optics Carriages}

1. Connect the portable motor controller to the receptacle on the PM10 support frame. Move the carriage to the most positive-z location. Remove the seismic restraints. Disconnect the portable motor controller from the PM10 support frame. Remove the carriage and precision clean it to level 50, the cleanliness being validated according to the procedures of MEL98-012 and MEL98-015, latest revision. It shall be packaged according to MEL99-014, latest revision and stored at a University-designated location. 
2. Connect the portable motor controller to the receptacle on the PM7 support frame. Move the carriage to the most positive-z location. Remove the seismic restraints. Disconnect the portable motor controller from the PM10 support frame. Remove the carriage and precision clean it to level 50 , the cleanliness being validated according to the procedures of MEL98-012 and MEL98-015, latest revision. It shall be packaged according to MEL99-014, latest revision and stored at a University-designated location.

3. Remove the PL3 Alignment Fixture from the PL3 mount and place it into the designated GFE container at the designated location.

4. Connect the portable motor controller to the receptacle on the PM8 support frame. Move the carriage to the most positive-z location. Remove the PSFs and the OMIF1 and deposit them into the designated GFE containers at the designated locations. Remove the seismic restraints. Disconnect the portable motor controller from the PM10 support frame. Remove the carriage and precision clean it to level 50, the cleanliness being validated according to the procedures of MEL98-012 and MEL98015, latest revision. It shall be packaged according to MEL99-014, latest revision and stored at a University-designated location.

5. Remove the PSFs and the OMIF2 from the PM9 location and deposit them into the designated GFE containers at the designated locations.

6. Remove the PSFs and the OMIF2 from the PL1 location and deposit them into the designated GFE containers at the designated locations.

L. Install a Crosshair and Bellows on the Top of the PM3 Enclosure

1. When delivered, the crosshair assembly will be precision cleaned internally and externally and packaged according to MEL99-014, latest revision. The bellows will be precision cleaned both internally and externally and packaged according to the same procedures. Internal cleanliness is maintained by blanking plates on both the top and bottom of these items. These plates are removed during installation. Note that the lower blanking plate of the crosshair has a gasket on the external surface.

2. The crosshair assembly must be installed in a clean area as described in MEL98-014, latest revision. Prior to installing the crosshair onto the upper surface of the trombone, the surface upon which the crosshair rests must be cleaned following the procedures given in MEL99-010, latest revision, and the cleanliness validated according to the procedures of MEL98-012 and MEL98-015, latest revision. Also, the area internal to the trombone, immediately below the fastener pattern, must be cleaned and validated according to the same procedures.

3. Remove the lower blanking plate, with attached gasket, from the crosshair and reserve it in a clean location close to hand. Note that there is also a gasket attached to the lower surface of the crosshair. Place the crosshair onto the trombone, aligning it with the fastener pattern on the top surface of the trombone. Place the previously removed blanking plate inside the trombone, with the gasket surface up. Align it with the 


\section{Appendix C to Scope of Work for IMI Services}

fastener pattern, and install the fasteners indicated so that the trombone upper surface is sandwiched between the blanking plate and the crosshair, with gaskets on each side.

4. Within the clean area, remove the top blanking plate from the crosshair and one of the blanking plates, with gasket attached, from the bellows. Note that there is a gasket on the surface of the bellows and none on the upper surface of the crosshair. Mount the open end of the bellows onto the top of the crosshair and fasten it with the hardware indicated. Leave the upper blanking plate in place on the bellows.

\section{Install the Vertical Beam Enclosure and Upper Bellows}

1. The vertical beam enclosure connects the crosshair on top of the trombone to the roving mirror enclosure located on the next level up of the switchyard. The enclosure is composed of a duct-like assembly with an appendage housing a motorized shutter located at a right angle to its vertical axis. The enclosure is installed so that this appendage is located over the trombone. There are bellows located at the top and bottom of the enclosure to accommodate axial and longitudinal misalignment.

2. The beam enclosure is attached to a column of the switchyard steel by means of two horizontal arms that are pre-mounted to the enclosure assembly. To accomplish the installation, a set of four mounting holes must be correctly located, drilled and tapped into this column. It should be appreciated that the $200 \mathrm{~kg}$ weight of the enclosure is cantilevered from these arms and that the enclosure is installed in a location in which it is difficult to work. Neither the upper or lower bellows connecting the enclosure to the crosshair and roving mirror enclosure can support the weight of the enclosure. It is anticipated that a vertically adjustable clamping arrangement will be required to support the enclosure against the switchyard column while the mounting holes are being located.

3. When delivered, the vertical beam enclosure will have been precision cleaned internally and packaged according to MEL99-014, latest revision. It will be under 50 $\mathrm{mm}$ ( 2 inches) of $\mathrm{H}_{2} \mathrm{O}$ internal pressure. The internal cleanliness is maintained by blanking plates on both the top and bottom of the enclosure. These will be removed during installation. The upper bellows will be cleaned internally and externally and packaged according to MEL99-014, latest revision.

4. The enclosure must be installed in a clean area as described in MEL98-014, latest revision. Temporarily mount the vertical enclosure to a column in the orientation shown, taking care that it is suspended between $1 / 2$ and 1 inch above the lower bellows that was previously installed on top of the crosshair. Remove the cover on the 4-inch port indicated, located midway on the more positive z-side of the enclosure, remembering that the enclosure is under pressure. Quickly (within 5 seconds) fasten a source of clean, HEPA-filtered to class 10, dry air, regulated to a pressure no greater than $114.3 \mathrm{~mm}$ (4.5 inches) of $\mathrm{H}_{2} \mathrm{O}$, to the port.

5. Remove the lower blanking panel from the vertical enclosure. Remove the upper blanking panel from the bellows on the crosshair. Lower the enclosure until contact is 
just made with the bellows. Use the supplied fasteners indicated to attach the vertical enclosure and bellows. Measure the distance between the top flange (not including the blanking panel) of the enclosure and the sealing face located on the bottom of the roving mirror enclosure. Lower the enclosure until this distance is no greater than indicated.

6. The roving mirror enclosure, to which the vertical enclosure attaches, was precision cleaned earlier in the contract. It is under approximately $50 \mathrm{~mm}$ (2 inches) of $\mathrm{H}_{2} \mathrm{O}$ pressure. Remove the blanking plate from the flange that protrudes downward from the roving mirror enclosure. Remove the blanking panel from the top of the vertical enclosure. Note that the sealing gaskets for both of these are located on the blanking plates, not the flanges.

7. Remove both blanking plates from the bellows and insert the bellows into the gap between the roving mirror enclosure and the vertical beam enclosure. Be careful not to dislodge the gaskets on the upper and lower flanges of the bellows. It will probably be necessary to lower the vertical beam enclosure in order to accomplish this. Using the fasteners indicated and furnished with the bellows, fasten the upper bellows to both the roving mirror enclosure and the vertical beam tube.

8. Adjust the vertical beam tube until the upper and lower bellows have the same degree of compression (expansion). Transfer punch, drill, and tap the four mounting holes into a column and mount the vertical beam enclosure to this column. Remove the clean air supply and replace the cover plate over the port.

\section{N. Install a Crosshair and Bellows on the Side of the PM3 Enclosure}

1. When delivered, the crosshair assembly and the bellows will be precision cleaned internally and packaged according to MEL99-014, latest revision. Internal cleanliness is maintained by blanking plates on sides of these items. These plates are removed during installation. Note that one of the blanking plates of the crosshair has a gasket on the external surface.

2. The crosshair assembly must be installed in a clean area as described in MEL98-014, latest revision. Prior to installing the crosshair onto the vertical surface of the trombone, the surface upon which the crosshair rests must be cleaned following the procedures given in MEL99-010, latest revision, and the cleanliness validated according to the procedures of MEL98-012 and MEL98-015, latest revision. Also, the area internal to the trombone, immediately on the other side of the fastener pattern, must be cleaned and validated according to the same procedures.

3. Remove the blanking plate with the gasket attached to the outer surface from the crosshair and reserve it in a clean location close to hand. Note that there is also a gasket attached to the flange of the crosshair. Place the crosshair onto the trombone, aligning it with the fastener pattern on the side of the trombone. Place the previously removed blanking plate inside the trombone, with the gasket surface toward the crosshair. Align it with the fastener pattern, and install the fasteners indicated, so that 


\section{Appendix C to Scope of Work for IMI Services}

the trombone vertical surface is sandwiched between the blanking plate and the crosshair, with gaskets on each side.

4. Within the clean area, remove the remaining blanking plate from the crosshair and one of the blanking plates from the bellows. Note that there is a gasket on the surface of the bellows and none on the upper surface of the crosshair. Mount the open end of the bellows onto the crosshair and fasten it with the hardware indicated. Leave the remaining blanking plate in place on the bellows.

O. Install the PM10 Housing

1. The interior of the PM10 mirror enclosure will be precision cleaned off site and packaged in accordance with MEL99-014, latest revision. It will be furnished to the subcontractor in this condition. The enclosure must be installed in a clean area as described in MEL98-014, latest revision.

2. The top surface of the support frame must be precision cleaned by wiping, as described in MEL99-010, latest revision, prior to the installation of the enclosure that rests on top of the support frame. The surfaces that are to be cleaned are indicated. The clean environment must be at least class 100 . The surfaces shall be cleaned to level 50, as determined by MEL98-012 and MEL98-015, latest revisions.

3. A gasket to seal between the surface of the support frame and the PM10 mirror enclosure will be installed on the horizontal top surface of the support frame. This gasket is installed following the NIF procedures, using the materials indicated in this document. The gasket material and the double-backed tape that attaches it to the support frame will be provided in bulk quantity to the subcontractor. They will be installed at the location indicated to the tolerances indicated. The nature of the required splice is indicated.

4. Before installing the PM10 mirror enclosure, the PM10 carriage must be placed back upon its rails and tested for electrical functionality. The carriage will be delivered precision cleaned and packaged according to MEL99-014, latest revision. After placing the carriage onto its rails, a 4 hour Hold Point is instituted to provide LLNL personnel access to test and adjust, if necessary, the electrical interlocks.

5. Place the PM10 enclosure upon the support frame, taking great care to bring the enclosure directly downward, with no lateral motion, so as not to cause separation of the gasket and the double-backed tape. The reason for this concern is that the tape does not reach full cure strength for 48 hours, and it is desired not to impose a Hold Point to allow for increased curing time.

P. Install the PM3 to PM10 Beam Enclosure and Bellows

1. This beam enclosure extends between the bellows on the side of the trombone and the bellows on the more $\mathrm{x}$-negative side of the PM10 enclosure. When delivered, the beam enclosure is precision cleaned internally and packaged according to MEL99-014, latest revision. Internal cleanliness of the enclosure is maintained by blanking plates 
mounted on each end. These plates are removed during installation. The beam enclosure must be installed within a clean area, as described in MEL98-014, latest revision, located at each end of the enclosure.

2. Increase the internal pressure of the PM10 enclosure to $50 \mathrm{~mm}$ ( 2 inches) of $\mathrm{H}_{2} \mathrm{O}$ above ambient. Temporarily support the beam enclosure at the height of the bellows located on the more negative x-side of PM10. Remove the blanking plate from the bellows of the PM10 enclosure, while maintaining flow through the enclosure. Remove the blanking plate from the end of the beam enclosure closer to the PM10 enclosure and connect the beam enclosure to the PM10 enclosure using the fasteners provided and indicated.

3. Adjust the supports for the beam enclosure so that it is aligned with the crosshair on the trombone and the bellows on PM10. Within the clean area, remove the remaining blanking plate from the crosshair and both of the blanking plates from the bellows, and the remaining blanking plate from the beam enclosure. Note that there is a gasket on the surface of the bellows and none on the surface of the crosshair. Mount the bellows between the crosshair and the beam tube. It may be necessary to compress the bellows mounted on the PM10 enclosure in order to accomplish this. Fasten the bellows to both the crosshair and beam enclosure with the hardware indicated.

4. While in a clean area, remove the source of clean air from the PM10 enclosure and reinstall the blanking plate covering the port.

\section{Q. Install the PM7 Mirror Enclosure and Bellows}

1. The PM7 mirror enclosure will be delivered with one bellows already attached to the enclosure at the point where the attachment of beam enclosures is to take place. This is located on the side that faces in the positive $x$-direction. There are two additional openings in the enclosure. One is on the side facing in the positive $x$-direction and the other on the side facing in the positive z-direction. Both are closed with blanking plates.

2. The interior of the PM7 mirror enclosure and bellows are precision cleaned off site and packaged in accordance with MEL99-014, latest revision. The assembly will be furnished to the subcontractor in this condition. The enclosure must be installed in a clean area as described in MEL98-014, latest revision.

3. The top surface of the support frame must be precision cleaned by wiping, as described in MEL99-010, latest revision, prior to the installation of the enclosure that rests on top of the support frame. The surfaces that are to be cleaned are indicated. The clean environment must be at least class 100 . The surfaces shall be cleaned to level 50, as determined by MEL98-012 and MEL98-015, latest revisions.

4. A gasket to seal between the surface of the support frame and the PM7 mirror enclosure will be installed on the horizontal top surface of the support frame. This gasket is installed following the NIF procedures, using the materials indicated in this document. The gasket material and the double-backed tape that attaches it to the 


\section{Appendix C to Scope of Work for IMI Services}

support frame will be provided in bulk quantity to the subcontractor. They will be installed at the location indicated to the tolerances indicated there. The nature of the required splice is indicated.

5. Before installing the PM7 mirror enclosure, the PM7 carriage must be placed back upon its rails and tested for electrical functionality. The carriage will be delivered precision cleaned and packaged according to MEL99-014, latest revision. After placing the carriage onto its rails, a 4 hour Hold Point is instituted to provide LLNL personnel access to test and adjust, if necessary, the electrical interlocks.

6. Prior to removing the protective packaging from the bottom of the enclosure, remove the blanking plate from the $\mathrm{z}$-facing side and install a source of clean, HEPA-filtered to class 10 , dry air, regulated to a pressure no greater than $10 \mathrm{~mm}(0.4$ inches $)$ of $\mathrm{H}_{2} \mathrm{O}$ above ambient. Remove the packaging and place the PM7 enclosure upon the support frame, taking great care to bring the enclosure directly downward, with no lateral motion, so as not to cause separation of the gasket and the double-backed tape. Install the fasteners indicated at the locations shown. Leave the clean air source in place.

\section{R. Install the PM10 to PM7 Beam Enclosure and Bellows}

1. This beam enclosure extends between the bellows on the more positive $x$-side of the PM10 enclosure and the bellows on the more $\mathrm{x}$-negative side of the PM7 enclosure. When delivered, the beam enclosure is precision cleaned internally and packaged according to MEL99-014, latest revision. Internal cleanliness of the enclosure is maintained by blanking plates mounted on each end. These plates are removed during installation. The beam enclosure must be installed within a clean area, as described in MEL98-014, latest revision, located at each end of the enclosure.

2. Increase the internal pressure of the $\mathrm{PM} 7$ enclosure to $50 \mathrm{~mm}$ ( 2 inches) of $\mathrm{H}_{2} \mathrm{O}$ above ambient. Temporarily support the beam enclosure at the height of the bellows located on the more negative X-side of PM7. Remove the blanking plate from the bellows of the PM10 enclosure, while maintaining flow through the enclosure. Remove the blanking plate from the end of the beam enclosure closer to the PM7 enclosure and connect the beam enclosure to the PM7 enclosure using the fasteners provided and indicated.

3. Adjust the supports for the beam enclosure so that it is aligned with the crosshair on the trombone and the bellows on PM7. Within the clean area, remove both of the blanking plates from the bellows, and the remaining blanking plate from the beam enclosure. Note that there is a gasket on the surface of the bellows and none on the surface of the crosshair. Mount the bellows between the crosshair and the beam tube. It may be necessary to compress the bellows mounted on the PM7 enclosure in order to accomplish this. Fasten the bellows to both the crosshair and beam enclosure with the hardware indicated.

4. Pressure test the beam path from the trombone through the PM7 enclosure for leakage as described in 3.09 . 
5. While in a clean area, remove the source of clean air from the PM7 enclosure and reinstall the blanking plate covering the port.

S. Install the PL1 Crosshair

1. When delivered, the crosshair assembly will be precision cleaned internally and packaged according to MEL99-014, latest revision. Internal cleanliness is maintained by blanking plates on both sides of these items. These plates are removed during installation.

2. The crosshair assembly must be installed in a clean area as described in MEL98-014, latest revision. Prior to installing the crosshair onto the support provided on the PM9/PL1 frame, the surface upon which the crosshair rests must be cleaned following the procedures given in MEL99-010, latest revision. The surfaces that are to be cleaned are indicated. The clean environment must be at least class 100 . The surfaces shall be cleaned to level 50, as determined by MEL98-012 and MEL98-015, latest revisions.

3. Remove from the crosshair the blanking plates. Place the crosshair onto the mount provided, as shown, aligning it with the fastener pattern and install the fasteners indicated.

T. Install the PM9/PL1 Mirror/Lens Enclosure and Bellows

1. The PM9/PL1 mirror enclosure will be delivered with two bellows already attached to the enclosure at the points where the attachment of beam enclosures is to take place. These are located on the two sides that face in the negative $\mathrm{x}$-direction. There is a third opening in the enclosure on the side facing in the positive $\mathrm{x}$-direction that is closed with a blanking plate.

2. The interior of the PM9/PL1 mirror enclosure and bellows assembly is precision cleaned off- site and packaged in accordance with MEL99-014, latest revision. The assembly will be furnished to the subcontractor in this condition. The enclosure must be installed in a clean area as described in MEL98-014, latest revision.

3. The top surface of the support frame must be precision cleaned by wiping, as described in MEL99-010, latest revision, prior to the installation of the enclosure that rests on top of the support frame. The surfaces that are to be cleaned are indicated. The clean environment must be at least class 100 . The surfaces shall be cleaned to level 50 , as determined by MEL98-012 and MEL98-015, latest revisions.

4. A gasket to seal between the surface of the support frame and the PM9/PL1 mirror enclosure will be installed on the horizontal top surface of the support frame. This gasket is installed following the NIF procedures, using the materials indicated in this document. The gasket material and the double-backed tape that attaches it to the support frame will be provided in bulk quantity to the subcontractor. They will be installed at the location indicated to the tolerances indicated there. The nature of the required splice is indicated. 


\section{Appendix C to Scope of Work for IMI Services}

5. Prior to removing the protective packaging from the bottom of the enclosure, remove the blanking plate from the rightmost of the openings on the $\mathrm{x}$-facing side. Install on that opening a source of clean, HEPA-filtered to class 10, dry air, regulated to a pressure no greater than $10 \mathrm{~mm}(0.4$ inches $)$ of $\mathrm{H}_{2} \mathrm{O}$ above ambient. Remove the packaging and place the PM9/PL1 enclosure upon the support frame, taking great care to bring the enclosure directly downward, with no lateral motion, so as not to cause separation of the gasket and the double-backed tape. The reason for this concern is that the tape does not reach full cure strength for 48 hours, and it is desired not to impose a Hold Point to allow for increased curing time. Install the fasteners indicated at the locations shown. Leave the clean air source in place.

\section{U. Install the PM7 to PM9/PL1 Beam Enclosure and Bellows}

1. This beam enclosure extends between the bellows on the more positive $\mathrm{x}$-side of the PM7 enclosure and the bellows on the more x-negative side of the PM9/PL1 enclosure. When delivered, the beam enclosure is precision cleaned internally and packaged according to MEL99-014, latest revision. Internal cleanliness of the enclosure is maintained by blanking plates mounted on each end. These plates are removed during installation. The beam enclosure must be installed within a clean area, as described in MEL98-014, latest revision, located at each end of the enclosure.

2. Increase the internal pressure of the $\mathrm{PM} 7$ enclosure to $50 \mathrm{~mm}$ ( 2 inches) of $\mathrm{H}_{2} \mathrm{O}$ above ambient. Temporarily support the beam enclosure at the height of the bellows located on the more negative $\mathrm{x}$-side of PM7. Remove the blanking plate from the bellows of the PM10 enclosure, while maintaining flow through the enclosure. Remove the blanking plate from the end of the beam enclosure closer to the PM7 enclosure and connect the beam enclosure to the PM7 enclosure using the fasteners provided and indicated.

3. Adjust the supports for the beam enclosure so that it is aligned with the crosshair on the trombone and the bellows on PM7. Within the clean area, remove both of the blanking plates from the bellows, and the remaining blanking plate from the beam enclosure. Note that there is a gasket on the surface of the bellows and none on the surface of the crosshair. Mount the bellows between the crosshair and the beam tube. It may be necessary to compress the bellows mounted on the PM7 enclosure in order to accomplish this. Fasten the bellows to both the crosshair and beam enclosure with the hardware indicated. Leave the source of clean air attached to the PM7 mirror enclosure.

\section{Install the PM8 Housing and Bellows}

1. The PM8 mirror enclosure will be delivered with one bellows already attached to the enclosure at the point where the attachment of beam enclosures is to take place. This is located on the side that faces in the positive x-direction. There are two additional openings in the enclosure. One is on the side facing in the positive $\mathrm{x}$-direction and the other on the side facing in the positive $\mathrm{z}$-direction. Both are closed with blanking plates. 
2. The interior of the PM8 mirror enclosure and bellows are precision cleaned off site and packaged in accordance with MEL99-014, latest revision. The assembly will be furnished to the subcontractor in this condition. The enclosure must be installed in a clean area as described in MEL98-014, latest revision.

3. The top surface of the support frame must be precision cleaned by wiping, as described in MEL99-010, latest revision, prior to the installation of the enclosure that rests on top of the support frame. The surfaces that are to be cleaned are indicated. The clean environment must be at least class 100 . The surfaces shall be cleaned to level 50, as determined by MEL98-012 and MEL98-015, latest revisions.

4. A gasket to seal between the surface of the support frame and the PM8 mirror enclosure will be installed on the horizontal top surface of the support frame. This gasket is installed following the NIF procedures, using the materials indicated in this document. The gasket material and the double-backed tape that attaches it to the support frame will be provided in bulk quantity to the subcontractor. They will be installed at the location indicated to the tolerances indicated there. The nature of the required splice is indicated.

5. Before installing the PM8 mirror enclosure, the PM8 carriage must be placed back upon its rails and tested for electrical functionality. The carriage will be delivered precision cleaned and packaged according to MEL99-014, latest revision. After placing the carriage onto its rails, a 4 hour Hold Point is instituted to provide LLNL personnel access to test and adjust, if necessary, the electrical interlocks.

6. Prior to removing the protective packaging from the bottom of the enclosure, remove the blanking plate from the z-facing side and install a source of clean, HEPA-filtered to class 10 , dry air, regulated to a pressure no greater than $10 \mathrm{~mm}(0.4$ inches $)$ of $\mathrm{H}_{2} \mathrm{O}$ above ambient. Remove the packaging and place the PM8 enclosure upon the support frame, taking great care to bring the enclosure directly downward, with no lateral motion, so as not to cause separation of the gasket and the double-backed tape. Install the fasteners indicated at the locations shown. Leave the clean air source in place.

W. Install the PM8 to PM9/PL1 Beam Enclosure and Bellows

1. This beam enclosure extends between the bellows on the PM8 enclosure and the two sets of bellows on the more X-positive side of the PM9/PL1 enclosure. When delivered, the beam enclosure is precision cleaned internally and packaged according to MEL99-014, latest revision. Internal cleanliness of the enclosure is maintained by blanking plates mounted on each end. These plates are removed during installation. The beam enclosure must be installed within a clean area, as described in MEL98-014, latest revision, located at each end of the enclosure.

2. Increase the internal pressure of the $\mathrm{PM} 8$ enclosure to $50 \mathrm{~mm}$ ( 2 inches) of $\mathrm{H}_{2} \mathrm{O}$ above ambient. Temporarily support the beam enclosure at the height of the bellows located on the side of PM8. Remove the blanking plate from the bellows of the PM9/PL1 enclosure, while maintaining flow through the enclosure. Remove the blanking plate 
from the end of the beam enclosure closer to the PM8 enclosure and connect the beam enclosure to the PM8 enclosure using the fasteners provided and indicated.

3. Adjust the supports for the beam enclosure so that it is aligned with the crosshair on the trombone and the bellows on PM8. Within the clean area, remove both of the blanking plates from the bellows, and the remaining blanking plate from the beam enclosure. Note that there is a gasket on the surface of the bellows and none on the surface of the crosshair. Mount the bellows between the crosshair and the beam tube. It may be necessary to compress the bellows mounted on the PM8 enclosure in order to accomplish this. Fasten the bellows to both the crosshair and beam enclosure with the hardware indicated.

4. Pressure test the PM9/PL1, bellows, PM8, and beam enclosures for leakage as described in 3.09 .

5. While in a clean area, remove the source of clean air from the PM7 enclosure and reinstall the blanking plate covering the port.

\subsection{MATERIAL HANDLING AND RIGGING}

A. The subcontractor shall perform rigging and handling operations in accordance with Section 15896, including the preparation and submittal of a rigging and handling procedure.

\subsection{WELDING REQUIREMENTS}

Welding and weld inspection shall be performed in accordance with the Section 05120, this section and the respective drawings.

1. Welding Processes

Welds on the external surface shall be of the Gas Tungsten Arc Welding (GTAW) or Gas Metal Arc Welding (GMAW) processes. All weld joints on the internal surfaces shall be performed with the GTAW process.

2. Joint Preparation

Before welding, joints shall be cleaned of all foreign materials such as oil, grease, paint, dust, and oxides or sulfides resulting from chemical reaction of the surface. Cleaning shall remove all visible evidence of contamination, including all stains and discoloration of the surfaces.

3. Weld Procedures

A Weld Procedure Specification (WPS) including Essential, Supplementary Essential, and Nonessential variables of ASME Code, Section 9 and a Procedure Qualification Record (PQR), signed by a weld inspector, are required in accordance with AWS D1.6 (AWS pre- 
qualified procedure mechanism shall not be used). As an alternative, the parallel requirements of ASME Boiler and Pressure Vessel Code (B\&PVC) Section IX may be utilized. The WPS and PQR or ASME equivalent shall be submitted to the University for acceptance.

4. Welder Performance Qualification

Each welder or welding operator utilized on this work shall be qualified at the time of the work in accordance with AWS D1.6 (WPQ) or ASME B\&PVC Section IX. Welder qualification records shall be submitted to the University for information.

5. Weld Symbols

Weld symbols on sketches and drawings shall be interpreted in accordance with AWS A2.4. Any conflicts or questions related to application or interpretation of weld symbols should be directed to the University for disposition and clarification.

6. Weld Quality and Acceptance Criteria

Weld joints shall be free of cracks, crevices or incomplete fusion. Limits of porosity shall be determined using acceptance criteria defined in AWS D1.6, Figure IV-4, or ASME B31.1. Internal welds shall have smooth transition with parent material, without rough edges along bead (maximum peak to valley height .030 inch), no undercut, free of splatter and no discoloration from oxidation. Weld finishes shall be smooth, enabling final cleaning processes and cleanliness verification.

\subsection{ALIGNMENT AND SURVEYING}

The components shall be aligned consistent with the coordinates and tolerances specified.

\subsection{PRESSURE LEAK TESTING}

The pressure leak testing of those portions of the Precision Diagnostic System (PDS) that are installed by the contractor under CSP 19 fall into two categories:

1. The elements of the PDS that are constructed in place. These are the trombone in Switchyard \#2, and the PM3 withdrawal enclosure in Switchyard \#1. These completed enclosures will be pressure checked by the contractor, with attention being paid to all joints.

2. The remaining elements of the PDS that are to be installed by the contractor are the mirror enclosures (PM10, PM7, PM8, and PM9/PL1), the beam line enclosures connecting these mirror enclosures, and the vertical beam enclosures mounted onto the trombone and PM3 withdrawal enclosure. All of these enclosures will have been pressure tested and certified to be suitable for use prior to them being furnished to the contractor. It is the responsibility of the contractor to install these onto their mating surfaces and to determine that the interface joints are gas-tight. 


\section{Appendix C to Scope of Work for IMI Services}

The equipment to be tested consists of one PDS in each switchyard.

Each PDS is divided into five separate zones for the purpose of the leak testing. For each switchyard, these zones are:

1. The trombone enclosure or PM3 withdrawal enclosure, depending upon the switchyard,

2. The combination of a vertical beam enclosure with a flexure at each end,

3. The combination of a flexure, a horizontal beam enclosure, a flexure, and the PM10 enclosure,

4. The combination of a flexure, a horizontal beam enclosure, a flexure, and the PM7 enclosure,

5. The combination of a flexure, a horizontal beam enclosure, the PM9/PL1 enclosure, and a flexure.

These zones and their leak test requirements are described in this section.

A. Pressure testing shall be performed in accordance with the Section 15122 and ASME, N510. When there is a discrepancy between the two, Section 15122 is the governing document.

B. The test pressure shall be a pressure that will support $101.6 \mathrm{~mm}$ (4 in.) of $\mathrm{H}_{2} \mathrm{O}$ above ambient atmospheric pressure. The contractor may use either the Constant Pressure Method (ASME N510, section 6.5.2) or the Pressure Decay Method (Section 15122), as is deemed suitable, for pressure testing of all zones.

C. Testing shall include examination of welded seams, flange joints, bellows seams and other areas of higher susceptibility to leakage. Testing shall be performed on each of the four zones specified below, and shown in the accompanying sketches.

Zone 1. This consists of the trombone enclosure (SY\#2) or the PM3 withdrawal enclosure (SY\#1), depending upon the switchyard. Subcontractor shall receive the panels, with gaskets mounted, that are necessary to complete the enclosing of these two enclosures which were fabricated in situ. The gaskets form seals between the panels and the constructed enclosure. The fasteners, which are supplied with the panels, are tightened to the torque indicated on those drawings that describe the panels. Pressure will be supplied through the port located on top of the enclosure at the more positive $\mathrm{z}$ end. As this is a dirty environment, it is not necessary to use clean air for this pressure test. After pressure leak tests have been completed on this zone, subcontractor shall remove the panels that were put in place for the test and return them to the area from which they were removed.

Zone 2. This is the combination of a vertical beam enclosure, a cross hair, and three bellows, as shown. Note that these five connected items are being maintained at a pressure of 50-mm ( 2 in.) of $\mathrm{H}_{2} \mathrm{O}$ above ambient pressure. The connection for leak checking is 
made at the port on the side of the vertical beam enclosure. Clean room procedures shall be used for this operation. All leak checking will be performed using a source of clean, HEPA-filtered to class 10, dry air, regulated to a pressure no greater than $114.3 \mathrm{~mm}(4.5$ inches) of $\mathrm{H}_{2} \mathrm{O}$. After pressure leak tests have been completed, the subcontractor shall reestablish a positive pressure of HEPA-filtered to class 10 , dry air at $50 \mathrm{~mm}$ (2 in.) of $\mathrm{H}_{2} \mathrm{O}$ above ambient pressure. This can be accomplished using the port on the side of the vertical beam enclosure.

Zone 3. This consists of the combination of a bellows, a horizontal beam enclosure, a bellows, the PM10 enclosure, a bellows, a horizontal beam enclosure, a bellows, and the PM7 mirror enclosure, as shown. All leak checking will be performed using the HEPAfiltered air, regulated to a pressure no greater than $114.3 \mathrm{~mm}$ (4.5 inches) of $\mathrm{H}_{2} \mathrm{O}$ generated by the source that was installed for assembly. After pressure leak tests have been completed on this zone, subcontractor shall reestablish the positive pressure at $50-\mathrm{mm}(2$ in.) of $\mathrm{H}_{2} \mathrm{O}$ above ambient pressure.

Zone 4. This is the combination of a bellows, a horizontal beam enclosure, a bellows, the PM9/PL1 enclosure, a bellows, a horizontal beam enclosure, the PM8 mirror enclosure, and a bellows, as shown. Clean room procedures shall be used for this operation. . All leak checking will be performed using the HEPA-filtered air, regulated to a pressure no greater than $114.3 \mathrm{~mm}$ (4.5 inches) of $\mathrm{H}_{2} \mathrm{O}$ generated by the source that was installed for assembly. After pressure leak tests have been completed on this zone, subcontractor shall reestablish the positive pressure at $50-\mathrm{mm}\left(2 \mathrm{in}\right.$.) of $\mathrm{H}_{2} \mathrm{O}$ above ambient atmospheric pressure.

\subsection{PAINTING}

Touch-up paint scratched or otherwise exposed previously painted surfaces, and paint the subcontractor-installed welds and adjacent surfaces per Section 09900.

\subsection{CLEANING}

The subcontractor shall meet the cleaning requirements of Sections 01625 and 15895. 


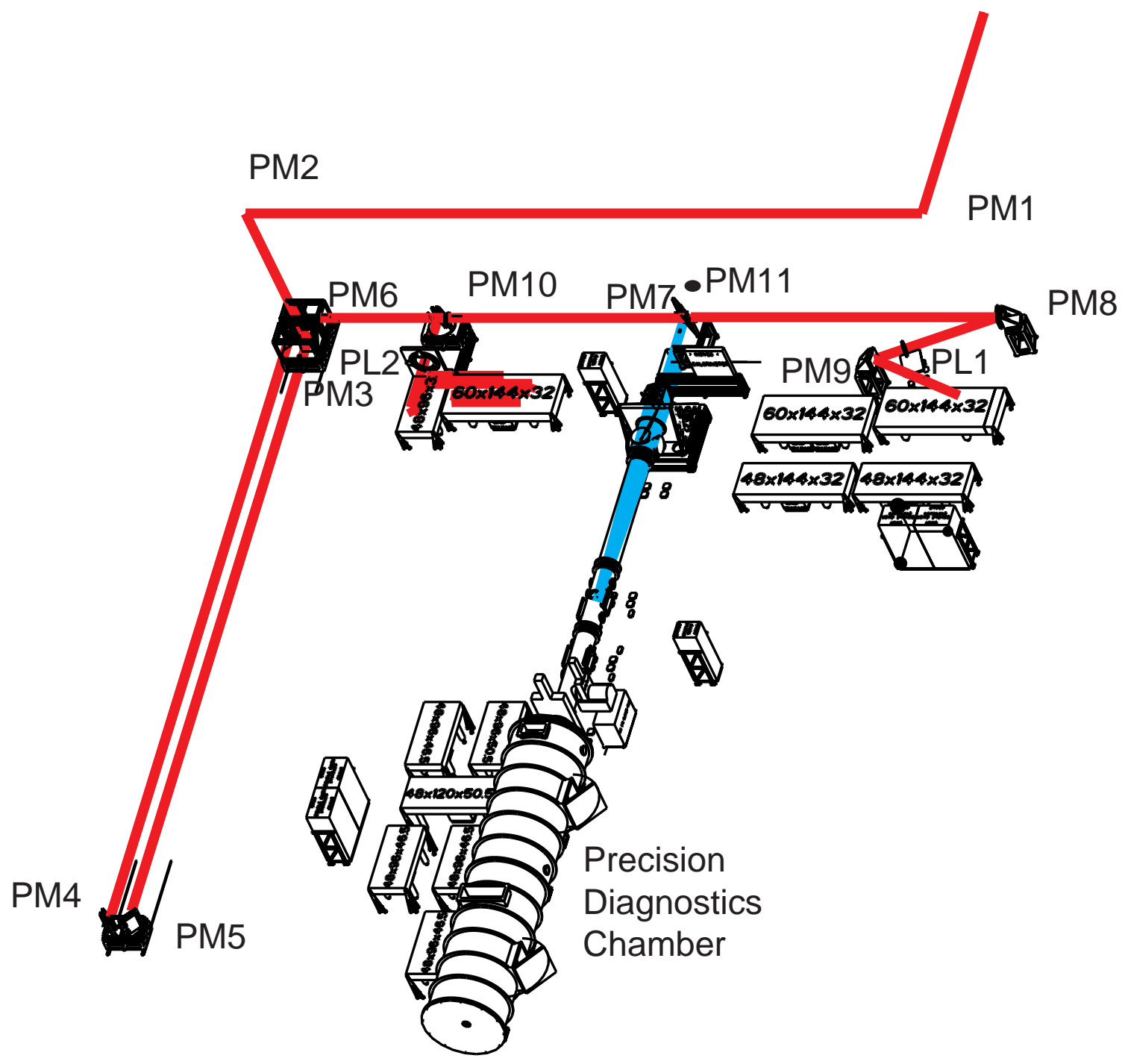

Figure 1 PDS Layout in Switchyard \#2 


\section{LASER BAY, SWITCHYARD, AND CAPACITOR BAY UTILITIES}

\section{PART 1 GENERAL}

\subsection{DESCRIPTION}

A. The purpose of this specification is to define minimum requirements for the installation of the utilities for the laser bays, the switchyards and the capacitor bays including the following components:

1. Argon System

2. Chilled Water System

3. Demineralized Water System

4. Fire Protection System

5. FOA Cooling System

6. Handing Systems

7. Hot Water System

8. Low Conductivity Water System

9. Nitrogen System

10. Power and Lighting Systems

11. Racks and Cables

12. Steel Support Structures

13. Tempered Water Systems

14. Laser Bay Vacuum Systems

15. Miscellaneous
a. Utility Pad for Argon System
b. Utility Pad for Tempered Water System
c. Utility Pad for Vacuum System
d. Closure of fire rated openings

\subsection{WORK INCLUDED IN THIS BID PACKAGE}

A. The work of this bid package shall include all labor, material, tools, equipment, shoring and temporary bracing, hoists, scaffolding and services needed to perform all the Laser Auxiliary Systems construction work, functional testing, and commissioning indicated on the drawings and/or described in the specifications, or that may be reasonably implied therefrom as being necessary for the completion and serviceability for the intended use of all items of work, which includes, but is not necessarily limited to, the following.

1. The complete, functioning Argon system including, but not limited to, the following:

a. Laser Bay 1

1) Purge to Transport Spatial Filters piping and Instrumentation \& Control.

b. Laser Bay 2

1) Purge to Transport Spatial Filters piping and Instrumentation \& Control. 
c. Switchyard 1

1) Airlock and blower system attached to Roving Mirror/Calorimeter System.

2) Complete, functional Purge Blower system, including valves and Instrumentation \& Control.

3) ULPA filters at all use points.

4) Argon headers and distribution piping including all valves, Instrumentation \& Control, orifice plates and appertunces.

5) Argon exhaust/purge piping including all valves, Instrumentation \& Control, orifice plates, and appertunces.

6) Supply piping and controls for purge to Roving Mirror/Calorimeter System.

d. Switchyard 2

1) Supply piping and controls for purge to Roving Mirror/Calorimeter System.

2) ULPA filters at all use points.

3) Argon exhaust/purge piping including all valves, Instrumentation \& Control, orifice plates, and appertunces.

4) Argon headers and distribution piping including all valves, Instrumentation \& Control, orifice plates, and appertunces.

5) Complete, functional Purge Blower system, including valves and Instrumentation \& Control.

6) Airlock and blower system attached to Roving Mirror/Calorimeter System.

e. Utility Pad

1) Humidifier HU-1

2) Seismic retrofit and painting of reconditioned Argon storage tank

3) 5,840 gal Argon Storage tank, 400 SCFM vaporizer, and Instrumentation \& Control.

2. Extension of the existing Chilled water system including, but not limited to, the following

a. Laser Bay 1

1) 2" CHWS and 2" CHWR lines, C1L, from the 4" Branch header to 4 locations above the 4 pre-amplifiers.

2) $11 / 2$ " CHWS and $11 / 2$ " CHWR lines, C1L, from the 4 " branch headers to the PAMMA location.

3) 4" CHWS and 4" CHWR branch headers, C1L, from 8" distribution headers that run along column line L through Laser Bay 1. Install insulation as shown.

b. Laser Bay 2

1) 4" CHWS and 4" CHWR branch headers, C1L, from the 8" distribution header that run along column line $\mathrm{C}$ through Laser Bay 2.

2) 2" CHWS and 2" CHWR lines, C1L, from the 4" Branch Header to 4 locations above Laser Bay 2the 4 Pre-Amps in Laser Bay 2.

c. Mechanical Room 5009

1) $21 / 2$ " CHWS and $21 / 2$ " CHWR lines, C1L from 6" headers to PACF 1,2,3,4 in Mechanical Room,

2) All lines, hangers, and fittings and make connections as shown on P\&ID Chilled Water System, DWG AAA96-106110.

3) 3" CHWS and 3"CHWR lines, C1L, from 6" headers to MACF-1,2,3,4 in Mechanical Room. 
4) All lines, hangers, and fittings and make connections as shown on P\&ID Chilled Water System, DWG AAA96-106110

3. Extension of the existing Compressed Air system including, but not limited to, the following

a. Capacitor Bays, Typical for each of 4 Bays.

1) Compressed air gas exhaust capacitor switches.

2) Lines to capacitor switches.

b. Laser Bay 1 and Laser Bay 2

1) Compressed Air ( $\mathrm{CA}$ ) piping, $\mathrm{C} 1 \mathrm{~K}$. Line sizes range from 3 " to $1 / 2$ ". As part of conventional utilities 3 " CA headers have been routed through the site. This work includes the tie-ins from the headers to the individual users.

c. Switchyard 1

1) Secondary and final fit up piping for Clean/Dry Compressed Air from a manifold in the Target Bay to Precision Diagnostics Systems in Switchyard.

d. Switchyard 2

1) Secondary and final fit up piping for Clean/Dry Compressed Air from a manifold in the Target Bay to Precision Diagnostics Systems in Switchyard.

4. Extension of the existing Demineralized Water system including, but not limited to, the following

a. Laser Bay 1

1) 1" DW line, PCV2, from tie-in to 2" DW header in Laser Bay 1 to PAMMA in Room 1023. Schematic of line shown on P\&ID AAA98-111655.

b. Laser Bay 2

1) 2" DW Line, PVC2, from tie-in to 3" DW line in Laser Bay 2 to Argon Storage Tank Pad. At Argon Storage Tank Pad make piping spec change to SS8 and tie-in to humidifier package.

5. Extension of the existing Fire protection system including, but not limited to, the following

a. Capacitor Bays, Typical for each of 4 Bays.

1) Sprinkler system under the mezzanine. Tie into building fire protection system

b. Laser Bay 1

1) Sprinklers below the beam path and within the main Amplifier, Power Amplifier, and PASS structures. Connect to risers installed by Conventional Facilities.

c. Laser Bay 2

d. Sprinklers below the beam path and within the main Amplifier, Power Amplifier, and PASS structures. Connect to risers installed by Conventional Facilities.

e. Switchyard 1

1) Sprinkler systems at four levels in the steel space frame (0'-0" level, 17'-6" level, 29'-10" level and 50'-6" level). Connect to risers installed by Conventional Facilities.

f. Switchyard 2

1) Sprinkler systems at four levels in the steel space frame ( $0^{\prime}-0^{\prime \prime}$ level, 17'-6" level, 29'-10" level and 50'-6" level). Connect to risers installed by Conventional Facilities. 
6. Extension of the FOA Cooling system (Base system installed by others) including, but not limited to, the following

a. Switchyard 1

1) Secondary piping and final fit up to Precision Diagnostic Equipment

b. Switchyard 2

1) Secondary piping and final fit up to Precision Diagnostic Equipment.

7. Complete, functional Material Handling Systems including, but not limited to, the following

a. Capacitor Bays, Typical for each of 4 Bays

1) Cable and conduit to power monorail hoists. Three monorails per Capacitor Bay.

2) Hoist monorails (Hoist furnished by others). Three monorails per Capacitor Bay.

b. Switchyard 1

1) 5 monorail cranes in Switchyard 1.

2) 5 Jib Cranes, $21 / 2$ ton capacity, in Switchyard 1

c. Switchyard 2

1) 5 Jib Cranes, 2 1/2 ton capacity in Switchyard 2.

2) 5 monorail cranes in Switchyard 2.

8. Extension of the existing Hot Water system including, but not limited to, the following

a. Mechanical Room 5009

1) 2" HWS and 2"HWR lines, C1L, from 4" headers to MACF-1,2,3,4 in Mechanical Room. All lines and fittings and make all connections to MACF units as shown on Hot Water System P\&ID.

2) $11 / 2$ " HWS and 1 1/2" HWR lines, C1L, from 4" headers to PACF-1,2,3,4 in Mechanical Room.

3) All lines and fittings and make all connections to PACF units as shown on Hot Water System P\&ID.

9. Extension of the existing Low Conductivity Water system including, but not limited to, the following

a. Laser Bay 1

1) $11 / 2$ " LCWS and $11 / 2$ " LCWR lines, C1L, from tie-in to 4 " headers in Laser Bay 1 to PAMMA in Room

2) Shutoff valves in Room 1023. Schematic shown on P\&ID AAA96-107745.

b. Laser Bay 1

1) $11 / 2$ " LCWS and $11 / 2$ " LCWR lines, C1L, from tie-in to 4 " headers in Laser Bay 1 to Precision Diagnostic and two sets of 1 " branches off of these $11 / 2$ " lines in Precision Diagnostic.

2) 4" LCWS and 4"LCWR from tie-ins to 6"LCWS and 6" LCWR headers at column line 28 through Laser Bay 1 and Switchyard 1. Cap lines in Switchyard 1 and install LCW bypass.

c. Laser Bay 2

1) 3" LCWS and 3" LCWR lines, C1L, from tie-ins to 6"LCWS and 6" LCWR headers at column line 28 through Laser Bay 2 and Switchyard 2. Cap lines in Switchyard 2 and install LCW bypass. 
2) $11 / 2$ "LCWS and $11 / 2$ " LCWR, C1L, branch connections from 3 " headers in Laser Bay 2. These branch connections will be extended to the Helium Compressor in the future. Install shut off valves at end of the branch connections.

3) $11 / 2$ " LCWS and1 1/2" LCWR lines, C1L, from 3" headers in Laser Bay 2 to Precision Diagnostic and two sets of 1" branches off of these $11 / 2$ " lines in Precision Diagnostic

d. Utility Pad

1) 2" LCWS and 2" LCWR lines, C1L, from tie-ins to 6" headers that run along column line 28 to tempered water pump skids.

2) 2" LCWS and 2"LCWR lines from tie-ins to 6" headers that run along column line 28 to vacuum system utility pad. Furnish and install 1/2" LCWS and 1/2" LCWR branch connections to 4 Vacuum Pumps.

10. Complete fire rated closure at Power Amplifier and at Main Amplifier high voltage cable opening through laser Bay walls. Typical for each of 4 Capacitor Bays

11. Complete installation for outdoor concrete slabs:

a. Argon utility pad.

b. Tempered Water utility pads.

c. Vacuum utility pads.

12. Extension of the Nitrogen system (Base system installed by others) including, but not limited to, the following:

a. Core Between Laser Bays

1) 10" Nitrogen between Laser Bay 1 and Laser Bay 2. Install through Laser Bay walls.

2) High pressure nitrogen, ( $\mathrm{N} 2 \mathrm{H}$ ), flow system to PAMMA.

b. Laser Bay 1

1) 10 " nitrogen supply line.

2) Drops, including manual dampers, from supply and return branches to FAU's.

Furnish and install flex connection at the FAU's. Final connection to FAU's by others.

3) All nitrogen make-up (supply) \& exhaust pipe, including dampers, valves, and filters. Make connection to $10 "$ nitrogen supply line.

4) 4" distribution N2 SS4 piping to 24 spatial filters in Laser Bay 1

5) $21 / 2$ " distribution N2 SS4 piping to PEPC LRU in Laser Bay 1

6) Nitrogen supply \& return duct from Laser Bay wall to end points above amplifiers. Main Amplifier ducts are 34 X 34 \& Power Amplifier Ducts are 30 X 30 .

7) 3" distribution N2 SS4 piping to PAM in Laser Bay 1

8) 8" and 4" distribution N2 SS4 piping to 24 main and power amplifiers in Laser Bay 1

9) Nitrogen supply \& return duct from Laser Bay wall to end points above amplifiers. Main Amplifier ducts are 34 X 34 \& Power Amplifier Ducts are 30 X 30 .

10) Nitrogen supply \& return duct from Laser Bay wall to end points above amplifiers. Main Amplifier ducts are 34 X 34 \& Power Amplifier Ducts are 30 X 30 . 
c. Laser Bay 2

1) 8 " and 4" distribution N2 SS4 piping to 24 main and power amplifiers.

2) 10" nitrogen supply line.

3) Drops, including manual dampers, from supply and return branches to FAU's. Furnish and install flex connection at the FAU's. Final connection to FAU's by others.

4) Nitrogen supply \& return branches, including motorized \& manual dampers, above amplifiers. Main Amplifier Branches are 12 X 28 \& Power Amplifier Ducts are 12 X 22.

5) $21 / 2$ " distribution N2 SS4 piping to PEPC LRU in Laser Bay 2

6) 3" distribution N2 SS4 piping to PAM in Laser Bay 2

7) 4" distribution N2 SS4 piping to 24 spatial filters in Laser Bay 2

8) All nitrogen make-up (supply) \& exhaust pipe, including dampers, valves, and filters. Make connection to 10" nitrogen supply line.

d. Mechanical Room 5009

1) Paint all pipe \& duct hangers and supports.

2) All utility connections to 8 nitrogen fan/filter units. Services include HWS, HWR, CHWS, \& CHWR. Furnish and install Chilled Water circulating pumps. Similar for 8 units.

3) Retrofit Nitrogen Fan/Filter Units - 8 total, 4 Serving Laser Bay $1 \& 4$ serving Laser Bay 2. Replace fan motors and reconfigure filters sections

4) Set Nitrogen Fan/Filter Units - 8 total, 4 Serving Laser Bay 1 \& 4 serving Laser Bay 2.

5) Supply \& return duct from each unit to Laser Bay wall. Similar for 8 units. 30 X 30 duct for Power Amplifiers. 34 X 34 duct for Main Amplifiers.

6) Nitrogen make-up and exhaust piping.

e. OAB Corridor

1) High pressure nitrogen, ( $\mathrm{N} 2 \mathrm{H}$ ), flow system.

f. Switchyard 1

1) High pressure nitrogen, ( $\mathrm{N} 2 \mathrm{H}$ ), flow system to the precision diagnostic area.

g. Switchyard 2

1) High pressure nitrogen, ( $\mathrm{N} 2 \mathrm{H}$ ), flow system to the precision diagnostic area is not defined.

2) Piping from utility pad to precision diagnostics. Final connection at precision diagnostics by others.

13. Extension of the existing Power and Lighting system including, but not limited to, the following:

a. Capacitor Bays, Typical for each of 4 Bays

1) Lighting under the mezzanine. Power from panel install by Conventional Facilities.

2) Fiber optic cable tray from MOR to capacitor bay control points (Capacitor switches). Fiber optic cable installation by others.

3) Cable \& conduit to multiple disconnect switches along mezzanine walls (480v). Power from panel install by Conventional Facilities.

4) Cable \& cable tray from disconnect switches along mezzanine walls to each capacitor module $(480 \mathrm{v})$. Final termination at capacitor modules by others. 
b. Switchyard 1

1) Lighting, cable and conduit at four levels in the steel space frame (-21'-9" level, 0'-0" level, 17'-6" level, and 29'-10" level). Connect to lighting panels installed by Conventional Facilities.

2) Receptacles, cable and conduit at five levels in the steel space frame (-21'-9" level, 0'-0" level, 17'-6" level, 29'-10" level and 50'-6" level). Connect to power panels installed by Conventional Facilities.

c. Switchyard 2

1) Receptacles, cable and conduit at five levels in the steel space frame (-21'-9" level, 0'-0" level, 17'-6" level, 29'-10" level and 50'-6" level). Connect to power panels installed by Conventional Facilities.

2) Lighting, cable and conduit at four levels in the steel space frame (-21'-9" level, 0'-0" level, 17'-6" level, and 29'-10" level). Connect to lighting panels installed by Conventional Facilities.

d. Laser Bay 1

1) Lighting, cable and conduit below the beam path and within the main Amplifier, Power Amplifier, and PASS structures. Connect to lighting panels installed by Conventional Facilities.

2) Receptacles, cable and conduit below the beam path and within the main Amplifier, Power Amplifier, and PASS structures. Connect to power panels installed by Conventional Facilities.

e. Laser Bay 2

1) Receptacles, cable and conduit below the beam path and within the main Amplifier, Power Amplifier, and PASS structures. Connect to power panels installed by Conventional Facilities.

2) Lighting, cable and conduit below the beam path and within the main Amplifier, Power Amplifier, and PASS structures. Connect to lighting panels installed by Conventional Facilities.

14. Set Racks for electronics, install Cable Tray, Conduit \& Cables including, but not limited to, the following

a. Capacitor Bays, Typical for each of 4 Bays

1) Cable tray for high voltage coaxial cable from capacitor modules across support ramp to Power Amplifier.

2) High voltage coaxial cable from capacitor modules across support ramp to Main Amplifier. Terminate at Amplifier. Termination at capacitors by others.

b. Laser Bay 1

1) Set Equipment Racks

2) Cable tray

3) Signal/control \& power wiring. Signal/control terminations by others (not part of Infrastructure). Power wiring consists of wiring from existing panels \& breakers (furnished by Conventional Facilities) and connecting to power strips in enclosure.

4) Rack cooling units. Furnish and install all piping.

c. Laser Bay 2

1) Set Equipment Racks

2) Cable tray 
3) Signal/control \& power wiring. Signal/control terminations by others (not part of Infrastructure). Power wiring consists of wiring from existing panels \& breakers (furnished by Conventional Facilities) and connecting to power strips in enclosure.

4) Rack cooling units. Furnish and install all piping.

d. Switchyard 1

1) Set Equipment Racks

2) Cable tray

3) Signal/control \& power wiring. Signal/control terminations by others (not part of Infrastructure). Power wiring consists of wiring from existing panels \& breakers (furnished by Conventional Facilities) and connecting to power strips in enclosure.

4) Rack cooling units. Furnish and install all piping.

e. Switchyard 2

1) Set Equipment Racks

2) Cable tray

3) Signal/control \& power wiring. Signal/control terminations by others (not part of Infrastructure). Power wiring consists of wiring from existing panels \& breakers (furnished by Conventional Facilities) and connecting to power strips in enclosure.

4) Rack cooling units. Furnish and install all piping.

15. Erect and align Structural Steel including, but not limited to, the following

a. Capacitor Bays, Typical for each of 4 Bays

1) .Grating, stairs, and handrails for mezzanine.

2) Special mezanine cable enclosure for capacitor power cable

b. Laser Bay 1

1) All Catwalks \& Platforms, Utility support structure, and beam tube supports.

c. Laser Bay 2

1) All Catwalks \& Platforms, Utility support structure, and beam tube supports.

16. The complete, functioning Tempered water system including, but not limited to, the following:

a. Laser Bay 1

1) Supply and return headers to and including the valve to each distribution header and the valve from each distribution return header. Includes valves, quick disconnects and flexible line to Rack Cooling units.

b. Laser Bay 2

1) Supply and return headers to and including the valve to each distribution header and the valve from each distribution return header.

c. Switchyard 1

1) Supply and return headers to and including the valve to each distribution header and the valve from each distribution return header. Includes valves, quick disconnects and flexible line to Rack Cooling units.

d. Switchyard 2

1) Supply and return headers to and including the valve to each distribution header and the valve from each distribution return header. Includes valves, quick disconnects and flexible line to Rack Cooling units. 
e. Tempered Water Utility Pad

1) Tempered water supply system which includes instruments and controls, expansion and air separation tanks, pumps, filters, heat exchangers, a by-pass with supply and return headers to LTAB.

17. The complete, functioning Laser Bay Vacuum system including, but not limited to, the following:

a. Laser Bay 1

1) 8" Backing Vacuum Header, SS5, from Vacuum Skids through Laser Bay 1 and four 6" Backing Vacuum Branch Headers, SS5, to four Spatial Filter clusters in Laser Bay 1.

2) $11 / 2$ " Backing Vacuum line, SS5, from the 6" Backing Branch Header to the Turbo Pump at 12 Transport Spatial Filters and 12 Cavity Spatial Filters.

3) 8" Rough Vacuum Header, SS5, from Vacuum Skids to 12 Beam Transport Spatial Filter Turbo Pumps.

b. Laser Bay 2

1) 8" Rough Vacuum Header,SS5, from Vacuum Skids to 12 Beam Transport Spatial Filter Turbo Pumps.

2) 8" Backing Vacuum Header, SS5, from Vacuum Skids through Laser Bay 2 and four 6" Backing Vacuum Branch Headers, SS5, to four Spatial Filter clusters in Laser Bay 2

3) $11 / 2$ " Backing Vacuum line, SS5, from the 6" Backing Branch Header to the Turbo Pump at 12 Transport Spatial Filters and 12 Cavity Spatial Filters in Laser Bay 2.

c. Switchyard 1

1) Continuation of 8" Rough Vacuum line, SS5, from Laser Bay 1 to Switchyard 1 and connect to Diagnostic Vessel in Switchyard 1.

d. Switchyard 2

1) Continuation of 8" Rough Vacuum line, SS5, from Laser Bay 2 to Switchyard 2 and connect to Diagnostic Vessel in Switchyard 2. Furnish and install Diagnostic Vessel in Switchyard 2.

e. Vacuum System Utility Pad

1) 4 vacuum skids on the Vacuum Pad on the East end of the LTAB. Each skid is approximately 4'x4'x8' and weighs approximately $5500 \mathrm{lbs}$. 8" VAC SS5 piping and 1" LCWR and LCWS are connected to each skid 


\section{TARGET BAY UTILITIES AND BEAM PATH ENCLOSURES}

\section{PART 1 GENERAL}

\subsection{DESCRIPTION}

A. The purpose of this specification is to define minimum requirements for the installation of the utilities and beam path enclosures for the target bay including the following components:

1. Argon System

2. Domestic Cold Water System

3. Enclosures

4. Fire Protection System

5. FOA Cooling System

6. EPS System

7. Compressed Air System

8. Low Conductivity Water System

9. Nitrogen System

10. Power and Lighting Systems

11. Racks and Cables

12. Handling Structures

13. Tempered Water Systems

14. Diagnostic Vacuum Systems

15. Helium System

16. Chamber Vacuum System

17. Miscellaneous
a. Utility Pad for Nitrogen System
b. Closure for Fire Rated Openings
c. Catwalks and Platform Structures

\subsection{WORK INCLUDED IN THIS BID PACKAGE}

A. The work of this bid package shall include all labor, material, tools, equipment, shoring and temporary bracing, hoists, scaffolding and services needed to perform all the Laser Auxiliary Systems construction work, functional testing, and commissioning indicated on the drawings and/or described in the specifications, or that may be reasonably implied therefrom as being necessary for the completion and serviceability for the intended use of all items of work, which includes, but is not necessarily limited to, the following

1. Handling Systems:

a. Furnish \& install Target Bay hoists \& cranes

b. Install the hoists and all supports for 16 hoists at the 40 ' level

c. Install the rotunda crane and all supports. 


\section{Appendix C to Scope of Work for IMI Services}

d. Install the lift and the boom lift.

1) Boom lift is to be installed by the IMI and supplied as GFE

2) All lift components and controls are installed by the IMI

2. The complete, functioning Target Bay Enclosures including, but not limited to, the following:

a. Set \& align LM-6/LM-7/LM-8 (Mirror Frames) which are LLNL furnished

b. Install Interstage Beam enclosure/bellows assemblies which are LLNL furnished as precision cleaned components

c. Install Retractable Beam Tubes which are LLNL furnished as precision cleaned with the gaskets \& bolt sets GFE which are precision cleaned also

d. Install the GFE Retractable Beam Tubes which include

1) Quad Beam tubes from mounting frames on Target Bay wall to LM-6/LM6/LM-8 enclosure assembly which are GFE furnished precision cleaned with the gaskets \& bolt

2) The lining or protective coating on concrete exposed to beam path

3) The mounting frames at beam path openings on Target Bay wall

4) Align the GFE Kinematic mounts

5) The GFE Kinematic mounts

6) The cover plates

7) Set \& align LM-6/LM-7/LM-8 mount structure (Mirror Frames) including the structure and hardware

8) Precision clean interior of entire assembly (in-situ)

3. Install the Target Bay services consisting of the following;

a. The argon point of use filters

b. The extensions to house utilities,

c. The addition of supplemental fire protection,

d. The supplemental lighting

e. The Laser control racks \& cables

4. All liquid and gaseous utilities in the Target Bay, on the Diagnostics Mezzanines

a. Target Chamber Vacuum system including roughing system, all controls, and all distribution piping up to the turbopumps.

b. Helium distribution piping and final connection to all use points.

1) Tritium piping

c. Diagnostics Vacuum system including roughing system, all controls, and all

1) distribution piping up to the turbo pumps.

d. Cryopumps including all controls and power

e. Compressed air - Secondary \& final fit-up piping from Conventional Facilities headers to all use points. Final connection to all Infrastructure use points. Final connection to Special Equipment by others.

f. Tempered water secondary \& final fit-up piping including connection to Racks on Diagnostics Mezzanines. Connection to Special Equipment by others

g. Nitrogen storage, conditioning system, all controls, and distribution piping including connection to Infrastructure elements. Connection to Special Equipment by others

h. Argon secondary \& Final fit-up piping including point of use connections to 1) filters at enclosures. Connection to Special Equipment by others 
i. Low Conductivity water - distribution piping Conventional facilities tie points to all use point. Final connection to all Infrastructure use points. Final connection to Special Equipment by others.

j. Electrical Power in the Target Bay and on the Diagnostics Mezzanines

k. Extend Conventional Facilities system for supplemental lighting \& receptacles in Target Bay, Switchyard, Laser Bays, and capacitor Bays

1. Extend the Fire Protection in the Target Bay and on the Diagnostics Mezzanines

m. Racks \& Cables in the Target Bay and on the Diagnostics Mezzanines

1) Provide power from load centers to power strips in each rack

2) Install all Laser control cable tray and conduit

3) Provide power to all load center

4) Install rack-Mounted Load Centers

5) Install rack cooling units Cooling Units

6) Set all Laser control racks

7) Install all Laser control cables and networks, including cable terminations connection to control hardware by LLNL

n. Install Target Chamber beam path elements

1) Install Calorimeter \& vacuum isolation valve

2) Machine and Install IOM spool piece

3) Precision clean Target Chamber interior 


\section{SPECIFIC INDUSTRIAL CONTROLS SYSTEMS (ICS) SUBSYSTEMS}

\section{PART 1 GENERAL}

\subsection{DESCRIPTION}

A. The purpose of this specification is to define minimum requirements for shop fabrication and delivery of specific ICS subsystem assemblies and associated software Programmable Logic Controller (PLC) logic coding. The ICS subsystem assemblies installation, connection, interconnecting cabling, testing, activation, and commissioning will be incorporated in currently planned BIS utilities installation packages or in separate related ICS installation packages. The following subsystems of the ICS are included:

1. Spatial Filter Vacuum System Controls

2. Synthetic Air Cooling System Controls

3. Argon System Controls

4. Tempered Water System Controls

5. Target Chamber Vacuum System Controls

6. FOA Thermal Control System

\subsection{WORK INCLUDED IN THIS BID PACKAGE}

A. The work of this package shall include all labor, material, tools, equipment, software, deliverables, and services to perform all shop fabrication and delivery of specific ICS subsystem assemblies and the associated software coding of the ControlLogix PLC logic for the identified subsystems.

B. The BIS IMI Software and Controls System Implementation Plan and resulting lower-tier plans and specifications define the detailed requirements for this work, which includes:

1. Ladder logic programming for the Allen-Bradley ControlLogix processors including the developed ControlLogix ladder logic source code in electronic form and in hardcopy.

2. Supervisory PC(s) associated with each subsystem.

3. RSView displays capable of stand-alone, manual control for each subsystem.

4. Panel assembly and wiring per University provided drawings.

a. Panel assembly drawings and wiring diagrams from the University will be used for shop fabrication and assembly by the Subcontractor.

b. Purchase all material required for the fabrication of each panel as indicated on the Bill Of Material list on each drawing provided by the University, less equipment racks, enclosures, and special equipment controllers provided by the University.

c. Appropriately mount all purchased components on each panel.

d. Install all wiring that connects between components within each panel. 


\section{Appendix C to Scope of Work for IMI Services}

5. Shop test panels, associated PLC logic, and RSView displays.

a. Cable together all associated panels in Subcontractor shop for each ICS subsystem and verify proper operation of each Input or Output..

b. Verify proper operation of the PLC logic for each Input or Output in Subcontractor shop. Closed loop controls will be simulated appropriately to verify proper programming.

6. Ship assembled panels and components to the NIF site for installation.

7. Verify proper installation and re-verify operation of the panels, PLCs, and supplied components once installation is completed.

8. Support operational and commissioning testing of the field devices connected to the supplied panels.

9. Provide training to operations personnel and to maintenance personnel for the provided subsystems. 